\title{
THE
}

\section{AMATEURS PRACTICAL}

\section{GARDEN-BOOK}

HUNN AND BAILEY

THE CARDENICRAFT SERIES 


\section{LIBRARY OF CONGRESS.} Chap. $\$ 3+5$

$$
\text { Shelf H } 9
$$

UNITED STATES OF AMERICA. 





\section{The Garden= $\mathbb{C r a f t}$ Series}

Edited by L. H. Bailey

\section{THE AMATEUR'S PRACTICAL GARDEN - BOOK}





\title{
THE \\ AMATEUR'S PRACTICAL GARDEN - BOOK
}

CONTAINING THE SIMPLEST DIRECTIONS FOR THE GROWING OF THE COMMONEST THINGS ABOUT THE HOUSE AND GARDEN

\author{
$\mathrm{BY}$ \\ C. E. HUNN \\ AND \\ L. H. BAILEY
}

Nelor 219ork

THE MACMILLAN COMPANY

LONDON: MACMILLAN \& CO., LTD.

1900

All rights reserved 


\title{
1 Jurary of Congrogeg \\ orfles of the \\ MiR2 31000 \\ heglster of Copyerights. \\ 4.7685 \\ mar. 24,1900
}

SECOND COPY,

\author{
62488 \\ Copyright, 1900 \\ BY THE MACMILLAN COMPANY
}


LIKE the love of music, books and pictures, the love of gardens comes with culture and leisure and with the ripening of the home life. The love of gardens, as of every other beautiful and refining thing, must increase to the end of time. More and more must the sympathies enlarge. There must be more points of contact with the world. Life ever becomes richer. Gardening is more than the growing of plants: it is the expression of desire.

As there must be many gardeners, so there must be many books. There must be books for different persons and different ideals. The garden made by one's own hands is always the best garden, because it is a part of oneself. A garden made by another may interest, but it is another person's individuality. A poor garden of one's own is better than a good garden in which one may not dig. Many a poor soul has more help in a plant in the window than another has in a plantation made by a gardener.

I would emphasize the home garden, made by the members of the family. I would preach the beauty of the common plants and the familiar 
places. These things are never old. Many times I have noted how intently an audience of plant-lovers will listen to the : ost commonplace details respecting the cultivation of plants with which they have been always familiar. There was nothing new in what they heard; but they liked to have the old story told over again, and every detail called up a memory.

The same questions are asked every year, and they always will be asked,- the questions about the simplest garden operations. Upon this desire for commonplace advice the horticultural journals live. A journal which publishes only things which are new would find little support. Some of these common questions I have tried to answer in this little book. I wish them answered in the simple and direct phrase of the gardener. Therefore I asked my friend C. E. Humn, gardener to the Horticultural Department of Cornell University, who lives with plants, to write advice for one who would make a garden; and this he did in a summer vacation. These notes, edited and amplified, now make this book.

Horticultural Department,

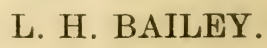

CoRnell Universitx.

ITHACA, N. Y., February 22, 1900. 


\section{AMATEUR'S \\ PRACTICAL GARDEN-BOOK}

Abobra viridiflora. A handsome tender climber with tuberous roots, that may be taken up in the fall and stored in a cellar. The foliage is dark and glossy, the flowers small and inconspicuous; but the small scarlet fruits are very effective in contrast to the leaves, making it a desirable sereen plant. It is sold by seedsmen. Seeds sown as soon as warm weather comes will give plants which bloom in the open (in a warm soil and exposure), and which reach a height of $58 \mathrm{ft}$. It is sometimes grown as a glasshouse plant. It is cucurbitaceous (allied to melons and gourds).

Abronia. Californian trailing perennials, but treated as hardy annuals. They thrive in any warm, open garden soil, and are very satisfactory for the margins of beas or borders. The little flowers are borne in clusters. A. latifolia or arenaria (yellow) and A. umbellata or grandiflora (pink) are the leading kinds. Usually sown where they are to bloom. Peel the husk off the seed nefore sowing.

Abutilons, or Flowering Maples as they are called by many, make fine house or bedding plants. Common kinds may be grown from seed or from cuttings of young wood. If the former, the seed should be sown in February or March in a temperature of not less than $60^{\circ}$. The seedlings should be potted when from four to six leaves have grown, in a rich, sandy soil. Frequent pottings should 
be made to insure a rapid growth, making plants large enough to flower by fall. Or, the seedlings may be planted out in the border when danger of frost is over, and taken up in the fall before frost: these plants will bloom all winter. About one-half of the newer growth should he eut off when they are taken up, as they are very apt to spindle up when grown in the house. When grown from euttings, young wood should be used, which, after being well rooted, may

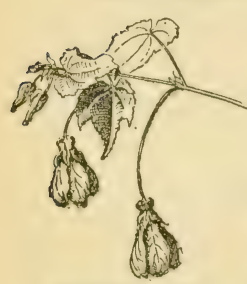

be treated in the same manner as the seedlings. The varieties with variegated leaves have been improved until the foliage effects are equal to the flower's of some varieties; and, these are a great addition to the conservatory or window garden. The staple spotted-leaved type is $A$. Thompsoni. A compact form, now much used Abutilon striatum for bedding and other outdoor work, is Saritzii, which is a horticultural variety, not a distinct species. The old-fashioned green-leaved A. striatum, from which A. Thomponi has mobably sprung, is one of the best. A. megapotumicum or rexillarium is a trailing or drooping red-and-yellow-flowered species, which is excellent for baskets. It propagates readily from seed. Abutilons are most satisfactory for house plants when they are not much more than a year old. They need no special treatment.

\section{Aconitum. Monk's HoOd. Wolf's Bane.} Hardy herbaceous perennials allied to larkspurs. They are showy border plants, usually flowering the first year from seed, if the seed is started early, and bearing panicles of quaint hood-shaped, rich flower's. The colors have a wide range, but are usually deep blue. The improved varieties are much superior in size and markings. Aconitums are most effective when planted in a mixed border : the flower stalks being held well up, show the blossoms to good advantage. Seed may be sown every two years, as the plants in their year-old and 2-year-old stage have the largest 
blossoms. Sow in gentle heat in March, transplanting to border when the weather is settled. Roots may be divided if desired, but best results are to be expected from seedlings. A. Napellus is the commonest one. The plants are very poisonous if eaten. Bloom in early summer. 2-3 ft.

Acrolinium. A low-glowing everlasting annual flower, white, violet, or rose in color. Seeds should preferably be started in a hotbed or window, and planted out when danger of frost is past; the flowers should be gathered when half expanded and hung in the shade to dry. Half-hardy. Plant 1 foot apart. Grow 10-15 in. high. See Everlastings.

Adlumia. Mountain Fringe. Allegheny Vine. One of the daintest of climbers, making a very rapid growth, and when once established seeding itself and thriving for years, growing 10 or 15 feet in a season. Give rich, rather moist soil. It is biennial, blooming the second year. Flowers like those of the

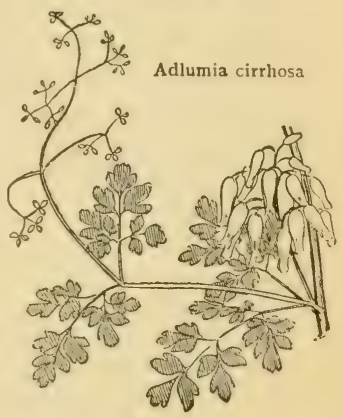
bleeding heart and other dicentras. It is native.

Adonis. A low-growing hardy annual or perennial of the easiest culture. It makes a fine mass effect, as the flower's are a striking dark scarlet or erimson color, and the plants are very free and continuous bloomers. Sow early in the spring where wanted. The perennial yellow-flowered sorts sometimes bloom the first year from seed. Adonises are very neat in habit, and the foliage is fine and interesting. $10-15 \mathrm{in.}$

\section{Agapanthus. AfricAN LILY. A tuberous-} rooted, well known conservatory or window plant. It lends itself to many conditions and proves satisfactory a large part of the year, the leaves forming a green arch over the pot, covering it entirely in a well grown specimen. The flowers 
are borne in a large cluster on stems growing from 2 to 3 ft. high, as many as two or three hundred bright blue flowers often forming on a single plant. A large, well grown plant throws up a number of flower-stalks through the early season. The one essential to free growth is an abundance of water and an oceasional application of manure water. Propagation is effected by division of the offsets, which may be broken from the main plant in early spring. After flowering, gradually lessen the quantity of water until they are placed in winter quarters, which should be a position free from frost and moderately dry. The dgapanthus, being a heavy feecler, should be grown in strong loam to which is added well rotted manure and a little sand.

Ageratum. A half-hardy annual, used as a border plant, for ribbon bedding for mass effect, or in mixed beds of geranium, coleuses and other plants. The seerls germinate readily, but as the plant is only half-hardy and is usually wanted in flower when planted out, it is usual to sow the seed in boxes placed in hotbeds or windows in March, transplanting the seedlings to small boxes or pots and growing the young plants on until the 1st of May, when they may be planted out. Pieces of young wood root very easily, and the gardener usually increases his stock by cuttings. The dwarf varieties are the most desirable, and the two colors, blue and white, may be planted together. 2-3 ft. Plants may be taken up in the fall and set in the house ; eut them back severely.

\section{Allegheny Vine. See Adlumia.}

Almond is about as hardy as the peach, but it blooms so early in the spring that it is little grown east of the Pacific slope. It is an interesting ornamental tree, and its early bloom is a merit when the fruit is not desired. The Almonds commonly sold by nurserymen in the east are 
hard-shell varieties, and the nuts are not good enough for commerce. The Almond fruit is a drupe, like the peach, but the flesh is thin and hard and the pit is the "Almond" of eommerce. Culture the same as for peach.

Flowering Almond is a very early-flowering bush, excellent for shrub-borders. It is usually grafted on plum stock, and one must take care to keep down the plum sprouts which sometimes spring from the root.

Aloe. Succulent tropical plants, sometimes seen in window gardens. Of easy culture. See that the pots have perfect drainage. Make a soil of sandy loam, with one-third or one-fourth part of broken brick. Pot firmly. Water whenever needed, but the soil and drainage should be such that the earth does not remain soggy or become sour. Aloes thrive year after year withont repotting. Usually propagated by cuttings. A. variegata is the commonest species.

Alonsoa. Tender annual. Not very well known, but a bright plant for second-row border or a low bedding plant. Planted against shrubbery or other protection after danger of frost is over, it lightens up a dark corner. 2-3 ft. Plant 10-15 in. apart, in a warm place protected from wind.

Alströmeria. The Alströmerias belong to the amaryllis family, being tuberous-rooted plants, having leafy stems and terminating in a cluster of from 10 to 50 small lily-shaped flowers of rich colors. Most of the kinds should be given pot culture, as they are easily grown and are not hardy in the open in the north. The culture is nearly that of the amaryllis, - a good, fibrous loam with a little sand, potting the tubers in early spring or late fall. Start the plants slowly, giving only water enough to cause root growth; but after growth has become established, a quantity of water may be given. After flowering they may be treated as are amaryllis or agapanthus. The plants grow $1-2 \frac{1}{2} \mathrm{ft}$. high. The flowers often have odd colors. 


\section{Althæa. See Hollyhock.}

Alyssum, Sweet. A low-growing, hardy, whiteflowered, very fragrant anumal which is much used for edgings, window boxes, and the like. It is of the easiest culture in any soil, but thrives best in a garlen loam of moderate fertility. Seeds may be sown as early as the ground can be well prepared in spring. The plant will begin to bloom when 2 or 3 inches high, and continue to bloom, as it grows, until after the first hard frosts. It makes a mat 1 to $2 \mathrm{ft}$. across. If immediate effects are not desired, the plants should be thinned out or transplanted to stand half a foot apart. It rarely stands more than a foot high. In the fall, plants may be cut back and put into pots or boxes, and they will bloom in the window. Better results in winter

Sweet Alyssum blooming are secured by starting seeds in boxes in August, September or October. There are certain hardy perennial yellow-flowered Alyssums which are useful for prominent edgings and for rockwork.

Amarantus. Decorative annuals. One species (with erect spikes) is known as Prince's Feather, another (with variegated foliage) as JOSEPH'S COAT, and still another (with drooping spikes) as LOVE-LIES-BLEEDING. Probably the finest of the list is A. salicifolius, often ealled Fountain Plant. This has graceful willow-shaped leaves, banded and tipped with carmine, bronze and orange. The tall kinds make fine sereens for unsightly objects. They may also be used against masses of green to add color. The Amaranths are half-hardy or tender plants, and should be sown in boxes in Mareh or

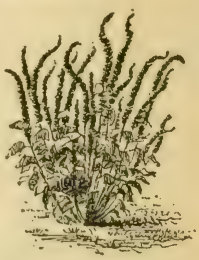

Prince's Feather April, to be planted out after all danger of frost is past. Seeds may also be sown where the plants are to stand. They were once among the most popular of garden plants, 
but for a few year's have been neglocted. Fine colors have recently been developed, and they are again becoming favorites. As they are rather coarse and weedy plants, do not use them with dainty flowers. Most kinds grow 2-3 ft. high and spread 2-3 $\mathrm{ft}$.

Amaryllis. Popular name of a variety of house or conservatory tender bulbs, hut properly applied only to the Belladonna Lily. Most of them are hippeastrums, but the culture of all is similar. They are satisfactory house plants. The one objection to their culture is the habit of the flower-stalk starting into growth hefore the leaves start. This is caused in most cases by stimulating root growth before the bulh has had sufficient rest. The bulbs should be dormant for four or five months in a dry place with a temperature of about $50^{\circ}$. When wanted to be brought into flower, the bulbs, if to be repotted, should have all the dirt shaken off and potted in soil composed of fibrous loam and leafmold, to which should be added a little sand. If the loam is a heavy one, place the pot in a warm situation; a spent hotbed is a good place. Water as needed, and as the flowers develop liquid manure may be given. If large clumps are well established in 8- or 10 -inch pots, they may be top-dressed with new soil containing rotted manure, and as growth increases liquid manure may be given twice a week until the flowers open. After flowering, gradually withhold water until the leaves die. The most popular species for window gardens is $A$. Johnsoni (properly a hippeastrum), with red flowers.

\section{Amethyst. See Browallia.}

Ammobium. A half-hardy perennial everlasting with white flowers. Thrives best in sandy soil. Sow seeds where plants are to stand. Although perennial, it blooms the first year from seed, and is usually treated as an annual. 2-3 ft. high. Plant 12-18 in. apart.

Ammoniacal Carbonate of Copper. See under Bordeaux Mixture. 
Anchusa. Hardy ammuals and perennials, fit for heavy borders. The plants grow to the height of 2 to 3 feet and bear purple or blue flowers, which are showy either on the plant or in bouquets. Propagated from seed sown in early spring, either where the plants are to stand or in boxes or hotbeds. The common kind is annual. Blooms in summer.

Anemone. Wind Flower. A group of hardy perennials. The best known of this genus is A. Japonica alba, or Honorine Jobert. This species blooms from August to November, and is at that season the finest of border plants. The pure white flowers, with lemon-colored stamens, are held well up on stalks 2-3 ft. high. The flower stems are long and excellent for eutting. This species may be propagated by division of the plants or by seed. The former method should be put into practice in the ponica. the fall. Sow the seed in boxes in a warm, sheltered situation in the border or under glass. The seed should be covered lightly with soil containing a quantity of sand and not allowed to become dry. A well enriched, sheltered position in a border should be given. There are red-flowered varieties.

The varieties of $A$. coronaria are tuberous-rooted plants. The tubers of these should be planted in the fall, late in September or early in October, in a well enriched, sheltered horder, setting the tubers 3 in. deep and from 4-6 in apart. The surface of the border should be mulched with leaves or strawy manure through the severe winter weather, uncovering the soil in Mareh. The flowers will appear in April or May, and in June or July the tubers should be taken up and placed in a dry place in sand until the following fall. This section is not as well known as it should be. The range of color is very wide. The flowers are often $2 \mathrm{in}$. across, and are lasting. These tubers may be planted in pots in 
the same manner as in the border, bringing them into the couservatory or house at intervals through the winter, where they make an excellent showing when in hloom.

The little wild Wind Flowers are easily colonized in a hardy border.

Annuals. The annual flowers of the seedsmen are those which give their best bloom in the very year in which the seeds are sown. True annuals are those plants which complete their entire life-cycle in one season. Some of the so-called annual flowers will continue to bloom the second and third years, but the bloom is so poor and sparse after the first season that it does not pay to keep them.

Most annuals will bloom in central New York if the seeds are sown in the open ground when the weather becomes thoroughly settled. But there are some kinds, as Cosmos and Moonflowers, for which our season is commonly too short to give good bloom. These kinds may be started early in the house or in hotbeds; and similar treatment may be given any plants of which it is desired to secure blooms before the normal time.

Prepare the ground thoroughly and deep. Annuals must make a quick growth. See that the soil contains enough humus or vegetable mold to make it rich and to enable it to hold moisture. If the ground is not naturally rich, spade in wellrotted manure or mold from the woods. A little commercial fertilizer may help in starting off the plants quickly. Prepare the land

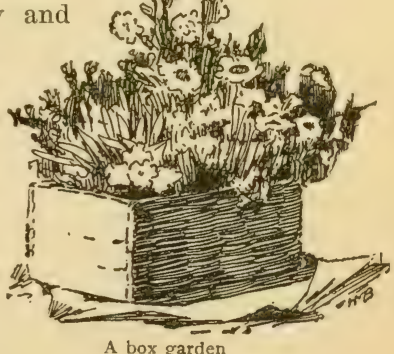
as early in spring as it is in fit condition, and prevent evaporation by keeping the surface loose by means of raking.

If the flowers are to be grown about the edges of the 
lawn, make sure that the grass roots do not run underneath them and rob them of food and moisture. It is well to run a sharp spade deep into the ground about the edges of the bed every two or three weeks for the purpose of cutting off any grass roots which may have run into the bed. If beds are made in the turf, see that they are $3 \mathrm{ft}$. or more wide, so that the grass roots will not undermine them. Against the shrub borders, this precaution may not be necessary. In fact, it is desirable that the flowers fill all the space between the overhanging branches and the sod.

Sow the seeds freely. Many will not germinate. Even if they do all germinate, the comborder

bined strength of the rising plantlets will break the crust on the hard soils; and in the thimning which follows, only strong and promising plants are allowed to remain. Better effects are also often secured when the colors are in masses, especially if the flowers are thrown into the bays of heavy shrub borders.

Plants continue to bloom for a longer period if they are not allowed to produce seeds. The flowers should be picked, if possible, as soon as they begin to fade.

In the selection of the kinds of annuals, one's personal preference must be the guide. Yet there are some groups which may be considered to be standard or general-purpose plants. They are easily grown almost anywhere, and are sure to give satisfaction. The remaining plants are mostly such as have secondary value, or are adapted to particular purposes or uses.

The groups which most strongly appeal to the writer as staple or general-purpose types are the following: Petunias, phloxes, pinks or dianthuses, larkspurs or delphiniums, calliopsis or coreopsis, pot marigold or calendula, bachelor's button or Centaurea Cyamus, clarkias, zinnias, marigolds or tagetes, collinsias, gilias, California poppies or eschscholtzias, 
verbenas, poppies, China aster's, sweet peas, nemophilas, portulacas, silenes, candytufts or iberis, alyssum, stocks or matthiolas, morning-glories, nasturtiums or tropæolums.

Annual flowers possess a great advantage over perennials in the fact that they appeal strongly to the desire for experiment. The seeds are sown every year, and there is sufficient element of uncertainty in the results to make the effort interesting; and new combinations can be tried each year.

Do not cut the old stalks down in the fall. They will stand in the snow all through the winter, and remind you of the bursting summer time and the long-ripening fall; and the snow-birds will find them in the short days of winter.

Some of the most reliable and easily grown annuals for the north are given in the following lists (under the common trade names) :

\section{WHITE FLOWERS}

Ageratum Mexicanum album. Alyssum, Common Sweet. Alyssum, Sweet, compacta. Centranthus macrosiphon albus.

Convolvulus major.

Dianthus, Double White Margaret.

Iberis amara.

Iberis coronaria, White Rocket.

Ipomøa hederacea.

Lavatera alba.

Malope grandiflora alba.
Matthiola (Stocks), Cut and Come Again.

Matthiola, Dresden PerpetMatthiola, Giant Perfection. Matthiola, White Pearl. Mirabilis longiflora alba.

Nigella.

Papaver (Poppy), Flag of Truce.

Papaver, Shirley.

Papaver, The Mikado.

Phlox, Dwarf Snowball.

Phlox, Leopoldii.

Zinnia.

\section{YELLOW FLOWERS}

Cacalia lutea. Calendula officinalis, ComCalendula officinalis, Meteor.
Calendula sulphurea. Calendula suffruticosa. Calliopsis bicolor marmorata. 


\section{Fellow Flowers-Continued}

Calliopsis cardaminæfolia. Calliopsis elegans picta. Cosmidium Burridgianum. Erysimum Peroffskianum. Eschscholtzia Californica. Hibiseus Africanus. Hibiscus, Golden Bowl. Ipomœa coceinea lutea.
Loasa tricolor, Tagetes, various kinds. Thunbergia alata Fryeri. Thunbergia alata aurantiaea. Tropæolum, Dwarf, Lady Bird.

'Tropæolum, Tall, Schulzi. Zinnia.

\section{BLUE FLOWERS}

Ageratum Mexicauum. Ageratum Mexicanum, Dwarf. Browallia Czerniakowski.

Browallia elata.

Centaurea Cyanus, Victoria Dwarf Compact.

Centaurea Cyanus minor.

China Asters of several varieties.

Convolvulus minor. Convolvulus minor unicaulis. Gilia achillerefolia. Gilia capitata. Iberis umbellata.
Iberis umbellata lilacina.

Kanlfussia amelloides.

Kaulfussia atroviolacea.

Lobelia Erinus.

Lobelia Erinus, Elegant.

Nigella.

Phlox variabilis atropurpurea.

Salvia farinacea .

Specularia.

Verbena, Black-blue.

Verbena coerulea.

Verbena, Golden-leaved.

Whitlavia gloxinoides.

\section{RED FLOWERS}

Cacalia, Scarlet.

Clarkia elegans rosea.

Convolvulus tricolor roseus.

Dianthus, Half Dwarf Early

Margaret.

Dianthus, Dwarf Perpetual.

Dianthus Chinensis, Double.

Gaillardia picta.

Ipomøa coccinea.
Ipomœa volubilis.

Matthiola annuus (Stocks).

Matthiola, Blood-red Ten

Weeks.

Matthiola grandiflora, Dwarf.

Papaver (Poppy) cardinale.

Papaver, Double.

Papaver, Mephisto.

Phaseolus multiflorus. 


\section{Red Flowers-Continued}

Phlox, Large-flowering Tropæolum, Dwarf, Tom Dwarf.

Phlox, Dwarf Fireball. Thumb.

Phlox, Black Warrior.

Salvia coccinea.

Saponaria.

Tropæolum, Dwarf.

Verbena hybrida. [fiance.

Verbena hybrida, Scarlet DeZinnia.

\section{GOOD FOR EDGINGS OF BEDS AND WALKS}

Alyssum, Sweet.

Brachycome.

Collinsias.

Dianthuses or Pinks.

Gypsophila muralis.

Iberis or Candytufts.

Leptosiphons.
Lobelia Erinus.

Nigellas.

Nemophilas.

Portulacas or Rose Moss.

Saponaria Calabrica.

Specularia.

\section{KINDS WHICH CONTINUE TO BLOOM AFTER FROST}

Abronia umbellata.

Adonis æstivalis.

Adonis autumnale.

Argemone grandiflora .

Calendulas.

Callirrhöe.

Carduus Benedictus.

Centaurea Cyanus.

Centauridium.

Centranthus macrosiphou.

Cerinthe retorta.

Cheiranthus Cheiri.

Chrysanthemums.

Convolvulus minor.

Convolvulus tricolor.

Dianthus of various kinds.

Elscholtzia cristata.

Erysimum Peroffskianum.
Erysimum Arkansanum.

Eschscholtzias, in several varieties.

Gaillardia picta.

Gilia Achilleæfolia.

Gilia capitata.

Gilia laciniata.

Gilia tricolor.

Iberis affinis.

Lavatera alba.

Matthiolas or Stocks.

Enothera rosea.

Enothera Lamarckiana:

Enothera Drummondii.

Phlox Drummondii.

Podolepis affinis.

Podolepis chrysantha.

Salvia coccinea. 
Kinds which Bloom after Frost-Continued

Salvia farinacea.

Salvia Horminum.

Verbenas.

Vicia Gerardii.

\author{
Virginian Stocks. \\ Viscaria elegans. \\ Viscaria oculata. \\ Viscaria coli-rosa.
}

\section{Antirrhinum. See Snapdragon.}

Apple, the "King of Fruits," thrives over a wider range of territory and under more varied conditions than any other tree fruit. This means that it is easy to grow. In fact, it is so easy to grow that it usually is neglected; and people wonder why the trees do not bear.

The selection of varieties of Apples for home use is, to a large extent, a personal matter; and no one may say what to plant. A variety that is successfully grown in one section may prove disappointing in another. One should study the locality in which he wishes to plant and choose those varieties which are the most successfully grown there,choosing from amongst the successful kinds those which he likes best and which seem best to meet the purposes for which he is to grow them. When the selection is made, the trees should be procured from a near-by nurseryman, if possible, as one is then able to select his own trees, receive them in the shortest time, and plant them before they have become dry.

The land on which an orchard is to be planted should have been in eultivation at least two year's previous to setting the trees and be in a fine physical condition. Dig the hole broad and deep enough to take in all the roots left after pruning off the bruised ends caused by digging up the tree, and trim back the branches at least two-thirds, making a smooth cut. Set the trunk in the center of the hole, and sift the fine dirt down through the roots, slightly lifting the tree once or twice in order that the fine soil may settle under the roots, making congenial soil for the new roots to run through. Fill in over the roots, gradually firming the soil 
alove with the feet. When the hole is full, firm the soil around the trunk to prevent whipping by the wind, leaving the surface level. If the trees are set in the fall a slight earthing up to the trunk may be beneficial in certain soils, and if set in a dry spring a mulch of straw or grass will benefit them. Two- or 3-yearold trees (usually the latter) are the most desirable for planting in home grounds. Commercial orchards are often planted exclusively with 2-year-olds.

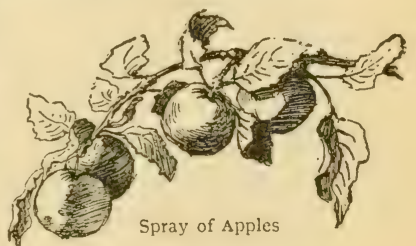

In orchard cultivation, Apple trees are usually planted 35 to $40 \mathrm{ft}$. apart each way. In home grounds they may be placed somewhat closer than this, especially if they are planted upon the boundaries, so that the limbs may project freely in one direction.

It is ordinarily advisable, especially in the humid climates east of the Great Lakes, to have the boly of the tree $3 \frac{1}{2}$ to $4 \frac{1}{2} \mathrm{ft}$. long. The limbs should be trimmed up to this point when the tree is set. From three to five main branches may be left to form the framework of the top. These should be shortened back one-fourth or one-half when the tree is set. Subsequent pruning should keep the top of the tree open and maintain it in more or less symmetrical form. See Pruning.

In orchard conditions, the trees should be kept in elean culture, especially for the first few years; but this is not always possible in home yards. In lieu of tillage, the sward may be mulched each fall with stable manure, and commercial fertilizer may be applied each fall or spring. If fruit is wanted rather than foliage and shade, care sbould be taken not to make ground too rich but to keep it in such condition that the tree is making a fairly vigorous growth, with good strong foliage, but is not overgrowing. An Apple tree in full bearing is usually in good condition if the twigs grow from 10 to 
18 in. each season. All leaf-eating insects may be kept off by spraying with Paris green. The Appleworm or codlinmoth may be kept in check by spraying with Paris green as soon as the blossoms fall, and again a week or ten days later. The leaf blight or apple-seab fungus may be kept in check by spraying with Bordeaux mixture just before the flowers open, and again after they fall (see spraying). A close watch should be kept for borers. Whenever the bark appears to be dead or sunken in patches, remove it and search for the cause. A borer will usually be found underneath the bark. About the base of the tree the most serious injury occurs from borers, since the insect which enter's there bores into the hard wood. His presence can be determined by the chips which are cast from his burrows. The only remedy is to dig out the larvæ. If they have got far into the wood, they can be killed by running a flexible wire into the burrows.

Apple trees should begin to bear when three to five years planted, and at ten years should be bearing good crops. With good treatment, they should continue to bear for thirty or more years. It is cheaper to buy trees from the nursery than to attempt to raise them for oneself.

The dwarf Apples are secured by grafting any variety on the Paradise or Doucin stocks, which are simply smallgrowing varieties of Apples. Dwarfs are much used in the Old World. There is no reason why they should not be used for home gardens in this country. They may be planted 8 to $10 \mathrm{ft}$. apart, and trained in various ways. The body or trunk should not be more than 1 or $2 \mathrm{ft}$. long. The top should be headed-in each year a third or a half of the annual growth. Dwarfs bear sooner than standards. A dwarf in full bearing should produce from a peck to a bushel of apples. Usually only the finer or dessert variety of Apples should be grown on dwarf trees.

Tany of the local varieties of Apples are excellent for home use. From the following list of dessert va- 
rieties, one can select a good assortment for the home garden:

Summer.-Early Joe, Primate, Garden Royal, Summer Pearmain, Early Harvest, Summer Rose, Sweet Bough, Summer Queen, Early Strawber'y, Williams Favorite.

Fall.-Chenango, Dyer, Jefferis, Jersey Sweet, Maiden Blush, Gravenstein, Fall Pippin, Mother (late fall to winter), Twenty Ounce.

Winter.-Newtown Pippin, Golden Russet, Bellflower, Belmont, King (late fall S. of N. Y.), Grimes Golden, Melon, Hubbardston (Nonesuch), Northern Spy, Jonathau, Fameuse or Snow, Lady, Rambo, Canada Red, York Imperial, Pommo Gris, Esopus Spitzenburg, Swaar, Peck Pleasant, Rhode Island Greening, Tallman Sweet, Sutton Beauty, Wagener, Seek-no-further.

Apricot. This fruit, usually thought to be too tender for the winters in the latitude of New Yark, has proved as hardy as the peach. Given the right conditions as to soil and exposure, it will yield abundant erops, ripening its fruits about three weeks in advance of early peaches. It would seem that more attention should be given to its cultivation. In western New York commercial orchards are now producing crops of as fine fruit as that brought from California. The introduction of the Russian varieties, a few years ago, added to the list several desirable kinds that have proved hardier and a little later in blooming than the old kinds. The fruits of the Russian varieties, while not as large as the other varieties, fully equal many of them in flavor, and they are very productive. The soil for Apricots should be rather dry; especially should the subsoil be such that no water may stand around the roots. The exposure should be to the north or west to retard the blooming period, as the one great drawback to their suceessful fruiting is the early blooming and subsequent freezing of the flowers or small fruits.

The two serious difficulties in the growing of Apricots 
are the ravages of the cureulio (see Plum) and the danger to the flowers from the spring frosts. It is usually almost impossible to secure fruits from one or two isolated Apricot trees, because the curculios will take them all. It is possihle, also, that some of the varieties need cross-pollination. The Apricot usually thrives best on strong soil; but otherwise the treatment which is given the peach suits the Apricot very well. The Russian varieties bear more profusely and with less eare than the old-fashioned and larger kinds. Amongst the best kinds of Apricots are Montgamet, Jackson, Royal, St. Ambroise, Early Golden, Harris, Roman and Moorepark. In the east, Apricots are rommonly worked on plums, but they also thrive on the peach.

Aquarium. A pleasant adjunct to a living room or conservatory is a large glass globe or glass box containing water, in which plants and animals are living and growing. A solid glass tank or globe is better than a box with glass siles, because it does not leak, but the box must be used if one wants a large Aquarium. For most persons it is better to buy the Aquarium box than to attempt to make it. Four things are important in making and keeping an Aquarium (according to Miss Rogers, in Cornell Nature-Study Leaflet No. 11):

"(1) The equilibrium between plant and animal life must be secured and maintained. Animals do not thrive in water where no plants are growing. Nature keeps plants and animals in the same pond, and we must follow her lead. The plants have three valuable functious in the Aquarium. First, they supply food for the herbivorous ereatures. Second, they give off a quantity of oxygen which is necessary to the life of the animals. Third, they take up from the water the poisonous carbonic acid gas which passes from the bodies of the animals. Just how the plants do this is another story. (2) The Aquarium must be ventilated. Every little fish, snail and insect wants air. A certain quantity of air is mixed with the water, and the 
creatures must breathe that or come to the surface for their supply. How does Mother Nature manage the ventilation of her aquaria, the ponds and streams? The plants furnish part of the air, as we have seen. The open pond, whose surface is ruffled by every passing breeze, is constantly being provided with fresh air. A tadpole or a fish can no more live in a long-necked bottle than a boy can live in a chimney. (3) The temperature should be kept between $40^{\circ}$ and $50^{\circ}$ Fahr. Both nature and experience teach us this. A shady corner is a better place for the Aquarium than a sunny window on a warm day. (4) It is well to choose such animals for the Aquarium as are adapted to life in still water. Unless one has an arrangement of water pipes to supply a constant flow of water through the Aquarium, it is best not to try to keep ereatures that we find in swift streams. Practical experience shows that there are certain dangers to guard against. Perhaps the most serious results come from overstocking. It is better to have too few plants or animals than too many of either. A great cleal of light, especially bright sunlight, is not good for the Aquarium. A pond that is not shaded soon becomes green with a thick growth of slime, or algæ. This does not look well in an Aquarium, and is apt to take up so much of the plant-food that the other plants are starved out. The plants in the school-room window will shade the Aquarium nicely, just as the trees and shrubs on its banks shade the pond. If we find this slime forming on the light side of our miniature pond we put it in a darker place, shade it heavily so that the light comes in from the top only, and put in a few more snails. These will make quick work of the green slime, for they are fond of it, if we are not."

The aquatic plants of the neighborhood may be kept in the Aquarium, - such things as myriophyllums, charas, eelgrass, duckmeats or lemnas, eabomba or fish grass, arrowleafs or sagittaria, and the ike; also the parrot's feather, 
to be bought of florists (a species of myriophyllum). Of animals, there are fishes (particularly minnows), water inscets, tadpoles, clams, snails. If the proper balance is maintained between plant and animal life, it will not be necessary to change the water so frequently.

Aquatics and Bog Plants. Many water plants are easily grown, and make a fine addition to the home garden. The sedges and other bog plants, the cyperus or umbrella plant, the common wild water lily, and in large grounds the nelumbium or Egyptian lotus, all may be grown with ease. For restricted grounds any of these, with the exception of the nelumbium, may be grown in tubs made by sawing an oaken barrel in two, filling each half from onethird to one-half with soil composed of good loam, sand and leaf-mold, setting the plants well into the soil and filling the tubs with water. These tubs should be sunk to the rim in the borders or lawn, both for a good appearance and to prevent too great evaporation. By a little care in filling with water, these plants may be well grown through the hottest weather. Most of the foreign water lilies are not hardy, but some of them may be grown with ease if the pond is covered in winter.

Native Aquaties may be colonized in streams or ponds. If artificial ponds are to be made, do not get them too deep. A foot or 15 inches is sufficient depth of water to stand above the crowns of the plants; and the greatest depth of water should not be more than $2 \frac{1}{2} \mathrm{ft}$. for all kinds of water lilies. Half this depth is often sufficient. The soil should be 1 to $2 \mathrm{ft}$. deep, and very rich. Cow manure may be mixed with rich loam. Roots of hardy water lilies may be planted as soon as the pond is elear of frost, but the tender kinds (which are also to be taken up in the fall) should not be planted till it is time to plant out geraniums. Sink the roots into the mud so that they are just buried, and weight them down with a stone or clod. In cold climates, protect the pond of hardy Aquaties by throwing boards over 
the pond and covering with hay, straw or evergreen boughs. It is well to supply an additional depth of water as a further protection.

Aquilegia. Columbine. These hardy perennials are general favorites for borders and rockwork. Blooming early in the season, they may be said to head the procession of the perennials. The ease with which they may be cultivated, their freedom of bloom, their varied colors and odd shape entitle them to the front rank among hardy plants. They are propagated by division of the plants in the spring or from seed sown in the fall. Seedlings may be expected to bloom well the second year. They require a moist, partially sheltered situation, with exposure to the sun. The common wild Columbine (often ealled "honeysuckle") is easily grown and is very attractive. Clumps of Columbine should stand 12-18 in. apart. 2-3 ft. high.

Araucaria, or Norfolk Island Pine, is now sold in pots by florists as a window plant. The common species (A. excelsa) is most excellent for this purpose, making a symmetrical evergreen subject. It keeps well in a cool window, or on the veranda in the summer. Protect it from direct sunlight, and give plenty of room. If the plant begins to fail, return it to the florist for recuperation.

\section{Argemone. See Priclily Poppy.}

Aristolochia, or Dutchinan's PiPe. A strong, woody twiner with very large, heavy leaves, forming a dense screen and having peculiarly shaped flowers. But one species is considered hardy north, $A$. Sipho. This will grow without special treatment and prove a satisfactory ornamental screen or porch plant. Reaches a height of 20 or 30 ft. Young plants need some protection in cold winters.

Artichoke. A tall, coarse peremial of the thistle tribe, producing flower-heads which are edible. When once established, it will last in bearing for a number of years. 
While this plant is not generally grown in this country, its merit as a supplementary vegetable for salads or cooking is great. It is usually grown from suckers from the root, but a start ean be made by sowing the seed. Sow in a border or seed box and transplant to the garden in early summer; and the following year a crop may be had. The parts of the plant used are the flower-heads and the young suckers, the former boiled or eaten raw as a salad. The young shoots may be tied together and blanched, using them like asparagus or Swiss chard. The fleshy scales of the head and the soft "bottom" of the head are the parts used. But few of these plants would be needed for a family, as they produce a number of flower-heads to a plant and a quantity of suckers. The plants should be set from 2 to $3 \mathrm{ft}$. apart in the row, the rows being $3 \mathrm{ft}$. apart. This vegetable is not quite hardy in the north, but a covering of leaves or barnyard litter to the depth of a foot will protect them well. The plant, being a perennial, will continue to yield for a number of years under good cultivation. These plants make no mean decorative subjects, either massed or in a mixed border, and from the rarity of their culture are always objects of interest.

Artichoke, Jerusalem, is a wholly different plant from the above, although it is commonly known as "Artichoke" in this country. It is a species of sunflower which produces potato-like tubers. These tubers may be used in lieu of potatoes. They are very palatable to hogs; and when the plant becomes a weed-as it often does-it may be exterminated by turning the hogs into it. Hardy.

Arundo, or REED, is one of the best of bold and ornamental grasses, excellent for the center of a large formal bed, or for emphatic points in a mixed border. It is perennial and hardy in the northern states, but it is advisable to give it a mulch on the approach of winter. Thrives in any rich soil, doing best where somewhat moist. 8-12 ft. The clumps enlarge year by year. 
Asparagus. A hardy herbacous pereunial, much grown for the soft, edible, early spring shoots. The culture of this, the finest of early vegetables, has been simplified in the past few years, and at present the knowledge required to suceessfully plant and grow a good supply need not be that of a professional. The old method of excavating to the depth of $3 \mathrm{ft}$. or more, throwing in from 4 to $6 \mathrm{in}$. of broken stone or bricks for drainage, then filling to within 16 to $18 \mathrm{in}$. of the surface with well rotted manure, with 6 in. of soil upon which to set the roots, has given place to the simple practice of plowing or digging a trench from 14 to $16 \mathrm{in}$. deep, spreading well rotted manure in the bottom to the depth of 3 or 4 in.; when well trodden down covering the manure with 3 or $4 \mathrm{in}$, of good garden soil, then setting the plants, with the roots well spread out, covering carefully with soil to the level of the garden, and firming the soil with the feet. This will leave the erowns of the plants from 4 to $5 \mathrm{in}$. below the surface. In setting, 1 -year-old plants will prove more satisfactory than older ones, being less liable to suffer from injury to the root system than those which have made a larger growth. Two years after setting the crop may be eut, but not sooner if a lasting bed is desired, as the effort to replace the stalks has a tendency to weaken the plant unless the roots are well established. The yearly treatment of an Asparagus bed consists of cleaning off tops and weeds in the fall and adding a dressing of well rotted manure to the depth of 3 or 4 in., this manure to be lightly forked into the hed the following spring; or, the tops may be allowed to stand for winter protection and the mulch left off. A top-dressing of nitrate of soda, at the rate of 200 pounds per acre, is often beneficial as a spring stimulant, especially in the case of an old bed. Good results will also follow an application of bone meal or superphosphate at the rate of from 300 to 500 pounds per acre. The practice of sowing salt on an Asparagus bed is almost universal. Still, beds that have never received a 
pound of salt are found to be as productive as those having received an annual dressing. Nevertheless, a salt dressing is recommended. In stubborn, heavy soil the best method to pursue in making a permanent bed would be to throw out all the dirt from the trench and replace with good, fibrous loam. Two rows of Asparagus $25 \mathrm{ft}$. long and $3 \mathrm{ft}$. apart would supply a large family with an abundance throughout the season, and if well taken care of will last a number of years. Conover's Colossal is the variety most generally grown, and is perhaps the most satisfactory sort. Palmetto, a variety originating at the south, is also very popular. A newer variety, called Donald White, originating near Elmira, N. Y., is recommended by the trade.

Asperula. Hardy annuals and perennials. The low-growing Asperula, with its blue or white flowers, is not as often used as it should be. The profusion of small flowers and the long season entitle it to a place in low borders. The flowers have a pleasing fragrance. Asperulas may be used effectively on rockwork. The common white species, or Woodruff, grows less than 1 foot. Grown readily from seeds, and blooms the first year. All Asperulas thrive best in a rather moist soil.

Asters, China. Half-hardy annuals, of easy culture. The China Aster has been for years a great favorite in both old-fashioned and modern gardens. With the improvements in shapes and colors, they are now the rivals of the chrysanthemum. As early as 1731 single white and red Asters were grown and described in England, and by 1845 they are mentioned as being very numerous in New England. The Germans were, perhaps, the first to improve the Asters, and the type most admired and sought fifty years ago was the full-quilled varieties. Now, however, the informal type replaces the stiff, formal quilled flowers of that period. Compare the Comet Aster of to-day with the Asters of even twenty years ago, and note the looseness of its broad rays, giving an artistic value 
far beyond the tall, stiff, purple-blue or whites of that period.

The early Aster's will bloom in August if the seed is sown in the open early in the season. They are represented by the Queen of the Market and Queen of Spring, either of which, if started in a hotbed or window, will begin to bloom the last of July. The Queen of the Market is probably the freest of growth, and with its long stems makes a very desirable variety for eut-flowers. In fact, in the rich, mellow soil in which Asters delight, this variety is likely to have its large flowers on stems so long and slender that the plants will need stakes.

The Victoria Aster's hold a well deserved place

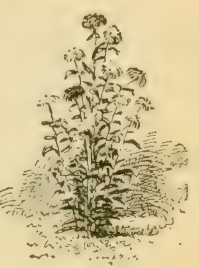

China Aster among the leading varieties, and with high culture will generally lead in size and profusion of bloom, the colors ranging from white to the darkest blue. The plants are also well adapted to pot culture. The chrysanthemumflowered Asters, both tall and dwarf, are excellent, as are the Truffaut Perfection and Peony-flowered. The Comet Asters are amongst the best. The New Branching type is now in great favor.

The culture of China Asters is easy. For early bloom the seeds should be sown in March in boxes of light soil and covered one-quarter of an inch with soil, the soil pressed down or firmed over them and the boxes placed in a hotbed or a sunny window and attention given to watering. When the seedlings are one inch high they should be transplanted to other boxes, setting the plants 3 inches apart or put into 2 -inch pots. These should be again placed in a frame and grown along until the ground has become comparatively warm. The soil will need to be well enriched, mellow, and if slightly moist under the surface the results will be all that could be wished. Asters will grow fairly well on rather light soil, even if not very rich, but the best results can only be obtained when the highest culture is 
given. If the rust attacks the plants, spray with ammoniacal carbonate of copper.

Aster, Native. Wild Aster's ale one of the glories of the American autumn. They grow almost everywhere in the north and east,-along roadsides, in meadows and swales. Their colors range from pure white to pink, and purple, and blue. From August until winter closes in, they are conspicuous features of the landscape, vying with the goldenrods in form and color, but surpassing them in color-range. Most of them are greatly improved when transferred to the border. They become Spray of wild Aster more attractive in general habit, and the flowers are usually more profuse and sometimes larger. They are of the easiest possible culture. They can he removed to home grounds in the fall or spring, and, with little care until they are established, will make most attractive displays of autumn color. The species are numerous and much confused, and it is not necessary to make a list of them here. Because of their free and careless habit, they are better adapted to planting in borders than in the formal flower beds.

Aubrietia deltoidea. A very handsome little trailing hardy perennial, covered with attractive purple flowers in early spring. Should be planted in masses for best effect.

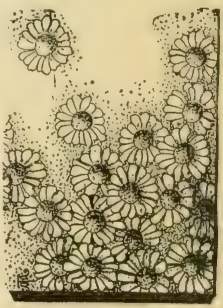

Wild Asters Propagated by cuttings or seeds, usually the latter. Excellent for rockwork and permanent low edgings.

\section{Auricula. A half-hardy perennial of the} Primrose tribe (Primula Auricula), very popular in Europe, but little grown in this country on account of the hot, dry summers. In this country usually propagated by seed, as for Cineraria ; but special varieties are perpetuated by off- 
sets. Seeds sown in February or March should give blooming plants for the next February or March. Keep the plants cool and moist, and away from the direct sun during the summer. Gardeners usually grow them in frames. In the fall, they are potted into 3 -inch or 4 -inch pots, and made to bloom either in frames as for violets or in a cool conservatory or greenhouse. In April, after blooming has ceased, repot the plants and treat as the previous year. From the best plants, offsets may be taken and treated the same as seedlings. As with most annual-blooming perennials, best results are to be expected with year-old or 2year-old plants. Auriculas grow $6-8$ in. high. Colors white and many shades of red and blue.

Azaleas are less grown in this country than in Europe, largely because of our hot, dry summers and severe winters. There are two common types or classes,the hardy or Ghent Azaleas, and the Indian Azaleas.

Ghent Azaleas thrive in the open along the seacoast as far north as southern New England. They require a sandy, peaty soil, and are treated as other shrubs are. The large flower-buds are liable to injury from the warm suns of late winter and early spring, and to avoid this injury the plants are often protected by covers or shades of brush. In the interior country, little attempt is made to flower Azaleas permanently in the open, although they may be grown if carefully tended and well protected. Both Ghent and Indian Azaleas are excellent pot-plants, for bloom in late winter and spring. The plants are imported in great numbers from Europe, and it is better to buy these plants than to attempt to propagate them. Pot them up in large-sized pots, keep them cool and backward for a time until they are established, then take them into a conservatory temperature, in which carnations and roses thrive. They should be potted in a soil made of half peat or well decayed mold and half rich loam; add a little sand. Pot firmly, and be sure to provide sufficient drainage. Keep off red spider by 
syringing. After blooming, the plants may be thinned by pruning out the straggling growths, and repotted. Set them in a frame or in a semi-shaded place during summer, and see that they make a good growth. The wood should be well ripened in the fall. After cold weather sets in, keep the Indian or evergreen kinds half-dormant by setting them in a cool, dull-lighted cellar or pit, bringing them in when wanted for bloom. The Ghent or deciduous kinds may be touched with frost without injury; and they may be stored in a cellar until wanted.

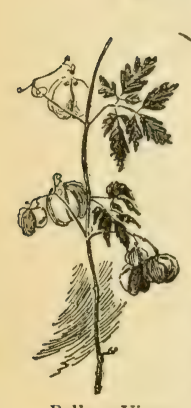

Bachelor's Button. Centaurea $C y$ b) anus and also Gomphrena. Sometimes applied to double-flowered Crowfoots.

Balloon Vine, or Cardiospermum. Annual tender tendril climber of very rapid growth. Seed should not be planted until the soil becomes warm. A very pretty effect ean be had by allowing the vine to run over some coarser vine, or into an evergreen tree. The balloon-like capsules show to good advantage between the leaves. It is also useful for covering piles of brush. Grows 8-12 ft. high. Give a warm, sunny place.

Balsams, or Impatiens. Tender annuals, producing both single and double flowers of many colors. These well known favorites are usually to be found in oldfashioned gardens. They are very likely to seed themselves, coming up in unexpected places and flourishing in neglect. They do best, however, in rich, sandy soil. If the seed is sown in boxes late in April and the plants transplanted several times they will be much dwarfer and the flowers much more double. A stately, though very formal and stiff, effect may be had by planting a row of Balsams in the rear of a low border, pinching off all the side shoots as they start and growing the plant to a single stem. This will become covered with the large blooms, giving it the appearance of a 
perfect columan of flowers. Balsams are injured by the sligntest frost. Seeds germinate quickly. Plants should stand 12-18 in. apart. They grow 18-30 in. high.

Bartonia. Hardy annual, with golden yellow, brilliant flowers. The tall-growing Bartonia ( $B$. aurca) may be used in a mixed border to good advantage. It is a bushy plant, reaching $2 \cdot 3 \mathrm{ft}$. high. The dwarf kind may be used as a border plant or in a rock garden, or as an edging. The fragrance of both tall and dwarf is very pronounced in the evening. The Bartonias are very easy to grow in a warm soil and sunny exposure. Their numerous thread-like, long stamens are very interesting.

Basket Plants. In order to have a good hanging basket, it is necessary that some provision be made to prevent too rapid drying out of the earth. It is customary, therefore, to line the pot or basket with moss. Open wire baskets, like a horse muzzle, are often lined with moss and used for the growing of plants. Prepare the earth by mixing some well decayed leaf-mold with rich garden loam, thereby making an earth which will retain moisture. Hang the basket in a light place, but still not in a direct sunlight; and, if possible, avoid putting it where it will be exposed to drying wind. In order to water the basket, it is often advisable to sink it into a pail or tub of water. Various plants are well adapted to hanging baskets. Among the drooping or vine-like kinds are the strawberry geranium, Kenilworth ivy, maurandya, German ivy, canary-bird flower, Asparagus Sprengeri, ivy geranium, trailing fuchsia, wandering Jew, and othonna. Among the erect-growing plants which produce flowers, Lobelia Erinus, sweet alyssum, petunias, oxalis, and various geraniums are to be recommended. Among foliage plants such things as coleus, dusty miller, begonia, and some geraniums are adaptable.

Baskets. For the picking and handling of fruit in the home garden, the common Climax basket, in 
various sizes, is the best receptacle. In these baskets the products may be sold. When the baskets are sent to market or to a friend, they should be neat and new looking;

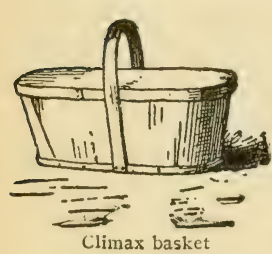
therefore keep them in a dry, dark place, as in an attic or loft, to prevent them from becoming warped and discolored.

Bean. Under the general name of Bean, many kinds of plants are eultivated. They are all tender, and the seeds, therefore, should not be planted until the weather is thoroughly settled; and the soil should be warm and loose. They are all annuals in northern countries, or treated as such.

The Bean plants may be classified in various ways. In respect to stature, they may be thrown into three general eategories; viz., the pole or elimbing Beans, the bush Beans, and the strict-growing or upright Beans (as the Broad or Windsor Bean). In respect to their uses, Beans again may be divided into three eategories; viz., those which are used as string or snap Beans, the entire pod being eaten; those which are used as shell Beans, the full-size but immature Beans being shelled from the pod and cooked; dry Beans, or those which are eaten in their dry or winter condition. The same variety of Bean may be used for all of these three purposes at different stages of its development; but as a matter of fact, there are varieties which are better for one purpose than the other. Again, Beans may be classified in respect to their species. Those species which are best known are as follows: (1) Common Bean, or Phaseolus vulguris, of which there are both tall and bush forms. All the common snap and string Beans belong here, as also the Speckled Cranberry types of pole Beans, and the common field Beans. (2) The Lima Beans, or Phaseolus lunatus. The larger part of these are pole Beans, but lately dwarf or bush varieties have appeared. (3) The Scarlet Runner, Phaseolus multiflorus, of which the 
Scarlet Runner and White Duteh Runner are familiar examples. The Searlet Runner is usually grown as an ornamental vine, and it is perennial in warm countries, but the Beans are edible as shelled Beans. The White Dutch Runner is oftener cultivated for food. (4) The Yard-Long, or Asparagus Bean, Dolichos sesquipedalis, which produces long and weak vines and very long, slender pods. The green pods are eaten, and also the shelled Beans. The French Yard-Long is the only variety of this type which is commonly known in this country. This type of Bean is popular in the Orient. (5) The Broad Beans, of which the Windsor is the common type. These are much grown in the Old World for stock feed, and they are sometimes used for human food. They grow to one strict, central, stiff stalk, to a height of $2-4$ or $5 \mathrm{ft}$., and they are very unlike other kinds of Beans in appearance. In this country, they are very little grown on account of our hot and dry summer's. In Canada they are somewhat grown, and are sometimes used in the making of ensilage.

The culture of the Bean, while of the easiest, often proves a failure as far as the first crop is concerned, because of planting the seed before the ground has become warm and dry. No vegetable seed will decay quicker than Beans, and the delay cansed by waiting for the soil to become warm and free from excessive moisture will be more than made up by the rapidity of growth when finally they are planted. Beans will grow in most any soil, but the best results may be obtained by having the soil well enriched and in good physical condition. From the 5th to the 10th of May in the latitude of central New York, it will be safe to plant Beans for an early crop. The Beans may be dropped 2 inches deep in shallow drills, the seeds to lie 3 inches apart. Cover to the surface of the soil, and if the ground be dry, firm it with the foot or the back of the hoe. For the bush varieties, allow $2 \mathrm{ft}$. between the drill-rows, but for the dwarf Limas $2 \frac{1}{2} \mathrm{ft}$. is better. Pole Limas are 
usually planted in hills 2-3 ft. apart in the rows. Dwarf Limas may be sown thinly in drills.

A large number of the varieties of both the green-podded and the wax-podded Beans are used almost exclusively as snap Beans, to be eaten with the pod while tender. The various strains of the Black Wax are the most popular string Beans. The pole or running Beans are used either green or dried, and the Limas, both tall and dwarf, are well known for their superior flavor either as shelled or dry Beans. The old-fashioned Cranberry or Horticultural Lima type (a pole form of Phaseolus vulgaris) is probably the best shell Bean, but the trouble of poling makes it unpopular. Dwarf Limas are much more desirable for small gardens than the pole varieties, as they may be planted much closer, the bother of procuring poles and twine is avoided, and the garden will have a more sightly appearance. Both the dwarf Limas and pole Limas require a longer season in which to mature than the bush varieties, and only one planting is usually made. But the bush varieties may be planted at intervals of two weeks from the first planting until the 10th of August. Each planting may be made on ground previously oceupied by some earlymaturing erop. Thus, the first to third plantings may be on ground from which has been harvested a erop of spinach, early radish or lettuce; after that, on ground where early peas have been grown; and the later sowings where beets or early potatoes have grown. String Beans for canning are usually taken from the last crop. One quart of seed will plant $100 \mathrm{ft}$. of drill; or 1 quart of Limas will plant 100 hills.

Limas are the richest of Beans, but they often fail to mature in the northern states. The land should not be very rich in nitrogen (or stable manure), else the plants will run too much to vine and be too late. Select a fertile sandy or gravelly soil with warm exposure, use some soluble commercial fertilizer to start them off, and give them the 
best of culture. Aim to have the pods set before the droughts of midsummer come. Good trellises for Beans are made by wool twine stretched between two horizontal wires, one of which is drawn a foot above the ground and the other 6 or $7 \mathrm{ft}$. high.

Bean plants are not troubled by insects to any extent, but they are sometimes attacked by blight. When this oecurs, do not plant the same ground to Beans again for a year or two.

Bedding. This term is used to designate the massing of plants in the open ground for the purpose of making a bold display of color. This color may be obtained with flowers or with strong effects of foliage. Bedding is ordinarily a temporary species of planting; that is, the bed is filled anew each year. However, the term may be used to designate a permanent plantation of plants which are heavily massed so as to give one continuous or emphatic display of form or color. Some of the best permanent bedding masses are made of the various hardy ornamental grasses, as eulalias, arundo, and the like.

Some bedding is very temporary in its effect. Especially is this true of spring Bedding, in which the plants used are tulips, hyacinths, erocuses or other early-flowering bulbous plants. In this case, the ground is usually occupied later in the season by other plants. These later plants are usually annuals, the seeds of which are sown amongst the bulbs as soon as the season is far enough advanced; or the annuals may be started in boxes and the plants transplanted amongst the bulbs as soon as the weather is fit. Many of the lowgrowing and compact, continuous-flowering annuals are excellent for summer Bedding effects. Some of the best plants for this purpose are mentioned in the following list:

Adonis æstivalis.

Adonis autumnalis.

Ageratum Mexicanum.

Ageratum Mexicanum, dwarf.
Bartonia aurea.

Cacalia.

Calendula officinalis, in several forms. 
Calendula pluvialis.

Calendula Pongei.

Calendula sulphurea, fl. pl.

Calendula suffruticosa.

Calliopsis bicolor marmorata.

Calliopsis cardaminæfolia.

Calliopsis elegans picta.

Callirrhoë involuerata.

Callirrhoë pedata nana.

Callirrhoë pedata.

Centaurea Americana.

Centaurea Cyanus, Victoria

Dwarf Compact.

Centaurea Cyanus minor.

Centaurea suaveolens.

Chrysanthemum Burridgeanum.

Chrysanthemum earinatum.

Chrysanthemum coronarium.

Chrysanthemum tricolor.

Convolvulus minor.

Convolvulus tricolor.

Cosmidium Burridgeanum.

Delphinium, single,

Delphinium, double.

Dianthus, Double White Half

Dwarf Margaret.

Dianthus, Dwarf Perpetual.

Dianthus Caryophyllus semperflorens.

Dianthus Chinensis, double.

Dianthus dentosus hybridus.

Dianthus Heddewigii.

Dianthus imperialis.

Dianthus laciniatus, Salmon Queen.
Dianthus plumarius. $[\mathrm{pl}$. Dianthus superbus, dwarf $\mathrm{fl}$. Dianthus, Picotee. Elscholtzia cristata. Eschscholtzia Californica. Eschscholtzia crocea. Eschscholtzia, Mandarin. Eschscholtzia tenuifolia. Gaillardia picta. Gaillardia picta Lorenziana. Gilia achilleæfolia. Gilia capitata. Gilia laciniata. Gilia linifolia. Gilia nivalis. Gilia tricolor. Godetia Whitneyi. Godetia grandiflora maculata. Godetia rubicunda splendens. Hibiscus Africanus. Hibiscus, Golden Bowl. Iberis affinis. Iberis amara.

Iberis coronaria. Iberis umbellata. Impatiens or Balsam. Lavatera alba. Lavatera trimestris. Linum grandiflorum. Madia elegans. Malope grandiflora. Matricaria eximia plena. Matthiola or Stock, in many forms.

Matthiola, Wallflower-leaved. Matthiola bicornis. 
Nigella or Love-in-a-Mist. Enothera Drummondii.

Enothera Lamarckiana.

Enothera rosea.

Enothera tetraptera.

Papaver or Poppy, of many kinds.

Papaver cardinale.

Papaver glaucum.

Papaver umbrosum.

Petunia, Ring of Emerald.

Phlox Drummondii, in many varieties.

Portulaca.

Salvia farinacea.

Salvia Horminum.

Salvia splendens.

Schizanthus papilionaceus,

Schizanthus pinnatus.

Silene Armeria.
Silene pendula.

Tagetes or Marigold, in many forms.

Tagetes erecta.

Tagetes patula.

Tagetes signata.

Tropæolum, Dwarf.

Verbena auriculæflora.

Verbena Italica striata.

Verbena hybrida.

Verbena cœrulea.

Verbena, Golden-leaved.

Viscaria cœli-rosa.

Viscaria elegans picta.

Viscaria oculata.

Zinnia, Dwarf.

Zinnia elegans alba.

Zinnia, Tom Thumb.

Zinnia Haageana.

Zinnia coccinea plena.

Summer bedding is often made by perennial plants which are carried over from the preceding year, or better, which are propagated for that particular purpose in February and March. Such plants as geranium, coleus, alyssum, scarlet salvia, ageratum and heliotrope may be used for these beds. It is a common practice to use geranium plants which are in bloom during the winter for bedding out during the summer, but such plants are tall and ungainly in form and have expended the greater part of their energies. It is better to propagate new plants by taking cuttings or slips late in the winter and setting out young, fresh, vigorous subjects.

Very bold and subtropical effects can be made by planting in the open such things as palms, bananas, crotons, araucarias, caladiums and cannas. Plants like bananas and palms, which are kept normally in pots, would better be left in the pots and plunged to the rims rather than turned out 
directly into the soil. In order to attain quick and continuous effects, it is advisable to set the plants rather close. As such plants are likely to be injured by strong winds, it is well to have subtropical beds in a somewhat protected place.

Another type of bed is that which attempts to make patterns or designs, or carpet-bedding. There are comparatively few plants which are adapted to this purpose, for the plants must be such as will stand shearing and which have very strong and constant colors of foliage. The most popular bedding plants are coleus (particularly the yellow Golden Bedder) achyranthes, alternanthera, Centaurea gymnocarpa, and such succulent plants as the house leeks. Some of the annual flowers may also be used for strong color effects, as Lobelia Erimus and sweet alyssum. Ordinarily the making of carpet-beds should be left to professional gardeners, since it requires much skill and care to make and keep the beds in perfect condition; and a ragged or imperfect carpet-bed is worse than no bed at all. Carpetbeds are really curiosities, and they have no more legitimate place in the general pictorial landscape design area than painted stones or sheared evergreens. Therefore, they should be placed by themselves at one side, where they do not interfere with the general design of the place. In public parks they make a very useful attraction when set off by themselves, the same as zoölogical gardens or other attractions do.

\section{Beefsteak Geranium is Begonia.}

Beets. Being one of the hardiest of spring vegetables, the seed may be sown as early in the spring as the ground can be worked. A light, sandy soil is the best on which to grow Beets to perfection, but any well tilled garden soil will raise satisfactory crops. On heavy soil the turnip Beet gives the best results, as the growth is nearly all at or above the surface. The long varieties, having tapering roots running deep into the soil, are apt to be mis- 
shapen unless the physical condition of the soil is such that the roots meet with little obstruction. A succession of sowings should be made, at intervals of from two to three weeks, until late summer, as the Beets are much more desirable in their young stage than when they have become old and woody. The Mangel-Wurzel and the Sugar Beet are usually grown as a field crop, and will not enter into the calculations of the home garden.

In order to hasten the season of the extra-early crop of Beets, the seeds may be sown in boxes or in the soil of a hotbed in February or March, transplanting the small plants to the open ground at the time the first sowing of seed is made. As the flat or turnip-rooted varieties grow at the surface of the ground, the seed may be sown thickly, and as the more advanced roots are large enough to use they may be pulled, leaving room for the later ones to develop, thus growing a quantity in a small area and having a long season of small Beets from one sowing. For winter use the late July sown seed will give the best roots, growing through the cool months of the fall to a medium size and remaining firm without being tough or stringy. These may be dug up after light frosts and before any severe cold weather, and stored in barrels or boxes in the cellar, using enough dry dirt to fill spaces between the roots and cover them to the depth of 6 inches. These roots, thus packed in a cool cellar, will be fit to use through the entire winter months. When it can be had, florists' or sphagnum moss is an excellent medium in which to pack roots for winter.

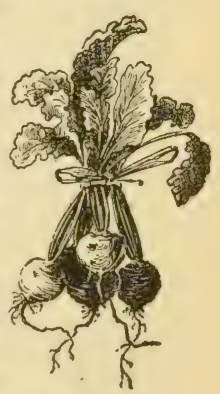

Early Beets

The early round or turnip varieties are best for early and summer use. The Long Blood Beets may be used for storing, but these require a longer season of growth.

Begonias. Tender bedding and house plants. Next to the geranium, Begonias are probably the most popular for house culture of the entire plant list. The ease of 
culture, profusion of bloom or richness of foliage, together with their adaptability to shade, make them very desirable.

Begonias may be divided into three sections: the fibrousrooted elass, which contains the winter-flowering varieties;

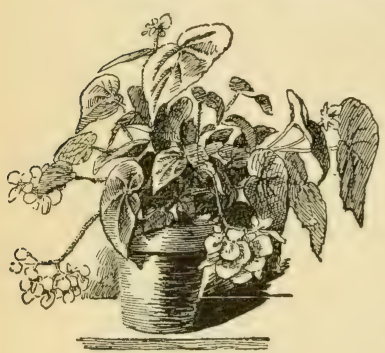

Fibrous-rooted Begonia

the tuberous-rooted, those which bloom through the summer, the tuber resting through the winter; and the Rex forms, or Beefsteak Geraniums, having large ornamental leaves.

The fibrous-rooted kinds may be propagated by seed or euttings, the latter being the usual method. Cuttings of half-ripened wood root easily, making a rapid growth, the plants flowering in a few months.

The tuberous-rooted varieties are propagated by division of the tuber or from seed, the former being rarely done except to increase the stock of some extra fine variety. The seeds, like those of all Begonias, are very small, and should be sown with great care. Simply sprinkle them on the surface of the soil, which should be a mixture of leafmold and sand, with the addition of a small amount of fibrous ioam. Watering should be done by setting the pot or box in which the seeds are sown in water, allowing the moisture to ascend through the soil. When the soil has become completely saturated, set the box in a shady situation, covering it with glass or some other object until the tiny seedlings appear. Never allow the soil to become dry. The seedlings should be transplanted, as soon as they can be handled, into boxes or pots containing the same mixture of soil, setting each plant down to the seed-leaf. They will need three or four transplantings before they reach the blooming stage, and at each one after the first, the amount of fibrous loam may be increased until the soil is composed of one-third each of loam, sand and leaf-mold. The addition of a little 
well rotted manure may be made at the last transplanting. These tuberous-rooted Begonias make superior bedding plants if given a shady situation and deep soil; but for the amateur they are perhaps better grown as pot-plants, for one is able to give them better conditions by that method. The flowers are both double and single, ranging in color from pure white and yellow to pink and red. After flowering the plants will die down and the tubers, after drying off, may be placed in a dry, warm place until spring.

The Rex type, having no branches, is propagated from the leaves. The large mature ieaves are used. The leaf may be cut

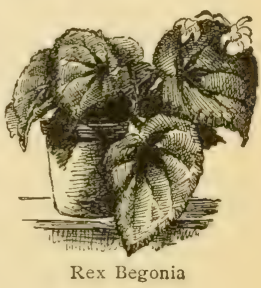
into sections having at the base a union of two ribs. These pieces of leaves may be inserted in the sand as any other cutting. Or a whole leaf may be used, cutting through the ribs at intervals and laying the leaf flat on the propagating bench or other warm, moist place. In a short time young plants having roots of their own will form. These may be potted when large enough to handle, and will soon make good sized plants. Rex Begonias usually grow little during winter. Be sure that the pots are well drained, so that the soil does not become sour. New plants-those a year or so old-are usually most satisfactory. Keep them away from direct sunlight.

An insidious disease of Begonia leaves has recently made its appearance. The best treatment yet known is to propa-

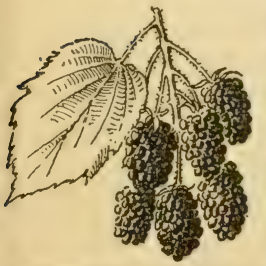

Ancient Briton Blackberry gate fresh plants, throwing away the old stock and the dirt in which it is grown.

\section{Bellis perennis. See Daisy.}

Blackberries. The one essential to the successful growing of Blackberries is a moist soil, - not one in which water will stand, but one rich enough in humus to hold sufficient moisture to carry the crop through the grow- 
ing season. It is usually found best to plant in the fall, earthing up slightly around the plants. The distance between the plants should be regulated by the variety. The smaller-growing kinds (as Early Harvest and Wilson) may

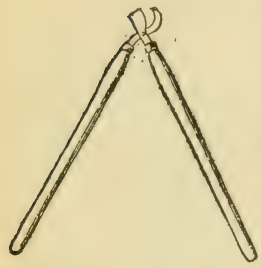

Shears for cutting out old canes

be planted $4 \times 7 \mathrm{ft}$, the rank-growing varieties (as Snyder) $6 \times 8 \mathrm{ft}$. Thorough eultivation throughout the season will help in a material degree to hold the moisture necessary to perfect a good crop. The soil should be cultivated very shallow, however, so as not to disturb the roots, as the breaking of the roots starts a large number of suckers that have to be cut out and destroyed.

Blackberries, like dewberries and raspberries, bear but one crop on the cane. That is, canes which spring up this year bear next year. From 3 to 6 canes are sufficient to be left in each hill. The superfluous ones are thinned out soon after they start from the ground. The old canes should be cut out soon after fruiting and burned. The new shoots should be pinched back at the height of 2 or $3 \mathrm{ft}$. if the plants are to support themselves. If to be fastened to wires, they may be allowed to grow throughout the season and be

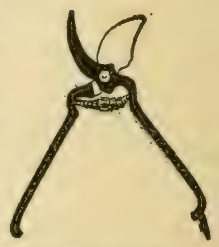

Shears for heading. in bushes

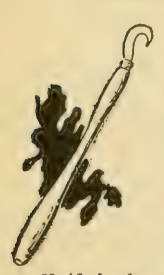

Knife hook for cutting out old canes eut back when tied to the wires in winter or early spring. Tools for the cutting out of the old canes are well represented in the pictures. Shears are used for shortening-in the canes.

Blackberry plants are sometimes laid down in cold climates, - the tops being bent over and held to the ground by earth or sods thrown on their tips.

Snyder is the most popular commereial variety; but Agawam, Ancient Briton, Taylor, and others are better in quality. A new patch should be planted every five or six years.

Blue Bottle. See Centaurea Cyanus. 
Bordeaux Mixture is a fungicide, used to combat mildews, leaf-diseases, blights, etc. It is sprayed on the plants with a spray pump or syringe, or it may be applied with a whisk broom. Apply enough of it so that the foliage looks blue. It is made as follows: Copper sulfate, 6 pounds; quicklime, 4 pounds; water, 40 to 50 gallons. Dissolve the copper sulfate by putting it into a bag of coarse cloth and hanging this in a vessel holding at least four gallons, so that it is just covered by the water. Use an earthen or wooden vessel. Slake the lime in an equal amount of water. Then mix the two and add enough water to make 40 gallons. It is then ready for immediate use, but will keep for some time. If the mixture is to be used on peach foliage, it is advisable to add an extra pound of lime to the above formula. When applied to such plants as earnations or cabbages, it will adhere better if a pound of hard soap is dissolved in hot water and added to the mixture. For rots, molds, mildews, and all fungous diseases.

Whilst Bordeaux Mixture is the best general fungicide, it discolors the plants until it washes off. On ornamental plants, therefore, a colorless fungicide may be preferable. In such cases, use the ammoniacal carbonate of copper solution, as follows : Copper carbonate, 1 ounce; ammonia, 1 volume $26^{\circ}$ Beaumé, $7 / 8$ volumes water (enough to dissolve the copper); water, 9 gallons. The copper carbonate is best dissolved in large bottles, where it will keep indefinitely, and it should be diluted with water as required. For the same purposes as Bordeaux Mixture.

Border. The word border is used to designate the heavy or continuous planting about the boundaries of a place, or along the walks and drives, or against the buildings, in distinction from planting on the lawn or in the interior spaces. A border receives different designations, depending upon the kinds of plants which are grown therein; that is, it may be a shrub border, a flower 
border, a hardy border for native and other hardy plants, a vine border, and the like. As a rule, the most effective planting is that which is thrown into masses, for one plant reinforces the other, and the flowers have a good setting or background. Very striking displays of foliage and flowers and plant forms can be made when massed together. As a rule, plants are more easily grown when planted in a border, since the whole area can be kept cultivated with ease; and if a plant becomes weak or dies, its place is readily filled by the neighboring plants spreading into it. Planting in masses is also essential to the best arrangement of the

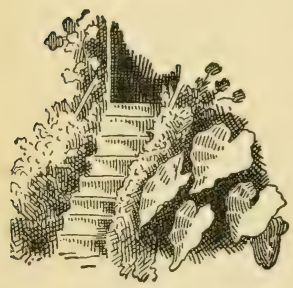

Planting by the steps yard, since the basis of any landscape is a more or less continuous greensward (see Lawn). The house occupies the central part of the area, and the sides are heavily massed or planted so as to make a framework for the whole place. The border may be mixed,-that is, composed of a great variety of plants, - or it may be made up of one continuous thing. In long and very striking borders, it is often best to have the background - that is, the back row - of one general type of plant in order to give continuity and strength to the whole group. In front of this a variety of plants may be set, if one desire.

The land should be rich. The whole ground should be plowed or spaded and the plants set irregularly in the space; or the back row may be set in a iine. If the border is composed of shrubs, and is large, a horse cultivator may be run in and out between the plants for the first two or three years, since the shrubs will be set from 2 to $4 \mathrm{ft}$. apart. Ordinarily, however, the cultivating is done by hand tools. After the plants are once established and the border is filled, it is best to dig up as little as possible, for the digging disturbs the roots and breaks off the crowns. It is usually best to pull out the weeds and give the border a 
top-dressing each fall of well rotted manure. If the ground is not very rich, a sprinkling of ashes or some commercial fertilizer may be given from time to time. The border should be planted so thick as to allow the plants to run together, thereby giving one continuous effect. Most shrubs should be set 3 feet apart. Things as large as lilaes may go 4 feet and sometimes even more. Common herbaceous perennials, like bleeding heart, delphiniums, hollyhocks, and the like, should go from 12 to 18 inches. On the front edge of the border is a very excellent place for annual and tender flowering plants. Here, ior example, one may make a fringe of asters, geraniums, coleus, or anything else which he may choose (see Flower Beds).

The border is an excellent place in which to colonize native or other interesting plants. A person comes across an attractive plant on his tramp and wishes it were in his garden. Whatever the time of year, he may break off the top close to the ground, take up the roots and plant them in the border. If a little attention is given to the plant for the first two or three weeks, as watering or mulching or shading, it should become established and give satisfactory bloom the following year. Two-thirds of the herbs which one would take up in this way, even in midsummer, should grow. Into the heary borders about the boundaries of the place the autumn leaves will drift and afford an excellent mulch. If these borders are planted with shrubs, the leaves may be left there to decay, and not be raked off in the spring. The general outline of the border facing the lawn should be more or less wavy or irregular, particularly if it is on the boundary of the place. Alongside a walk or drive, the margins may follow the general directions of the walk or drive.

There are three rules for the choosing of plants for a hardy border. Choose (1) those which you like best, (2) those which are adapted to the climate and soil, (3) those 
which are in place or in keeping with that part of the grounds. See Herbs, Shrubs, Trees.

\section{Borecole is Kale.}

Borers. There is no sovereign remedy for borers except to dig them out. Do not rely upon washes or other applications. If trees are examined two or three times a year, it is not a laborious undertaking to dig them out, as they will not be deep in the wood. If they do get deep in the wood, thrust a wire into the burrow. By the chips east from the holes, or by the dead bark, the presence of borers may be detected. Apple and peach trees are particularly liable to attack. The flat-headed apple-tree borer works just underneath the bark on any part of the trunk or large branches. The round-headed apple-tree borer eats into the wood at the erown.

Boxes of many sizes can be utilized in which to grow plants. Excellent effeets of bulbs and annuals may be had in old soap boxes. The boxes may be placed in the best situations for the growth of the plants, and they ean receive better attention than the large flower bed. Vines planted about the edge will hide the sides, - such vines as Kenilworth ivy, moneywort, maurandya, trailing fuchsia, and the like.

\section{Brachycome. See Swan River Daisy.}

Broccoli. This is almost identical with the Cauliflower, except that it usually requires a longer season and matures in the fall. It is grown more generally in Europe than in this country. The special merit of Broccoli is its adaptability for late summer planting and its rapid growth in the late fall. It is said that a large proportion of Broceoli is used in the manufacture of pickles. The culture is the same as for Cauliflower,- deep, moist soil well emriched, cool weather, and the destruction of the eabbage worm. 
The young plants may be grown in a coldframe or in a well protected border, sowing the seed about the 15th of May, transplanting into rows in July. In sections in which early fall frosts are not to be feared, the plants may be set two weeks later, say August 1, as all vegetables of the cabbage family make the best growth through the cool months of September and October. The plants should be set $18 \mathrm{in}$. apart in the rows, the rows being from $2 \frac{1}{2} \mathrm{ft}$. to 3 ft. apart.

Browallia elata is a very fine tender annual, giving a border or mixed bed a dash of amethyst blue not often found in flowers. It is a strong-growing plant with a profusion of bloom, and no doubt one of the choicest plants of its color in cultivation. There are other species with white flowers that serve as contrast, and may be grown with this. All of the kinds may be taken up and potted in the fall, cutting the plant well back, and a profusion of bloom may be obtained through the winter months if attention is given to pinching off the seed porls. In the garden, let the plants stand $12 \mathrm{in}$. apart. The plants grow 1-2 ft. high.

Brussels Sprouts. This is a vegetable that should be more generally known, as it is one of the choicest of the cabbage family, and may be had at its best after the season for cauliflower has passed. It is the better for being touched by the fall frosts. The parts used are the buttons or sprouts (miniature cabbage heads) that grow thickly along the stem. These should be cut off rather than broken. The very small hard "sprouts" or buttons are the best. The culture is essentially the same as for late cabbage or broccoli. One ounce will sow $100 \mathrm{ft}$. of drill, or make upward of 2,000 plants. Set plants in field 2-3 ft. apart. They require the entire season in which to grow.

\section{Budding. See Grafting.}


Bulbs. The outdoor culture of bulbs is extremely simple. They eare for themselves throughout a greater part of the year, many of them flowering when no other plants are able to grow and bloom out of doors.

While all the so-called Holland bulbs will thrive in any kind of soil, they will all do better by being planted in a deep, sandy soil well enriched with well rotted manure. But do not let the manure come into direct contact with the bulb. Even heavy elay soil may be fitted for the growing of bulbs by the addition of sharp sand, either worked into the soil or placed directly under the bulb when planted. To make a bulb bed, choose, if possible, a sandy soil and throw out the top soil to the depth of 6 in. Put into the bottom of the bed about $2 \mathrm{in}$. of well rotted manure and spade it into the soil. Throw back half of the top soil, level it off nicely, set the bulbs firmly on this bed and then cover them with the balance of the soil ; in this way one will have the bulbs from 3 to $4 \mathrm{in}$. below the surface. In the fall months the top of the ground is cooler than at the depth of 5 or 6 in. and the top of the bulb will not want to grow, while the bottom, which is always in a hurry, will send out roots, to push out the leaves and flowers the next spring. When the weather is cold enough to freeze a hard crust on the soil, the bed should have its winter overeoat. This may be straw, hay, cornstalks or leaves spread over the bed to the depth of 6 in. if the material is coarse; but if leaves are used, $3 \mathrm{in}$. will be enough, because the leaves lay close together and may smother out the frost that is in the ground and let the bulbs start. What we want is to keep them asleep until spring, because if they start too early the hard freezes of March and early April will spoil their beauty if the leaves or flowers are near or above the surface. Early in April, in New York, the eovering may be removed gradually, and should all be off the beds before the leaves show above the ground.

If there is no sandy place for the beds, make them 
as directed, leaving the stones in the bottom of the bed for drainage. Then, when ready to set the bulb, place a large handful of sand where the bulb is to go and set the bulb on it. This will keep the water from standing around the bulb. Very fine results may be had on heavy soil by this method.

As to kinds of bulbs, select hyacinths, tulips or narcissus or daffodils, with snowdrops or crocuses of various colors around the edge. For the culture of these and other bulbs, see the various articles throughout the book.

The growing of flowering bulbs through the winter adds to the list of house plants a charming variety. The labor, time and skill required is much less than that of growing many of the larger plants more commonly used for winter decorations. The larger number of winter bulbs may be left out of doors until within four to six weeks of the time when they are wanted in flower. Hyacinths, narcissus, tulips, and crocus can be made to flower in the winter without difficulty. Secure the bulbs so as to be able to pot them by the middle or last of October, or if earlier all the better. The soil should be rich, sandy loam, if possible; if not, the best one can get, to which add about one-fourth the bulk of sand and mix thoroughly. If ordinary flower pots are to be used, put in the bottom a few pieces of broken pots, chareoal or small stones for drainage, then fill the pot with dirt so that when the bulus are set on the dirt the top of the bulb is even with the rim of the pot. Fill around it with soil, leaving just the tip of the bulb showing above the dirt. If the soil is heavy, a good plan is to sprinkle a small handful of sand under the bulb to carry off the water, the same as is done in the beds outdoors. If one does not have pots he may use boxes. Starch boxes are a good size to use, as they are not heary to handle; and excellent flowers are sometimes obtained from bulbs planted in old tomato cans. If boxes or cans are used, care must be taken to have holes in the bottoms to let the water run 
out. A large size hyacinth bulb will do well in a 5-inch pot. The same size pot will do for three or four narcissuses or eight to twelve crocuses.

After the bulbs are planted in the pots or other receptacles, they should be placed in a cool place, either in a cold pit or cellar, or on the shady side of a building, or, better yet, plunged or buried up to the rim of the pot in a shady border. This is done to force the roots to grow while the top stands still; as only the bulbs with good roots will give good flowers. When the weather gets so cold that a crust is frozen on the soil, the pots should be covered with a little straw, and as the weather gets colder more straw must be used. In from six to eight weeks after planting the bulbs, they should have made roots enough to grow the plant, and they may be taken up and placed in a cool room for a week or so, after which, if they have started into growth, they may be taken into a warmer room where they can have plenty of light. They will grow very rapidly now and will want lots of water, and after the flowers begin to show, the pots may stand in a saucer of water all the time. When just coming into bloom the plants may have full sunlight part of the time to help bring out the color of the flowers.

\section{Bushes. See Shrubs.}

Cabbage. For an early crop, the plants must be started either in February or early March, or the previous September and wintered over in coldframes. This latter method was once a common practice by gardeners near large cities, but the building of greenhouses to replace the many hotbeds of the market-gardener has changed the practice in many localities, and now most of the early Cabbages in the north are grown from seed sown in January, February or March. The plants are hardened off in March and early April and planted out as early as possibie. The private grower, or one with a small garden, may often procure his early plants from the market-gardener much eheaper 
than he can grow them, as usually only a limited number of early Cabbage plants are wanted; but for the midseason and main crop, the seed may be sown in May or June, setting the plants in July.

For early planting, the number of varieties is limited to three or four. For an intermediate crop the list is more extended, and the late varieties are very numerous. The early list is headed by the Jersey Wakefield, a variety which heads very quickly, and, although not one of the solid kinds, is generally grown. The Early York and Winnigstadt are good varieties to follow it. The latter especially is solid and of very good quality. For the midseason, the Succession and All Season are of the best, and for the winter supply the Drumhead, Danish Ball and Flat Dutch types are the leaders. One of the best of the Cabbages for

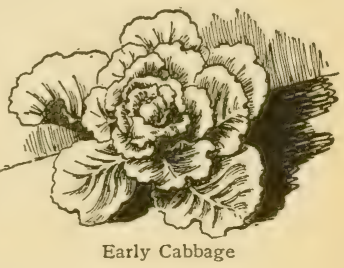
table use is seldom seen in the garden - the Savoy Cabbage. It is a type with netted leaves, making a large, low-growing head, the center of which is very solid and of excellent flavor, especially late in the fall, when the heads have had a slight touch of frost. Savoy should be grown in every private garden.

The seed-bed should be made mellow and rich. A good border will do. The seed is sown preferably in rows, thus allowing thinning of the plants and the pulling of any weeds that germinate. The young plants will well repay attention to watering and thinning. The rows should be 3 or $4 \mathrm{in}$. apart. When the plants are large enough to transplant, they may be planted where early vegetables have been grown. Set the plants from 18 to 24 in. apart in the row, the rows being $3 \mathrm{ft}$. apart for the medium-growing kinds. One ounce of seed will furnish about two thousand plants. All Cabbages require deep and rich soil, and one that holds moisture well. 
The best remedy for the Cabbage worm is to kill the first brood on the very young plants with Paris green. After the plants begin to head, pyrethrum or salt water may be used. On a small area, hand-picking may be recommended.

The maggot is the most serious Cabbage pest. After studying the seventy odd remedies proposed, Slingerland concludes that 6 are efficient and practicable : growing the young plants in closely covered frames; tarred paper cards placed snugly about the base of the plants to keep the fly away ; rubbing the eggs from the base of the plant; handpicking of the maggots; treating the plants with emulsion of carbolic acid; treating them with carbon bisulfide. The insecticidal materials are injected or poured into the soil about the base of the plant.

Respecting these two insecticides, Slingerland remarks: "Always use the crude carbolic acid, as it is much cheaper than the purified and is nearly, if not quite, as effective. It will probably be safer if used as an emulsion than if simply diluted with water. We would advise that it be made by the follow formula: 1 pound of hard soap or 1 quart of soft soap dissolved in 1 gallon of boiling water, into which 1 pint of crude carbolic acid is then poured and the whole mass agitated into an emulsion, which will remain in this condition for a long time. In treating the plants, take one part of this standard emulsion and dilute it with 30 equal parts of water; it probably can be used stronger without injury to the plants. If the emulsion is cold and semisolid, use several parts of warm water at first. Begin the treatment early, a day or two after the plants are up, or in the case of Cabbages and Caulifiowers the next day after they are set in the field, and repeat it once each week or 10 days until about May 20 in our state. While we have little faith in the preventive effects of the early treatments, we do believe that the emulsion will then kill many of the eggs and recently hatched maggots. If it could be applied with 
some force through a syringe or force pump, it might not be necessary to go to the trouble of first removing some of the earth from about the plants. It must be remembered that its success will depend on the eggs or maggots being hit with it. None of the Cabbages in our experiment were injured in the least by an application containing nearly twice as much of the acid, and there is but little danger of its injuring the tenderest foliage of radishes, turnips or onions; if any injury manifests itself on these crops, dilute the emulsion with 40 or 50 or more parts of water, instead of 30 . A knapsack or wheelbarrow sprayer would prove a very useful instrument in applying the emulsion on a large scale."

The carbon bisulfide is best injected into the soil by means of a long-nosed syringe. Slingerland (Cornell Bulletin 78 ) illustrates a specially made syringe or injector for this purpose: "Thus Cabbage plants ean be treated once, and once is usually sufficient, at the rate of about 10 plants for 1 cent for the liquid, using about 1 teaspoonful to each plant. As the injector will last for years, and several neighbors might join in the purchase and use of one instrument, its cost would practically not influence this estimate of the cost of killing the maggots. We believe it is the cheapest, most effective, and most practicable method yet devised for fighting this pest on crops of Cabbages and cauliflowers; on erops or radishes, turnips, or onions it will probably be too expensive except where choice or new varieties are attacked. The carbolic acid emulsion will prove the most practicable on these last crops."

The club-root, which causes the roots to become greatly thickened and distorted, is difficult to manage if Cabbages or allied plants are grown continuously on land in which diseased plants have been raised. Changing the location of the Cabbage or Cauliflower patch is the best procedure. If very different crops, as corn, potatoes, peas, tomatoes, etc., are grown on the land, the disease will be starved out in two or three years. 
Cacalia. Tassel Flower. Ladies' Paint BRUsh. A quaint old annual, in two colors, searlet and orange. It is easily grown, and makes a fine second-row plant for a border, contrasting well with Browallia or Ageratum. Sow where the plants are to stand. Let plants stand 10-12 inches apart. Grow $1 \frac{1}{2}-2 \mathrm{ft}$. high.

Cactus. This class of plants is often seen in small collections of house plants, to which they add interest, being altogether different from other plants. All Cacti are easy to grow, requiring but little care and enduring the heat and dryness of a living room much better than most other plants. Their requirements are ample drainage and a sandy soil. Cactus growers usually make a soil by mixing pulverized plaster or lime refuse with garden loam, using about two-thirds of the loam. The very fine parts, or dust, of the plaster, are blown out, else the soil is likely to cement. They may be rested at any season by simply setting them away in a dry place for two or three months, and bringing them into heat and light when they are wanted. As new growth advances they should have water occasionally, and when in bloom they should be watered freely. Withhold water gradually after blooming until they are to be rested.

Some of the most common species in cultivation are the Phyllocactus species, often called the Night-blooming Cereus. These are not the true Night-blooming Cereuses, which have angular or cylindrical stems, covered with bristles, while this has flat, leaf-like branches; the flowers of these, however, are very much like the Cereus, opening at evening and elosing before morning, and as the Phyllocacti may be grown with greater ease, blooming on smaller and younger plants, they are to be recommended. See Cereus.

The Epiphyllum, or Lobster Cactus, is one of the best of the family, easy of culture. It bears bright-colored blossoms at the end of each joint. When in flower, which 
will be through some of the winter months, this requires a richer soil than the other Cacti. Opuntias, or prickly pears, are often grown as border plants through the summer. In fact, all the family may be planted out, and if a number of varieties are set in a bed together they make a striking addition to the garden. Be very careful not to bruise the plants. It is better to plunge them in the pots than to turn them out of the pots.

Caladium. Tuberous-rooted, tender perennial plants which are used for conservatory decorations, and also for subtropical and bold effects in the lawn. The plants which are commonly known under this name are really Colocasias. The plants should be rested during the winter, being kept in a warm cellar or under a greenhouse bench, where they are not liable to frost or dampness. The roots are usually kept covered with earth during the winter, but they are kept dry. Early in the spring the roots are put into boxes or pots and are started into growth, so that by the time settled weather comes they will be 1 or 2 feet high and ready to set directly into soil. When set out of doors, they should be given a place which is protected from strong winds, and one which does not receive the full glare of direct sunlight. The soil should be rich and deep, and the plants should have an abundance of water. Cala-

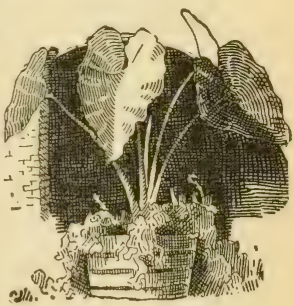

Caladium or Colocasia diums are most excellent plants for striking effects, especially against a house, high shrubbery or other background. If they are planted by themselves, they should be in clumps rather than scattered as single specimens, as the effect is better. See that they get a good start before they are planted in the open ground.

Calceolaria. Small greenhouse herbs which are sometimes used in the window-garden. They are not very satisfactory plants for window treatment, howerer, since 
they suffer from dry atmosphere and from sudden changes of temperature. In the window-garden they should be protected from strong, direct sunlight. They are grown from seeds. If the seeds are sown in early summer and the young plants are transplanted as they need, flowering specimens may be had for the late fall and early winter. In the growing of the young plants, always avoid exposing them to direct sunlight; but they should be given a place which has an abundance of sereened or tempered light. A new crop of plants should be raised each year. There is a race of shrubby Calceolarias, but it is little known in this country. One or two species are annuals which axe adaptable to cultivation in the open garden, and their little, ladyslipper-like flowers are attractive. However, they are of secondary importance as annual garden flowers.

Calendula. These are the well known PoT Marigolds, and add a bright spot to any garden. Annual. Especially are they fine in the cool days of the fall, when many of the annual flowers have gone to seed. The places of short-lived plants may be filled by sowing seed of Calendulas in May, seattering them through the border and allowing the plants to grow where they come up. Easy of growth and hardy. 1-2 ft. high. Should stand 8-12 in. apart. Colors, yellow and orange.

\section{California Poppy (Eschscholtzia Californica).}

Low perennial, poppy-like plant, grown as a hardy annual. It is certainly one of the best low-growing annuals, bloom-

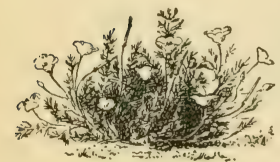

California Poppy ing through a long season and being at its best through the cool days of fall, after touched by frost. Most of the varieties have flowers of fine shades of orange or yellow, making a bright spot in the border at all times. They are like the pot marigolds, in that once planted they seed themselves. They are never out of place, and should be left to bloom wherever they may be. Flowers open only in sunshine. 
As cut-flowers they are excellent, a large bowl of them glowing like a golden ball, especially if they are emphasized by a few blue larkspurs or batchelor's buttons.

Propagated by seed, which would best be sown as soon as ripe, thus giving the plant an early start, and having bloom through the season. They make attractive mats of foliage. 12-18 in. high. Let the plants stand 10-20 in. apart.

Calla (properly Richardia). Egyptian Lily. All things considered, this is one of the most satisfactory of winter house plants, lending itself to various conditions. The requirements of the Calla are rich soil and an abundance of water, with the roots confined in as small a space as possible. If a too large pot is used the growth of foliage will be very rank, at the expense of the flowers, but by using a smaller sized pot and applying liquid manure the flowers will be produced freely. A 6 -inch pot will be large enough for all but an exceptionally large bulb. If desired, a number of bulbs may be grown together in a larger pot. The soil should be very rich but fibrous-at least one-third well rotted manure will be none too much, mixed with equal parts of fibrous loam and sharp sand. The tubers should be planted firmly and the pots set in a cool place to make roots. After the roots have partially filled the pot, the plant may be brought into heat and given a sunny position and an abundance of water. An occasional sponging or washing of the leaves will free them from dust. No other treatment will be required until the flowers appear, when liquid manure may be given. The plant will thrive all the better at this time if the pot is placed in a saucer of water. In fact, the Calla will grow finely in an aquarium. The Calla may be grown through the entire year, but it will prove more satisfactory, both in leaf and flower, if rested through part of the summer. This may be done by laying the pots on their sides in a dry, shady place under shrubbery, or if in the open slightly covered with straw or other litter to keep 
the roots from becoming extremely dry. In September or October they may be shaken out, cleaning off all the old soil, and repotted, as already mentioned. The offsets may be taken off and set in small pots and given a year's growth, resting them the second year and having them in flower that winter.

The spotted Calla has variegated foliage and is a fine plant for mixed collections. This blooms in the spring, which will lengthen the season of Calla bloom. The treatment of this is similar to that of the common Calla.

Calliopsis is a garden name for Coreopsis.

Callirhoë. C. pedata is a hardy annual which has large, graceful blossoms of violet or red. Is it a very free-blooming plant. Should be started in a frame and planted out where wanted. 2-3 ft. high and grows bushy. Plants should stand $1 \frac{1}{2}-2 \mathrm{ft}$. apart.

Camellia. Year's ago Camellias were very popular, but they have been erowded out by the informal flowers of recent times. Their time will come again. They are half-hardy woody plants, blooming in late winter and spring. During the blooming season keep them coolsay not over $50^{\circ}$ at night and a little higher by day. When blooming is done they begin to grow, then give them more heat and plenty of water. See that they are well ripened by winter. Always sereen them from direct sunlight. Do not try to force them in early winter, after the growth has ceased. Their summer quarters may be in a protected place in the open air. Propagated by cuttings in winter, which should give blooming plants in two years. Use a porous soil for Camellias, with considerable leaf-mold.

Campanula. Bell Flower. But one of the Campanulas eommonly listed by seedsmen is an annual, $-C$. macrostyla, a clean-leaved plant, growing 2 feet high, spreading over the ground, and bearing a profusion of large, violet, 
bell-shaped flowers. The Canterbury Bell is the best known. It is biennial, but if started early and transplanted will bloom the first season. The perennial Campanulas are most excellent for borders. C. Carpatica is particularly good for edgings.

\section{Canary Bird Flower. See Nasturtium.}

Candytuft. Well known sweet-scented hardy annuals, in red, purple, and white; easy of culture and fine for cutting. One of the best of edging plants for the front row. The plants grow from 6 in. to $1 \mathrm{ft}$. tall. Sow seeds where the plants are to grow, letting plants stand 6-12 in. apart. They do not last the entire season, and successive sow-

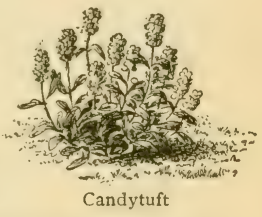
ings may well be made. There are also perennial kinds.

Canna is now the favorite bedding plant. The improvements made in the past ten years, in size and markings of the flowers, have created a liking for the plant. The tropical effect of a large bed of Cannas, either mixed or of one color, is not surpassed by any other plant used for bedding purposes.

The Canna may be grown from seed and had in bloom the first year by sowing in February or March, in boxes or pots placed in hotbeds or warmhouse, first soaking the seeds in warm water for a short time. Attention to transplanting as needed and removal to the ground only when it is well warmed are the necessary requirements. The majority of Cannas, however, are grown from pieces of the roots (rhizomes), each piece having a bud. The roots may be divided at any time in the winter, and if early flowers and foliage are wanted the pieces may be planted in a hotbed or warmhouse in early April, started into growth and planted out where wanted as soon as the ground has warmed and all danger of frost is over. A hardening of the plants, by leaving the sash off the hotbeds, or setting the 
plants in shallow boxes and placing the boxes in a sheltered position through May, not forgetting a liberal supply of water, will fit the plants to take kindly to the final planting out. After frost has injured the tops, the roots may be dug, choosing, if possible, a dry day. The soil is shaken off and the roots stored in a warm, dry place through the winter. If the cellar is too dry the roots are liable to shrivel, in which case it would be best to cover them with soil or sand, filling in around the roots to exclude the drying air.

Cannas grow 3 to $7 \mathrm{ft}$. high. For dense mass effects, plant 12-18 in. apart. For individual plants, or for best bloom, give more room. Fine clumps may be had by planting out the entire old root, not Canna Cannas want a rich, warm soil and a sunny dividing it. Cannas want a rich, warn
place. They are very easy to grow.

Canterbury Bell is a Campanula.

Carbonate of Copper. See Bordeaux Mixture.

Cardiospermum. See Balloon Vine.

Carnations are of two types, the outdoor or garden varieties, and the indoor or foreing kinds. Normally, the Carnation is a hardy perennial, but the garden kinds, or Marguerites, are usually treated as annuals. The foreing kinds are flowered but once, new plants being grown each year from euttings.

Marguerite Carnations bloom the year the seed is sown, and with a slight protection will bloom freely the second year. They make attractive house plants if potted in the fall. The seeds of these Carnations should be sown in boxes in March and the young plants set out as early as possible, pinching out the center of the plant to make them branch freely. Give the same space as for garden pinks.

The winter-flowering Carnations have become prime favorites with all flower lovers, and a collection of winter 
house plants seems incomplete without them. Carnations grow readily from cuttings made of the suckers that form around the base of the stem, the side shoots of the flowering stem, or the main shoots before they show flower buds. The cuttings from the base make the best plants in most cases. These euttings may be taken from a plant at any time through the fall or winter, rooted in sand and potted up, to be held in pots until the planting out time in the spring, usually in April, or any time when the grouna is ready to handle. Care should be taken to pinch out the tops of young plants while growing in the pot, and later while in the ground, eausing them to grow stocky and send out new growths along the stem. The young plants sbould be grown cool, a temperature of $45^{\circ}$ suiting them well. Attention

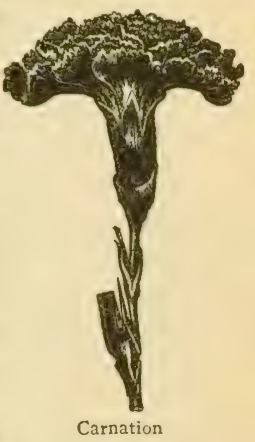
should be given to spraying the cuttings each day while in the house to keep down the red spider, which is very partial

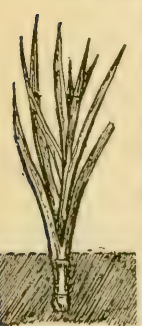
to the Carnation. In the summer, the plants are grown in the field, and not in pots. The soil in which they are to be planted should be moderately rich and loose. Clean cultivation should be given throughout the summer. Frequently pinch out the tops. The plants are taken up in September and potted firmly, and well watered; then set in a cool, partially shaded situation until root growth has started, spraying the foliage often, and watering the plant only as it shows need of water.

ting The usual living-room conditions as to moisture and heat are not such as the Carnation demands, and care must be taken to overcome the dryness by spraying the foliage and setting the plant in a position not exposed to the direct heat of a stove or the sun. In commercial houses, it is not often necessary to spray established plants. Pick off most or all of the side buds, in order to add to the size of 
the leading flowers. After all is said, it is probably advisable in most cases to purchase the plants when in bloom from a florist, and after blooming either throw them away or store them for planting in the spring, when they will bloom throughout the summer.

Carpet Bedding. See Bedding.

Carrot, while essentially a farm crop in this country, is nevertheless a most acceptable garden vegetable. It is hardy and easily grown. The extraearly varieties may be forced in a hotbed, or seed may be sown as soon as the ground is fit to work in the spring. The stump-rooted, or half-long varieties, are sown for the general garden crop. Well enriched, mellow loam, deeply dug or plowed, is best suited to the requirements of Carrots. The seed for the main erop may be sown as late as July 1. Sow thickly, thinning to $3-4$ in. in the row. The Early Carrots rows, if in a garden that is hand-worked, may be 12 in. apart. If the cultivation is done by a horse, the rows should be from 2 to $3 \mathrm{ft}$. apart. One ounce will sow 100 feet of drill.

Castor Oil Plant. In the entire list of quickgrowing plants there is none that excels this for rapidity of growth, grace of foliage and rich effect. Used either as a specimen plant, with eannas, caladiums, or for a tropical bed, or as a screen, it gives the most satisfactory results. Seeds sown early in the house, and the plants grown in the full light, make fine, stocky plants to set out about the middle of May. With rich soil and plenty of water,

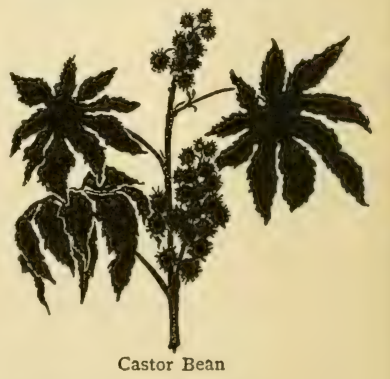

Castor Bean

they will grow without a check until frost. Height, 5-12 ft. For screens, plant 3-4 ft. apart. There are varieties with differing shades of foliage. 
Cauliflower. The general culture of Cauliflower is much like that of cabbage, except that the Cauliflower, being more tender, should be more thoroughly hardened off before setting out. Still, it is essential that the plants be set out as early as possible, as the warm weather of June causes them to make imperfect heads unless the soil is filled with moisture. No garden erop will as well repay the cost and time of thorough irrigation, either by running the water between the rows or applying it directly to the plants. When it is impossible to furnish water, it would be a good plan to mulch heavily with straw or some other substance. This mulch, if put on just after a heavy rain, will hold the moisture for a long time. When the heads begin to form the outside leaves may be brought together and tied above the head, excluding the direct sunshine and keeping the head white and tender. No vegetable will respond more quickly to good culture and well manured soil than the Cauliflower, and none will prove such an utter failure when neglected. It is imperative that care be taken to destroy all the cabbage worms before the leaves are tied in, as after that

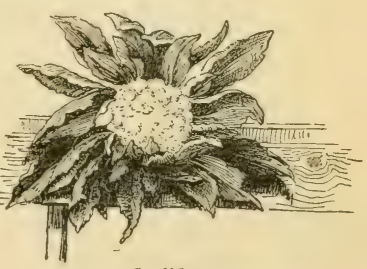

Cauliflower it will be impossible to see or reach them. Cauliflower prospers best in moist soil and a cool climate. From 1,000 to 1,500 plants may be grown from 1 ounce of seed. Good Cauliflower seed is very expensive.

For winter crop, seeds may be started in June or July, as for late cabbage.

Erfurt, Snowball and Paris are popular early varieties. Nonpareil and Algiers are good late kinds.

Celeriac, or Turnip-Rooted Celery. This tuber has the celery flavor in a pronounced degree, and is used for flavoring soups and for celery salad. It may be served raw, sliced in vinegar and oil, or boiled. The culture 
is the same as given for celery, except that no earthing or blanching is required. About an equal number of plants are obtained from the same weight of seed as from celery seed. Celeriac is extensively used abroad, but, unfortunately, is little grown in America.

Celery has become one of the favorite relish and salad vegetables, and is now very generally grown. The self-blanching varieties have simplified the culture so that the amateur, as well as the expert, may have a supply through at least six months of the year. The so-called new culture, which consists of setting the plants close together and causing them to shade each other, can be recommended for the garden when a supply of well rotted manure is to be had, and when any amount of water is available. This

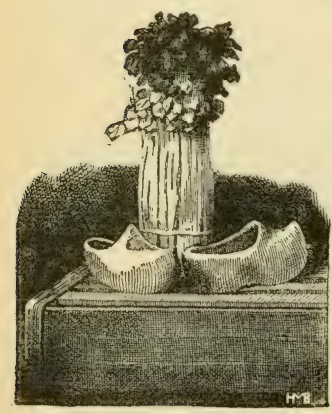

Celery method is as follows: Fork or spade into the soil a large quantity of manure to the depth of $10-12$ in., pulverize the soil until the ground for the depth of 4-6 in. is in very fine condition. Then set the plants in rows 10 in. apart and the plants but 5 or 6 in. apart in the rows. It will be seen that plants set as close as this will soon fill the soil with a mass of roots and must have large amounts of plant-food, as well as a large quantity of water; and the making of such a bed can be recommended only to those who can supply these needs.

The common practice in home gardens is to plow or dig a shallow trench, setting the plants in the bottom and hoeing in the soil as the plants grow. The distance apart of the rows and plants will depend on the varieties. For the dwarf varieties, such as White Plume, Golden Self-blanching and others of that type, the rows may be as close as $3 \mathrm{ft}$. and the plants 6 in. in the rows. For the large-growing varieties, as Kalamazoo, Giant Pascal and, in fact, most of the late varie- 
ties, the rows may be from $4 \frac{1}{2}$ to $5 \mathrm{ft}$. apart and the plants 7 or 8 in. in the row.

The seed for an early crop should be sown in February or early in March in shallow boxes, which may be placed in a hotbed or sunny window, or sown directly in the soil of a hotbed. Cover the seeds thinly and press the soil firmly over them. When the seedling plants are about one inch high they should be transplanted to other boxes or hotbeds, setting the plants 1 in. apart in rows 3 in. apart. At this transplanting, as with the following ones, the tall leaves should be cut or pinched off, leaving only the upright growth, as with the utmost care it is almost impossible to prevent the outside leafstalks from wilting down and dying. The roots of the plants should also be trimmed back at each transplanting in order to increase the feeding roots. The plants should be set as deep as possible, care being taken, however, not to allow the heart of the plant to be covered up. The varieties usually grown for an early crop are the so-called self-blanching varieties. They may be made fit for the table with much less labor than the late crop, the shade required to blanch the stalks being much less. When only a few short rows are grown in a private garden, sereens of lath may be made by driving stakes on each side of the row and tacking lath on, leaving spaces of an inch or more for the light to enter ; or each head may be wrapped in paper, or a tile drain pipe may be set over the plant. In fact, any material that will exclude the light will render the stalks white and brittle.

The seed for the main or fall crop should be sown in April or early May in a seed bed prepared by forking fine, well rotted manure into a fine soil, sowing the seed thinly in rows 8 or $10 \mathrm{in}$. apart, eovering the seed lightly and firming over the seed with the feet, hoe or back of a spade. This seed bed should be kept moist at all times until the seed germinates, either by close attention to watering or by a lath screen. The use of a piece of cloth laid directly on 
the soil, and the bed wet through the cloth, is often recommended, and if the cloth is always wet and taken off the bed as soon as the seed sprouts it can be used. After the young plants have grown to the height of 1 or 2 in. they must be thinned out, leaving the plants so that they do not touch each other, and transplanting those thinned-if wantedto other ground prepared in the same manner as the seed bed. All these plants may be sheared or cut back to induce stockiness.

If in a private garden, the ground on which the fall crop is usually set will likely be land from which a crop of some early vegetable has been taken. This land should be again well enriched with fine, well rotted manure, to which may be added a liberal amount of wood ashes. If the manure or ashes are not easily obtained, a small amount may be used by plowing or digging out a furrow 8 or 12 in. deep, scattering the manure and ashes in the bottom of the trench and filling it up almost level with the surface. The plants should be set about the middle of July, preferably just before a rain. The plant bed should have a thorough soaking shortly before the plants are lifted, and each plant be trimmed, both top and root, before setting. The plants should be set from 5 to 6 in. apart in the rows and the earth well firmed around each one.

The after-cultivation consists in thorough tillage until the time of "handling" or earthing up the plants. This process of handling is accomplished by drawing up the earth with one hand while holding the plant with the other, packing the soil well arouna the stalks. This process may be continued until only the leaves are to be seen. For the private grower, it is much easier to blanch the Celery with boards or paper, or if the Celery is not wanted until winter, the plants may be dug up, packed closely in boxes, covering the roots with soil, and placed in a dark, cool cellar, where the stalks will blanch themselves In this manner Celery may be stored in boxes in the hous 
cellar. Put earth in the bottom of a deep box, and plant the Celery in it. An ounce of seed will furnish about three thousand plants.

Centaurea. Showy annuals and perennials. C. Cyanus is the Corn Flotver or Bachelor Button, familiar to every flower lover, and always seen in oldfashioned gardens. This is a fine plant for borders or mixed beds, and also gives good flowers for bouquets. A bunch of the Corn Flower, with a sprinkling of yellow marigolds or California poppy, makes a rich effect. These Centaureas are easy of culture, seeding themselves after once being planted, and coming up year after year in great profusion. There are blue, white and rose varieties. Annuals. 2-3 ft. Hardy.

The silver-leaved Centaureas are used only for foliage effects. They are excellent for ribbon beds or border lines. The seed of these should be started in a hotbed or box in Narch, the young plants being set out where wanted when the ground becomes warm. These species are perennials, and are sometimes grown from euttings. $C$. candidissima and $C$.gymnocarpa are among the best white-leaved bedders.

Centranthus. Low-growing hardy annuals in two colors, red and white. They make very effective covering for low rockwork, and are also suitable for vases or lawn baskets. Sow where the plants are to stand, or start indoors if early bloom is wanted. $1 \mathrm{ft}$. Thin to 10-12 in. apart.

Century Plant, or AgAve. These are fine ornamental plants for the window-garden or conservatory, requiring but little care and growing slowly, thus needing repotting only at long intervals. When the plants havo outgrown their usefulness as house plants, they are still valuable as porch decorations, for plunging in rockwork or about rustic nooks. The striped-leaved variety is the most desirable, but the common type, with its blue-gray leaves, is highly ornamental. 
There are a number of dwarf-growing species of Agave that are not so common, although they may be grown with ease. Such plants add novelty to a collection, and may be used through the summer as noted above or plunged with cactus in a bed of tropical plants. All succeed well in loam and sand in equal parts, adding a little leaf-mold in the case of the small varieties. The more common species are propagated by suckers from around the base of the established plants. A few kinds having no suckers must be grown from seed. As to watering, they demand no special care. Agaves will not stand frost.

Cereus. Under the name of Night-Blooming Cereus, several species of Cacti are eultivated. The name is sometimes applied to species of Phyllocactus, the flowers of which, in white and shades of red, sometimes open at nightfall. Phyllocactuses are easy to grow. See Cactus. The true Night-blooming Cereuses, however, are species of the genus Cereus. The commonest one is C. nycticalus, but C. grandiflorus, C. triangularis and others are oceasionally seen. These true Night-blooming Cereuses all have long rodlike stems, which are eylindrical or angular. These stems often reach a height of 10 to $30 \mathrm{ft}$., and they need support. They should be trained along a pillar or tied to a stake. They are uninteresting leafless things during a large part of the year; but in midsummer, after they are three or more years old, they throw out their great tubular flowers, which open at nightfall and wither and die when the light strikes them next morning. They are very easily grown, either in pots or planted in the natural soil in the conservatory. The only special eare they need is good drainage at the roots, so that the soil will not become soggy.

Cherry. Of Cherries there are two common types, the sweet Cherries and the sour Cherries. The sweet Cherries are larger and taller-growing trees. They comprise the varieties known as the Hearts, Bigarreaus and Dukes. The sour Cherries include the various kinds of 
Morellos and pie Cherries, and these usually ripen after the sweet Cherries. The sour Cherries make low, round-headed trees. The fruits are extensively used for canning. Cherry trees should be planted when 2 and 3 years old. Too rich soil tends to make growth at the expense of fruit, particularly in the sweet Cherries. For the sweet types, a strong, gravelly loam is best. Sour Cherries thrive well on clay loams.

Trees of the sour Cherry should be planted 18 by $18 \mathrm{ft}$. apart, in well prepared under-drained soil. The trees may be slightly trimmed back each year, keeping the head low and bushy.

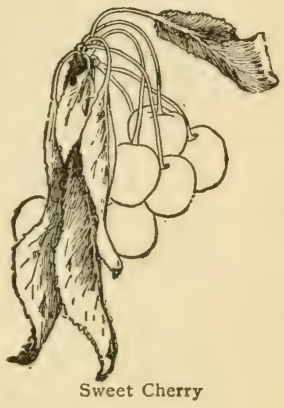

The sweet Cherries have proved disappointing in many instances from the rotting of the fruit. This may never be entirely avoided, but good cultivation, soil not too rich in nitrogen, attention to spraying, and picking the fruit when

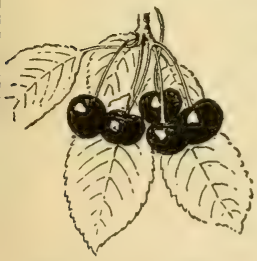

Black Tartarian Cherry dry, will lessen the loss very much. In years of severe rotting, the fruit should be picked before it becomes fully ripe, placed in a cool, airy room and allowed to color. It will be nearly as well flavored as if left on the tree; and, as the fungus usually attacks only the ripe fruit, a considerable part of the crop may be saved. Set the trees 25 or 30 ft.apart.

Leaf-blight is readily controlled by timely spraying with Bordeaux mixture. The eureulio or fruit worm is best controlled by jarring, as for plums (which see).

Of sweet Cherries, Windsor is the most popular variety. Other good kinds are Napoleon, Governor Wood, Dikeman, Black Tartarian. Of sour Cherries, Ostheim and Early Richmond are very early and productive, but better kinds are Montmoreney and English Morello.

Chervil. The curled Chervil is a good addition to the list of garnishing vegetables, and adds flavor to 
dishes when it is used to season. Sow seeds and cultivate the same as parsley.

The tuberous Chervil resembles a short carrot or parsnip. It is much esteemed in France and Germany. The tubers have somewhat the flavor of a sweet potato, perhaps a little sweeter. They are perfectly hardy, and, like the parsnip, the better for frosts. The seed may be sown in September or October, as it does not keep well; or as soon as the ground is fit to work in the spring, it being slow to germinate after the weather becomes hot and dry. One packet of seed will give all the plants necessary.

Chestnuts. Of Chestnuts there are three types in cultivation: the European, the Japanese, and the American. The American, or native Chestnuts, of which there are several improved varieties, are 'the hardiest and most reliable, and the nuts are the sweetest, but they are also the smallest. The Japanese varieties are usually injured by the winter in central New York. The European varieties are somewhat hardier, and some of the varieties will thrive in the northern states. Chestnuts are very easily grown. They usually bear better when two or more trees are planted near each other. There are fer really good Chestnut orehards in North Ameriea, but Chestnut planting is now considerably agitated. Sprouts in old Chestnut clearings are often allowed to remain, and sometimes they are grafted to the improved varieties. The young trees may be grafted in the spring by the whip-graft or cleft-graft method; but the eions should be perfectly dormant, and the operation should be very earefully done. Even with the best workmanship, a considerable percentage of the grafts are likely to fail or to break off after two or three years. The most popular single variety of Chestnut is the Paragon, which bears large and excellent nuts when the tree is very young. When the home ground is large enough, two or three of these trees should be planted near the borders. 
Chicory. The Magdeburg Chicory is the variety usually spoken of, it being the one most extensively grown. The roots of this, after being ground and roasted, are used either as a substitute or an adulterant of coffee.

The Witloof, a form of Chicory, is used as a salad, or boiled and served in the same manner as Cauliflower. The plants should be thinned to 6 in. In the latter part of summer they should be banked up like celery, and the leaves used after becoming white and tender. This and the common wild Chicory are often dug in the fall, the leaves cut off, the roots packed in sand in a cellar and watered until a new growth of leaves starts. These leaves grow rapidly and are very tender, making a fine salad vegetable. One packet of seed of the Witloof will furnish plants enough for a large family.

\section{Chrysanthemums are both annual and per-} ennial. The annual Chrysanthemums must not be confounded with the well known fall-flowering kinds, as they will prove a disappointment if one expects large flowers of all colors and shapes. The annuals are mostly coarsegrowing plants, with an abundance of bloom and a rank smell. The flowers are single in most eases, and not very lasting. They are useful for massing and also for cut-flowers. They are among the easiest of hardy annuals to grow. The stoniest part of the garden will usually suit them. 1-2 ft. Colors white and shades of yellow, the flowers daisy-like.

Amongst perennial kinds, Chrysanthemum frutescens is the well known Paris Daisy or Marguerite, one of

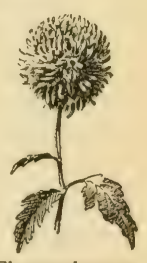
Chrysanthemum the most popular of the genus. This makes a very fine potplant for the window-garden, blooming throughout the winter and spring months. It is usually propagated by euttings, which, if taken in spring, will give large blooming plants for the next winter. Gradually transfer to larger pots or boxes, until the plants finally stand in 6 -inch or 
8 -inch pots or in small soap boxes. There is a fine yellowflowered variety.

In variety of form and color, and in size of bloom, the

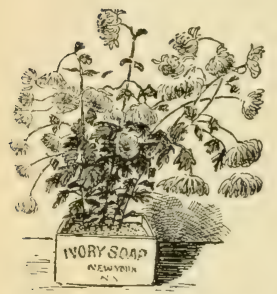

Chrysanthemums in a box florists' Chrysanthemum is one of the most wonderful of plants. It is a late autumn flower, and it needs little artificial heat to bring it to perfection. The great blooms of the exhibitions are produced by growing only one flower to a plant and by feeding the plant heavily. It is hardly possible for the amateur to grow such specimen flowers as the professional florist or gardener does; neither is it necessary. A well-grown plant with fourteen to twenty flowers is far more satisfactory as a window plant than a long, stiff stem with only one immense flower at the apex. Their culture is simple, much more so than that of many of the plants commonly grown for house decoration. Although their season of bloom is short, the satisfaction of having a fall display of flowers before the geraniums, begonias and other house plants have recovered from their removal from out of doors, repays all efforts.

Cuttings taken in March or April, planted out in the border in May, well tended through the summer and lifted before frost in September, will bloom in October or November. The ground in which they are planted should be moderately rich and moist. The plants may be tied to stakes. When the buds show, all but the center one of each cluster on the leading shoots should be picked off, as also the small lateral branches. A thrifty bushy plant thus treated will usually have flowers large enough to show the character of the variety, also enough flowers to make

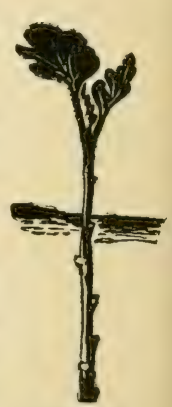

Cutting of Chrysanthemum a fine display. As to the receptacle into which to put them when lifted from the border, it need not be a flower pot. A pail or soap box, with holes bored for drain- 
age, will suit the plant just as well, and by covering the box with cloth or paper the difference will not be noticed. If euttings are not to be had, young plants may be bought

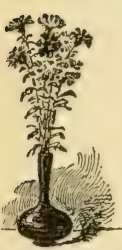

Vase of small Chrysanthemums of the florists and treated in the manner described. Buy them in midsummer or earlier.

It is best not to attempt to flower the same plant two seasons. After the plant has bloomed, the top may be cut down, and the box set in a cellar and kept moderately dry. In February or Mareh, bring the plant to the sitting-room window and let the shoots start from the root. These shoots are taken for euttings to grow plants for the fall bloom.

There is a hardy race of Chrysanthemums, very excellent for the border. Mulch in winter. The best bloom is usually given the first and second years.

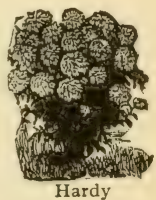

Chrysanthemum

Cineraria. A tender greenhouse plant. It may be grown as a house plant, although the conditions necessary to the best results are hard to obtain outside of a greenhouse. The conditions for their growing are a cool temperature, frequent repotting and guarding against the attacks of the greenfly. Perhaps the last is the most difficult, and with one having no facilities for fumigating, it will be almost impossible to prevent the difficulty. A living room usually has too dry air for Cinerarias. The seed, which is very minute, should be sown in August or September to have plants in bloom in January or February. Sow the seed on the surface of fine soil and water very lightly to settle the seeds into the soil. A piece of glass or a damp cloth may be spread over the pot or box in which the seeds are sown, to remain until the seeds are up. Always keep the soil damp, but not wet. When the seedlings are large enough to repot, they should be potted singly in 2- or 3 -inch pots. Before the plants have become pot-bound, they should again be repotted into larger pots, until they are in at least a 6 -inch pot in which to 
bloom. In all this time, they should be grown cool and, if not possible to fumigate them with tobacco smoke, the pots should stand on tobaceo stems, which should be moist at all times. The general practice, in order to have bushy plants, is to pinch out the center when the flower buds show, causing the lateral branches to start, which they are slow to do if the central stem is allowed to grow. Plants bloom but once.

Cives. These belong to the onion family, and are propagated by division of the root. They may be planted in a permanent place in the border, and, being hardy, will remain for years. The leaves are the parts used, as the roots are very rank in flavor. The leaves may be cut frequently, as they readily grow again.

Clarkia. The Clarkias are among the popular hardy edging and vase annuals, bearing rose, white or bordered flowers in great profusion. The double-flowering varieties are the most showy, but the single ones will prove very satisfactory. The seeds may be sown where the plants are wanted, or started in frames for earlier flowers. 6-18 in. high. Thin to 6-12 in. apart. Plant in a warm soil and sunny place.

Clematis. One of the best of woody climbing vines. The common C. Flammula, Tirginiana, panisulata and others are used frequently to eover division walls or fences, growing year after year without any eare and produeing quantities of flowers. C. paniculata is now planted very extensively. The panicles of star-shaped flowers entirely cover the vine and have a pleasant fragrance. One of the best of all fall-flowering vines, and hardy North. Clings well to a chicken-wire trellis.

The large-flowered section, of which Jackmani is perhaps the best known, is very popular for pillar or porch climbers. The flowers of this section are large and showy, running from pure white, through blue, to searlet. Of this 
class, the most serviceable purple is Jackmani; white, Henryi ; blue, Ramona ; crimson, Madame E. André.

The Flammula class may be propagated by division of the roots. The large-flowered kinds are propagated by layers or root-grafting on C. Flammula and others.

A deep, mellow, rich soil, naturally moist, will suit the requirements of Clematis. In dry times apply water freely, particularly for the large-flowered kinds. Also provide trellis or other support as soon as they begin to run. Clematis usually blooms on the wood of the season: therefore prune in winter or early spring, in order to secure strong new

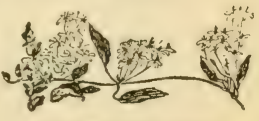

Clematis paniculata flowering shoots. The large-flowered kinds should be cut back to the ground each year; and other kinds may be similarly treated unless they are wanted for permanent bowers.

The Clematis root disease is the depredation of a nematode or eel-worm. It is seldom troublesome in ground which thoroughly freezes.

\section{Climbers. Treated under Vines.}

Cobra. This is most commonly seen in the greenhouse, although it is one of the best of tender climbers for porches. Seed sown in February or March, and grown in gentle heat, will make suitable plauts for setting out by June. It may also be grown from euttings of the young wood, taken in February and rooted in brisk heat. The flowers of $C$. scandens are shaped very much like those of the Campanulas, but are larger. They open a greenish white and deepen to a dark purple in the course of a few days. The vines in full bloom have a gradation of colors as the flowers are in different stages of development. The variegated form of $C$. scandens should be propagated by cuttings to hold the variegation. Grows $10-15 \mathrm{ft}$. Tender. Climbs by means of tendrils.

Cockscomb. Celosia cristata is the well known Cockscomb, having combs or heads of scarlet, crimson, 
rose and yellow. The combs are often saved for winter bouquets by cutting them off before thoroughly ripe and drying them. The feathered section comprises tall-growing plants with plumes of various colors which, with the colored leaves of some varieties, make a striking feature in a border. The Celosias, being tender, should be started in a hotbed or frame, potted off when out of the seed-leaf, and planted out in well enriched soil after danger of frost is past. $1 \frac{1}{2}-2 \frac{1}{2} \mathrm{ft}$. high.

Coldframe. A Coldframe is a simple, low structure, covered with glass or oiled paper or cloth, in which plants are grown without artificial heat. It differs from the hotbed in the fact that it has no bottom heat. The atmosphere in the Coldframe is warmer than that outside, because it is protected from the winds and because there is more or less of the sun's heat stored up in the earth. For the details of construction of the Coldframe, see Hotbed.

A Coldframe is ordinarily used for later work than the hotbed: that is, seeds may be sown in a Coldframe from two to three and sometimes four weeks in advance of their sowing in the open; whereas in a hotbed the seeds may be started from one to three months earlier than they may be out of doors. Coldframes are sometimes used for the wintering over of hardy plants which are started in the fall. For example, cabbage seed may be sown in September in a Coldframe and the young plants may be protected therein during the winter. If they are properly grown and hardened off, they will not be injured by the winter, even though they freeze. Lettuce and sometimes cauliflowers are earried over in the same way. Coldframes are also used to receive plants which have outgrown the hotbed and must be transplanted. Plants which need hardening off may also be transplanted from the hotbed into the Coldframe. The Coldframe in these cases is an intermediate stage between the hotbed and the open field. 
Coleus. A well known foliage plant for pot culture or bedding. It was used very extensively at one time in ornamental bedding and ribbon borders, but owing to its being tender has lost in favor, and its place is largely taken by other plants. Cuttings root very readily. It may also be grown from seed, although the types have not become fixed, and a large number of differently marked plants may be had from the same packet. This would not be a drawback in the window-garden, unless a uniform effect is wished. Sow the seed in gentle heat in March. Make new plants from euttings each year, and throw the old ones away.

Collards. This is a name given to a kind of kale, used when young as greens; also to young cabbages used in the same way. The seed of any early cabbage may be sown thickly in rows 18 inches apart, from early spring to late fall. The plants are cut off when 6 or 8 inches high and boiled as are other greens. The kale Collards is grown in the South, where eabbages fail to head. It grows to the height of 2 to 6 feet, furnishing a large quantity of leaves.

Collinsia. A hardy annual that should be sown in the fall, where wanted, if early flowers are desired. The flowers of all the varieties are showy, either in masses or planted in a border. Give them a position near the front, as the plants rarely exceed 18 inches in height.

\section{Columbine. See Aquilegia.}

Compost. See Manure.

\section{Convolvulus. See Morning-Glory.}

Coreopsis, or Calliopsis. Very showy hardy annuals, growing from 1 to 3 feet high, and covered throughout the season with a profusion of bloom. The colors range from lemon-yellow to dark velvety brown. Excellent for cutting, and very effective in mixed borders. They thrive in 
any garden soil if they have full sunlight. Sow where they are to grow, letting the plants stand 6-12 in. apart for mass effects.

Corn Salad. This is one of the earliest spring salad vegetables, coming into condition to use with spinach, and needing the same culture. Sown in the fall, and covered with straw or hay when cold weather sets in, it will start into rapid growth when the covering is removed in Mareh or April. Or the seed may be sown in early spring, and plants will be fit to use in six or eight weeks. One packet of seed will suffice for a small family.

Corn, Sweet, is not so generally used as it should be. Usually when planted at all, only one planting of one kind is made. The ears come to edible maturity almost simultaneously, and a short season of Sweet Corn is the result. The first planting should be made from May 1 to 10 , planting early, intermediate and late varieties at the same time, then at intervals of two weeks until the middle of July, when the late varieties should be planted, thus having a succession from the first crop until October. The soil for Corn should be rich in plant-food, and the coarser manure left from the preparation of the ground for small crops may be used to good advantage. Corn for the garden is better planted in drills, the drills 3 feet apart, dropping the seed from 10 to 12 inches apart in the drills. One quart of seed will plant 200 hills.

For extra early, Marblehead, Adams, Vermont, Minnesota and Early Cory are favorites. For later crop, Crosby, Hickox, Shoe Peg and Stowell Evergreen are now popular.

Cosmos. The Cosmos grown in a locality free from early fall frosts is certainly a beautiful thing, but there are probably few flowers that have caused so much disappointment to the flower lover in the North. The seed germinates very freely. The plants grow with great vigor, and if the season permits, an abundance of bloom may be 
had in September. An early-flowering strain of dwarf Cosmos has been offered by the trade for several years; and each year there seems to be an improvement in the size and colors, so the time may shortly come when this will equal the late-flowering varieties, making the culture of Cosmos more satisfactory. Cosmos flowers are borne on long stems, and the color's are in white and fine shades of red. The foliage is also fine. Seed should be sown in gentle heat, in the greenhouse, hotbed or window in early April, and the young plants transplanted when 2 inches ligh, setting the plants well down in the soil and giving at least 3 inches between the plants, as they are very likely to spindle up, with weak stems, if crowded. When danger of frost is over, set them out in a warm, well sheltered position, 3 feet apart. After the plants start into growth, pinch out the top to induce a bushy growth. If situated where the wind can whip them, they should have a stake driven close to the stem, and be tied to it for support. Flowers of Cosmos are on the order of single Dahlias.

Cranberry. The growing of Cranberries in artificial bogs is an American industry. The common large Cranberry of markets is also a peculiarly American fruit, since it is unknown in other countries except as the fruit is shipped there. Cranberries are grown in bogs, which may be flooded. The whole area is kept under water during the winter time, largely to prevent the plants from winter injury by the heaving and freezing and thawing of the bogs. Flooding is also employed at intervals for the purpose of drowning out insects, mitigating drought, and protecting against frost and fires. Every good Cranberry bog should have facilities for flooding. The ordinary practice is to choose a bog which has a creek running through it, or through which some creek or ditch may be diverted. At the lower side of the bog flood gates are provided, so that when the gates are shut the water backs up and floods the area. It is best that the bog be comparatively flat, so that the water 
will be of approximately equal depth over the whole area. At the shallowest places the water should stand about a foot above the plants. The water is usually let on the bog early in December and kept on until April or early May. No flooding is done during the rest of the year unless there is some particular occasion therefor.

All the wild and turfy growth should be taken off the bog before the vines are set. This is done either by digging it off and removing it bodily, or by drowning it out by means of a year's flooding. The former method is generally considered to be the better. After the turfy growth is removed, the bog is smoothed and covered 2 or 3 in. deep with clean sand. The vines are now set, the lower ends of them being shoved through the sand into the richer earth. In order to prevent a too rapid and tangled growth of vine, it is customary to resand the bog every three or four years to a depth of one-fourth or one-half inch. When sanding is not practicable, the vines may be mown off when they become too luxuriant.

The plants for setting are merely euttings or branches of the vines. These cuttings may be from 5 to $10 \mathrm{in.long.}$ They are inserted into the ground in a hole made by a crowbar or stick. They are usually planted at distances of 12 to 18 in. each way, and the vines are allowed to cover the entire ground as with a mat. In three years a good crop should be secured, if the weeds and wild growth are kept down. A crop ranges between 50 to 100 barrels per acre.

Cress. The Upland Cress, or the true Pepper Grass, may be grown on any garden soil. Sow early in the spring. It makes a rapid growth and ean be ent from four to five weeks. Succession of sowings must be made, as it runs quickly to seed. The curled variety is the one usually grown, as the leaves may be used for garnishing as well as for salads. One packet of seed will be sufficient for each sowing. Any good soil will do. Sow thickly in drills 
12-18 in. apart. In summer it runs to seed quickly, so that it is usually grown in spring and fall.

The Water Cress is more exacting in its culture, and can only be successfully grown in moist places, such as edges of shallow, slow-running creeks, open drains, or beds excavated near such streams. A few plants for private use may be grown in a frame, provided a retentive soil is used and attention given to watering the bed often. Water Cress may be propagated from pieces of the stem, used as cuttings. If one is fond of Water Cress, it is well to colonize it in some clean creek or pool. It will take care of itself year by year. Seeds may also be used for propagating it.

Crocus. A hardy bulb, easily grown and giving good satisfaction either in the border or seattered through the lawn. They are also forced for winter (see $B$ Bulbs). They are so cheap and lasting that they may be used in quantity. A border of them along the edges of walks, little clumps of them in the lawn, or masses in a bed, give the first touch of color as the spring opens. They may be forced with ease planted in pots or shallow boxes, put away in a cool place and brought into the house at any time through the winter. A low temperature will bring them into bloom in perfection in about four weeks from the time they are brought in. They can be had in the windowgarden in this way.

A sandy soil suits the Crocus admirably. Plant in the fall, in the open, setting them 3 to 4 inches deep. When they show signs of failing, take up the bulbs and reset them. They tend to rise out of the ground, because the new bulb or corm forms on the top of the old one. If best results are desired, it is well to renew the bed occasionally by buying new bulbs. Crocus beds may be filled later in the season with quick-growing annuals.

Croton. Under this name many varieties and so-called species of Codiæum are grown for conservatory decoration, and latterly for foliage bedding in the open. 
The colors and shapes of the leaves are very various and attractive. The Crotons make good window-garden subjects, although they are very liable to the attack of the mealy bug. They are propagated readily by cuttings of half-ripened wood any time during winter or spring. The plants should be given an abundance of light in order to bring out their fine colors; but it is usually advisable to sereen them from the direct rays of the sun when they are grown under glass. If the red spider or the mealy bug attack them, they may be syringed with tobaceo water. Plants which are propagated indoors during the winter may be massed in beds out of doors during the summer, where they make very striking effects. Give them rich, deep soil, and be sure that they are syringed frequently enough on the under side of the leaves to keep down the red spider. If the plants have been gradually subjected to strong light before they are taken out of doors, they will stand the full sunlight and will develop their rich colors to perfection. In the fall they may be taken up, eut back and used for windowgarden or conservatory subjects. Crotons are shrubs or small trees, and they may be transferred into large pots or tubs and grown on into large tree-like specimens.

Cucumber. For early use, the Cucumber is usually started in a hotbed or coldframe by sowing the seed on pieces of sod 4 to 6 inches square, turned grass side down. Three or four seeds are placed on or pushed into each piece of sod and covered with 1 to 2 inches of fine soil. The soil should be well watered and the glass or cloth placed over the frame. The roots will run through the sod. When the plants are large enough to set out, a flat trowel or a shingle may be slipped under the sod and the plants moved to the hill without check. In place of sod, old quart berry boxes are good; after setting in the hill the roots may force their way through the eracks in the baskets. The baskets also decay rapidly. Flower pots may be used. These plants from the frames may be set out when danger 
of frost is over, usually by the 10th of May, and should make a very rapid growth, yielding good-sized fruits in two months. The hills should be made rich by forking in a quantity of well rotted manure, and given a slight elevation above the garden - not high enough to allow the wind to dry the soil, but slightly raised so that water will not stand around the roots. One ounce of seed will plant fifty hills. The hills may be 4-5 ft. apart each way.

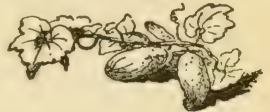

Cucumbers

The White Spine is the leading general-purpose variety. For very early or pickling sorts, the Chicago, Russian, and other picklings are good.

The striped beetle is an inveterate pest on Cucumbers and squashes. Following is the latest advice (Hall and Sirrine, New York State Experiment Station): "Poisons can be used with success against these beetles for only a short time in the spring, when they begin to feed; and again, in the fall, against beetles of the new brood. This fall poisoning will succeed only where there is not an abundance of wild fall flowers; for the beetles will desert any poisoned crop for the unpoisoned flowers and will feed upon the flowers to a considerable extent, anyhow, if they are to be found. Green arsenite, dry, gave best results. It was found a waste of the poisons to apply them in Bordeaux mixture, as the mixture so repelled the insects that they would not eat the sprayed vines to secure the poison. These poisons, applied in water, are liable to burn or stunt the plants. It is necessary, then, if we wish to poison the beetles, to use a trap crop to attract the insects and to apply the poison to this crop instead of to the plants we design to protect. On small areas it may be advisable to shut in the small plants of the growing erop by the well known elothtopped boxes; by the tent-like cloth covers spread over arched hoops or wires; by boxes made from a rectangular piece of cloth and two short 6 -inch boards with cleats attached to insert in the soil and hold the boards upright; or even 6- 
inch wire plate-covers. Covers, however, are too expensive on large areas, and they have the disadvantage of frequently making the plants weak, so that winds will suap them off or twist and ruin them when the cover's have to be removed. If covers are used alone, their removal leaves the unprotected vines not only for feeding places but for breeding places for the beetles.

"Bordeaux mixture, if thoroughly and frequently applied, makes as efficient a protection as the covers, is much cheaper, and at the same time protects the plants from diseases. This mixture (1-to-11 formula) should be sprayed upon the Cucumbers when they are just well up, again when they show the third leaf, and the third time just before the plants commence to form rumers. The early application can probably best be made with a knapsack sprayer, and later ones by any good pump sprayer. The three applications should not cost over $\$ 2$ per acre. The Bordeaux mixture is a much better repellant, according to station tests, than kerosene, turpentine, tobacco dust, cow manure, burdock infusion, slug shot, bug death, or any other known compound. Indeed, all materials of this class, supposed to drive away the beetles by their distasteful odor, proved failures when used alone. Air-slaked lime, dusted over the vines, will make them unpalatable to the beetles, but the lime is liable to stunt the plants. It may be used, with care, by those whose crop is not large enough to warrant purchase of a spraying outfit.

"All of these appliances or applications, envers, Bordeaux mixture or lime, merely protect the young plants until they are strong enough to stand the injury from the beetles; they do not kill the insects. To do this, trap crops are needed. As the squash is the beetle's favorite food plant, this vegetable should be planted - in single rows along the margins of small patches, in several rows around large fields - about four days before the Cucumbers or melon seeds are sown. When these trap plants are up and 
the beetles appear about them, dust about half the plants with green arsenite, reserving the other half for use if rain or heavy dew makes the poison soluble and kills the vines first treated. The beetles, attracted by their favorite tidbit, will feed upon the squash vines and be poisoned by the arsenite. When the Cucumbers or melons are up, unless they are protected by covers, spray with Bordeaux, and poison more of the squash vines. When the beetles commence to pair, the squashes may be cultivated up, leaving only a few vines for the beetles to feed upon at flowering time, as the insects prefer the squash flowers and will not molest the others. Beans may be used with some success as a fall catch crop, where wild flowers are not too plentiful. They should be planted on the Cucumber or melon fields; and when the beetles leave the old vines to feed upon the fresh bean plants, they should be treated to liberal doses of poison as well."

The mildew on the vines can be prevented hy Bordeaux mixture spray.

Currants. The Currant, being one of the hardiest and most productive of fruits, is often neglected, the patch allowed to become foul with grass, never thinned or trimmed, the worms eating the leaves until, in the course of time, the plants weaken and die. Along the fence is no place to plant Currants, or, indeed, any other fruit; plant out in the open, at least 5 feet from anything that will interfere with cultivation. No fruit crop will respond more readily to good care than the Currant. Clean cultivation and a liberal use of manure or fertilizers will certainly be followed by well paying crops. One- or two-year-old plants may be set 4 by 6

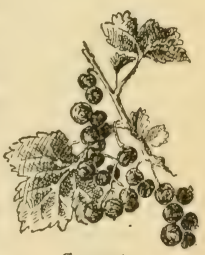

Currants feet. Trim the bush by cutting off most of the sucker's below the surface of the ground. If the season is dry, a mulch of straw or leaves will assist the plants to establish themselves. 
The red and white Currants bear mostly on two-year-old or older wood. A succession of young shoots should be allowed to grow to take the place of the old bearing wood. Cut out the canes as they grow older. The partial shade afforded by a young orchard suits the Currant well, and if the ground is in good condition no bad results will follow to the orchard, provided the Currants are removed before the trees need the entire feeding space.

A Currant patch should continue in good bearing for 10 to 20 years, if properly handled. One very important point is to keep the old, weak canes cut out, and a succession of two to four new ones coming from the root each year. For home use, White Imperial and Moore's Ruby are excellent. Prince of Wales is a heavy bearer and excellent for cooking. Wilder, Victoria, Cherry and White Grape are meritorious varieties.

To combat the Currant worm, spray thoroughly with Paris green to kill the first brood, just as soon as holes can be seen in the lower leaves - usually before the plants are in bloom. For the second brood, if it appear, spray with white hellebore. For borers, eut out and burn the affected canes.

Cuttings. Cuttings are parts of plants which are inserted in soil or water with the intention that they shall grow and make new plants. They are of various kinds. They may be classified, with reference to the age of the wood or tissue, into two classes; viz., those made from perfectly hard or dormant wood (taken from the winter twigs of trees and bushes), and those made from more or less immature or growing wood. They may be classified again in respect to the part of the plants from which they are taken, as root Cuttings, tuber Cuttings (as the ordinary "seed" planted for potatoes), stem Cuttings and leaf Cuttings.

Dormant wood Cuttings are used for grapes, currants, gooseberries, willows, poplars and many other kinds of soft- 
wooded trees and shrubs. Cuttings are ordinarily taken in fall or winter, but eut into the proper lengths and then buried in sand or moss where they do not freeze, in order that the lower end may heal over or callus. In the spring these Cuttings are set in the ground, preferably in a rather sandy and well drained place. Usually, hardwood Cuttings are made with two to four joints or buds, and when they are planted, only the upper bud projects above the ground. They may be planted erect, as the picture shows, or somewhat slanting. In order that the Cutting may reach down to moist earth, it is desirable

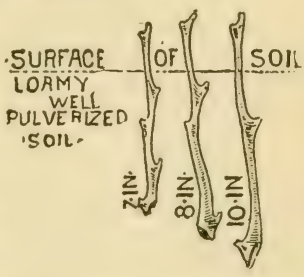

The planting of dormant wood Cuttings that it should not be less than 6 inches long; and it is sometimes better if it is 8 to 12 inches. If the wood is short-jointed, there may be several buds on a Cutting of this length; and, in order to prevent too many shoots from arising from these buds, the lowermost buds are often cut out. Roots will start as readily if the lower buds are removed, since the buds grow into shoots and not into roots. Cuttings of currants, grapes, gooseberries, and the like may je set in rows which are far enough apart to admit of easy tillage either with horse or hand tools, and the Cuttings may be placed from 3 to 8 inches apart in the row. After the Cuttings have grown for one season, the plants are usually transplanted and giren more room for the second year's growth, after which time they are ready to be set in permanent plantations. In some cases, the plants are set at the end of the first year; but two-year plants are stronger and usuwhich has given ally preferable.

rise to a shoot

Root Cuttings are used for blackberries, raspberries, and a few other things. They are ordinarily made of roots from the size of a lead pencil to one's little finger, and are cut in lengths from 3 to 5 inches long. The Cuttings 
are stored the same as stem Cuttings and allowed to callus. In the spring they are planted in a horizontal or nearly horizontal position in moist, sandy soil, being entirely covered to a depth of 1 or 2 inches.

Softwood or greenwood Cuttings are always rooted under cover; that is, in a greenhouse, coldframe or dwelling house. They are usually made of wood which is mature enough to break when it is bent sharply. When the wood is so soft that it will bend and not break, it is too immature, in the majority of plants, for the making of good Cuttings. One to two joints is the proper length of a greenwood Cutting. If of two joints, the lower leaf should be eut off and the upper leaves eut in two, so that they do not present their entire surface to the air and thereby evaporate the plant juices too rapidly. If the Cutting is of only one joint, the lower end is usually cut just above a joint. In either case, the Cuttings are usually inserted in sand or well washed gravel, nearly or quite up to the leaves. Keep the bed uniformly moist throughout its depth, but avoid any soil which holds so much moisture that it becomes muddy and sour. These Cuttings should be shaded until they begin to emit their roots. Coleus, geraniums, fuchsias, and nearly all the common greenhouse and house plants, are propagated by these Cuttings or slips.

Leaf Cuttings are often used for the fancy-leaved begonias, gloxinias, and a few other plants. The young plant usually arises most readily from the leaf-stalk or petiole. The leaf, therefore, is inserted into the ground much as a green Cutting is. Begonia leaves, however, will throw out young plants from the main veins when these veins or ribs are cut. Therefore, well-grown and firm begonia leaves are sometimes laid flat on the sand and the main veins eut; then the leaf is weighted down with pebbles or pegs so that these cut surfaces come into intimate contact with the soil beneath. The begonia leaf may be treated in various other ways and still give good results. See Begonia. 
In the growing of all greenwood Cuttings, it is well to remember that they should have a gentle bottom heat; the soil should be such that it will hold moisture and yet not remain wet ; the air about the tops should not become close and stagnant, else the plants will damp off ; and the tops should be shaded for a time.

An excellent method of starting Cuttings in the living room is to make a double pot, as shown in the picture. Inside a 6 -inch pot, set a 4 -inch pot. Fill the bottom, $a$, with gravel or bits of brick, for drainage. Plug the hole in the inside pot. Fill the spaces between, c, with earth, and in this set the Cuttings. Water may be poured into the inner pot, $b$, to supply the moisture.

Cutworms. Probably the remedy for Cutworms most often practiced in gardens, and which cannot fail to be effective when faithfully carried out, is handpicking with lanterns at night or digging them out from around the base of the infested plants during the day. Bushels of Cutworms have been gathered in this way, and with profit. When from some cause success does not attend the use of the poisoned baits, discussed next, hand-picking is the only other method yet recommended which can be relied upon to check Cutworm depredations.

By far the best methods yet devised for killing Cutworms in any situation are the poisoned baits; hand-picking is usually unnecessary where they are thoroughly used. Poisoned bunches of elover or weeds have been thoroughly tested, even by the wagon-load, over large areas, and nearly all have reported them very effective; lamb's quarters (pigweed), pepper-grass and mullein are among the weeds especially attractive to Cutworms. On small areas the making of the baits is done by hand, but they have been prepared on a large scale by spraying the plants in the field, cutting them with a scythe or machine, and pitching 
them from wagons in small bunches wherever desired. Distributed a few feet apart between rows of garden plants at nightfall, they have attracted and killed enough Cutworms often to save a large proportion of the crop; if the bunches can be covered with a shingle, they will keep fresher much longer. The fresher the baits, and the more thoroughly the baiting is done, the more Cutworms one can destroy. However, it may sometimes happen that a sufficient quantity of such green succulent plants eannot be obtained early enough in the season in some localities. In this case, and we are not sure but in all cases, the poisoned bran mash can be used to the best advantage. It is easily made and applied at any time, is not expensive, and thus far the results show that it is a very attractive and effective bait. A tablespoonful can be quickly dropped around the base of each cabbage or tomato plant, small amounts can be easily scattered along the rows of onions, turnips, ete., or a little dropped on a hill of corn, cucumbers, etc. It was used on sweet potato hills in New Jersey last year, and "served as a complete protection, the Cutworms preferring

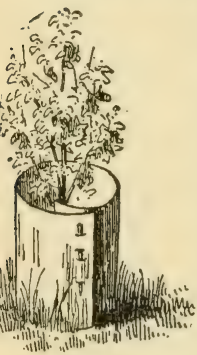

Protection from cutworms the bran." It is well to apply it on the evening of the day the plants are set out.

The best time to apply these poisoned baits is two or three days before any plants have come up or been set out in the garden. If the ground has been properly prepared, the worms will have had but little to eat for several days and they. will thus seize the first opportunity to appease their hunger upon the baits, and wholesale destruction will result. The baits should always be applied at this time wherever Cutworms are expected. But it is not too late usually to save most of a crop after the pests have made their presence known by cutting off some of the plants. Act promptly and use the baits freely.- $\boldsymbol{M}$. $\boldsymbol{V}$. Slingerland. 
Cutworms may be kept away from plants by making a collar of stiff paper or tin about the base, as in the picture; but this is not practicable on a large scale.

Cyclamen. A tender greenhouse tuberous plant, sometimes seen in the window-garden. Cyclamens may be grown from seed sown in April or September in soil containing a large proportion of sand and leaf-mold. If sown in September, they should be wintered in a coolhouse. In May they should be potted into larger pots and placed in a shaded frame, and by July will have become large enough for their flowering pot, which should be either a 5- or 6 -inch one. They should be brought into the house before danger of frost, and grown cool until through flowering. A temperature of $55^{\circ}$ suits them while in flower. After flowering, they will need a rest for a short time, but should not become very dry, or the bulb will be injured. When they start into growth, they should have the old soil shaken off and be potted into smaller pots. At no time should more than half the tuber be under the soil.

Tubers large enough to flower the first year may be obtained from the seedsmen at moderate prices; and unless one has facilities for growing the seedlings for a year, purchase of the tubers will give the best satisfaction. The soil best suited to the Cyclamen is one containing two parts leaf-mold, 1 part each of sand and loam.

Daffodils are a kind of Narcissus. They are hardy, and require the treatment rocommended for Crocus. They may be naturalized in the grass, but they usually do not persist long on account of our hot, dry summers. Daffodils have been much improved of late. Plant in the fall, 4-6 in. deep. Excellent old garden plants.

Dahlia. The Dahlia is an old favorite which, on account of its formal flowers, has been in disfavor for a few years, although it has always held a place in the rural districts. Now, however, with the advent of the cactus and 
semi-cactus types (or loose-flowered forms), and the improvement of the singles, it again has taken a front rank among late summer flowers, coming in just in advance of the Chrysanthemum.

The single varieties may be grown from seed, but the double sorts should be grown from cuttings of young stems or from division of the roots. If cuttings are to be made, it will be necessary to start the roots early either in a hotbed or house. When the growth has reached 4 or 5 inches, they may be cut from the plant and rooted in sand. Care should be taken to eut just below the joint, as a cutting made between two joints will not form tubers. The most rapid method of propagation of named varieties is to grow from cuttings in this way. In growing the plants from roots, the best plan is to place the whole root in gentle heat, eovering slightly. When the young growth has started, the roots may be taken up, divided, and planted out 3 to 4 feet apart. This plan will ensure a plant from each piece of root, whereas if the roots are divided while dormant, there is danger of not having a bud at the end of each piece, in which ease no growth will start.

The Dahlia flourishes best in a deep, rich, moist soil, although very good results ean be had on sandy soil, provided plant-food and moisture are furnished. Clay should be avoided. If the plants are to be grown without stakes, the center of each plant should be pinched out after making two or three joints. By doing this the lateral

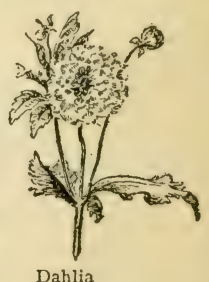

Dahlia branches will start near the ground and be stiff enough to withstand the winds. In most home gardens the plants are allowed to reach their full height, and are tied to stakes if necessary. Dahlias are very susceptible to frost. The tall kinds reach a height of 5-8 feet.

After the first frost, lift the roots, let them dry in the sun, shake off the dirt, trim off tops and broken parts, and 
store them in a cellar as you would potatoes. Cannas may be stored in the same place.

Daisy. The perennial English Daisy, or Bellis peremis, is a prime favorite as an edging plant. The cheerful little flowers show early in the spring, and with a little care bloom continuously through a long season. They should be given well enriched, moist soil, and be mulched through hot weather. The usual method of propagation is by division of the erowns, made in cool weather. They may also be grown from seed, but the chances are that many inferior flowers will be produced. Set the plants 3 or 4 inches apart. Height 3 to 5 inches. The colors are white, pink and red. Hardy if mulched in winter, but best results are obtained if plants are renewed frequently.

Many other plants are called Daisy, particularly the wild Asters, the Ox-eye Daisy or Whiteweed, and the Paris Daisy (Chrysanthemum frutescens).

Damping Off is the rotting off of cutting's or young plants near the surface of the soil. It is the work of fungi; but these fungi are injurious beeause they find conditions congenial to their rapid growth. Prevention is worth more than cure. See that the soil is wet clear through, not wet on top and dry beneath. Keep it as dry as possible on the surface. Avoid soggy soils. On peaty soils, sprinkle sand or coal ashes to keep the top dry. Give the plants free eirculation of air. Give them abundance of room. If Damping Off threatens, transplant.

Dandelion. This common weed would hardly be recognized if seen under eultivation in the vegetable garden. The plants attain a large size and the leaves are much more tender. The seed may be selected from the best field-growing plants, but it is better to buy the French seed of the seedsmen.

Sow in spring in well manured soil, either in drills or in hills 1 foot apart. A eutting of leaves may be had in Sep- 
tember or October, and some of the stools may stand until spring. The delicacy of the leaves may be improved by blanching them, either by the use of boards or earth. One trade packet of seed will supply a large number of plants. The whole plant is destroyed when the erop of leaves is taken.

Datura. BRuguansia. Large-growing annuals with large, trumpet-shaped flowers. The coloring of some of the flowers is very attractive, but the odor of the plant is unpleasant. Plants should be set 4 feet apart. They grow 3-4 feet high, bear large leaves, and therefore make good low screens. Frost kills them. Sow seed where plants are to grow; or, better, start them in the house three or four weeks before the weather is fit for planting outside. Some of the Daturas are weeds. The great spiny seed pods are interesting.

\section{Delphinium. See Larkspur.}

Dewberry. The Dewberry may be called an early trailing blackberry. The culture of this, as of the blackberry, is very simple; but, unlike the latter, some support should be given to the eanes, as they are very

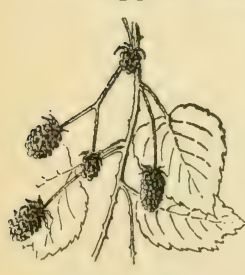

Lucretia Dewberry slender and rank growers. A wire trellis or large-meshed fence-wire answers admirably; or (and this is the better general method) they may be tied to stakes. The fruits are large and showy, which, combined with their earliness, makes them desirable; but they are usually deficient in fiavor. The Lucretia is the leading variety in cultivation.

Lay the canes on the ground in winter. In the spring tie all the canes from each plant to a stake. After fruiting, eut the old canes and burn them (as for blackberries). In the meantime, the young eanes (for next year's fruiting) are growing. These may be tied up as they grow, to be out of the way of the cultivator. Dewberries are one to two weeks earlier than blackberries. 
Dianthus, or Pink. Under this head are included Chinese Pinks, Sweet William, Picotee, Carnation (which see), and the perennial or Grass Pinks. All of them are general favorites.

The Chinese Pinks (Dianthus Chinensis, or Heddewigii) are now very popular. They are biennials, but flower the first year from seed, and are treated as hardy annuals. They have a wide range of color and markings. Some of them are as double as a rose, and are edged, splashed or lined with other colors. The single ones are very brilliant and are profuse bloomers. Sow seeds where plants are to stand, or if early bloom is desired, start in the house. Set the plants $6-10$ in. apart. They grow 8-15 in. high. They bloom until after frost. Of easiest culture in any good soil, and should be even more popular. The petals are often quite deeply and oddly eut.

The Sweet William is an old-fashioned perennial, having flowers of many combinations of color, growing for several years when once planted, but being the better for renewal every two years. Raising new stock from seeds is usually better than dividing old plants. Of late years, the Sweet William has been much improved.

The perennial garden or Grass Pinks are low-growing, with highly perfumed flowers. They are very useful for permanent edgings, although the grass is likely to run them out unless a clean strip is kept on either side. Divide the old plants when the edging begins to fail; or raise new plants from seed. Seedlings usually do not bloom much the first year. Usually perfectly hardy.

Dibbers are hand tools used for making holes in which to set plants or to drop seeds. They are better than a hoe or a spade

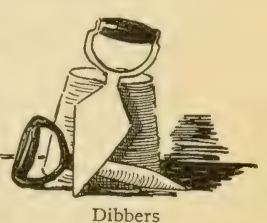
for most transplanting. For small plants, as cabbages and tomatoes, a cylindrical Dibber is generally used. (See the lower one in the cut.) It ean be made from an old spade 
handle or any hardwood stick. When broad holes are wanted, the triangular iron Dibber (sold by dealers) is excellent. It is particularly useful in hard soils.

Dicentra includes the Bleeding Heart; also the native little Dutchman's Breeches and Squirrel Corn, and a few other species. All are hardy perennials of the easiest culture, blooming in spring. In common with all perennial herbs, they are benefited by a winter mulch of leaves or litter. Propagated by dividing the clumps.

Dictamnus. Fraxinella or Gas Plant. An old border plant (perennial herb) with white or pale red flowers. The leaves of the plant emit a strong odor when rubbed, likened to that of the lemon verbena. It has been advertised as the Gas Plant from the fact that the plant exudes an oily matter that may be ignited, especially in warm, dry weather. Propagated by seeds, which should be sown as soon as ripe. The plant blooms the third year, and improves with age. Set plants 3 feet apart. Height 2 to 3 feet.

Dill. An annual aromatic herb that will seed itself if seeds are left to ripen, and an abundance of plants may always be had. The culture is of the easiest. The seeds are often used to flavor pickles.

Diseases. Diseases of plants may be caused by some physiological disturbance to the plant system, or by the incursions of some parasitic organism, as insects or fungi. The work of insects, however, is ordinarily not elassed with plant Diseases (see Insects). Of Diseases which are caused by plant parasites or by physiologieal disturbances, there are two general groups :

(1) Parasitic fungous Diseases, such as the apple-seab, black-rot and mildew of the grape, leaf-blight of the plum and pear, black-knot, and the like. These Diseases are characterized by definite spots, discolorations or excrescences, which are more or less seattered over the surface of 
the leaf, fruit or branch. As a rule, the leaves and fruits which are attacked have a tendeney to drop from the tree. The general treatment for these Diseases is to spray with some fungicidal mixture, like the Bordeaux mixture or the ammoniacal carbonate of copper. The treatment is useful in proportion as it is applied early and thoroughly. After the fungus once gets into the tissues of the host-plant, it is difficult, if not impossible, to kill it. If, however, the fungicide is upon the plant before the fungus is, the parasite may not be able to obtain a foothold. Even after it does obtain a foothold, it is probable, however, that the spray will check its spread by preventing the development of its external parts.

(2) The physiological and bacterial Diseases, or those which are termed constitutional troubles. In these cases there are rarely any definite spots, as in the attacks of parasitic fungi, but the entire leaf, or even the entire plant, or a large part of it, shows a general weakening and Disease, as if there were some cutting off of the accustomed source of nourishment. Such Diseases are very likely to be seen in a general yellowing and death of the leaf, in the dying of the leaf along the main veins and around the edges, showing that the difficulty is one which affects the entire leaf, and not any particular part of it. In general, there is a tendency for the foliage in plants so attacked to wither up and hang on the tree for a time. The peachyellows and pear blight are Diseases of this kind. There are no specific treatments for troubles of this sort. They must be approached by what physicians call prophylaxis that is, by methods of sanitation and prevention. The diseased plants or parts are cut away and burned. All those conditions which seem to favor the development of the Disease are removed. Varieties which are particularly susceptible are discarded. Careful management in matters of this sort is often much more important than any attempt at specific treatment. 


\section{Dolichos. Mentioned under Hyacinth Bean.}

Dracænas of the conservatories (properly mostly CoRdylines) are sometimes used as house plants. Protect from direct sunlight, keep an even and fairly high temperature, water freely when they are growing. When the plants begin to fail, return them to the florist for recuperation, where they may have equable conditions. They are handsome long-leaved foliage plants, excellent for jardinieres.

Drainage serves two purposes: first, to carry superfluous water from the land; second, to lower the watertable or hard-pan, and to make the soil loose and friable above. Nearly all hard clay lands are much benefited by draining, even though they are not too wet. The region of free or standing water is lowered and air is admitted into the soil, rendering it fine and mellow. For carrying off mere surface water, surface or open ditches are sufficient; but if the soil is to be ameliorated, the drain must be beneath the surface. The best underdrains are those which use hollow or cylindrical tiles, but very good results may be had by making drains from stones. In regions where there are many flat stones, a very good conduit may be laid with them, but they are likely to get out of order. If there is considerable fall to the ditch, the bottom may be filled for the space of 10 inches or a foot with common stones rolled in, and the water will find its way between them. If the stones are even deeper than this, the results will be better; and such ditches also provide place for disposing of superfluous stones.

The deeper the ditch the further it will draw on either side. It should always be deep enough to be protected from freezing, particularly if tiles are used. Three feet should be the least depth, and $3 \frac{1}{2}$ feet is a good average depth. Drains as deep as this need not be placed oftener than 2 to 3 rods apart, unless, in garden conditions, it is desired to 
very thoroughly ameliorate a heavy clay soil, in which case they may be placed every 20 feet. The better the fall the quicker the drain will act and the more permanent it will be, as it will tend to clean itself and not fill up with silt. It is important that the outlet be entirely free, and it should be protected with stones or mason work. The roots of some trees, particularly of willows and elms, are attracted by tile drains, and often fill up the pipes. When the drain goes near such trees, therefore, it is well to cement the joints. In general practice, however, the joints should not be cemented, because a large part of the drainge water enters at those places. In laying the tiles, it is well to cover the joints with inverted sod, tarred paper, wisps of straw, stones or other material. This prevents the fresh earth from falling in between the joints, and by the time the material is decayed the earth will have become so thoroughly set that no further trouble will result. Although underdrains take off superfluous water, nevertheless an underdrained soil will hold more moisture than one which is not drained, particularly in the case of clay lands with high subsoils. This is because fine, mellow soils are ablo to hold more moisture than very loose and open or very dense and compact ones. A well constructed underdrain should last indefinitely.

\section{Dutchman's Pipe. See Aristoloctia.}

Echeveria. Tender succulents largely used for carpet bedding and rock gardens. Echereria secunda is sometimes called OLD-Hen-AND-Chickens, from the little plants that grow out from the stem of the parent plant and show around the edges of the rosette top; but the hardy Henand-Chickens of old gardens is a different but closely allied plant (Sempervirum tectorum). All the species are of easy culture and thrive on sandy soil. They should not be planted out until all danger of frost is over and the ground thoroughly warm. Propagated by the offsets. Height 3 
inches. The name Echeveria is now given up by botanists for Cotyledon.

Egg-plant. Guinea Squash. Unless one has a greenhouse or a very warm hotbed, the growing of Eggplants in the North should be left to the professional gardener, as the young plants are very tender, and should be grown without a check. The seed should be sown in the hotbed or greenhouse about April 10, keeping a temperature of from $65^{\circ}$ to $70^{\circ}$. When the seedlings have made three rough leaves, they may be pricked out into shallow boxes, or, still better, into 3 -inch pots. The pots or boxes should be plunged to the rim in soil in a hotbed or coldframe so situated that protection may be given on chilly nights. The 10th of June is early enough to plant them out in central New York. The soil in which they are to grow cannot well be made too rich, as they have only a short season in which to develop their fruits. The plants are usually set 3 feet

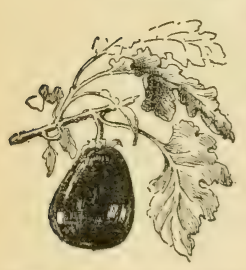

New York Purple Egg-plan apart each way. A dozen plants are sufficient for the needs of a large family, as each plant should yield from two to six large fruits. The fruits are fit to eat at all stages of growth, from those the size of a large egg to their largest development. One ounce of seed will furnish 600 to 800 plants.

The New York Improved Purple is the standard variety. Black Pekin is good. For early, or for a short-season climate, the Early Dwarf Purple is excellent.

Endive. As a fall salad vegetable, this should be better known, it being far superior to lettuce at that time and as easily grown. For fall use, the seed may be sown from June to August, and as the plants become fit to eat about the same time from sowing as lettuce does, a succession may be had until cold weather. The plants will need protection from the severe fall frosts, and this may be given by earefully lifting the plants and transplanting to a 
frame, where sash or cloth may be used to cover them in freezing weather. The leaves, which constitute practically the whole plant, are blanched before being used, either by tying together with some soft material or hy standing boards on each side of the row, allowing the top of the boards to meet over the center of the row. The rows should be $1 \frac{1}{2}$ or 2 feet apart, the plants 1 foot apart in the rows. One ounce of seed will sow 150 feet of drill.

\section{Eschscholtzia. See Culiformia Poppy.}

Eutoca. Hardy early-flowering annuals having pink or blue flowers, goorl for masses. Sow seed early where wanted. Height 1 foot. Eutocas are properly classed with Phacelias.

Evergreens. Evergreens are plants which hold their foliage in winter. Ordinarily, however, in this country the word Evergreen is understood to mean coniferous trees with persistent leaves, as pines, spruces, firs, cedars, junipers, arborvite, retinosporas, anil the like. These trees have always been farorites with plant lovers, as they have very distinctive forms and other characteristies. Many of them are of the easiest culture. It is a common notion that, since spruces and other conifers grow so symmetrically, they will not stand pruning; but this is an error. They may be pruned with as good effect as other trees, and if they tend to grow too tall the leader may be cut out without fear. A new leader will arise, but in the meantime the upward growth of the tree will be somewhat checked, and the effect will be to make the tree dense. The tips of the branches may also be headed in with the same effect. The beauty of an Evergreen lies in its natural form; therefore, it should not be sheared into unusual shapes, but a gentle trimming back, as suggested, will tend to prevent the Norway spruce and others from growing open and ragged. After the tree attains some age, 4 or 5 inches may be taken off the ends of the main branches every year or two with 
good results. This slight trimming is ordinarily done with Waters' long-handled pruning shears.

There is much difference of opinion as to the proper time for the transplanting of Evergreens, which means that there is more than one season in which they may be moved. It is ordinarily unsafe to transplant them in the fall in northern climates or bleak situations, since the evaporation from the foliage during the winter is likely to injure the plant. The best results are usually secured when they are transplanted just as new growth is beginning, rather late in the spring. Some people also plant them in August, and the roots secure a hold of the soil before winter. In transplanting conifers, it is very important that the roots be not exposed to the sun. They should be moistened and covered with burlays or other material. The holes should be ready to receive them. If the trees are large, or if it has been necessary to trim in the roots, the top should be eut when the tree is set. Large Evergreens (those 10 feet and more high) are usually best transplanted late in winter, at a time when a large ball of earth may be moved with them. A trench is dug around the tree, it being deepened a little day by day so that the frost can work into the earth and hold it in shape. When the ball is thoroughly frozen, it is hoisted onto a stone-boat and moved to its new position.

For low hedges or screens, one of the most serviceable Evergreens is the arborvitre in its various forms. Red cedars are also useful. Perhaps the handsomest of all of them for such purposes is the ordinary hemlock spruce; but it is usually difficult to move. Transplanted trees from nurseries are usually safest. If the trees are taken from the wild, they should be selected from open and sunny places. For neat and compact effects near porches and along walks, the dwarf retinosporas are very useful. Most of the pines and spruces are too coarse for planting very close to the house. They are better at some distance removed, where they serve as a background to other planting. If they are wanted for 
individual specimens, they should be given plenty of room, so that the limbs will not be crowded and the tree become misshapen. Whatever else is done to the spruces and firs, the lower limbs should not be trimmed up, at least not until the tree has become so old that the lowest branches die. Some species hold their branches much longer than others. The oriental spruce (Picen orientalis) is one of the best in this respect. The occasional slight heading-in, which we have mentioned, will tend to preserve the lower limbs, and it will not be marked enough to alter the form of the tree.

Everlastings are flowers which retain their shape and usually their color when they are dried. MLst of them are members of the composite family. In order to have them hold shape and color, eut them with very long stems just before they are fully expanded, and hang them in an airy place a way from the sun. They are all annuals, or grown as such, and are of very easy culture. Sow speds where the plants are to stand. Good kinds are Ammobium, Gomphrena or Bachelor's Buttons, Rhodanthe, Helichrysum, Xeranthemum, and Acroclinium. Certain wild composites may be similarly used, particularly Anaphalis and species of Gnaphalium. Some of the grasses make excellent additions to dry bouquets (see Grass). With these dry bouquets, various seed pods look well.

Fenzlia. Little hardy annuals, having a profusion of bloom through the entire summer. The flowers are a delicate pink, with yellow throat surrounded by dark spots. A charming edging plant or window box subject. Sow the seed in boxes or where plants are wanted, and thin to the distance of 10 inches. Height 3 to 4 inches. Now elassed with Gilia.

Ferns. Probably the one Fern grown most extensively as a house plant is the small-leaved Maidenhair Fern (or Adiantum gracillimum). This and other species are among the finest of house plants, when sufficient moisture 
can be given. They make fine specimens, as well as serving the purpose of greenery for cut-flowers. Other species often grown for house plants are A. cuneatum and $A$. Capillus-Teneris. All these do well in a mixture of fibrous sod, loam, and sand, with ample drainage material. They may be divided if an increase is wanted.

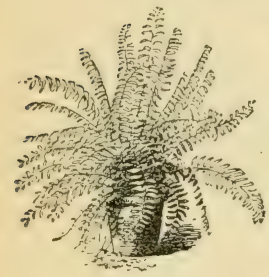

Boston Fern

Other Ferns for house culture include Nephrolepis exaltata. This is no doubt the most easily grown of the list, flourishing in a sitting-room. The new variety of $N$. exaltata, called the Boston Fern (see figure), is a decided addition to this family, having a drooping habit, covering the pot and making a fine stand or bracket plant.

Several species of Pteris, particularly $P$. serrulata, are valuable house Ferns, but require a warmer situation than those mentioned above. They will also thrive better in a shady or ill-lighted corner.

Perfect drainage and care in watering have more to do with the successful growing of Ferus than any special mixture of soils. If the drainage material in the bottom of the pot or box is sufficient, there is little danger of overwatering; but water-logged soil is always to be avoided. Do not use elay soils. Ferns need protection from the direct sunshine, and also a moist atmosphere. They thrive well in a close glass box, or window-garden, if the conditions can be kept equable.

The native Ferns transplant easily to the garden, and they make an attractive addition to the side of a house, or as an admixture in a hardy border. The Ostrich and Cinnamon Ferns are the best subjects. Give all outdoor Ferns a place which is protected from winds, otherwise they will shrivel and perhaps die. Sereen them from the hot sun, or give them the shady side of the building. See that the soil is uniformly moist, and that it does not get too hot. Mulch with leaf-mold in the fall. 
Fertilizers. Soil is productive when it has good physical texture, plant-food, and a sufficient supply of moisture. Even though it has an abundance of plant-food, if its texture is not good, it will not raise a good crop. Soil has good texture when it is open, mellow, friable, rather than loose and leachy, or hard and eloddy. Commercial Fertilizers add plant-food, but usually they have only a small influence in correcting faulty texture. Therefore, before concentrated Fertilizers are applied to land, it should be gotten into good physical condition by judicious tillage and by the incorporation of vegetable mold or humus. The leading source of humus in most gardens is stable manure. See Manure.

The plant-food in commercial Fertilizers is largely in a soluble or quickly available condition. Therefore, a little Fertilizer applied late in the fall or early in the spring will tend to start the plants off quickly in the spring and to cause them to become established before the trying weather of summer. For garden purposes, it is usually advisable to buy one of the so-called complete Fertilizers; that is, one which contains nitrogen, potash and phosphoric acid. If a luxuriant growth of stalk and foliage is wanted rather than flowers or fruit, an application of nitrogen alone is usually advisable. The most readily available nitrogen in commercial form is that which is afforded by nitrate of soda and sulfate of ammonia. In garden practice this may be applied at the rate of 300 to 400 pounds an acre, although this quantity is more than is profitable to use in most general field or agricultural conditions. If it is desired to have stout, stocky plants, with early and profuse bloom, it is ordinarily advisable to use somewhat sparingly of nitrogen and to use a little more heavily of potash and phosphoric acid. This is especially true of the leguminous plants, which have the power of appropriating atmospheric nitrogen, and among such plants are sweet peas. Heavy fertilizing of sweet pea land with strong stable manure tends to 
make the vines grow too tall and to bear comparatively few flowers. For dressing of lawns, a Fertilizer which is comparatively rich in nitrogen is usually to be advised.

An important value of commercial Fertilizers is to use them to start off the plants quickly in the spring. The food is available and acts at once. When used for this purpose, the Fertilizer may be applied in the hill; but when it is desired for the enriching of the land and for the support of the crop throughout the season, it should be applied to the entire surface. Always avoid putting the Fertilizer on the crown of the plant, or directly in contact with it. It is usually better to work the Fertilizer in lightly. For most garden operations, it is better to apply in spring.

\section{Feverfew. See Pyrethrum.}

Fig. The Fig is little grown in the East except as a curiosity, but on the Pacific coast it has gained more or less prominence as an orchard fruit. The trees are usually planted at distances of about 18 to 25 feet apart. Figs will stand considerable frost, and seedling or inferior varieties grow out of doors without protection as far north as Virginia. Many of the varieties fruit on young sprouts, and, inasmuch as the roots will stand considerable cold, these varieties will often give a few Figs in the northern states. Figs have been fruited in the open ground in Michigan. In all frosty countries, however, the Fig should be laid down during the winter time. The following notes from Professor Massey, of North Carolina, indicate how this may be done:

"The light hoar-frosts that have occurred here affected vegetation only on low grounds, and today (November 5) our gardens on high ground show no signs of frost. Lima beans and tomato vines are as green as in summer time, and this morning we gathered ripe Figs from our trees in the garden - the latest I have ever known Figs to ripen. As the early crop of Figs ripens in July (if it escapes the 
winter frosts, for the fruit is now set on the trees), and the late crop begins in August and continues to ripen in succession till frost, it is easy to see what a desirable fruit the Fig is. In this section it is easy to have a great abundance of Figs, and it is possible almost anywhere in the United States to have both early and late crops in abundance by taking a little trouble to protect the trees in winter. Years ago the writer grew Figs in abundance in a very cold locality in

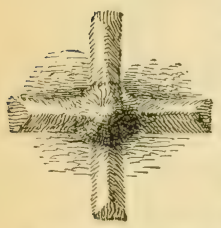

Fig branches covered with earth northern Maryland, and never failed to get a good crop. Where the winter temperature seldom drops lower than $18^{\circ}$ or $20^{\circ}$ above zero, Figs will need no special protection if sheltered from cold winds. In colder climates they should be branched from the ground, and, after the leaves have fallen, be bent to the ground in four bundles and covered with earth, making a sharp mound over the center and sloping off like a four-pointed star or cross, as shown in the cuts, taken from Bulletin 74 of North Carolina Experiment Station."

Flower Beds. Two classes of subjects are to be considered in the discussion of Flower Beds: those concerned with the location of the bed; those concerned with the actual making of the bed itself. Most persons do not consider the former subject. If one wants a flower garden in which there is to be a collection of plants grown for the plants' sake, the garden should be placed at the rear or one side, and may be laid out in regular fashion like a vegetable garden. If the flowers are to be a part of the home picture, - that is, a part of the place itself, - then they may be freely distributed amongst the border planting, or as edgings along groups of shrubbery. It is rarely, if ever, allowable to place formal beds in the lawn in home grounds. The place for carpet-bedding is usually in parks or other public areas, in sections which are set aside and devoted to that 
particular purpose, the same as another section may be devoted to a zoülogical garden, play-ground or to other speeific use. Flowers which are grown in the middle of the lawn have little relation to other planting, and they have no background to show them off to good advantage. It is also difficult to grow them in small beds in the grass, since they are exposed to sun and wind, and the grass roots absorb the food and moisture. In the formal bed, every effort must be made to keep it prim, otherwise it becomes displeasing; whereas, if the flowers are planted more or less promiscuously in large, irregrular borders, or along the edge of shrubbery, the failure of one or even of a dozen plants is not a serious matter. The growing of plants in formal designs requires so much care and attention that a large part of the fun of plant-growing is lost. Such plant-growing should ordinarily be left to those who make a business of it.

In making a Flower Bed, see that the ground is well drained; that the subsoil is deep; that the land is in a mellow and friable condition, and that it is rich. Each fall it may have a muleh of rotted manure or of leaf-mold, which may be spaded under deeply in the spring ; or the land may be spaded and left rough in the fall, which is a good practice when the soil has much clay. Make the Flower Beds as broad as possible, so that the roots of the grass running in from either side will not meet beneath the flowers and rob them of food and moisture. It is well to add a little commercial fertilizer each fall or spring.

Flowering Maple. See Abutilon.

Forget-me-not. This old favorite grows so easily, looks so cheerful, and with a little care will bloom so long, that it should have a place in every collection of flowering plants. It is perennial, but the best results may be had by dividing the roots as often as every other year; or seedlings may be taken up from around the old plants. They require a moist soil, with shade a part of the day. They will thrive exceedingly if grown in a frame like 
pansies. Easily grown from seeds, usually blooming the first fall. Excellent for low edgings. Height 6 inches.

Four-o'clock. MirABILIs. Tender annual, a plant of old-fashioned gardens, and always interesting. Grows 2 to 3 feet high. Drop seeds where the plants are to stand, thinning them to 12 to 18 inches apart. The colors are white and pink. There are variegated-leaved forms; also dwarfs. Excellent for the back row in a bed of annuals.

Foxglove, or Digitalis. Foxgloves make most effective border plants, either as a background or planted among other things. The tall flower-spikes are covered during the blooming period with funnelshaped drooping flowers in various colors and with fine markings. Some of the newer varieties have flowers that rival the Gloxinias in shadings and markings. The plants are perfectly harly, growing in one situation for a number of years; but, as with many other peremials, they are all the better for being divided at intervals. They may be grown realily from seed. Sow in boxes under glass or in the border where wanted. They bloom the second year. A rich, deep soil and partial shade suit their requirements.

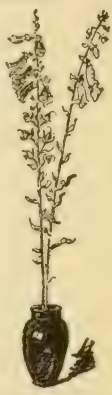

Foxglove Period of bloom, July and August. Height 2 to 4 feet.

Frame. See Hotbed and Coldframe.

Freesia. One of the best and most easily handled winter-flowering bulbs. The white or yellowish bell-shaped flowers are produced on slender stalks just above the foliage, to the number of six to eight in a cluster. They are very fragrant, and last for a considerable time when picked. The bulbs are small, and look as though they could not produce a growth of foliage and flowers, but even the smallest mature bulb will prove satisfactory. Several bulbs should be planted together in a pot, box or pan, in October, if wanted for the holidays, or later if wanted at 
Easter. 'The plants bloom from ten to twelve weeks from planting, under ordinary care. No special treatment is required; keep the plants cool and moist through the growing season. The soil should contain a little sand mixed with fibrous loam, and the pot should be well drained. After flowering, gradually withhold water and the tops will die down, after which the roots may be shaken out and rested until time to plant in fall. Care should be taken to keep them perfectly dry. The bulbs increase rapidly from offsets. Plants may also be grown from seed, which should be sown as soon as ripe, giving blooming plants the second or third year. Height 12 or 15 inches. Easy to bloom in the window. The white form (Freesia refracta alba) is the best. See Bulbs.

Fritillaria, or Fritillary. Bulbous plants, the commoner species hardy. Only the Crown Imperial is well known in this country. This is an old-fashioned plant, which takes care of itself when once planted. The other hardy Fritillarias are treated like tulips.

Frost. The light frosts of late spring and of early fall may be prevented by any means which will keep the air in motion, or which will fill the air with moisture or cloud-like vapor, so that there is less radiation from the ground. When frost is expected, it is well to water the plants and the ground thoroughly. This will ordinarily protect them from two or three degrees of still frost. The water should be applied just at nightfall. On larger areas, it is often practicable to make a smudge. In order to be effective, the smudge must be rather dense and lie over the whole area, and it should be kept up until the danger from frost is past. Naterial which burns very slowly and with much smoke is preferable. Moist manure or straw or other litter is useful. Materials which are dry enough to blaze are of little use. Ordinarily, frost comes towards morning. It is well to have the piles of rubbish ready at nightfall and have them lighted toward the latter part of 
the night, when the frost is expected. The smudge should be kept up until sunrise. It is well to have these piles of smudge material on all sides of the area; or if the area is on a slope, it may be sufficient to have them on the upper side, for there is usually a movement of air down the hillside and the area will thereby be covered with the smudge. For a thorough protection, it is best to have many small piles rather than a few large ones. If the piles are placed every ten feet around the areas, better results are to be expected. There are especially prepared tar-like materials for use in smudging plantations, but they are little used in this country, although some of them are excellent.

Fuchsia. Well-known window or greenhouse shrub. It is readily grown from cuttings. Soft, green wood should be used for euttings, and it will root in about three weeks, when the cuttings should be potted. Take care not to have them pot-bound while in growth, but do not over-pot when bloom is wanted. Given warmth and good soil, they will make fine plants in three months or less. In well protected, partially shady places they may be planted out, growing into miniature bushes by fall. Plants may be kept on from year to year; and if the branches are well eut back after blooming, abundant new bloom will come. But it is usually best to make new plants each year from cuttings,

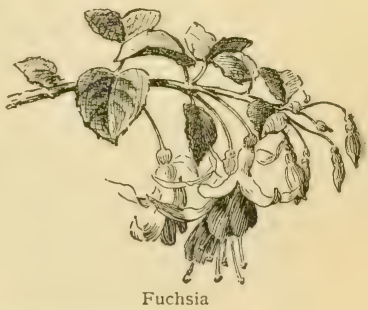
since young plants usually bloom most profusely and demand less care. Fuchsias are amongst the best of window subjects.

\section{Fumigation is mentioned under Insects.}

Fungi. Flowerless, leafless plants, living mostly on food (either living or dead) which has been prepared by other plants or by animals. Molds, mushrooms and puff- 
balls are familiar examples. Some of the parasitic kinds cause great damage to the plants or animals on which they live. Examples of these injurious parasitic kinds are applescab fungus, potato mildew, grape mildew, corn smut fungus, and the like. Most of these are combated by spraying with materials containing copper or sulfur.

Funkia, or Day Lily. Hardy perennial herbs, growing in dense clumps and bearing attractive foliage. They are of the easiest culture. $F$. subcordata, the whiteflowered species, is commonest. Of blue-flowered forms there are several, of which $F$. orata (or $F$. ccrulea) is perhaps the best. Funkias are excellent for borders, or as a formal eldging to long walks or drives. There are variegated forms. Funkias grow 12 to 24 inches high, and the flower cluster's stand still higher. Propagated by dividing the roots. Day Lily is a name applierl also to species of Hemerocallis, which are yellow-flowered lilies.

Gaillardias are plants that should have a place in every garden, either as border plants or for cutting. The flowers are very showy and lasting in bouquets, as well as on the plants. The double form has perfect balls of color. Gaillardias are both annual and perennial. The perennials usually have flowers much larger than the annuals; and they bloom the first year if seed is started early. These are also propagated by seed or euttings. If from seed, it should be sown under glass in February or March, setting out the young plants where wanted when danger of frost is

over. The euttings may be made of the new growth Gaillardia picta in the fall and wintered over in the house. Set 2 feet apart. Height 2 feet, blooming from July until hard frosts. The perennials are usually orange.

The annual kind (Gaillardia picta of florists) is probably the best kind for the home garden. It is of the easiest culture. Hardy. Two feet. Sow seeds where 
plants are to bloom. The colors of the flowers are in rich shades of yellow and red.

\section{Galanthus. See Snowdrop.}

Garlic. An onion-like plant, the bulbs of which are used for flavoring. Little known in this country except amongst those of foreign birth. It is multiplied the same as multiplier onions - the bulb is broken apart and each bulbule or "clove" makes a new compound bulb in a few weeks. Hardy; plant in early spring, or in the South in the fall. Plant 2 to 3 inches apart in the row.

\section{Gas Plant is Dictamnus.}

Geranium. What are generally known as Geraniums are, strictly speaking, Pelargoniums, which see. The true Geraniums are mostly hardy plants, and therefore should not be confounded with the tender Pelargoniums. Geraniums are worthy a place in a border. They are hardy perennials, and may be transplanted early in the spring, setting them 2 feet apart. Height 10 to 12 inches.

The common wild Cranesbill (Geranium maculatum) improves under cultivation, and is an attractive plant when it stands in front of taller foliage.

Gilia. Low-growing hardy annuals, good for front borders or rockwork, growing from seed very quickly and continuing in flower a long season. They will do well in light soil. Sow seed in the fall or early spring where plants are wanted. Gilia tricolor, blue, white and yellow, is the best, but there are excellent white and red sorts.

Gladiolus. A popular summer-flowering bulbous plant, thriving best in moist, sandy loam, that has had an application of well rotted manure the previous year. No manure should be used the year of planting, as it has a tendency to rot the bulbs. Plantings may be made from the time the ground is in condition to work in the spring until late in June. In planting, the bulbs should be set 3 inches 
deep and 8 to 10 inches apart, unless they are to be grown in groups, when they may be planted five or six in the space of 1 foot. Stakes should be furnished each plant to support the flower-spike. When in groups, one stake may be used, setting it in the middle of the circle.

Gladioli are increased by bulblets formed around the old bulbs (or corms), or they may be grown from seed. The bulblets should be planted in drills in April or May, and will grow to flowering size in one or two years. In the same way, seed sown early in drills, grown through the summer, the little bulbs taken up and stored through the winter and again planted out, will often make bulbs large enough to flower the second year.

Care should be taken to lift all bulbs before freezing weather, as most varieties are tender. They should be harvested with the tops on, and laid away in a cool, dry place to ripen. The tops are then cut off and the bulbs stored in a dry place (fit for potatoes, but drier) until wanted the following spring. See Bulbs.

Glaucium, or Horned Poppy. The kind most cultivated ( $G$. Tuteum) has bright yellow flowers in July and September. The flowers, contrasting with the deep cut glaucous leaves, make a fine effect in the mixed or ribbon border. Seed may be sown in the open ground where wanted. Thin to 12 inches apart. Height 12 to 20 inches. Perennial; but treated as a hardy annual.

Gloxinia. Choice greenhouse tuberous-rooted perennials, sometimes seen in window gardens, but really not adapted to them. Gloxinias must have a uniform moist and warm atmosphere and protection from the sun. They will not stand abuse or varying conditions. Propagated often by leaf-cuttings, which should give flowering plants in one year. From the leaf, inserted half its length in the soil (or sometimes only the petiole inserted) a tuber arises. This tuber, after resting until midwinter or later, is planted and flowering plants soon arise. Gloxinias also grow readily 
from seeds, which may be germinated in a temperature of about $70^{\circ}$. Flowering plants may be had in a year if seeds are sown in late winter or early spring. This is the usual method. Soil should be porous and rich.

Godetia. Very free-blooming annuals in fine colors, harmonizing well with the California poppy. Many of the varieties are beautifully blotched with contrasting colors. They are very satisfactory plants for solid beds or border lines, blooming from June to October. Seed may be sown in heat, and seedlings planted in open ground at a distance of 18 inches apart when danger of frost is over. A rather poor soil will cause them to bloom better than one very rich, as they are inclined to make a rank growth. Height 1 to 2 feet.

Golden Feather. See Pyrethrum.

Goldenrod (Solidago of many species). The Goldenrod of the wayside is so familiar that the thought of bringing it into the garden is distasteful to many persons. But if given a suitable place in a well enriched border, no plant has greater possibilities. A large clump against a hedge of green, or massed behind a well grown plant of the blue-flowering wild asters, makes a striking contrast. They bloom late in the season, and the rich yellow and golden color's and the graceful forms are always pleasing.

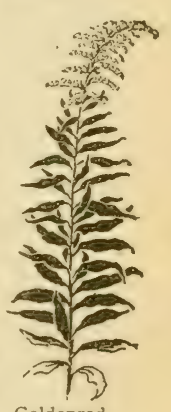

Goldenrod

Goldenrods will grow more vigorously and the blooms be larger if the roots are divided every third or fourth year. There are several species catalogued by nurserymen, and some of the stock is superior to the wild type, either having a larger truss of flowers or blooming later. Goldenrods range in height from 2 to 6 feet. All are easily propagated by division. Transplant in the fall, if conveniont, although spring planting may be equally successful.

Gomphrena. Bachelor's Button. Globe Amaranth. A useful everlasting for winter bouquets. Seed 
may be sown in heat in March, the plants transplanted once before setting out to cause them to grow stocky and branching; or seed may be sown in a warm place where the plants are to grow. The flowers, to retain their colors, should be cut before fully expanded and dried in a dark, airy place. See Everlastings. Set the plants 18 inches apart. Height 12 inches. The heads resemble clover heads. The term Bachelor's Button is also given to the cornflower (Centaurea Cyanus).

Gooseberry. Since the advent of the practice of spraying with fungicides to prevent mildew, the culture of the Gooseberry has increased. There is now no reason why, with a little care, good crops of many of the best English varieties may not be grown. The price for Gooseberries good fruits of Gooseberry is usually remunerative, as the market is rarely overstocked by the sudden ripening of the crop, since the fruits ripen through a long season. A large part of the crop is picked green for culinary purposes. The leading market variety is Downing, a native sort, which is little subject to mildew. Several of the English varieties have proved of value, having larger fruits than the natives. Whitesmith, Chautauqua, Triumph and Industry are among the best.

The propagation of the Gooseberry is similar to that of the currant, although the practice of earthing up a whole plant, eausing every branch thus eovered to throw out roots, is common with the European varieties. The rooted branches are eut off the following spring and planted in nursery rows or sometimes directly in the field. In order to succeed with this method, the plant should have been eut back to the ground so that all the shoots are yearling.

Pruning is essentially the same as for the currant (which see); and the treatment of the currant worm is the same as for that fruit.

Gooseberries should be set (either in fall or spring) 3 to 
4 feet apart; rows 5 to 7 feet apart. Select a rich, rather moist soil. The tops need no winter protection. If mildew and worms are to be kept in check, spraying must be begun with the very first sign of trouble and be thoroughly done.

Gourds are valuable as rapid-growing screen vines, the curious fruits of many varieties alding much to their attractiveness. Cultivation the same as for melons or squashes. Height 10 to 15 feet. Provide a chicken-wire trellis; or let them run on a brush pile.

Grafting. (trafting is the operation of inserting a piece of a plant into another plant with the intention that it shall grow. It differs from the making of euttings in the fact that the severed part grows in another plant rather than in the soil. There are two general kinds of Grafting - one of which inserts a piece of branch in the stock (Grafting proper), and one which inserts only a bud with little or no wood attriched (budding). In both cases the success of the operation depends upon the growing together of the cambium of the cion (or cutting) and that of the stock. The cambium is the new and growing tissue which lies underreath the bark and on the outside of the growing wood. Therefore, the line of demarcation between the bark and the wood should coincide when the cion and stock are joined. The plant upon which the severed piece is set is called the stock. The part which is removed and set into the stock is called a cion if it is a piece of a branch, or a bud if it is only a single bud with a bit of tissue attached. The greater part of Grafting and budding is done when the cion or bud is nearly or quite dormant. That is, Grafting is usually done late in winter and early in spring, and budding may be done then, or late in summer, when the buds have nearly or quite matured.

The prime object of Grufting is to perpetuate a kind of plant which will not reproduce itself from seed or of which seed is very diffeult to obtain. Cions or buds are therefore 
taken from this plant and set into whatever kind of plant is obtainable and on which they will grow. Thus, if one

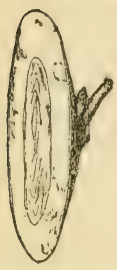

The bud severed from its twig wants to propagate the Baldwin apple, he does not for that purpose sow seeds thereof, but takes cions or buds from the tree and grafts them into some other apple tree. The stocks are usually obtained from seeds. In the case of the apple, young plants are raised from seeds which are obtained mostly from cider factories, without reference to the variety from which they eame. When the seedlings have grown to a certain age, they are budded or grafted; and thereafter they bear fruit like that of the tree from which the cions were taken.

There are many ways in which the union between cion and stock is made. Budding may be first discussed. It consists in inserting a bud underneath the bark of the stock, and the commonest practice is that which is shown in the illustrations. Budding is mostly performed in July, August and early September, when the bark is still loose or will peel. Twigs are cut from the tree which it is desired to propagate, and the buds are cut off with a sharp knife, a shield-shaped bit of bark (with possibly a little wood) being left

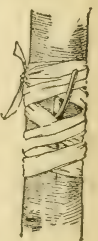

The bud tied with them (see illustration). The bud is then shoved into a

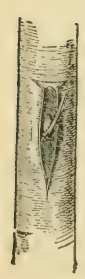

The bud inserted slit made in the stock, and it is held in place by tying with some soft strand. In two or three weeks the bud will have "stuck" (that is, it will have grown fast to the stock), and the strand is eut to prevent its strangling the stock. Ordinarily the bud does not grow until the following spring, at which time the entire stock or branch in which the bud is inserted is eut off an inch above the bud; and the bud thereby receives all the energy of the stock. Budding is the commonest Grafting operation in nurseries. Seeds of peaches may be sown in spring, and the plants which result will be ready for budding that same August. The following spring, or 
a year from the planting of the seed, the stock is cut off just above the bud (which is inserted near the ground), and in the fall of that year the tree is ready for sale; that is, the top is one season old and the root is two seasous old, but in the trade it is known as a 1-year-old tree. In apples and pears the stock is usually two years old before it is budded, and the treo is not sold until the top has grown two or three years. Budding may be performel also in the spring, in which ease the bud will grow the same seasou. Budding is always done in young mranches, preferably in those not more than one year old.

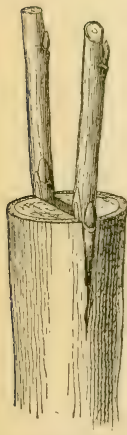

Cleft-graft

Grafting is the insertion of a small branch (or cion), usually bearing more than one bud. If Grafting is done on small stoeks, it is customary

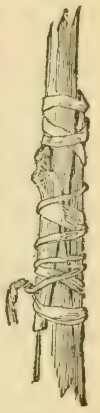

Whip-graft to employ the whip-graft, which is illustrated in the margin. Both 'stock and cion are cut across diagonally, and a split made in each, so that one fits into the other. The graft is tied securely with a string, and then, if it is above ground, it is also waxed carefully. In larger limbs or stocks, the common method is to employ the cleft-graft. This consists in cutting off the stock, splitting it and inserting a wedge-shaped cion in one or both sides of the split, taking care that the eambium layer of the cion matches that of the stock. The exposed surfaces are then securely covered with wax. Grafting is usually performed early in the spring, just before the buds swell. The cions should have been cut before this time, when they were perfectly dormant. Cions may be stored in sand in the cellar or in the ice house, or they may be buried in the field. The object is to keep them fresh and dormant until they are wanted.

If it is desired to change the top of an old plum,

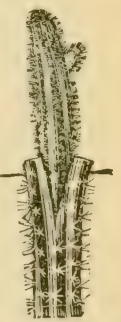

Cleft-grafting a Cactus apple or pear tree to some other viriety, it is usually done by means of the cleft-graft. If the tree is very young, bud- 
ding or whip-grafting may be employed. On an old top the cions should begin to bear when three to four years old. All the main limbs should be grafted. It is important to keep down the suckers or water-sprouts from around the grafts, and part of the remaining top should be cut away each year until the top is entirely changed over (which will result in two to four years).

A good wax for eovering the exposed parts is made as follows: Resin, 4 parts by weight; beeswax, 2 parts; tallow, 1 part. In making the wax, the materials are first broken up and melted together. When thoroughly melted the liquid is poured into a pail or tub of cold water. It soon becomes hard enough to handle, and it is then pulled and worked over until it becomes tough or "gets a grain," at which stage it becomes the color of very light-colored manilla paper. When wax is applied by hand, the hands must be well greased. Hard cake tallow is the best material for this purpose. In top-grafting large trees, it is well to carry a supply of tallow when waxing, by smearing the backs of the hands before entering the tree.

Grape. One of the surest of fruit crops is the Grape, a crop each year being reasonably cortain after the third year from the time of setting the vines. The Grape does well on any soil that is under good eultivation and well drained. A soil with considerable clay is better under these circumstances than a light, sandy loam. The exposure should be to the sun; and the place should admit of cultivation on all sides. One- or 2 -year-old vines should be planted, either in the fall or early spring. At planting the vine is cut back to 3 or 4 eyes, and the roots are well shortened in. The hole in which the plant is to be set should be large enough to allow a full spreading of the roots. Fine soil should be worked around the roots and firmed with the feet. If the season should be dry, a mulch of coarse litter may be spread around the vine. If all the buds start, the strongest one or two may be allowed to grow. 
The ranes arising from these buds should be staked and allowed to grow through the season; or in large plantations the firstyear canes may be allowed to lie on the ground. The second year one cane should be cut back to the same number of eyes as the first year. After growth begins in the spring, two of the strongest buds should be allowed to remain. These two canes now arising may be grown to a single stake through the second summer, or they may be spread horizontally on a trellis. These are the canes which form the permanent arms or parts of the vine. From them start the upright shoots which, in succeoding years, are to bear the fruits.

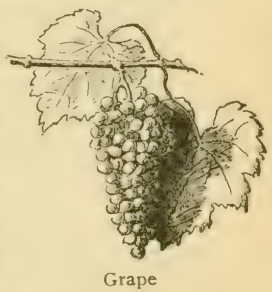

In order to understand the pruning of Grapes, the operator must fully grasp this prineiple: Fruit is borne on wood of the present season, which arises from woor of the previous sectson. To illustrate: A growing shoot, or cane of 1899 , makes buds. In 1900 a shoot arises from each bud; and near the base of this shoot the Grapes are borne (1 to 4 clusters on each). While every bud on the 1899 shoot may produce shoots or canes in 1900, only the strongest of these new canes will bear fruit. The skilled Grape-grower can tell by the looks of his cane (as he prunes it in winter) which buds will give rise to the Grape-producing wood the following season. The larger and stronger buds usually give best results; but if the cane itself is very big and stout, or if it is very weak and slender, he does not expect good results from any of its buds. A hard, well-ripened cane the diameter of a man's little finger is the ideal size.

Another principle to be mastered is this: A vine should bear only a limited number of clusters, - say from 30 to 80. A shoot bears clusters near its base; beyond these clusters the shoot grows on into a long, leafy cane. An average of two clusters may be reckoned to a shoot. If the vine is strong enough to bear 60 clusters, 30 good buds must be left at the pruning (which is done from December to late February). 
The essential operation of pruning a Grape vine, therefore, is each year to cut back a limited number of good canes to a few buds, and to cut off entirely all the remaining canes or wood of the previous season's growth. If a cane is eut back to 2 or 3 buds, the stub-like part which remains is called a spur. Present systems, however, cut each cane back to 8 or 10 buds (on strong varieties), and 3 or 4 canes are left, - all radiating from near the head or trunk of the vine. The top of the vine does not grow bigger from year to year, after it has once covered the trellis, but is cut back to practically the same number of buds each year. Since these buds are on new wood, it is evident that they are each year farther and farther removed from the head of the vine. In order to obviate this difficulty, new canes are taken out each year or two from near the head of the vine, and the 2-year or 3-year-old wood is cut away.

The training of Grapes is a different matter. A dozen different systems of training may be practiced on the same trellis and from the same style of pruning, - for training is only the disposition or arrangement of the parts.

On arbors, it is best to carry one permanent arm or trunk from each root over the framework to the peak. Each year the canes are cut back to short spurs (of 2 or 3 buds) along the sides of this trunk.

Grapes are set from 6 to 8 feet apart in rows which are 8 to 10 feet apart. A trellis made of 2 or 3 wires is the best support. Slat trellises eateh too much wind and blow down. Aroid stimulating manures. In very cold climates, the vines may be taken off the trellis in early winter and laid on the ground and lightly covered with earth. Along the boundaries of home lots, where Grapes are often planted, little is to be expected in the way of fruit because the ground is not well tilled. For mildew and rot, spray with Bordeaux mixture. See Spraying.

Concord is the most cosmopolitan variety, but its quality is not the best. For the home garden, a good selection may 
be made from the following list: Winchell or Green Mountain, Camphell Early, Worden, Concord, Niagara, Moore Diamond, Tergennes, Agawam, Salem, Wilder, Iona, Brighton, Delaware.

Grapery. The European grapes rarely thrive out of doors in eastern America. Grape houses are necessary, with or without artificial heat. Fruit for home use may be grown very satisfactorily in a cold Grapery (without artificial heat). A simple lean-to against the south side of a building or wall is cheap and serviceable. When a separate building is desired, an even-span house rumning north and south is preferable. There is no advantage in having a curved roof, except as a matter of looks. A compost of four parts rotted turf to one of manure is laid on a sloping cement bottom outside the house, making a border 12 feet wide and 2 feet deep. The cement may be replaced with rubble on well drained soils, but it is a poor makeshift. Every three years the upper 6 inches of the border should be renewed with manure. The border inside the house is prepared likewise. Two-year-old potted rines are planted about 4 feet apart in a single row. Part of the roots go through a erevice in the wall to the outer border and part remain inside; or all may go outside if the house is desired for other purposes. One strong cane is trained to a wire trellis hanging at least 18 inches from the glass, and is cut back to 3 feet the first year, 6 the second, and 9 the third. Do not be in a hurry to get a long cane. Pruning is on the spur system, as recommended for arthors on page 120 . The vines are usually laid on the ground for winter and covered with leaves or wrapped with eloth.

As soon as the buds swell in early spring, tie the vines to the trellis and start out one shoot from each spur, rubbing off all others. After the berries begin to color, however, it is better to leave all further growth to shade the fruit. Pinch back each of these laterals two joints beyond the second bunch. To keep down red spider and thrips, the 
foliage should he sprayed with water every bright morning except during the blooming season. At least one-third of the berries should be thinned from each bunch; do not be afraid of taking out too many. Water the inside border frequently all through the summer, and the outside oceasionally if the season is dry. Mildew may appear in July. The best preventives are to syringe faithfully, admit air freely, and sprinkle sulfur on the ground.

Fruit may be kept fresh on the vines in a warm (or artificially heated) Grapery until late Decomber: in a coldhouse it must be picked before frost. After the fruit is off, ventilate from top and bottom and withhold water, so as to thoroughly ripen the wood. Along in November the canes are pruned, covered with straw or wrapped with mats and laid down till spring. Black Hamburg is superior to all other varieties for a cold Grapery; Bowood Museat, Museat of Alexandria and Chasselas Musque may be added in the warmhouse. Good vines will live and hear almost indefinitely.S. W. Fletcher.

Grasses of various kinds are grown for ornament, the most popular types being the hardy perennials, which make attractive clumps in the lawn or border. The best of the permanent kinds in the North are the various sorts of Eulalia (properly Miscanthus). When once established they remain for years, making large and bold clumps. The striped kind, or zebra grass, is particularly good. These grasses thrive in any good soil. They grow from 4 to 7 feet high. The great reed, or Arundo Donax, is a bold subject and perfectly hardy. In a rich and rather moist soil, it grows 10 to 12 feet high when well establishd. Pampas Grass is most excellent in the Middle States and South. Some of the big native grasses and sedges make attractive lawn clumps.

Grasses are also grown for dry or everlasting bouquets. For this purpose, small-growing delicate annual species are mostly used. Good types are speeies of agrostis, briza, 
bromus, eragrostis, and pennisetum. Seeds of these and of others are sold by seedsmen. With ordinary treatment, they thrive in any garden soil.

For notes on sod-making, see Lawn.

Greenhouse. In America the word Greenhouse has come to be applied to all kinds of glass-houses in which plants are grown. Originally the word was applied to those houses in which plants are merely preserved or kept green during the winter. Other types of glass-houses are the conservatory, in which plants are displayed; stove or hothouse, in which plants are grown in a high temperature; the propagating pit, in which the multiplication of plants is carried forward; and the houses which have various temperatures, as cold, cool and intermediate. The principles which underlie the construction and management of glass-houses are too extensive to be discussed here. The reader should refer to special books on the topic. For the general subjest, Taft's "Greenhouse Construction" and "Greenhouse Management" are excellent. For particular applications to floriculture, Hunt's "How to Grow Cut-flowers" is a standard work. For applications to the foreing of vegetable crops, Bailey's "Forcing-Book" may perhaps be consulted.

The smaller the glass-house the more difficult it is to manage, because it is likely to be more variable in temperature, moisture and other conditions. This is particularly true if the house is a small lean-to against the south side of a dwelling house, for it becomes very hot at midday and comparatively cold at night. In order to moderate the heat in these little houses, it is ordinarily advisable to use ground glass for the roof or to whitewash it. The house conservatory may be heated by a coal stove, but the best results are rarely to be attained in this case. A stove is likely to leak gas, and the temperature is more or less uneven. The best results are to be attained when the conservatory is heated by steam or hot water, piped in the modern fashion with wrought iron pipes, which go together with threads. If the 
conservatory is heated from the heater which supplies the dwelling house, it should have an extra amount of pipe; otherwise it will be necessary to keep the dwelling house too hot for comfort in order to maintain the conservatory at its proper temperature. It is always best, when practicable, to heat the conservatory with a separate apparatus. There are various small hot water and steam heaters, the size of coal stoves, which are excellent for the purpose. For a small conservatory, hot water is usually preferable to steam, since it is less likely to fluctuate. For large establishments, however, the steam is usually the better. For further discussions of related subjects, see Hotbed, Mindow Garden, Potting and Tatering.

Grevillea. A very graceful greenhouse plant, suitable for house culture. The plants grow freely from seed, and until they become too large are as decorative as ferns. Grevilleas are really trees, and are valuable in greenhouses and rooms only in their young state. They withstand much abuse. They are now very popular as jardiniere subjects. Seeds sown in spring will give handsome plants by the next winter.

Gypsophila. BABY's BREATH.

Gypsophita muratis is one of the dainty little plants called Baby's Breath. It is a low-growing annual forming compact mounds of green, thickly covered with little pink flowers. It is one of the most attractive border plants in cultivation. It is also a charming pot-plant. G. puniculata is a hardy perennial having panicles of bluish white flowers. This is very graceful, and the flowers are fine for cutting and for use with sweet pea bouquets or with other choice flowers. The panicles are so lasting that they may be used in winter bouquets. The annuals may be planted 1 foot apart; the perennials 3 feet. Both are readily grown from seed, and bloom the first year.

Hardy. A relative term, used to denote a plant which endures the climate (particularly the winter 
elimate) of a given place. Half-hardy plants are those which withstand some frost or uncongenial conditions, but will not endure the severity of the climate. Tender plants are those which are injured by light frosts.

Hedges. Hedges are much less used in this country than in Europe, and for several reasons. Our climate is dry, and most Hedges do not thrive so well here as there; labor is high-priced, and the trimming is therefore likely to be neglected; our farms are so large that much fencing is required; timber and wire are cheaper than live Hedges. However, they are used with good effects about the home grounds. In order to secure a good Hedge, it is necessary to have a thoronghly well-prepared, deep soil, to set the plants close, and to shear them at least twice every year. For evergreen Hedges the most serviceable plant in general is the arborvite. The plants may be set at distances of 1 to $2 \frac{1}{2}$ feet apart. For choice Hedges about the grounds, particularly outside the northern states, some of the retinosporas are very useful. One of the most satisfactory of all coniferous plants for Hedges is the common hemlock, which stands shearing well and makes a very soft and pleasing mass. The plants may be set from 1 to 3 feet apart. Other plants which hold their leaves and are good for Hedges are the common box and the privets. Box Hedges are the best for very low borders about walks and flower beds. The dwarf variety can be kept down to a height of 6 inches to a foot for any number of years. The larger-growing varieties make excellent Hedges 3,4 and 5 feet high. The ordinary privet or prim holds its leaves well into winter in the North. The so-called Californian privet holds its leaves rather longer and stands better along the seashore. In the southern states, nothing is better than Citrus trifoliata.

For Hedges of deciduous plants, the most common species are the buckthorn, the European thorn apple or cratregus, osage orange, and various kinds of roses. 
Hedges should be trimmed the year after they are set, although they should not be trimmed very closely until they reach the desired or permanent height. Thereafter they should be sheared into the desired form in spring or fall. If the plants are allowed to grow for a year or two without trimming, they lose their lower leaves and become open and straggly. Osage orange and some other plants are plashedthat is, the plants are set at an angle rather than perpendicularly, and they are wired together in such a way that they make an impenetrable barrier just above the surface of the ground.

\section{Helianthus. See Sunflower.}

Helichrysum. These are perhaps the most popular of the Everlastings (which see), having large flowers of several colors. They grow readily from seed, blooming from July to October. Height 10 inches to 2 feet. Should be planted or thinned to stand 18 inches apart.

Heliotrope. A universal favorite house or border plant, growing readily from enttings or seeds, and producing quantities of fragrant violet, purple or white flowers. One of the best methods of cultivation is to set a strong plant in the border and peg the new growths to the ground, where they will root and form a perfect mat, flowering profusely during the fall months until frost. They will endure the temperature of a living room well if the room is not too dry. Red spider is a natural enemy of the Heliotrope, and when.once it obtains a foothold is a very difficult pest to manage, but frequent syringing with water will keep it in check. A light, rich soil and an abundance of heat are their requirements. Height 1 to 3 feet. Propagated by euttings or layers.

Hellebore (White Hellebore) is often used for the killing of currant-worms and other insects (see Currant). It is not so poisonous as the arsenites, and therefore is to be preferred when it is necessary to apply a poison to nearly 
ripe fruit. It is usually applied in a spray with water, at the rate of $1 / 3$ ounce to the gallon. It is harmless to foliage.

Helleborus, or CHRistuns Rose, may be had in flower at the holidays if grown in a frame and protected. The usual time for it to flower in the open border is in Narch or early April. It will continue to bloom for many years if grown in a shady place. Roots may be divided as an increase is wanted. It may also be grown from seeds; and seedlings may be expected to bloom a year from the spring in which they are sown. Height 6 to 10 inches.

Hemerocallis, or YelLow DAY LILY. The advice given under Funkia will apply to this.

Herbs are plants which die to the ground in winter. They may be annual, biennial, or perennial. For a list of annual Herbs suitable for the flower garden, see the articles on Ammuls and Bediding. A border or free mass of perenuial Herbs is one of the charms of any place. It is informal, easy of care, and self-sustaining. The large part of the mass should be composed of common and hardy things-wild or from gardens-and incidental features may be made of the choicer and rarer exotics. In most cases, plants look better when judiciously mixed than when planted one kind in a bed. See Border.

Hibiscus. Ammuals and perennials, some of them shrubs, with showy, hollyhock-like flowers. The annual Hibiscuses are very satisfactory. They grow quickly and flower freely. The flowers are usually white or yellow, of large size, and appear from July on. The herbaceous peremnial kinds are amongst the best of hardy border plants, blooming in late summer and fall. The commonest of these is Hibiscus Moscheutos. Give rich, moist soil.

The greenhouse species are old favorites. They may be used in outdoor bedding through the summer, lifted in the fall and eut back. Keep rather dry and dormant during winter. Propagated by cuttings. 


\section{Hippeastrum. Consult Amaryllis.}

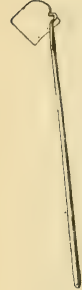

Hoes should be of several patterns if the most efficient work is to be done in the garden. The ordinary Hoe is adapted only to the rougher and coarser Hoe-work, such as digging and fitting the ground. For much of the subsequent tillage, some of the narrow blade and pointed Hoes are excellent. For eutting off weeds, the push Hoe or searifier is excellent.

Hollyhock. These old garden favorites Common
hoe have been neglected of late years, primarily because the Hollyhock rust has been so prevalent, destroying the plants or making the munsightly. The double varieties seem to suffer the most; and for that reason, and from the fact that

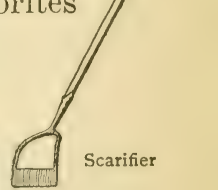
the less formal type is in favor, the single varieties are now the most generally grown. Their culture is very simple. The seed is usually sown in July or August, and the plants set where wanted the following spring. They will bloom the same year in which they are transplanted - the year following the seed-sowing. New plants should be set every two years, as the old erowns are apt to rot or die after the first

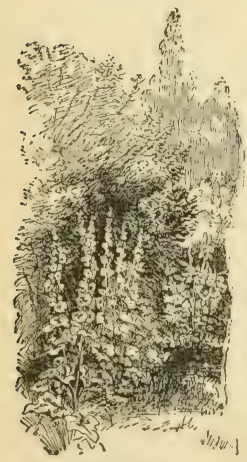

Hollyhocks flowering. For rust, spray early with Bordeaux mixture or ammoniacal carbonate of copper.

Hop, Ornamental. Humulus Japonicus, or the annual Hop, is one of the best rapid-growing sereen vines in eultivation. It makes a dense canopy of attractive foliage. The leaves are finely eut, and in one variety variegated with white. This variegated variety is a fine vine for a porch or front sereen, always attracting attention to its markings. This Hop is propagated by seed sown in boxes in March. When once established, it will seed itself and start as soon as the soil becomes warm. Set plants 4 to 8 feet apart. Height 8 to 20 feet. 
Horseradish. As a kitchen garden vegetable, this is usually planted in some out-of-the-way spot and a piece of the ront dug as often as needed, the fragments of roots being left in the soil to grow for further use. This method results in having nothing but tough, stringy roots, very unlike the product of a properly planted and well eared for bed. The best roots are those planted in the spring at the time of setting early eabbage, and dug as late the same fall as the weather will permit. It becomes, therefore, an ammual erop. The roots for planting are small pieces, from 4 to 6 inches long, obtained when trimming the roots dug in the fall. These pieces may bo packed in sand and stored until wanted the following spring. In planting, the roots should be set with the upper end 3 inches below the surface of the ground, using a dibber or sharppointed stick in making the holes. The erop may be planted between rows of early-sown beets, lettuce or other crop, and given full possession of the ground when these crops are harvested. Where the ground is inclined to be stiff or the subsoil is near the surface, the roots may be set in a slanting position. In fact, many gardeners practice this method of planting, thinking that the roots make a better growth and are more uniform in size.

\section{Hotbed. A Hotbed is a frame or box which} has artificial heat and a transparent covering and in which plants are grown. It differs from a coldframe (which see) in the fact that it has artificial bottom heat. This bottom heat is usually supplied by fermenting organic matter, chiefly horse manure, but hot air, hot water or steam conveyed in pipes, may be employed. It is covered with sash of which the normal or standard size is 3 feet wide and 6 feet long. These sashes are laid crosswise the box or frame. The standard size of frame is 6 feet wide and 12 feet long. A "frame," therefore, accommodates four sashes. However, the frame may be of any length desired. This frame is ordinarily made of boards, and the back of it is 3 or 4 
inches higher than the front, so that the sashes slope to the sun. It is customary to have a space of 6 to 10 inches between the earth and the sash on the lower or front side. The manure which is used to heat the bed may be placed on top of the ground and the frame set on the pile, or it may be placed in a pit. If the land is warm and well drained, it is ordinarily better to have a pit from 1 to Section of a Hotbed 2 feet deep and to set the frame over it. This is especially the case if it is desired to have a permanent Hotbed yard. The place in which the frames are set should be protected from the cold and prevailing winds by a rising slope, a high board fence, a building, hedge, or other obstruction. If the frame yard is near the main buildings, it will be much more accessible in rainy or snowy times, and the plants are likely to have better care. Water should also be handy.

The time of starting a Hotbed will depend upon the kinds of plants to be grown, the amount of time which one wishes to gain, and something, also, on the quality of the manure. The hardier the plant the earlier it can be started. In the latitude of New York, from the first to the middle of March is the usual time for starting a Hotbed. In this bed are sown seeds of early flowers and such regetables as cabbage, cauliflower, tomato, ete. In the raising of auy plants in the Hotbed, it is very essential that they do not become "drawn" or "leggy." In order to prevent this, they must be given plenty of room, thorough ventilation on all pleasant days, and not too great heat. It is well to transplant them once or twice before they are finally set in the field, especially if they are started, in New York, as early as the first or middle of March. When they are transplanted, they can bo set in another Hotbed or in a coldframe; but it is important that the succeeding frames ir which they are set should not be very much colder than the one in which they grew, else they may become stunted. It is well, however, to transplant 
them into a gradually cooler and freer atmosphere in order to harden them off, so that they may go into the open ground without danger. On every pleasant day, raise the sash at the upper end 1 or 2 inches, or if the sun shines brightly and the wind does not blow, give even more air ; and eventuilly strip off the sashes entirely. It is very important that the plants are not kept too close and grown too soft. It is usually advisable to sow cabbage, lettuce and other hardy plants in different frames from tomatoes and other tender thiugs, in order that the proper reciuirements may he given to each. At night the Hotheds (at least early in the season) will need more protection than the glass sash. It was formerly the custom to use thick rye-straw mats to cover Hotbeds, but it is now a common practice to use the straw matting which can be bought of carpet dealers. This is rolled out on the sashes at night in one or two thicknesses; and if the weather is sharp, board shutters, the size of the sash, may be laid on top. As the manure heat begins to fail give more and more air, so that the plants may be able to shift for themselves when the bottom heat is finally exhausted.

Fresh horse manure is the material which is commonly used for the heating of Hotbeds. If it can be secured from livery stalles, so that it is all of nearly or quite the same age, better results may be expected. Manure from highly fed horses usually heats better than that from horses which receive little grain, or in which there is very much litter. Put the manure in a pile, preferably under cover, and as soon as it shows signs of heating, fork it over in order to mix the entire mass and to cause it to heat evenly. When it is steaming throughout the whole mass, it may be put in the bed. Assuming that the Hotbed has a pit beneath it, it is well to put in 2 or 3 inches of coarse litter in order to keep the manure off the cold ground. The manure is then put in and tramped down, in layers of 4 to 6 inches each. If the manure is of the right consistency, it will pack without be- 
coming dense and soggy; that is, it will spring a little beneath the feet. If it has too much litter, it will fluff up under the feet and not pack well. From 18 to 24 or even 30 inches of manure is placed in the pit. On top, an inch of dry straw or light leaf-mold may be placed to serve as a distributor of the heat to the earth above. From 3 to 4 inches of rich, light earth is placed upon this, in which to sow the seed. The manure will ordinarily heat violently for a few days. Place a soil thermometer in it, and as soon as the temperature begins to fall below $90^{\circ}$ the seeds of tomatoes and $e g \Omega$-plants may be sown; and when it begins to fall below $80{ }^{\circ}$ the seeds of cabbages, lettuce and cauliflower may be sown. If the frame is not placed over a pit and the manure is put on top of the ground, it will be necessary to allow the body of manure to project 1 or 2 feet in all directions in order to prevent the edges of the bed from freezing.

In starting plants in a Hotbed, one must not expect to gain as much time in the crop as he gains in the starting of the seeds: that is, if he starts the seeds two months ahead of the normal season, he will not gain two months in the ripening of the crop. Ordinarily, he cannot expect to gain much more thin one-half the time, particularly if the plants are transplanted to the field from the Hotbed.

Some plants may be grown to maturity in the Hotbed, particularly lettuce and radishes. After Hotbeds have been emptied of their plants, the sashes may be stored away, and the frames, with their spent manure, used for the growing of an early summer crop of melons or cucumbers.

\section{House Plants. See Window-Garden.}

Hyacinth Bean (Dolichos Lablab). A very Hyacinth bean rapid-growing twiner, bearing fragrant flowers of purple or white. It is a fine screen plant. Plant seeds when the ground is warm where the plants are to grow; or they may be started early in pots. Height 10 feet. 
Hyacinths are most popular winter-or springflowering bulbs. Hyacinths are hardy, but they are often used as window or greenhouse plants. They are easy to grow and very satisfactory. For winter flowering the bulbs should be procured early in the fall, potted in Octolere in soil composed of loam, leaf-mold and sand. If ordinary flower pots are used, put in the bottom a ferw pieces of broken pots, charcoal or small stones for drainage; then fill the pot with dirt, so that when the bulb is planted the top will he on a level with the rim of the pot. Fill in around the bulb with soil, leaving just the tip of the bulb showing. These pots of bulbs should be placed in a cold pit, cellar or on the shady side of a building. In all eases, plunge the pot in some cool material (as cinders). Before the weather becomes cold enough to freeze a crust on the ground, the pots should have a protection of straw or leaves to keep the bulbs from severe freezing. In from six to eight weeks the bulbs should have made roots enough to grow the plant, and the pots may be placed in a cool room for a short time. When the plants have started into growth, they may be placed in a warmer situation. Watering should be carefully attended to from this time, and when the plant is in bloom the pot may be set in a saucer or other shallow dish containing water. After flowering, the bulbs may be ripened by gradually witholding water until the leaves die. They may then be planted out in the border, where they will bloom each spring for a number of years, but will never prove satisfactory for forcing again. The open ground eulture of Hyacinths is the same as for tulips, which see. See Bulbs.

Water Culture of Hyacintls. - The Hyacinth is the most popular of the Duteh bulbs for growing in vases. The Narcissus may be grown in water, and do just as well, but it is not as pretty in glasses as the Hyacinth. Glasses for Hyacinths may be had of florists who deal in supplies, and in various shapes and colors. The usual form is tall and narrow, with a cup-like mouth to receive the bulb. They are 
filled with water, so that it will just reach the base of the bull, when it has been placed in position in the eup above. The vessels of dark-colored glass are preferable to those of clear glass, as roots prefer darkness. When the glasses, or bowls as above mentioned, have been arranged, they are set away in a cool, dark place to form roots like potted bulbs. Results are usually secured earlier in water than in soil. To keep the water sweet, a few lumps of charcoal may be put in the glass. As the water evaporates, add fresh; add enough so that it runs over, and thereby renews that in the glass. Do not disturb the roots by taking out the bulb.

\section{Hydrangea. One of the commonest lawn} shrubs is Hydrangea paniculata. The commonest fault in growing it is seattering the plants over the lawn, where they suffer in the competition with grass roots, and do not show off to advantage. It is far better to mass them in front of taller things. The Hydrangea blooms on wood of the season; therefore it should be pruned after bloom - in winter or early spring (see Pruning). Cut back heavily, in order to secure the strong new shoots upon which the flowers are borne.

\section{Hyssop. See Sweet Herbs.}

Ice Plant, or Mesembrianthenum. Fine little plants for rockwork or edging. The majority of the species are greenhouse and window plants, but a few can be recommended for outdoor planting. A very sunny location, with gravelly soil, will give the best results, either in the open or in the house. Easily propagated by pieces of the plant laid on moist sand in a somewhat sumy place. The common Ice Plant of window-gardens is readily grown from seeds or slips. It is prized for its glandular-glistening thick foliage (whence the common name). The little flowers, which open in sunshine, are also interesting.

Impatiens Sultani is a generally known conservatory plant, making a charming pot subject for warm 
greenhouse or a room. It is readily propagated from seed or cuttings, seed being preferable. Flowers bright pink-red. Of easy culture in a fairly moist atmosphere. Height about 18 inches.

\section{Insects. For horticultural purposes, Insects} might be grouped into three general classes: borers, or those which live inside the plant tissue ; chewing Insects which live on the outside of the plant; and the sucking Insects.

As a general statement, it may be said that the digging out of borers is the only complete remedy. Sometimes an application of something to the body of the tree may keep them out, but it is al-

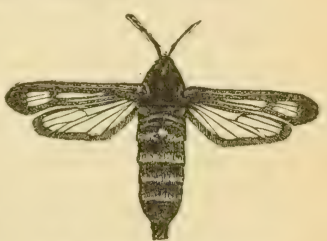

Moth of one of the borers ways uncertain ; and it usually involves more work than to dig them out. All trees which are subject to borers (especially apples, peaches and pears) should be examined at least twice every year. See Borers.

The general run of chewing or biting Insects may be killed by the arsenical poisons. Such Insects are the common types of worms and beetles which feed on foliage. The leading poison which is now used for this purpose is Paris green (which see). Hellebore and pyrethrum are useful

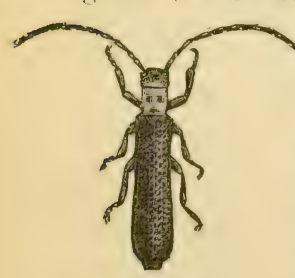

A beetle borer

when it is not advisable to use arsenical poisons.

The sucking Insects include all the kinds of plant lice, the squash bug and all the scale Insects. These are dispatched by some material which kills by external application, especially material which has kerosene or petroleum in it. The common material heretofore used for this purpose is kerosene and soap emulsion; but it is now believed that the emulsion of kerosene and water is fully as efficient, and since machines have been perfected for automatically mixing it, it is a much more practicable remedy. See Kerosene Emulsion. 
In the fighting of ail Insects, success depends upon taking them in time. If something is known of the life history of the Insect, very much will be gained, for the operator

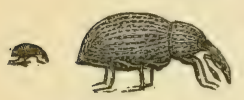
may be on hand as soon as the Insect is expected to appear.

Insects on House Plants.-The most troubloWeevil-achewing insect some or common Insects with which the amateur is likely to meet in the window-garden or conservatory are the red spider, mite, mealy bug, aphis, and scale.

The red spider is a very minute Insect with a reddish body. Its presence may be suspected whenever plants are growing in a warm and dry place. Usually it first appears on the under side of leaves, but it multiplies rapidly, and will soon not be so choice of position. It sucks the juices of the leaves, and they soon indicate the injury by a dull appearance, and also, in many cases, by small whitish or paler areas on the upper surfaces. The mite is of similar habits and size, but is of a pale color, with black on its back. It appears under the same conditions as the red spider. These pests are small, but are very serious if allowed to multiply unchecked. They should be looked after as soon as their presence is detected.

The remedy is to arrange for keeping the air about the plants more moist, and giving drenchings of the foliage with clear or soapy water. The latter is most effective. The soap used may be simply the eommon washing soap, or that sold at drug stores known as whale-oil soap. In fighting them, care must be used not to keep the soil soaked with water, or it will check the plants in vigor and only add to the strength of the enemy. Even florists sometimes get into just such a predicament. Flagging and extreme variations in dryness and humidity of the air, checking the vigor of plants, favor the appearance and presence of the red spider quite as much as extreme and continued dryness of the air.

The aphides or plant lice are readily discernable when 
they appear on plants, as they are sure to do under nearly all conditions. They are small, have elongated, succulent bodies, move about slowly and awkwardly, on rather long, hairlike legs, and are most commonly of a pale green color, though often brown or reddish, and sometimes of other shades. Fumigation of the plants in a closed box with burning tobaceo stems will kill them. Latterly florists evaporate a liquid extract of tobaceo (which is sold by dealers in florists' supplies) by dropping a hot iron into a pan of it. A tea made by soaking tobaceo stems in water for a few hours, and applied with a syringe, is effective, and a safe remedy in inexperienced hands. A tablespoonful of tobaceo sheep-dip, or extract of tobaceo, to a couple of gallons of water, also makes an effective syringing or dipping solution. As mentioned above, we should use care, especially in the winter time, when the soil often dries out slowly, to avoid soaking it when already wet or sufficiently moist.

Mealy bug has a small, flat, tortoise-shaped body, from about one-sixteenth to one-eighth of an inch long. The Insects collect in masses in the axils of the leaves. They are covered with a white mealy or cottony substance, and are readily recognized, although persons unfamiliar with their appearance have sometimes mistaken them for bits of down or cotton lodged upon the foliage or in the axils of the leaves. The young are small, and likely to escape observation unless one looks closely. They are flat, of a creamy or pinkish tint, and lie close to the surface of the leaves, especially on the under surface. Coleus and bouvardias are among the plants upon which mealy bugs are most often found. Owing to the oily nature of their covering, which sucks its food it is difficult to wet their bodies with any ordinary liquid that may be applied for the purpose of destroying them. Fir-tree oil is one of the most effective remedies for them. This liquid is rather expensive, but for a small collection a gallon can will 
last for a long time. It is also effective against other Insects. For mealy bugs, two tablespoonfuls of the oil to one pint of water will make an effective dipping or spraying solution. Soft or rain-water should be used, and tin, wooden, or earthenware vessels. Galvanized iron vessels are to be avoided. Apply forcibly with a syringe or atomizer, preferably in the evening. If effective, the mealy bug will turn buff-color. For other Insects, except for the scale, mentioned below, the solution will not need to be more than half or a fourth so strong. Where there are only a few mealy bugs, the plant may be gone over with a soft brush and the Insects erushed.

Scales are most commonly of a brown or whitish color, flat or tortoise-shaped, and easily seen. They adhere closely by the under surface of their bodies to the stems, branches, and foliage of woody plants. The mature Insect is stationary, and its body at length becomes a shell containing hundreds of eggs. These hatch, and the young emerge from the shell, crawl about, and settle, to develop into the familiar form. A strong solution of fir-tree oil, like that used for mealy bugs, is a good remedy. A strong solution of whale-oil soap, made by adding an ounce or more of the soap to three gallons of water, even more if necessary, is also useful in combating them. After dipping or syringing the plants they may be allowed to stand over night, when they should be rinsed off with clear water. Applications may need repeating every three or four days until the Insects are gotten rid of. It is difficult, for a time, to tell when they are dead. If killed, the bodies will fall off easily, and in the case of the - soft-shelled species shrivel up somewhat after a time. Kerosene and water emulsion (see $K$ crosene) will kill them.

Insecticide. A substance which will kill insects. Insecticides are of two general classes - those that kill by contact (see Kerosene), and those that poison the insect (see Paris Green and Hellebore). 
Iris. Many handsome perennials, of which the Blue Flag is familiar to every old-fashioned garden. Most Irises thrive best in a rather moist soil, and some of them may be colonized in the water in margins of ponds. Gardeners usually divide them into two sections - the tuberousrooted or rhizomatous, and the bullous. A third divisionthe fibrous-rooted - is sometimes made. The common and most serviceable species belong to the tuberous-rooted section. Here belongs the beautiful and varied Japanese Iris, Iris lacrigata (or I. K(emlferi), which is among the most deserving of all hardy pereunials. Most of these Irises need no special care. They are propagated by division of the rootstocks. Plant the pieces 1 foot apart if a mass effect is desired. When the plants begin to fail, dig them up, divide the roots, discard the old parts and grow a new stock, as before. I. Susiana, of this section, is one of the oddest of Irises, but it is not quite hardy in the North. Of the bulbous section, most species are not hardy in the North. The bulbs should be taken up and replanted every two or three years. The Persian and Spanish Irises belong here. The bulbs give rise to but a single stem.

Kale. A low-growing, spreading plant belonging to the cabbage family and extensively used for winter and spring greens. The same culture as given to late cabbage is suitable. At the approach of severe freezing weather a slight protection is given in the North. The leaves remain green through the winter and may be gathered from under the snow at a time when material for greens is searce. Some of the Kales are very ornamental because of their blue and purple curled foliage. The Scotch Curled is the most popular variety. Kales are extensively grown at Norfoll, Va., and southward, and shipped north in winter. Let the plants stand 18 to 30 inches apart. Young cabbage plants are sometimes used as Kale. See Collards. Borecole is a kind of Kale. Sea Kale is a wholly different vegetable (which see). 
Kerosene is fatal to insects. It is likely to injure plants if applied full strength, although if applied in full sunlight (so that evaporation takes place rapidly) it may do no harm. It is safest to apply it in dilution. Of late, there are pumps which mix or emulsify Kerosene and water in definite proportions, and this mixture (in the proportion of $\frac{1}{5}$ or $\frac{1}{4}$ Kerosene) is fatal to insects and usually harmless to plants. The standard Kerosene emulsion is with soap, but the perfection of mechanical devices for emulsifying it with water is probably destined to supplant the soap emulsion.

Kerosene Emulsion.- Hard soap, $1 / 2$ pound ; boiling soft water, 1 gallon; Kerosene, 2 gallons. Dissolve the soap in the water, add the Kerosene, and churn with a pump for 5 to 10 minutes. Dilute 10 to 25 times before applying. Use strong emulsion, diluted four times in winter, for all seale insects. For insects which suck, as plant-lice, mealy bugs, red spider, thrips, bark-lice or scale. Cabbage-worms, currant-worms, and all insects which have soft bodies can also be suceessfully treated.

Kohlrabi. This vegetable looks like a leafy turnip growing above ground. If used when small ( 2 to 3

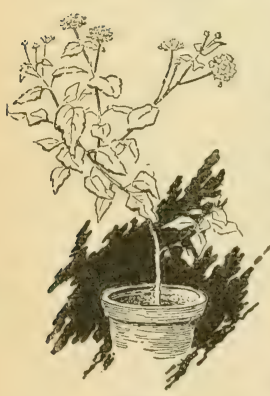

Lantana inches in diam.), and not allowed to become hard and tough, it is of superior quality. It should be more generally grown. The culture is very simple. A succession of sowings should be made from early spring until the middle of summer, in drills 18 inches to 2 feet apart, thinning the young plants to 6 or 8 inches in the rows. It matures as quickly as turnips. One ounce of seed to 100 feet of drill.

Lantana is a popular greenhouse pot-plant, and is occasionally seen in windowgardens, being grown for the profusion of its orange-red, heliotrope-shaped flowers. In the South, and sometimes in the North, it is planted out for the summer. 
It is very easy to grow, and also to propagate by means of euttings. Although the flowers of the common species are ill-scented, the profusion of bloom makes it desirable.

\section{Larkspur. DeLPhiniun. The Larkspurs are} among the very best hardy plants, being free-flowering and having a good habit. They should be in every mixed border, particularly the perennial kinds. The tall flowerspikes, showing above the cut foliage, give the plant a striking effect. The flowers are in shades of blue in most varieties. The plants are propagated by division of root or from seed. The latter method will give good results, although the resulting plants are not likely to be the same variety as the seed plant.

As winter approaches, a covering of coarse litter should be thrown over the erowns of the perennial kinds. The plants will come into bloom in late June and continue for a long season. Plants should be set 3 to 5 feet apart if in rows, but they are seen to better advantage when mixed with other border plants. Height of plants from 3 to 5 feet.

The annual Larkspur may be grown from seed sown in heat and transplanted to the ground in May; or seed may be sown where the plants are wanted and the seedlings thinned to 1 foot. These seedlings will bloom in June, and continue through the summer. Plants grow from 8 to 18 inches high.

Lathyrus. See Pea, Everlasting; also, Sweet Pea.

Lawns. In order to have a good Lawn, two things are essential : first, a pleasing surface or contour; second, a dense, firm sod.

Inasmuch as the Lawn is, or should be, a permanent thing, it is necessary that the greatest care be exercised to grade the land and to thoroughly prepare it before any seeds are sown. About a new building the filling should be allowed to settle, so that the finished surface will slope 
gradually away from the foundations and the steps. If the land is very hard elay, or if the place is rather low, it is always well to lay tile under-drains at frequent intervals. Everything should be done to cause the land to be deep and loose, so that the grass roots will run far into the soil and not be pressed for lack of moisture in a dry time. If the land has not had applications of manure in recent years, it is well to plow in, or to spade in, a liberal quantity of well-rotted litter from the barnyard. Work this into the soil as deeply as possible. If the hardpan is rather high, it is well to subsoil the area or to trench it (that is, to spade it up two or three spades deep). If the It is fun to make a garden

land is apparently not fertile in plant-food, it is well to add a dressing of some commercial fertilizer to the surface when the grass seed is sown. This will start the grass quickly and allow it to get a foothold before the severe weather of midsummer comes.

The kind of grass seed to sow will depend upon the region and also upon the personal tastes of the owner. The one standard Lawn grass is June grass or blue grass (Poa pratensis). The seeds of this grass are sold in the hulls, and therefore the bushel weighs only fourteen pounds. Not less than two and onehalf to three bushels should be sown to the acre. In the southern states, June grass will not hold, and Bermuda grass is used, being sown about as thick as recommended for the June grass. There are various prepared Lawn grass mixtures which are excellent, but the June grass alone will give a very excellent Lawn in a short time. Whether one shall sow white clover in his Lawn depends mostly upon his personal taste. If he likes the white clover, it is well to put in a quart or two of seed to the acre, sowing it separately

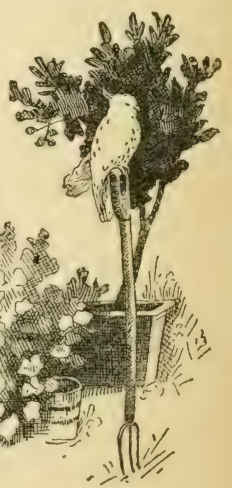

A garden corner 
from the June grass in order to get an even distribution. Some persons like to see the white clover in certain parts of the Lawn. It thrives very well where the land is rather moist. In parts of the East, Rhode Island bent grass is used for lawns.

The grass seed should be sown in the cool of the rear. It may be sown in September and thereby become established be-

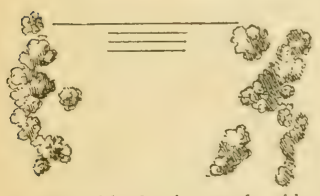

A lawn, with planting on the sides fore winter; or it may be sown very early in the spring.' In newly made Lawns, it is a good plan to grade the area thoroughly in the fall, allowing it to settle in the winter; and then, if the surface remains even, to sow the grass seed on one of the latest snows in spring. By sowing it on the snow, one can see that it is distributed evenly; and when the snow melts, the seed is carried into the land and does not need covering. It is well to sow three or four quarts per acre of timothy seel, for the timothy germinates very quickly, and makes a green area the first season, but is killed out as soon as the June grass gains a foothold. Timothy will not stand the continued cutting, whereas the June grass will. The timothy, therefore, serves as a temporary covering to the land, indicating where the borders are, and thereby outlining the area for the Lawn mower to cut. The timothy seed should be sown separately from the June grass in order to insure even distribution. On hard lands it is well to sow two or three quarts per acre of crimson elover seed. The long roots of this plant tend to improve the physical condition of the soil; and when they decay, they leare nitrogen in the soil for the grass to use. Since crimson clover is an annual plant, it will not do any permanent mischief in the Lawn.

The first season the weeds will probably come up thickly, especially if the land is rich. These weeds should not 
be pulled, for whenever one is pulled out of the ground, many grass plants are rooted up and the surface is made uneven. The only way in which to keep down weeds is to mow them frequently with a Lawn mower. They will not appear in any great numbers the second year, unless there should be some perennial weeds, like dandelion or dock; and these may be pulled out the first fall or the following spring.

It is rare that one secures a perfectly good and uniform. sod from one sowing of seed; especially is this true if the soil varies in different parts of the area. If the surface contour is satisfactory, it is unwise to dig up the areas on which the seed has not caught. It is best to rake them over with a steel rake in fall or spring, sowing on a little commercial fertilizer rather rich in nitrogen, and sow more seed. Nearly every Lawn will need patching in this way from year to year. If the Lawn is attended to in fall and spring by sowing grass seed, the weeds will rarely do serious mischief. When weeds are troublesome on the Lawn, it means that there is not sufficient grass, and every effort should be made to get more grass. Therefore, when the perennial weeds are pulled out, sow more grass seed.

When narrow -leaved plantain bothers, it is an indication.

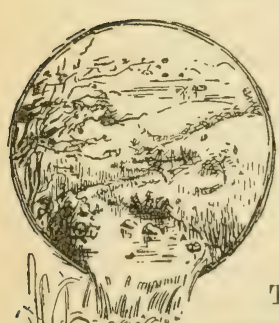
that the land is too poor and dry for grass. In such cases, the land usually lacks humus or vegetable matter; and in various severe incursions of the plantain, it may be necessary to spade up the weedy areas and to work rotted manure into the soil. Usually, however, the plantain can be killed out by enriching the soil and sowing more grass seed. The common practice of sprinkling Lawns is nearly always pernicious, since the water is not supplied in sufficient amount to wet down very far, and the grass tends to make surface roots. When the watering is omitted the plants suffer. The more a Lawn is sprinkled, the more the grass depends upon 
the sprinkling. If it is necessary to water the Lawn, the water should be allowed to run directly from the hose until the surface area is completely soaked. It is best to do this at nightfall. When the water is applied by means of a sprinkler, a large part of it evaporates and does no good to the ground. The fundamental treatment of the Lawn is to have the land so deep and porous that the grass roots strike deep into the soil and do not need the surface water. A Lawn which is well made will need watering only in unusually dry times.

Mow the Lawn frequently when it is growing rapidly, -in spring and early summer. In the fall mow less frequently, and let it go into the winter with a long coat of grass. If the Lawn is mown as often as is needed, it will not be necessary to rake off the trimmings. In fall, top-dress the Lawn with commercial fertilizer at the rate of 500 pounds to the acre. If the Lawn has not been raked clean of all the trimmings and decayed refuse which covers the surface of the ground, it is not necessary to dress it with stable manure ; for manure is unsightly, unsavory, and often brings in weeds. Many persons make the mistake of raking the Lawn clean in late fall.

Closely associated with the making of the Lawn is the general arrangement of the planting. It is the common fault to scatter the planting. Much better effects are secured by massing or grouping the planting. See Borders and Flower Beds. Particularly along the boundaries and about the foundations of buildings, the shrubbery aud other plants may be massed to excellent effect. In large places there should be more or less mass planting along the walks and drives. In the curves and retreats of these plantings one will find many pleasant corners; and here the children may have their play-houses and their pets. A little brook winding across a corner or along one side of a Lawn may make a pleasant picture if it is allowed to take on a half-wild character. 
Layers are parts (usually stems) of plants laid down on the earth while still attached to the parent, with the expectation that they will take root and ean then be separated as independent plants. All vine-like plants ean be propagated readily by means of Layers; so ean most softwooded plants, as willows, maples, eurrants, etc. It is usual to put down the branches in the fall. In a year they

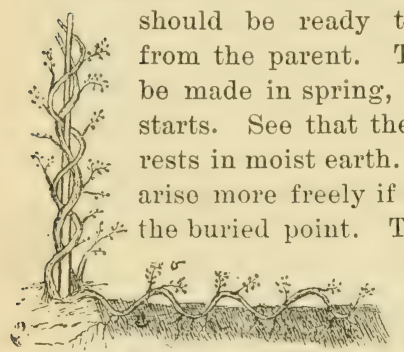

Several layers from one vine

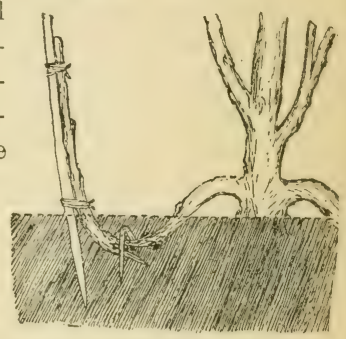

A layer

Leek. This belongs to the onion family, and is used mostly as flavoring for soups. Well grown Leeks have a very agreeable and not very strong onion flavor. Leek is of the easiest culture, and is usually grown as a second crop, to follow beets, early peas, and other early stuff. The seed should be sown in a seed-bed in April or early May and the seedlings planted out in the garden in July, in rows 2 feet apart, the plants being 6 inches apart in the rows. The plants should be set deep if the neck or lower part of the leaves is to be used in a blanched condition. The soil may be drawn towards the plants in hoeing, to further the blanching. Being very hardy, the plants may be dug in late fall, and stored in the same manner as celery, in trenches or in a cool root-cellar. One ounce of seed to 100 feet of drill. 
Lettuce is probably the most extensively grown salad vegetable. It is now in demand, and is procurable, every month in the year. The winter and early spring crops are grown in foreing-houses and coldframes, but a supply from the garden may be had from April to November, by the use of a cheap frame in which to grow the first and last crops, relying on a succession of sowings for the intermediate supply. Seed for the first erop may be sown in a coldframe in March, growing the erop thick and having many piants which are small and tender; or, by thimning out to the distance of 3 inches and allowing the plants to make a larger growth, the plants pulled up may be set in the open ground for the next erop. Sowings should be made in the garden from April to Oetober, at short intervals. A moist loeation should be selected for the July and August sowings. The early and late sowings should be of some loose-growing variety, as they are in edible condition sooner than the cabbage or heading varieties.

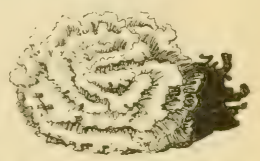

Plant of heading lettuce

The cabbage varieties are far superior to the loosegrowing kinds for salads. To be grown to perfection, they should have very rich soil, frequent cultivation and an oceasional stimulant, such as liquid manure or nitrate of soda. The Cos Lettuce is an upright-growing type much esteemed in Europe, but less grown here. The leaves of the full grown plants are tied together, thus blanching the center, making it a desirable salad or garnishing variety. It thrives best in summer. One ounce of seed will grow 3,000 plants or sow 100 feet of drill. In the garden, plants may stand 6 inches apart in the rows, and the rows may be as close together as the system of tillage will allow.

Lily. Bulbous plants of many kinds. It has been said of this family of plants that it has no "poor relations," each of them being perfect in itself. Many of the ehoicest kinds are comparatively unknown, although 
easy to cultivate. In fact, all of the Lilies may be grown with comparative ease. A light, rich, well-drained soil, mellow to the depth of at least 1 foot, a handful of sand under each bulb if the soil is inclined to be stiff, and planting so that the crown of the bulb will be at least 4 inches below the surface, are the general requirements. One exception to the depth of planting is Lilium auratum, or Golden-Banded Lily. This should be planted deeperat least 8 inches below the surface - as the new bulbs form over the old one and soon bring the bulbs to the surface if they are not planted deep.

While Lilies may have partial shade, they should never be planted near or under trees. The shade or protection of tall-growing, herbaceous plants is sufficient. In fact, the best results, both as to growth and effect, may be had by planting amongst low shrubbery or border plants. Most kinds are the better for remaining undisturbed for a number of years; but if they are to be taken up and divided, or moved to other quarters, they should not be allowed to become dry. The small bulbs, or offsets, may be planted in

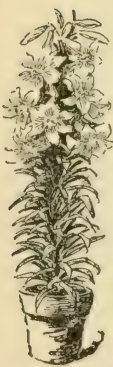

Easter Lily the border, and if protected will grow to flowering size in two or three years. In taking up bulbs for division it is best to do so soon after the tops die after blooming. At least this should be done early in the fall, not later than October, giving the plants a chance to become established before freezing weather. A mulch of coarse litter or evergreen boughs should be placed over the bulbs after the ground has become frozen, to be gradually removed as the spring advances.

As pot-plants some Lilies are very satisfactory, especially those that may be forced into bloom through the winter. The best kinds for this purpose are L. Harisii (Easter Lily), L. longiflorum, and L. candidum. Others may be forced with success, but these are the ones most generally used. The winter culture of these for forcing is 
the same as for Hyacinths (in pots), which see. The article on Bulbs gives directions for both outdoor and indoor growing which are directly applicable to Lilies.

\section{Lily, Chinese Sacred. See N'arcissus.}

Lily-of-the-Valley. A perfectly hardy little plant, bearing racemes of small white bell-shaped flowers in early spring. For ordinary cultivation, sods or mats of roots may be dug from any place in which the plant is colonized. Usually it thrives best in partial shade; and the leaves make an attractive mat on the north side of a building, or other shudy place, in which grass will not grow. The plants will take care of themselves year after year.

For forcing indoors, imported roots or "pips" are used, as the plants are grown for this particular purpose in parts of Europe. These roots may be planted in pots, and treated as recommended for winter-flowering bulls, under Bulbs. Florists force them in greater heat, however, often giving them a bottom heat of $80^{\circ}$ or $90^{\circ}$; but skill and experience are required in order to attain uniformly good results in this case.

Line. A garden Line is one of the most convenient things connected with garden operations. It is always wanted when long rows of seed are to be sown, and it is also necessary in laying out walks or drives. A very simple, yet handy, holder for a line is shown on the margin. The pin is driven in the soil at the starting point, and the line is unwound as the operator walks towards the end of l low feet long for common garden A garden Line operations.

Lobelia. Some of these are well-known garden plants, being used very freely as edging for ribbon beds or basket plants. They require a loose, rich soil, and 
some stimulant when in full flower. The flowers continue through a long season. They propagate freely from seed. Lobelia Erimus, in blue, 6 inches high, is one of the most popular of all annual edging plants. In Europe various perennial Lobelias are popular, but they are seldom seen in American gardens.

\section{London Purple. Discussed under Paris Green.}

\section{Love-Lies-Bleeding. See Amarantus.}

Manure adds plant-food to the soil, and it also improves the texture or physical condition of the soil. This latter effect is often its greatest value. If one wants mere plant-food alone, he may often do better to add it in some more concentrated form. See Fertilizers. Manure, when thoroughly incorporated with the soil, makes the ground congenial for the plant. It is important, in garden operations, that the Manure be rotted or composted, or "short" or "fine," as the gardeners say. It then incorporates readily with the soil and quickly gives up its fertility. Manure is composted by letting it decay in piles. The compost pile should be flat on top, so that it will eatch the rains, and 3 to 5 feet high.

The most desirable Manure for the garden and for house plants is probably old cow Manure. It does not burn or lose its strength. It may be kept for a number of years if piled under shelter, becoming more available each year. It mixes well with soil and leaf-mold. When once rotted, this manure is very lasting and easily assimilated by plants. Horse Manure is very likely to become overheated, and to lose its value; and it is too loose and dry for many purposes. Pig Manure, unless well composted with soil or refuse, is usually too heavy and rich. Sheep Manure is at its best when used in a liquid form, although it is most excellent to mix with soil to loosen it.

All garden refuse, such as vines, leaves, decaying vegetables, will make Manure if composted with soil; and if the 
wash water is thrown on the compost pile much fertility will be added. Wood ashes from stoves, the chip dirt from the woodshed - in fact, almost any substance that will decaywill furnish plant-food, and should be added to the compost pile. This pile should be turned often, to mix the material.

When practicable, it is best to apply Manure in the fall, as it then has time to become incorporated with the soil before spring. Beds which are to be used for flowers next year may be dressed with Manure in the fall and deeply spaded, leaving the surface rough and loose. It is well to be careful that the Manure does not contain weed seeds.

Marigold. The Marigolds of the old-fashioned gardens are still among the best of plants for fall color. They are hardy annuals of the easiest culture, and are always certain of giving strong and excellent results. They have been much improved of late years. The old-fashioned African Marigolds grow 2 to 3 feet high, and they are useful for seattering in mixed borders or making large masses or displays of color in the remoter parts of the place. The French or dwarf Marigolds grow about 1 foot high and are more tufty in their habit. They are better adapted for edgings than for mass effects in the main parts of the grounds. All Marigolds may be sown where the plants are to stand, since the flowers are usually not wanted until late summer or early fall, at which time they usually give their best bloom. If they are wanted earlier, however, the seeds may be started in the house or hotbed. Tall rarieties may be allowed to stand from 10 to 18 inches apart and the dwarfs at somewhat less distances.

Matthiola will be found under stoctis.

Mignonette. Probably no flower is more generally grown for its fragrance than this. The Mignonette needs a cool soil, only moderately rich, shade part of the day, and careful attention to eutting the flower-stalks before the seeds are ripe. If a sowing be made in late April, fol- 
lowed by a second sowing in early July, the season may be extended until severe frosts. There are few flowers that will prove as disappointing if the treatment it needs is omitted. Height 1 to 2 feet. Treated as a half-hardy annual. It can be sown in pots late in summer and had in the house in winter.

Moon-Flowers are species of Morning-Glories that open their flowers at night. A well-grown plant trained over a porch trellis, or allowed to grow at random over a low tree or shrub, is a striking object when in full flower at dusk or through a moonlit evening. In the southern states the Moon-Flower is a perennial, but even when well protected does not survive the winters in the North. Cuttings may be made before danger of frost and wintered in the house, or the plants may be grown from seed sown in January or February. Cuttings usually give best results in the northern states, as the seasons are not long enough for seed plants to give good bloom. Seeds should be scalded or filed just before sowing. The true Moon-Flower is Ipomca Bona-Nox, white-flowered; but there are other kinds. This grows 20 to 30 feet where the seasons are long enough.

Morning-Glory is perhaps the most popular of all twining herbs, because of the ease with which it may be grown, the quickness with which it covers the object, and the quantities of bright, cheerful flowers it bears. Many of the kinds - in fact all that are generally known - may be readily grown from seed, flowering early in the summer. Morning-Glories Tender annuals. Give rich soil and plenty of water. The beautiful cypress vine belongs to this group. It requires the same treatment as the Norning-Glory, but the seeds should be scalded just previous to sowing.

Dwarf Morning-Glories (Connolvulus tricolor). They come into flower much sooner than the tall climbing varieties, 
and are covered with flowers through a long season. They may be used with fine effect in vases or large hanging baskets. Give a full sumny exposure. May thrive on soil that is not very rich. They grow 1 foot high. Half-hardy annuals.

Mulberry. Both for fruit and ornament the Mulberry should be more generally planted. Even if the fruit is not to the taste, the tree is naturally open-centered and round-headed, and is an interesting subject; some of the varieties have finely cut leares. The fruits are in great demand by the birds, and after they begin to ripen the strawberry beds and cherry trees are free from robins and other fruit-eating birds. For this reason alone they are a valuable tree for the fruit-grower. Trees may be purchased cheaper than one ean propagate them.

If planted in orchard form, place them 25 to 30 feet apurt. About the borders of a place they can go closer. The Russian varieties are often planted for windbreaks, for they are very hardy and thrive under the greatest neglect; and for this purpose they may be planted 8 to 20 feet apart. The Russians make excellent screens. They stand clipping well. New American, Trowbridge and Thorburn are leading kinds of fruit-bearing IIulberries for the North. The true Downing is not hardy in the northern states; but New Ameriean is often sold under this name. Mulberries thrive in any good soil, and need no special treatment.

Mulch is used both in protecting plants from the severe freezing of winter and the severe drought of summer. The same material may be used in either case, although it is now considered best to make an earth Milch to prevent evaporation and retain the moisture through the dry season. This earth Mulch is made by breaking the crust of the soil and leaving it in fine particles. This may be done with a horse cultivator, a hoe or a rake. In fact, any tool which leaves the top of the soil loose will be instrumental in preventing evaporation of soil water. See 
Tillage. The Mulching of the ground around blackberries, currants gooseberries or raspberries with straw or hay is often practiced to keep the fruits clean; and the winter Mulch of strawberry beds is used between the rows for the same purpose, as well as to retain moisture and to afford winter protection. Winter Mulch usually consists of leaves, straw, hay, rough manure, boughs of evergreens, or any coarse material that will protect the plants from severe freezing and the heaving caused by alternate freezing and thawing. This winter Alulch should be removed as spring advances, unless it is of such a character as to be worked into the soil to add fertility or to loosen heavy lands. Near the seacoast salt hay is considered to be an ideal Mulch. The winter Mulch must not contain too strong or heavy manures, or plants may be injured by the leaching. For flower borders and shrubbery, muck or peat makes a good winter Mulch. Ordingrily the Mulch may be placed on to the depth of 4 to 6 inches, and if it is of loose material it may be still deeper. If dry and loose, mice may nest in it and girdle the trees or bushes. Even perfectly hardy plants are benefited by a winter Mulch, because it improves the soil. Autumn leaves, as they drift into shrubberies, make an ideal Mulch; it is not always necessary to remove these leaves. See Lawn.

Mushroom. There is no science of Mushroom growing. Certain conditions have been found to give success, but it is not known why. These conditions may be imitated ever so closely and complete failure result. There are many "systems" advised, each system the result of somebody's success; but one camnot be sure of success by following any one of them. Good results are frequently attained when all rules are broken. The following paragraphs are from "Farmers' Bulletin," No. 53 (by William Falconer), of the U.S. Dept. of Agriculture (March, 1897):

Mushrooms are a winter crop, coming in from September till April or May - that is, the work of preparing the 
manure begins in September and ends in February, and the packing of the crop begins in October or November and ends in May. Under extraordinary conditions the season may begin earlier and last longer, and, in fact, it may continue all summer.

Mushrooms can be grown almost anywhere out of doors, and also indoors where there is a dry bottom in which to set the beds, where a uniform and moderate temperature can be maintained, and where the beds can be protected from wet overhead, and from winds, drought, and direct sunshine. Among the most desirable places in which to grow Mushrooms are barns, cellars, closed tunnels, sheds, pits, greenhouses, and regular Mushroom houses. Total

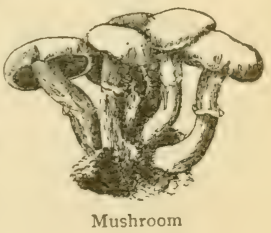
darkness is not imperative, for Mushrooms grow well in open light if shaded from sunshine. The temperature and moisture are more apt to be equable in dark places than in open, light ones, and it is largely for this reason that Mushroom houses are kept dark.

The best fertilizer for IIushrooms, so far as the writer's experience goes, is fresh horse manure. Get together a lot of this material (short and strawy) that has been well trampled and wetted in the stable. Throw it into a heap, wet it well if it is at all dry, and let it heat. When it begins to steam turn it over, shake it well so as to mix thoroughly and evenly, and then tramp it down solid. After this let it stand till it again gets quite warm, then turn, shake, trample as before, and add water freely if it is getting dry. Repeat this turning, moistening and trampling as often as it is needful to keep the manure from "burning." If it gets intensely hot, spread it out to cool, after which again throw it together. After being turned in this way sereral times, and the heat in it is not apt to rise above $130^{\circ} \mathrm{F}$., it should be ready to make up in the beds. By adding to the manure at the second or third turning one-fourth or one-fifth of its bulk of 
loam, the tendency to intense heating is lessened and its usefulness not at all impaired. Some growers prefer short manure exclusively, that is, the horse droppings, while others like a good deal of straw mixed in with this. The writer's experience, however, is that, if properly prepared, it matters little which is used.

Ordinarily the beds are only 8 to 10 inches deep; that is, they are faced with 10 -inch-wide hemlock boards, and are only the depth of this board. In such beds put a layer of fresh, moist, hot manure, and trample it down firm until it constitutes half the depth of the bed; then fill up with the prepared manure, which should be rather cool $\left(100^{\circ}\right.$ to $115^{\circ}$ F.) when used, and pack all firmly. If desired, the beds can be made up entirely of the prepared manure. Shelf beds aro usually 9 inches deep; that is, the shelf is bottomed with 1 -inch boards and faced with 10 -inch-wide boards. This allows about 8 inches for manure, and 1 inch rising to 2 inches of loam on top. In filling the shelf beds the bottom half may be of fresh, moist or wettish, hot manure, packed down solid, and the top half of rather cool prepared manure, or it may be made up of all prepared manure. As the shelf beds can not be trodden and can not be beaten very firm with the back of the fork, a brick is used in addition to the fork.

The beds should be spawned after the heat in them has fallen below $100^{\circ} \mathrm{F}$. The writer considers $90^{\circ} \mathrm{F}$. about the best temperature for spawning. If the beds have been covered with hay, straw, litter or mats, these should be removed. Break each brick into twelve or fifteen pieces. The rows should be, say, 1 foot apart, the first one being 6 inches from the edge, and the pieces should be 9 inches apart in the row. Commeneing with the first row, lift up each piece, raise 2 to 3 inches of the manure with the hand, and into this hole place the piece, covering over tightly with the manure. When the entire bed is spawned pack the surface all over. It is well to cover the beds again with straw, hay or mats, to keep the surface equally 
moist. The flake spawn is planted in the same way as the brick spawn, only not quite so deep.

At the end of eight or nine arays the mulching should be removed and the beds covered with a layer of good loam 2 inches thick, so that the Nushrooms can come up in and through it. This gives them a firm hold, and to a large extent improves their quality and texture. Any fair loam will do. That from an ordinary field, wayside or garden is generally used, and it answers admirably. There exists an idea that garden soil surfeited with old manure is unfit for Mushroom beds because it is apt to produce spurious fungi. This, however, is not the case. In fact, it is the earth most commonly used. For molding the beds the loam should be rather fine, free and mellow, so that it can be easily and evenly spread and compacted firmly into the manure.

If an even atmospheric temperature of from $55^{\circ}$ to $60^{\circ} \mathrm{F}$. can be maintained, and the house or cellar containing the Mushroom beds is kept close and free from drafts, the beds may be left uncovered, and should be watered if they become dry. But no matter where the beds are situated, it is well to lay some loose hay or straw or some old matting or carpet over them to keep them moist. The covering, however, should be removed just as soon as the young Mushrooms begin to appear above ground. If the atmosphere is dry, the pathways and walls should be sprinkled with water. The mulching should also be sprinkled, but not enough to cause the water to soak into the bed. However, if the bed should get dry, do not hesitate to water it.

Muskmelon. The natural soil for melons is a light, sandy loam, well enriched with rotted manure, although good crops may be grown on soil naturally heavy if the hills are prepared as they should be. When only heary soil is available, the dirt where the seeds are to be planted should be thoroughly pulverized and mixed with fine, well rotted manure. A sprinkling of leaf-mold or chip-dirt will help to lighten it. On this hill from ten to 
fifteen seeds may be sown, thinning to four or five vines when danger of insects is over. The season may be advanced and the damage from insects lessened by starting the plants in hotbeds. This may be done by using fresh sod, cut into 6 -inch pieces, placing them grass-side down in the hotbed, sowing eight to ten seeds on each piece, and covering with 2 inches of light soil. When all danger of frost is over, and the ground has become warm, these sods may be carefully lifted and set in the prepared hills. The plants

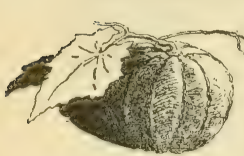

Muskmelon usually grow without check, and fruit from two to four weeks ahead of those from seed planted directly in the hill. Old quart berry boxes are excellent to plant seeds in, as, when they are set in the ground, they very quickly decay, eausing no restriction to the roots. Netted Gem, Hackensack, Emerald Gem, Montreal, Osage, and the Nutmeg Nelon are popular varieties. One ounce of seed will plant about fifty hills.

For insects, see Cucumber.

Musk Plant is an old-fashioned house plant of easy culture. Raise a new stock from seeds as soon as the plants begin to fail.

Narcissus. Hardy bulbous plants, including the daffodils, jonquils, and other forms. The ease with which these plants may be grown, the beauty and fragrance of the flowers, as well as their lasting qualities when cut, would seem to make their culture in this country more popular than it is. Good bulbs planted in September or October are sure to bloom in April or May. The bulbs may remain in the ground for a number of years, although the best results will be had by digging them up every three years, and resetting in a different location. Select a moist, loamy soil, slightly protected from the sun. No manure should come directly in contact with the bulb, but if needed to hold moisture the manure may be spaded down to the depth of twelve inches. 
Narcissus may be forced into flower through the winter, as described under Bulbs. The most popular for winter bloom is the "Chinese Sacred Lily." This grows in water without any soil whatever. Secure a bowl or glass dish, about three times the size of the bulb; put some pretty stones in the bottom; set in the bulb and build up around it with stones so as to hold it stiff when the leaves have grown; tuck two or three small pieces of charcoal among the stones to keep the water sweet, then fill up the dish with water and add a little every few days, as it evaporates. Set the dish in a warm, light place. In about six weeks

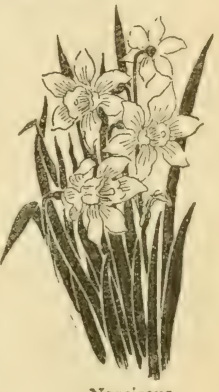

Narcissus

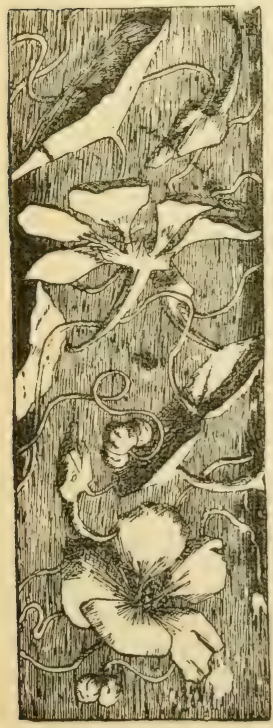

Nasturtium the fragrant, fine white flow ers will fill the room with perfume.

\section{Nasturtiums (Tropceolums) are} both dwarf and climbing. The Dwarf Nasturtiums make one of the most showy second-row plants for the border. The colors of the flowers have a wide range and the plants bloom profusely. It is not, however, the plant in flower that is the greatest consideration, but the flowers themselves as cut-flowers. No flower makes a finer display in vase or bowl than these rich color's, all harmonizing well and lighting up a room as very few of the common easily grown flowers do. The same may be said of the tall-growing Nasturtiums, although the flowers of these form part of their effectiveness as screen vines. Few climbers make a more rapid growth, and none are better adapted to hide unsightly objects in our yards or gardens. 
For a long season of flowers and a large growth of vine the seed should be sown late in March or early in April, in boxes or pots, the plants carried along until the first of May, and planted out where wanted. The

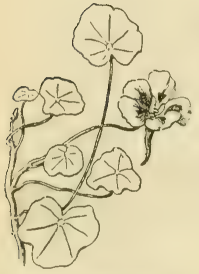

Dwarf Nasturtium dwarf varieties bloom more freely and the fowers are of better color in rather poor soils, while for rapid growth of vine a well enriched border would be the best. The dwari varieties may be planted 2 or 3 feet apart, and the tall ones as wanted to make a screen. The tall kinds grow 5 to 8 feet. All Nasturtiums are tender.

Nicotiana. Tender annuals (or grown as annuals). They are fine plants for borders or pots, the tall-growing varieties making a very fine show when in flower, having pure white flowers with long, tubular necks, the season of bloom being from July to October. The seeds are very fine, and should be sown on the surface of the soil, in boxes or pots. When planted out they should be set from 2 to 5 feet apart, according to kind. Some of the giant Nicotianas are excellent subjects for temporary screens ; so is tobacco, which is also a Nicotiana.

Nicotiana affinis is one of the best of all garden flowers. Its long white flowers are fragrant at evening, They close in the hot sun. It is a halfhardy annual of easiest culture. Height 2 to 3 feet.

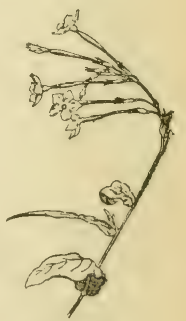

Nicotiana affinis

Enothera. Evening Primirose. A very interusting group of plants, opening their flowers at evening. Many of them are fragrant and attract night insects, especially the large moths, seldom seen until dusk. The opening of the flowers of the large-flowering varieties is a source of pleasure and surprise, as one flower follows another in opening, and in a large plant the late opening flowers seem to burst all at one time. The perennial species may be propa- 
gated by division or seed, the annuals by seed. Set the tall kinds 2 to 3 feet apart. Height 1 to 3 feet. All of easy culture.

Okra. From the green pods of this vegetable is made the well-known Gumbo soup of the South, where the plant is more extensively grown than in the North. The pods are also used in their green state for stews, and are dried and used in winter, when they are nutritious, and form no little part of the diet in certain sections of the country. The seeds are very sensitive to cold and moisture, and should not be sown until the ground has become warm - the last week in May or the first of June being early enough in New York. The seed should be sown in a drill 1 inch deep, the plants thinned to stand 12 inches in the row. Give the same cul-

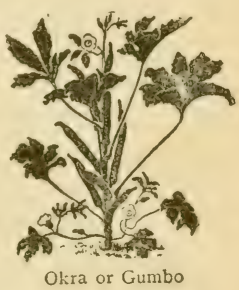
ture as for corn. One ounce will sow 40 feet of drill. Dwarf varieties are best for the North. Green Density and Velvet are leading varieties.

\section{Oleander. While there are many named va-} rieties of the Oleander, but two are often seen in general cultivation. These are the common red and white varitties. Both these, as well as the named varieties, are of easy management and well adapted to home culture, growing in pots or tubs for several years without special care. Well-grown specimens are very effective as porch or lawn plants, or may be used to good advantage in mixed beds of tall-growing plants, plunging the pot or tub to the rim in the soil. The plants should be eut back after flowering. They should bo rested in any out-of-the-way place through the winter. When brought out in the spring, they should be given sun and air in order to make a sturdy growth. Propagation is effected by using well-ripened wood for cuttings, placed in a close frame; or the slips may be rooted in a bottle or can of water, care being taken to supply water as evaporation takes place. After being rooted, they may be 
potted, using soil with a large proportion of sand. Well established plants may be repotted in good loam and well rotted manure.

Onions are grown from seeds ("black seed") for the main erop. They are also grown from sets (which are very small Onions, arrested in their development), from "tops" (which are bulblets produced in the place of flowers), and from multipliers or potato onions, which are compound bulbs.

The extremely early crop of Onions is grown from sets, and the late or fall crop is grown from seed sown in April or early May. The sets may be saved from the crop harvested the previous fall, saving no bulbs measuring over $3 / 4$

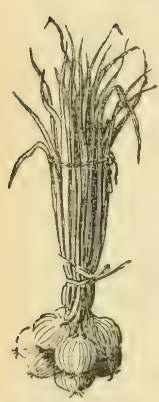

Early Onions of an inch in diameter, or, better, they may be purchased from the seedsman. These sets should be planted as early as possible in the spring, preferably on land that has been manured and trenched in the fall. Plant in rows 12 inches apart, the sets being 2 or 3 inches in the row. Push the sets well down into the ground and cover with soil, firming them with the feet or a roller. In cultivating, the soil should be thrown towards the tops, as the white stems are usually sought as an indication of mildness. The crop will be in condition to use in from three to four weeks, and may be made to last until small seed Onions are to be had. Tops or multipliers may also be used for the early crop.

In growing Onions from seed, it is only necessary to say that the seed should be in the ground very early in order that the bulhs make their growth before the extreme hot weather of August, when, for want of moisture and because of the heat, the bulbs will ripen up while small. Early in April, in New York, if the ground is in condition, the seed should be sown thickly in drills from 12 to 16 inches apart, and the ground above the seeds well firmed. Good cultivation and constant weeding is the price of a good crop 
of Onions. In cultirating and hoeing, the soil should be kept away from the rows, not covering the growing bulbs, but allowing them to spread over the surface of the ground. When the crop is ready to he harvesterl, the bulbs may be pulled or cultivated up, left to dry in douhle rows for several days, the tops and roots taken off, and the hulbs stored in a dry place. Later in the season they may be allowed to freeze, covering with chaff or straw to hold thein frozen, and kept until early spring; but this method is usually unsafe with beginners, and always so in a changeable climate. Onion seed should always be fresh when sownpreferably of the last year's erop. One ounce of Onion seed will sow 100 feet of drill.

One of the recent methors of obtaining extra largo bulbs from seed is to sow the seed in a hothed in February or early March, and transplant to the open ground in April.

The Danvers, Prizctaker, Globe and Wethersfield are farorite varieties, with the addition of White Queen or Barletta for pickling.

Oxalis. A number of hardy species of this are excellent plants for rockwork and edging. The greenhouse species are very showy, growing without extra care, and blooming freely through the late winter and spring months; these are mostly increased by bulbs, a few by division of the root. $O$. violacea is one of the commonest of house-plants. Give a sunny window, for the flowers open only in sun or very bright light. The bulloous kinds are treated as recommended for Bulbs, except that the bulbs must not freeze.

Palms. No more graceful plant for room decoration can be found than a well-grown specimen of some species of Palms. Most Palms are well auapted for this purpose when small, and as the growth is usually very slow, a plant may be used for many years. Again, the plants thrive better in partial shade. They may be grown in a sitting or drawing-room more satisfactorily than most 
house-plants. One of the frequent causes of failure in the culture of the Palm is the over-potting and subsequent overwatering. A Palm should not be repotted until the mass of roots fills the soil; then a pot only a size larger should be used. Use ample drainage in the bottom to carry off excess of water. Although the plants need a moist soil, water standing at their roots proves injurious. A soil composed of well rotted sod, leaf-mold and a little sand will meet their requirements. Among the best Palms for house culture are Arecas,

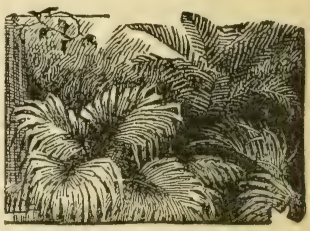

Palmis

Cocos Weddelliana, Latania, Kentia, Chamærops and Phœnix. Cycas may also be regarded as a Palm.

The date Palm may be grown from seed of the common commercial date. Seed of the other varieties may be purchased from leading seedsmen, but, as the seed germinates only under favorable conditions, and the Palm is a very slow-growing plant while young, the best plan is to purchase the plants from A table Palm

a dealer when wanted. When the plants become weak or diseased, take them to a florist for treatment and recuperation.

Pandanus, or Screw PINE. The Pandanus utilis and $P$. Veitchii are exceedingly ornamental, and are well adapted to house culture. The singular habit of growth, bright, glossy leaves, and the ability to withstand the dust and shade of a dwelling room, make them a desirable addition to the house collection. They are propagated by the offsets or young plants that grow around the base of the trunk; or they may be increased by seed. If by the former method, the offsets should be eut off and set in sand, at a temperature of $65^{\circ}$ or $70^{\circ}$. The cuttings root 
slowly and the plants for a time make a very slow growth. The general cultural treatment is that of palms, which see.

Pansy is without doubt the most popular spring flower in eultivation. The strains of seed are many, each containing great possibilities. The culture is simple and the results are sure. Seed sown in August or September, in boxes or a frame, will make plants large enough to reset in November and bloom the following March; or they may be left until March in open seed-beds before setting out. Also, if they are sown very thinly in the frames they may remain undisturbed through the winter, blooming very early the following spring. 'The frame should be protected by mats, boards or other covering through the severe cold, and as the sun gains strength, care should be taken to keep them from heaving by alternate thawing and freezing. Seed sown in boxes in January or February will make fine blooming plants by April, taking the place of those blooming earlier.

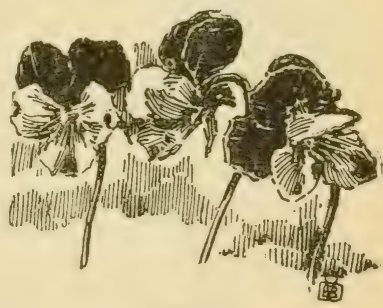

Pansies

The requisites for satisfactory Pansy culture are rich, moist, cool soil, protection from the noonday sun, and attention to keeping them from going to seed. As the ground becomes warm a mulch of leaf-mold or other light material should be spread over the bed to retain moisture and exclude heat. Spring and fall give the best bloom.

Paris Green is the leading arsenical insectieide. It is usually applied in a water spray, at the rate of 1 pound of the poison to 150 to 200 gallons of water. Add $1 / 2$ pound of lime to prevent injury to foliage. Potatoes will usually stand a stronger mixture; peaches and some other plants do not need one so strong. Make the Paris Green into a paste with water before adding it to the 200 gallons, that it may mix better. Paris Green may be added to Bordeaux 
mixture with excellent results, counting the Bordeaux as if it were so much water; in this case it will not be necessary to add lime to the Paris Green. The Paris Green is used only for cherving insects, as worms and beetles. London purple is used in the same way.

Parsley. The curled Parsley is used almost exclusively as a garnish for meats and salads, although the flavor in soups is fine. The seed is slow to germinate, and often the second or third sowing is made, thinking the first is a failure; but usually after what would seem a long time the young plants will be seen. When sown in the open ground, it should be thinned to stand 3 or 4 inches in the row, the rows being 10 to 12 inches apart. A fow plants in a border will give a supply for a large family, and with a little protection will live over winter. Roots may be lifted in the fall, put into boxes or old cans, and grown in a sunny window for winter use.

Parsnips are one of the vegetables that are the better for the winter's freeze, although they are of good quality if taken up after the fall frosts and packed in soil, sand or moss in the cellar. The seed, which must be not over one year old, should be sown as early as possible in well prepared soil, firmed with the feet or roller. As tho seed germinates rather slowly the ground often becomes crusted or baked over the seeds, in which case it should bo broken and fined with a garden rake. This operation often means the success of the crop. Radish or calbage seeds may be sown with the Parsnip seed to mark the row and break the crust. One ounce of seed will sow 200 feet of drill. Thin to 6 inches apart in the row.

Pea. Who does not long for the time when early Peas are fit to use? And how many know the great difference in quality between the smooth and the wrinkled Peas? The first are a little the earliest to be planted and 
to become fit for use, and on that account should be planted in a small way. For the kitehen-garden the dwart and half-dwarf varieties are the best, as the tall kinds will need brush or wire to support them, eausing comsiderahle trouble and labor and not being as neat in appearance. The tall varieties yield a larger erop than the dwarfs, but as the rows must be made from 3 to 5 feet apart, the dwarf ones, which are planted only 6 to 8 inches apart, will give as large a yield on the same area. Always plant double rows of the tall varieties: that is, two rows from 4 to 6 inches apart, with the brush or wire between, the double rows being from 3 to 5 feet apart, according to varieties. The dwarf varieties should be planted four rows in a block, each row being only 6 or 8 inches apart. The Peas on the two center rows may be picked from the outside. Leave a space of 2 feet and plant the same. At the time of the first planting only the smooth varieties should be sown, but hy the middle of April in New York the ground will be warm and dry enough for the wrinkled sorts. A succession should be sown that will come to maturity one after the other, extending the season six or eight weeks. If a further supply is wanted the early quick-maturing varieties may be sown in August, usually giving a fair crop of Peas in September and early October. In the hot weather of midsummer they often do not thrive so well. One quart of seed will plant about 100 feet of drill.

Pea, Everlasting (Lathyrus latifolius). These Peas do not have the colors or fragrance of the Sweet Pea, but are fine for planting against rocks, stumps, or fences. They bloom through a long season, and, being perfectly hardy, will live for years. Height 2 to 6 feet. Raised from seeds or from cuttings, usually the former. Keep the seed pods picked off to lengthen period of bloom.

\section{Pea, Sweet. See Sweet Pea.}

Peach. Given the proper exposure, Peaches 
may be fruited in many sections where now it is thought impossible to have a crop. It is usually the practice of the amateur to set Peach trees in the shelter of some building, exposed on the south or east to the sun, and "in a pocket" as regards winds. This should be reversed, except in the close vicinity of large bodies of water. The fruit buds of Peaches will stand very cold weather when perfectly dormant, often as low as $12^{\circ}$ or $18^{\circ}$ below zero in New York; but if the buds once become swollen, comparatively light freezing will destroy the crop. Therefore, if the trees be set on elevations where a constant air drainage may be obtained, sheltered, if at all, on the south

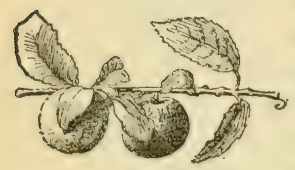

Peaches and east, from the warming influence of the sun, the buds will remain dormant until the ground becomes warm, and the chances of a failure will be lessened. This advice applies mostly to interior sections. A well drained, sandy loam or gravelly soil suits the Peach better than a heavy soil; but if the heavier soil is well drained, good crops may be obtained.

Peaches are short-lived at best, and one should be satisfied with three or four crops from each tree. They bear young, usually a partial crop the third year. If a crop may he had every other year until the trees are eight or ten years old, they will have well repaid the effort of cultivation. But they often bear twice this long. Young trees may be set every four or five years to replace older ones, thus having trees at a bearing age at all times on a small place. Trees should be set 14 to 18 feet apart each way. A good selection of varieties for home use would be Early York, Alexander, Hale Early, Mountain Rose, Early Crawford, Wheatland, Stump, Elberta, Stevens, Oldmixon, Late Crawford and Smock.

Peach trees are always bought when they are one year old, that is, one year from the bud. For example, the bud is set in the fall of 1898 . It remains dormant until the 
spring of 1899 , when it pushes into vigorous growth; and in the fall of 1899 the tree is ready for sale. Peach trees which are more than a year old are scarcely worth the buying. It is a common practice, when setting Peach trees, to prune them back to a whip, leaving a stub bearing not more than one bud where each branch is eut off.

The three great enemies of the Peach are the borer, the yellows and the curculio.

The borer is best handled by digging it out every spring and fall. Trees which are attacked by the borer have an exudation of gum aljout the erown. If the borers are dug out twice a year they will not get sufficient start to make the operation very laborious. It is the only sure way.

The yollows is a communicable disease, the cause of which is not definitely known. It shows itself in the fruit ripening prematurely, with distinct red spots which extend through the flesh, and later by the throwing out of fine, branching, twiggy tufts along the main branches. The only treatment is to pull out the trees and burn them. Other trees may be set in the same places.

For a discussion of curculio, see the remarks under Plum.

Pear. No fruit plantation should be considered complete without trees of various kinds of Pears, ripening fruits from early in August till winter. The late varieties are generally good keepers, and extend the season into February, thus supplying fruit for six or seven months.

As the Pear grows to perfection on quince, the dwarf tree is peculiarly adapted to planting on small home grounds, and is often used as a boundary plant, or to serve the purpose of a screen. These dwarf trees should be set deep-4 to 6 inches below the union - to prevent the stock from growing. Dwarf trees may be set as near together as 10 to 16 feet, while the standard or tall-growing Pears should be set 18 to 25 feet apart. Trees are planted when two or three years old. 
The Pear thrives on clay soil, if well underdrained, and for this reason may succed in places where other fruits might fail. A good, steady growth should be maintained, but the use of nitrogenous manures should be avoided, as they tend to make a rank growth and invite attacks of Pear

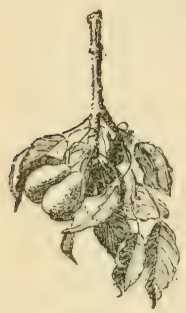

Bartlett Pears blight, which is the worst enemy of the Pear. For summer fruits: Osband's Summer, Bartlett, Clapp and Manning Elizabeth are among the best. For autumn: Duchess, Flemish Beauty, Bose, Louise Bonne, Seckel and Sheldon. For winter fruit: Anjou, Clairgeau, Lawrence and Winter Nelis are excellent. Kieffer is an excellent commercial fruit, but it is too poor to be given space in the home ground except as an ornamental tree.

Of the Pear blight, Duggar writes as follows:

"Remedies. (a) The knife and the saw. - With a disease working as this does, it is very evident that there is no chance either for cure or prevention by means of spraying. The heroic treatment of the knife and saw must be adopted and vigorously pursued, as has been claimed from the beginning. The blackened leaves alone must not serve as signs of the diseased area, but one must examine earefully the branches and remove them 6 inches or more below the lowest discolorations. Often before cutting, pruners slice the bark downward to see where the injury ends. This should not be done; it is better to be sure that you are below the infected area, and run no such risk of infecting anew the tissues below. The cut surfaces of larger limbs and branches should be painted for protection against wound rots.

"(b) When to cut.-Cutting out diseased portions should be done whenever the disease is evident. This may check the injuries temporarily; but it has been shown that much can be done in the autumn to prevent the establishment of the disease the following spring. It has long been 
known that the disease may pass the winter in the branches by a slow growth in the neighborhood of late infections. Thorough work of eradication should especially ve performed after the season of growth. Then cut out every diseased branch and burn, so that in the spring when the suceulent growth begins again, there will be few places in which insects may come in contact with the bacterial exudations.

"(c) Conditions faroring the discase. - The knife is our only hope of extermination; but there are undoubtedly conditions which favor the disease. In a succulent, rapidly growing tree the bacteria find more favorable conditions for their development than in one which grows slowly, yet with sufficient vigor. For this reason, too much nitrogenous manure is dangerous; and, for the same reason, a succulent growth induced by severe pruning should be aroided."

Pelargoniums. Here belong the plants known as Geraniums - the most satisfactory of house-plants, and extensively used as beclding plants. No plants will give better returns in leaf and flower; and these features, added to the ease of propagation, make them general favorites. Cuttings of partially ripened wood root very easily, grow to blooming size in a short time, and, either planted out or grown in a pot, make fine decorations. The common or "Fish" Geraniums are much more satisfactory when not more than a year old. Take cuttings from the old plants at least once a year. In four or five months the young plants begin to bloom. Plants may be taken up from the garden and potted, but they rarely give as much satisfaction as young, vigorous

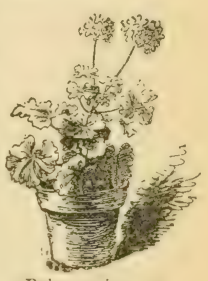

Pelargunium, or Geranium subjects. Repot frequently until they are in 4- to 5-inch pots; then let them bloom.

The show Pelargoniums are those commonly known as Lady Washington Geraniums. These have but one period of bloom, usually in April, but they make up in size and 
coloring. This section is more difficult to manage as a house plant than the common Geranium, needing more direct light to keep it stocky, and being troubled by insects. Still, all the trouble taken to grow them will be well repaid by the handsome blossoms. Take cuttings in late spring, after flowering, and blooming plants may be had the following year. Good results are sometimes secured by keeping these plants two or three years. Cut back after each blooming season.

For house culture the Geraniums need a rich, fibrous loam, with the addition of a little sand; good drainage is also an essential.

Peony. The herbaceous Peony has long had a place in the garden, and is now in general use as an early flowering plant. It is perfectly hardy, and free from the many diseases and insects that attack so many fine plants. The single and semi-double varieties are very fine, the flowers becoming large as the plant becomes well established. The herbaceous section is readily increased by division. The tree Peonies are increased by grafting. They grow in some cases to the height of 3 or more feet, and are covered with large, very double flowers of rich colors. Height 2 to 3 feet.

Peppers are tender while young, although they will endure a heavy frost in the fall. Their culture is that recommended for eggplants. A small seedsman's packet of seed will be sufficient for a large number of plants, say two hundred. The large Bell Peppers are the mildest, and are used for making "stuffed Peppers" and other dishes. The small, hot Peppers are used for seasoning and sauces.

Petunia. The improvement made in the size and markings of the Petunia has been marked of late. Now almost every shade of color may be found, aside from yellow. A bed of Petunias makes a mass of color equaled by few other 
flowers. They also make very fine single plants for pots, baskets or window-boxes, blooming freely through the winter, and emitting a delicate fragrance. The single varieties grow freely from seed, but if plants of one special color are wanted euttings should be made. These euttings root easily and bloom early. Cuttings will have to be macle of the double varieties to increase their number. For common Petunias, sow seeds where plants are to grow, in a warm, sunny place; or, for earlier bloom, seeds may be started

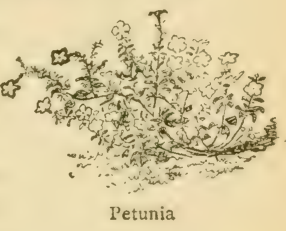
in the house. Thin to 8 to 12 inches apart. The season of bloom is eut short only by frost or other causes.

Phlox. Both the perennial and the annual Phloxes are most valuable. Excepting the petunia, no plant will give the profusion of bloom with as little care as the annual Phlox (Phlox Drummondii). Masses of one color or of contrasting color's make very effective ribbon borders or edging beds. The perennial species are very showy, having almost as wide a range of color as the annuals. They grow to the height of 3 feet. They are most effective in the back row of a border. The perennials have been much improved of late. They are hardy.

The annual Phlox is propagated by seed sown early in the spring in the border, or in March in boxes and transplanted. The perennial Phlox is increased by division of the roots, the flowers being larger and more highly colored by dividing at least every three years. The annual Phlox blooms early, and continues until late in the fall. The perennial blooms from July to frost.

\section{Pink. See Dianthus and Carnation.'}

Plum. Of Plums there are three general or common types: first, the common Domestica or European Plum, which gives rise to all the older varieties, like Lombard, Bradshaw, Green Gage, the Prunes, the Egg Plums, 
the Damsons, and the like; second, the Japanese Plums, which have become popular within the last ten years, and which are adapted to a wider range of country than the Domesticas; third, the native Plums of several species or types, which are adapted to the plains, the middle and southern states, where the Domestica Plums do not thrive, and some kinds to the cold North.

Wherever the Domestica and Japanese Plums can be grown, the native Plums are not destined to become popular; but many of the natives are much hardier than others, and are therefore adapted to regions in which the Domestica and Japanese are not safe. Other's of them are well adapted to the middle and southern states. The Domestica and Japanese Plums are considerably hardier than peaches, but not so hardy as the apple. The northern limit of their general cultivation is the southern peninsula of Michigan, central and southern Ontario, central New York and central New England.

Plums thrive on a great rariety of soils, but they do better, as a rule, on those which are rather heavy and have a considerable content of clay. In fact, many of the varieties will thrive on clay as hard as that upon which pears will grow. On the other hand, they often thrive well upon light, and even almost sandy soils.

The trees are set when they are two and three years from the bud. It is preferable to have Plum trees on stocks of the same species, but it is not always possible to secure them at the nurseries. In the South, Plums are worked mostly on peach roots, and these make excellent trees where the climate is not too severe, and especially upon the lighter lands on which they are planted in the South. In the North the larger part of the Plum stocks are grown on the Myrobalan Plum roots. This Myrobalan is an Old World species of Plum, of smaller growth than the Domestica. This stock, therefore, tends to dwarf the tree, and it is also likely to throw up sprouts from the roots. Plum trees 
are set from 12 to 18 feet apart. Miany growers like to set them 8 feet apart in rows, and have the rows from 16 to 20 feet apart.

Plums are pruned much the same as apples and pears. That is, the top is thinned ont from year to year, and all superfuous branches and broken or diseased wood are removed. If the soil is very strong and the trees are close together, it may be well to head them in a little each year, especially those varieties which grow very strong and robust.

The varieties of Plums are very'numerous. Of the Iomestica or European type, some of the best are Bradshaw, Imperial Gage, Jefferson, Reine Claude, Coe Golden Drop, Quackenbos, Fellemburg, German Prune, Copper. The Lombard is the most cosmopolitan varifty, and is always sure to give a crop, but the quality is not so good as that of the others mentioned. For culinary purposes, some of the Damsons, which are very small-fruited varieties, are excellent. Of Japanese Plums, the best so far tested for the North are Red June, Abundance, Burbank, Chabot and Satsuma. For a very early cherry-like Plum for home use, the Berger is excellent. Of the native Plums, the most cosmopolitan variety is Wild Goose. Excellent

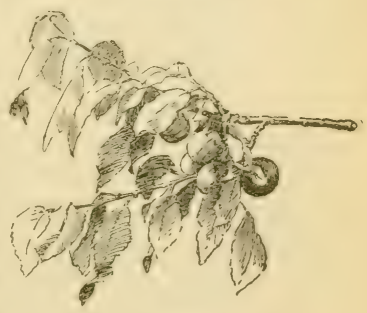

Plums varieties are Weaver, Quaker, Forest Garden, Wayland, and others.

There are four leading difficulties in the growing of Plums - leaf blight, fruit rot, black knot, and ourculio.

The leaf blight usually comes on about midsummer, the leaves becoming spotted and dropping off. The remedy for this trouble is to spray thoroughly with Bordeaux mixture, beginning soon after the fruits have set, and before the trouble begins to show. 
The fruit rot may be prevented by the same means - that is, by spraying with Bordeaux mixture. It is usually best to begin just after the fruits are well set. A very important consideration in the checking of this disease is to thin the fruit so that it does not hang in clusters. If one fruit touches another, the rot spreads from fruit to fruit in spite of the spraying. Some varieties, like Lombard and Abundance, are susceptible to this injury.

The black knot is best kept in check by cutting out the knots whenever they can be seen, and burning them. As soon as the leaves drop, the orchard should be gone over and all knots taken out. Orchards which are thoroughly sprayed with Bordeaux mixture for the leaf blight and fruitrot fungus are less liable to attacks of black knot.

The curculio, or the insect which is the parent of the worms in the fruit, is the inveterate enemy of the Plum and other stone fruits. The mature beetle lays the eggs in the fruits when they are very small, usually beginning its work about as soon as the flower's fall. These eggs soon hatch, and the little maggot bores into the fruit. Those fruits which are attacked whilst very young ordinarily fall from the tree, but those which are attacked when they are half or more grown may adhere to the tree, but are wormy and gummy at the picking time. The mature beetles are sluggish in the mornings, and are easily jarred from the trees. Taking advantage of this fact, the fruit-grower may jar them into sheets; or, in large orchards, into a large canvas hopper, which is wheeled from tree to tree upon a wheelbarrow-like frame, and undor the apex of which is a tin can into which the insects roll. There is a slit or opening in one side of the hopper, which allows the tree to stand nearly in the middle of the canvas. The operator then gives the tree two or three sharp jars with a padded pole or mallet. The edges of the hopper are then quickly shaken with the hands and the insects roll down into the tin receptacle. In this receptacle there is kerosene oil, or it may be emptied from time to time. Just 
how long this machine is to be run in the orchard will depend entirely upon circumstances. It is advisable to use the catcher soon after the blossoms fall, for the purpose of finding out how abundant the insects are. If a few insects are caught upon each tree, there is indication that there are enough of the pests to make serious trouble. If after a few days the insects seem to have disappeared, it will not be necessary to continue the hunt. In some years, especially in those succeeding a very heavy crop, it may be necessary to run the curculio-catcher every morning for four or five weeks; but, as a rule, it will not be necessary to use it oftener than two or three times a week during that season; and sometimes the season may be shortened by one-half. The insects fall most readily when the weather is cool, and it, therefore, is best to get through the whole orchard, if possible, before noon. Upon eloudy days, however, the insects may be caught all day. A smart man can attend to 300 to 400 full-bearing trees in six hour's if the ground has been well rolled or firmed, as it should be before the bugging operation begins. But whether the operation is troublesome or not, it is the price of Plums, and the grower must not expect to succeed long without it. The same treatment is essential to the saving of peaches and rarely, also, of sour cherries.

Poppy. These showy annuals and perennials should be more generally grown. Nothing will lighten up a corner better than the hardy oriental Poppy, or the solid erimson or scarlet annual Poppies. All of the varieties grow readily from seer, which, in most cases, should be sown where the plants are to bloom. The seeds of the oriental and the Iceland Poppy may be sown in pots, the plants wintered over in a frame and carefully planted out the second spring. The Poppy is very impatient of root disturbance, however, and the safest method is to sow the seed where wanted.

Portulaca, or Rose Moss. Brilliant little ten- 
der annuals, low-growing and sun-loving. They usually seed themselves, and once established will continue for years. Many of the varieties will produce a good percentage of flowers as double as roses and of many colors. Seed should be sown where wanted. They bloom freely in light, sandy soil in the full blaze of the sun.

Potato. The common practice of growing Potatoes in ridges or elevated hills is wrong, unless the soil is so wet that this practice is necessary to insure proper drainage; but in this case the land is not adapted to the growing of Potatoes. If the land is elevated into ridges or hills, there is a great loss of moisture by means of evaporation. During the last cultivating the Potatoes may be hilled up slightly in order to cover the tubers; but the hills

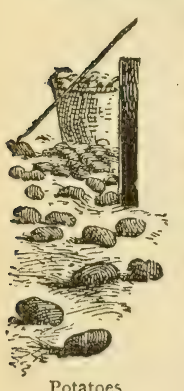
should not be made in the beginning. Land for Potatoes should be rather loamy in character, and ought to have a liberal supply of potash, either naturally or supplied in the drill, by means of an application of sulfate of potash. See that the land is deeply plowed or spaded, so that the roots can penetrate deeper. Plant the Potatoes 3 or 4 inches below the natural surface of the ground. It is ordinarily best to drop the pieces in drills. A continuous drill may be made by means of dropping one piece every 6 inches, but it is usually thought best to drop two pieces about every 12 to 18 inches. The drills are far enough apart to allow good cultivation. If horse cultivation is used, the arills should be at least 3 feet apart.

Small Potatoes are considered not to be so good as large ones for planting. One reason is because too many sprouts arise from each one, and these sprouts are apt to crowd each other. The same is true of the tip end or seed end of the tuber. Even when it is cut off, the eyes are so numerous that one secures many weak shoots rather than two or three strong ones. It is ordinarily best to cut the Potatoes 
to two or three eyes, leaving as much tuber as possible with each piece. From seven to eight bushels of Potatoes are required to plant an acre.

For a very early crop in the garden, tubers are sometimes sprouted in the cellar. When the sprouts are 4 to 6 inches high the tubers are earefully planted. It is essential that the sprouts are not broken in the handling. In this practice, also, the tubers are first cut into large pieces, so that they will not dry out too much.

The staple remedy for the Potato bug is Paris green, 1 pound of poison to 150 to 200 gallows of water, with a little lime (see Paris Green). For the blight, spray with Bordeaux mixture, and spray thoroughly. Bordeaux mixture will also keep away the flea beetle to a large extent.

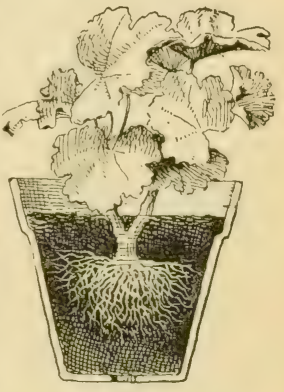

Too deep

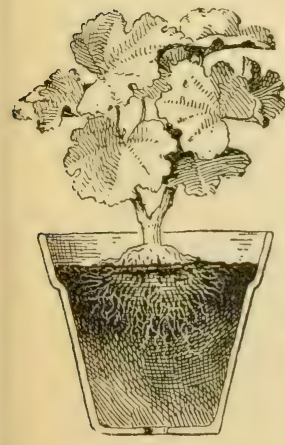

Plant too high

Potato, Sweet. See Sweet Potato.

Potting. The operation of potting a plant, while in itself simple, is very often associated with suecess or failure in the growth of the plant. The first and most common reason of failure is using too large a pot; the second, imperfect drainage; and the third, the poor physical condition of the soil.

A small-rooted cutting or a feeble plant should have a pot only large enough to hold soil sufficient to surround the roots to the extent of 1 or 2 inches. More soil would hold too much moisture, thus excluding the air. As the plants grow and the ball of dirt becomes well eovered with white roots, and before these roots become dark in color, the plant should be repotted, using a pot one size larger and usually 
a little richer soil. This operation should continue until the plant has made the desired growth. If it is desired to

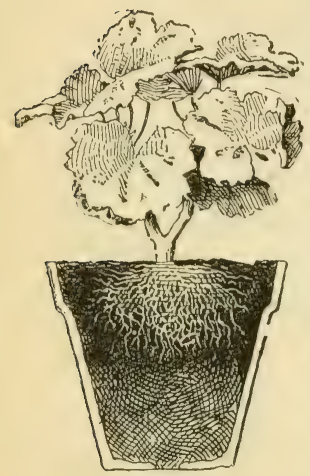

Too full grow a geranium, fuchsia, begonia, or plants of a similar character, large enough for a window plant-say to the height or breadth of two feet,-a 6-inch pot will be large enough, provided the soil is rich enough to continue the growth of the plant while in flower. It often happens that pots of the various sizes are not to hand; and in case the pot is too large, it should have the drainage increased until it will take up as much room in the bottom as the pot is too large. Bear in mind that the soil should not hold free water. After the plant has filled the pot with roots it will often be necessary to supply more food as the soil becomes exhausted. This may

be done by digging out the top soil down to the young, white roots, replacing with new soil in which a little rotted manure, a pinch of bone-meal or other plantfood, has been added. Liquid manure may be used. This liquid manure is made from well rotted cow-, horse-, or sheep-manure thrown into a tub or barrel, covered with water, and allowed to stand until the strength of the manure is soaked out. This liquid should be diluted before using with elear water until it has the color of weak coffee. If used with judgment, nothing will cause a better

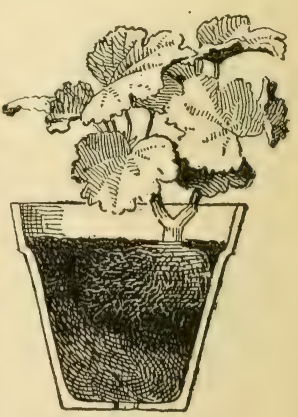

Careless growth or a greater quantity of flowers.

The drainage may consist of any coarse material, such as old broken pots, small stones, pieces of charcoal, and the like, over which should be placed small broken sod or a little 
moss to keep the dirt from washing through and eventually stopping up the crevices through which the excess water should flow.

A safe rule to follow in first potting the majority of house-plants, is to use one-third turf-loam, one-third leafmold or decayed leaves, and one-third sand, thoroughly mixed. Reduce the amount of leaf-mold and sand at successive pottings, adding a little well rotted manure, until, when the plants have been potted in 6 -inch pots, at least fourfifths of the soil is turfy loam. Press the soil firmly in the pot and around the plant. Never fill the pot level full of soil, else the plant cannot be watered.

Prickly Poppies, or ARGEulones, are hardy annuals, with large, bluish striking foliage and yellow flowers. They are easily grown in a warm soil and sunny exposure. Sow the seeds where the plants are to stand. Thin to 12 to 18 inches apart. They grow 2 feet high.

Primulas, or Primroses, are of

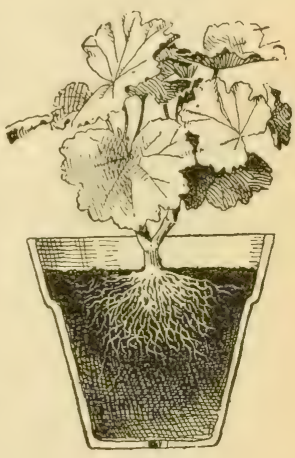

Good ! various kinds. One of them is the Auricula (which see). Others are hardy border plants. The true or English cowslip is one of these; also the plants commonly known as Polyanthus. Hardy Primulas grow 6 to 10 inches high, sending up trusses of yellow and red flowers in early spring. Propagated by division, or by seed sown a year before the plants are wanted. Give them rich, moist soil.

The Primula of the winter-garden is mostly the $P$. Sinensis (Chinese Primrose), grown very extensively by florists as a Christmas plant. With the exception of the full double varieties, it is usually grown from seed. The seed sown in March or April will make large flowering plants by November or December, if the young plants are shifted to larger pots as needed. The seed should be sown on the flat 
surface of the soil, composed of equal parts loam, leaf-mold and sand. The seed should be pressed down lightly and the soil watered carefully to prevent the seed from being washed into the soil. Very fine sphagnum moss may be sifted over the seed, or the box set in a moist place, where the soil will remain wet until the seeds germinate. When the plants are large enough they should be potted separately or pricked out into shallow hoxes. Frequent pottings or transplantings should be given until September, when they

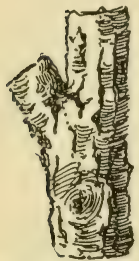

Improper way to make the wound

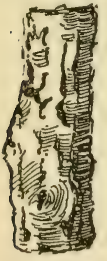

Proper way should be in the pots in which they are to bloom. The two essentials to successful growth through the hot summer are shade and moisture. Height 6 to 8 inches. Bloom in winter and spring.

At present the "baby Primrose" (Primula Forbesi) is popular. It is treated in essentially the same way as the Sinensis. All Primulas are impatient of a dry atmosphere and fluctuating conditions.

Prince's Feather. See Amarantus. Prunes are varieties of plums with firm, meaty flesh, and which readily make dried fruit. Some of the Prunes are commercially grown in the East, but they are sold in the green state as other plums are; and they are adapted to all the uses of other plums. Prunes are cultivated like other plums.

Pruning. There are two general types of inquiry connected with the question of Pruning: First, that which has to do with the healing of the wounds; and second, that which has to do with the shaping of the top and the general welfare of the tree.

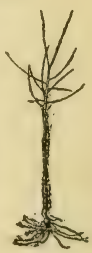

Before

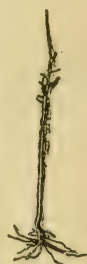

After

When a limb is cut off, it heals by being covered with callus tissue, which grows out from the cambium zone between the bark and wood and rolls over the face of the 
wound. The hard wood itself never heals; that is, the cells do not have the power of making new cells; therefore the old wood is simply covered up, or hermetically sealed as a cap is put on a fruit jar. It is evident, therefore, that no kind of dressing will hasten the healing of this wound. The merit of a dressing is to keep the wound sound and healthy until the callus naturally covers it over. All things considered, the best dressing is probably thick linseed-oil paint.

So far as the wound is concerned, the best time for Pruning is ordinarily in the spring, when the vital activities are beginning; but the season also influences fruit-bearing and wood-mak-

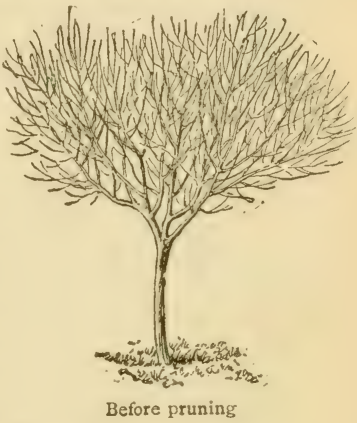
ing, and these questions should be considered. Those wounds heal best which are on strong main limbs, where there is a full flow of nutritious sap. The limb should be cut off so that the wound is parallel with the trunk npon which it sits, and close to it. That is to say, the longer the stub, the less rapid in general is the healing of the wound. It is the custom to eut the limb just outside the bulge at its base; but, in most cases, it is better to cut through this bulge, and to have the wound close to the main trunk.

Heavy Pruning of the top tends to the production of wood; therefore the severe Pruning of orchard trees, following three or four years of neglect, sets the trees into heavy wood-bearing, and makes them more vigorous. Such treatment generally tends away After pruning

from fruit-bearing. This heavy Pruning is usually necessary in neglected orchards, however, to bring trees back 
into shape and to revitalize them; but the best Pruningtreatment of an orchard is to Prune it a little every year.

It should be so Pruned that the tops of the trees will be open, that no two limbs will interfere with each other, and so that the fruit itself will not be so abundant as to overload the tree. Pruning is a means of thinning. In general, Sickle saw it is best to prune orchard trees late in winter or early in spring. It is ordinarily better, however, to leave peaches and other tender fruits until after the buds have swollen, or even after the flowers have fallen, in order that one may determine how much they have been injured by the winter. Grape vines should be Pruned in winter or not later (in New York) than the first of March. If Pruned later than this, they may bleed. The above remarks will apply to other trees as well as to knife. Goes fruits.

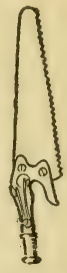

It should be borne in mind that Pruning has two ob-

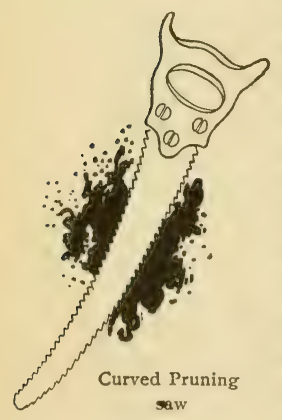
jects: one is to merely trim the tree or to make it assume some designed shape; the other is to make the tree more vigorous or more fruitful, or to make some other change in its character. These ideals are well illustrated in the Pruning of ornamental shrubs. If one wants to have the shrubs sheared into some particular shape, the shearing may be done at almost any time of the year; in fact, it is better to do it two or three times each year in order to keep the trees trim and neat. If, however, the desire is to secure more flowers, the case is a very different one. Some shrubs and trees bear their flowers on the wood of the preceding year. Such, for example, are the early flowering shrubs like lilaes and the snowballs. The flower buds are made the fall before. In this ease, Pruning

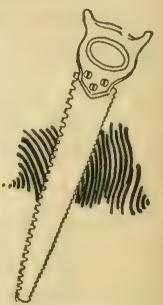

Common double edge saw 
the shrub in winter cuts off the flower buds. The ideal time for Pruning them, therefore, is just after the flowers have passed. The flower buds will form later in the season for the production of the flowers the following spring. Other shrubs, however (particularly those which blossom late in the season), bear on wood of the current year's growth. That is, the clematis blossoms in late summer and fall on wood which grew that same season. The greater the quantity of strong wood which grows in any season, therefore, the greater the quantity of bloom in that

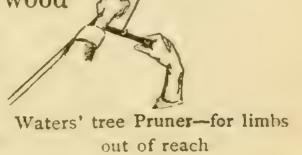
season. With such shrubs, it is well to out of reach

Prune in winter or early spring, and to Prune rather heavily. The abundance of new shoots which arise may be expected to bear flowers later on in the same season.

Following are some shrubs which, for best results in flower-bearing, may be Pruned when dormant (in winter) : camellia, Jackmani type of elematis, cornus, hibiscus (shrubby), hydrangea, many loniceras or honeysuckles, philadelphus or mockorange, some spireas.

Shrubs which may be Pruned when in leaf (just after blooming): lilac, deutzia, weigelas, exochorda, springflowering loniceras, tree peony, flowering almond, some spireas and viburnums, wistaria.

The marginal illustrations show how apple, pear and plum trees may be Pruned when received from the nursery. Cut back the roots to fresh, unbroken wood.

Various kinds of useful tree Pruners are shown "in the margins. See also Seraping.

Pumpkin. See Squash.

An excellent Pruning saw. The blade is on a swivel 
Pyrethrum. The little, low-growing yellowfoliaged Feverfew, called Golden Feather, is used extensively for edging and design beds. Propagated by cuttings, as are geraniums.

The tall-growing species are very fine border plants, being easy to grow and having showy flower's, in colors ranging from white through lilae to crimson. Their flowers appear in June and last a month, when, if the plants are cut down, they will flower again in the fall. The Persian insect powder is made from the dried flower heads of some of these species. Propagated by seed or division. Hardy and fine.

Radishes should be grown quickly in order to have them at their best. They become tough and woody if grown slowly or allowed to stay in the ground too long. A light soil, well enriched, will grow most of the early varieties to table size in from three to five weeks. To have a supply through the early months,

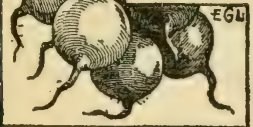

Spring Radishes sowings should be made every two weeks. For summer, the large white or gray varieties are best. The winter varieties may be sown in September, harvested before severe frosts, and stored in sand in a cool cellar. When they are to be used, if thrown into cold water for a short time they will regain their erispness. Sow Radishes thickly in drills, 12 to 18 inches apart. Thin as needed.

\section{Raspberry. Both the red and black Rasp-} berries are essentials of a good garden. A few plants of each will produce a supply of berries for a family through six or eight weeks, provided both early and late varieties are planted. A cool situation, soil that will hold moisture without being wet, and a thorough preparation of the ground, are the conditions necessary to success. The blackcap Raspberries should be set 3 to 4 feet apart, the rows 6 
or 7 feet; the rerl varieties 3 feet apart, the rows 5 feet apart. Spring setting is usually preferable.

As with blackberries and dewberries, Raspberries bear on last year's canes, and these canes bear but once. Therefore cut out the old canes after fruiting, or before the following spring, thus destroying such insects and fungi as may have lodged on them. New canes should have grown in the meantime, 3 to 6 to a hill.

The first year after the plants are set the canes should be pinched back when they reach the height of from 30 to 36 inches. If a very vigorous growth has been made the first season two canes may be left for fruiting, but in the case of weak growth only one cane should be allowed to fruit. In ease of low-growing varieties - those that have been pinched back short-a mulch of straw or grass around the plants at fruiting time will help to hold the moisture, and also serve to keep the fruits clean in case of heavy rains. A Raspberry plantation will last three to five years. The black varieties are propagated by layers, the tip of a cane being laid in the soil in midsummer; by fall the tip

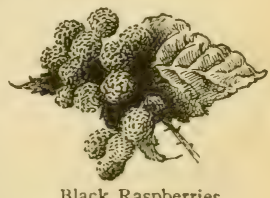

Black Raspberries will have taken root and may be separated. The red varieties are propagated by suckers from the roots. In nurseries both blacks and reds are often propagated by means of root-cuttings.

For red rust, pull out the plant, root and branch, and burn it. Short rotations-fruiting the plants only two or three years - and burning the old canes and trimmings, will do much to keep Raspberry plantations healthy. Spraying will have some effect in combating anthracnose. Raspberries may be bent over to the ground so that the snow will protect them, in severe climates.

Varieties are always changing in favor. Good blackcaps are Gregg, Ohio, and Kansas. Good red and purple sorts are Shaffer, Cuthbert, Loudon, and others. 


\section{Rhododendrons are broad-leaved evergreen} shrubs which require a fibrous or peaty soil and protection from bleak winds and hot suns in winter. It is well to plant them amongst trees for protection. In the North, mulch heavily with leaves in the fall. See that the soil is made fibrous with leaf-mold or other material. Rhododendrons bloom from winter buds: therefore prune just after flowering, if at all.

Rhubarb, or Pie Plant. This is usually propagnted by division of the fleshy roots, small pieces of which will grow if separated from the old, established roots and planted in rich, mellow soil. Poor soil should be made rich by spading out at least 3 feet of the surface, filling with well rotted manure to within 1 foot of the level, throwing in the top soil and setting the roots with the crowns 4 inches below the surface, firming them with the feet. The stalks should not be cut for use until the second year, but the first, as well as the succeeding falls, some coarse manure should be thrown over the crowns, to be forked or spaded in lightly when spring opens.

In growing seedling Rhubarb, the seed may be sown in a coldframe in March or April, protected from freezing, and in two months the plants will be ready to set in rows, 12 inches apart. Give the plants good cultivation, and the following spring they may be set in a permanent place. At this time the plants should be set in well prepared ground, at a distance each way of from 4 to 5 feet, and treated as those set with pieces of roots.

If given good eare and well manured, the plants will live for years and yield abundantly. Two dozen good roots will supply a large family.

\section{Ricinus. See Castor Oil Plant.}

Roses. It seems to be the first desire of the home maker, when he considers the planting of his grounds, to set out Roses. As a matter of fact, it should be one of 
the last things to do. Roses are essentially flower garden subjects, rather than lawn subjects. That is to say, the flowers are their chief beauty. They have very little to commend them in the way of foliage or habit, and they are inveterately attacked by insects and sometimes by fungi. In order to get the best results with Roses, they should be placed in a bed by themselves, where they can be tilled and pruned and well taken care of ; and they should be grown as specimen plants, as other flower garden plants are. The ordinary garden Roses should rarely be grown in mixed borders of shrubbery.

If it is desired to have Roses in mixed borders, then the single and informal types should be chosen. The best of all these is Rosa rugosa. This has not only attractive flowers through the greater part of the season, but it also has very interesting foliage and a striking habit. The great profusion of bristles and spines gives it an individual and strong character. Even without the flowers, it is valuable to add character and cast to a foliage mass. The foliage is not attacked by insects or fungi, but remains green and glossy throughout the year. The fruit is also very large and showy, and persists on

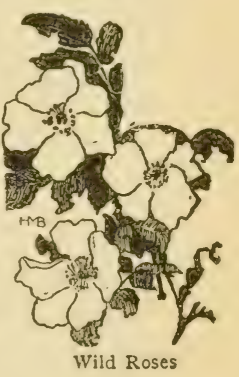
bushes well through the winter. Some of the wild Roses are also very excellent for mixing into foliage masses, but, as a rule, their foliage characteristics are rather weak, and they are liable to be attacked by thrips.

Probably the most extensively grown class of Roses is the Remontant or Hybrid Perpetual. These, while not constant bloomers, are so easy of culture and give such good returns for the care and labor, that their popularity grows each year. The list of good varieties is very extensive, and while a few, such as General Jacqueminot, Paul Neyron, Marshall P. Wilder, Victor Verdier, Anne de Diesbach, and Ulrich Brunner, are seen in most collections, one 
eannot go far wrong in planting any of the list. Two of the Hybrid Chinese Roses may go with the Remontants, having the same season of bloom and being about as hardy. These are Magna Charta and Mme. Plantier.

The next group in point of hardiness, and superior to the foregoing in continuity of bloom, are the Hybrid Noisettes, such as Coquette des Alpes, Coquette des Blanches, and Elise Boelle. The blooms of these are white, often tinted with pink, very double and fragrant.

The Hybrid Tea section, containing Duchess of Albany, La France, Meteor and Wootton, is very fine. These are not hardy in the North, but if protected by a frame, or if grown in pots, wintered in a pit, no class of Roses will give more general satisfaction.

The Bourbon section contains three of the best bedding Roses,-Apolline, Hermosa, and Souvenir de la .Malmaison. These will bloom continually through the fall months until severe frost, and with a little protection will prove hardy.

The Bengal Roses, of which Agrippina is a leading variety, bloom through a long season, but are not hardy, and should be protected in a pit. They also make very fine pot-plants.

The Moss Roses are well known, and are desirable in a general collection.

The little Polyantha Roses, with Cecile Brunner and Clothilde Soupert as two of the best, are always attractive, either when planted out or grown in pots.

The climbing Roses, which bloom later in the season than the Remontants, are very useful as pillar and screen plants. The old Queen of the Prairies and Baltimore Belle are still in favor. A newer and better variety is the Crimson Rambler.

The Tea Roses have proved more disappointing to the amateur than any other. No one can resist the temptation to try to have a fer of these highly perfumed, richly colored 
Roses, but unless one has a conservatory or an especially favored location in the house, the results do not pay for the trouble. A few blooms may be had outdoors with plants set in the spring, but on the approach of winter they must be taken up and protected by more seeure means than is taken with other Roses. If potted and grown in the house, they are the first plants to become infested with red spider; or if grown cool enough to escape that pest, they will be subject to an attack of mildew. Still, the results are well worth striving for, and a few persons will find the proper conditions; hut the Tea Rose is essentially a florist's flower.

All Roses are heavy feeders and require rich, moist soil. A clay soil, if well enriched and having perfect drainage, is ideal. Pruning should be carefully done, preferably in the spring. All weak growth should be eut out and the balance well cut back. The flowers of all Roses, except the Yellow Persian and the

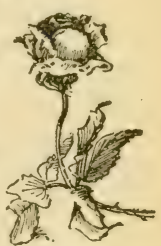

Hybrid Tea Rose Harrison's Yellow, being borne on the new wood, the bushes should be cut back half or more of their growth.

In the majority of cases, Roses on their own roots will prove more satisfactory than budded stock. On own-rooted stock, the suckers or shoots from below the surface of the soil will be of the same kind, whereas with budded Roses there is danger of the stock (usually Manetti or Dog Rose) starting into growth and, not being discovered, outgrowing the bud, taking possession, and finally killing out the weaker growth. Still, if the plants are set deep enough to prevent adventitious buds of the stock from starting, there is no question that finer Roses may be grown than from plants on their own roots.

The summer insects that trouble the Rose are best treated by a forceful spray of clear water. This should be done early in the day and again at evening. Those having city water or good spray pumps will find this an easy method of keeping Rose pests in check. Those without 
these facilities may use whale oil soap, fir-tree oil, good soap suds, or Persian insect powder.

Roses in Winter. Although the growing of Roses under glass is a business which would better be left to florists, as already said, the following advice may be useful to those who have conservatories:

When growing forcing Roses for winter flowers, florists usually provide raised beds, in the best-lighted houses they have. The bottom of the bed or bench is left with cracks between the boards for drainage; the cracks are covered with inverted strips of sod, and the bench is then covered with four or five inches of fresh, fibrous loam. This is made from rotted sods, with decayed manure incorporated at the rate of about one part in four. Sod from any drained pasture-land makes good soil. The plants are set on the bed in the spring or early summer, from 12 to 18 inches apart, and are grown there all summer.

During the winter they are kept at a temperature of $58^{\circ}$ to $60^{\circ}$ at night, and from $5^{\circ}$ to $10^{\circ}$ warmer during the day. The heating pipes are often run under the benches, not because the Rose likes bottom heat, but to economize space and to assist in drying out the beds in case of their becoming too wet. The greatest care is required in watering, in guarding the temperature and in ventilation. Draughts result in checks to the growth and in mildewed foliage.

Iryness of the air, especially from fire heat, is followed by the appearance of the minute red spider on the leaves. The aphis, or green plant louse, appears under all conditions, and must be kept down by syringing with tobaceo-tea or fumigation with tobaceo stems.

An effectual and preferable method now employed for destroying the aphis is to fumigate with the vapor arising from a pan containing a gallon of water and a pint of strong extract of tobacco. To generate the vapor, a piece of redhot iron is dropped into the pan. From one to three or four pans are required to a house, according to its size. For the 
red spider, the chief means of control is syringing with either clear or soapy water. If the plants are intelligently ventilated and given, at all times, as much fresh air as possible, the red spider is less likely to appear. For mildew, which is easily recognized by its white, powdery appearance on the foliage, accompanied with more or less distortion of the leaves, the remedy is sulfur in some form or other. The flowers of sulfur may be dusted thinly over the foliage; enough merely to slightly whiten the foliage is sufficient. It may be dusted on from the hand in a broadeast way, or applied with a powder-bellows, which is a better and less wasteful method. Again, a paint composed of sulfur and linseed oil may be applied to a portion of one of the steam or hot-water heating pipes. The fumes arising from this are not agreeable to breathe, but fatal to mildew. Again, a little sulfur may be sprinkled here and there on the cooler parts of the greenhouse flue. Under no circumstances,

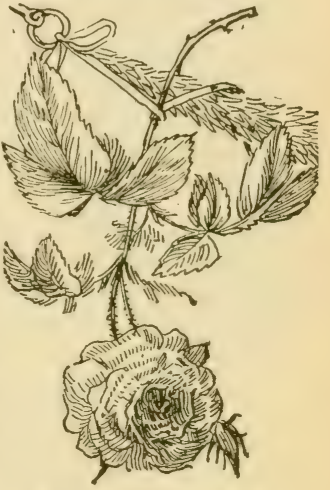

A Hybrid Perpetual Rose however, ignite any sulfur in a greenhouse. The vapor of burning sulfur is death to plants.

Propagation.-The writer has known women who could root Roses with the greatest ease. They would simply break off a branch of the Rose, insert it in the flower-bed, cover it with a bell-jar, and in a few weeks they would have a strong plant. Again they would resort to layering; in which case a branch, notehed half way through on the lower side, was bent to the ground and pegged down so that the notched portion was covered with a few inches of soil. The layered spot was watered from time to time. After three or four weeks roots were sent forth from the notch and the branch or buds began to grow, when it was known that the layer had formed roots. 
Several year's ago a friend took a cheese-box, filled it with sharp sand to the brim, supported it in a tub of water so that the lower half inch of the box was immersed. The

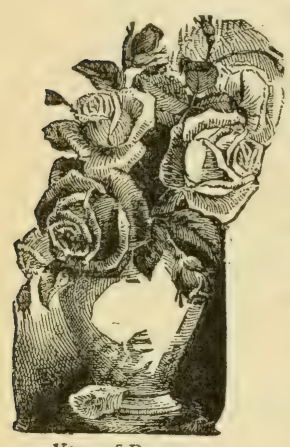

Vase of Roses sand was packed down, sprinkled, and singlejoint Rose cuttings, with a bud and a leaf near the top, were inserted almost their whole length in the sand. This was in July, a hot month, when it is usually difficult to root any kind of eutting; moreover, the box stood on a southern slope, facing the hot sun, without a particle of shade. The only attention given the box was to keep the water high enough in the tub to touch the bottom of the cheese-box. In about three weeks he took out three or four dozen of as nicely rooted cuttings as could have been grown in the greenhouse.

The "saucer system," in which cuttings are inserted in wet sand contained in a saucer an inch or two deep, to be exposed at all times to the full sunshine, is of a similar nature. The essentials are, to give the cuttings the "full sun" and to keep the sand saturated with water.

Whatever method is used, if euttings are to be transplanted after rooting, it is important to pot them off in small pots as soon as they have a cluster of roots one-half inch or an inch long. Leaving them too long in the sand weakens the cutting.

Sage is a perennial, but best results are secured by resowing every two or three years. Give a warm, rich soil. Hardy.

Salpiglossis. Very fine half-hardy annuals. The flowers, which are borne in profusion, are of many colors, and rival in inarkings most other annuals. The flowers are short-lived if left on the plant, but will hold well if cut and placed in water. Seed should be sown in 
heat in February or March, the seedlings grown along until May, when they may be planted out. It is usually best to pinch out the centers of the plants at this time to cause them to branch.

Salsify, ol' VEGETABLE Oyster. Salsify is one of the best of winter and early spring vegetables, and should be grown in every garden. It may be cooked in several different ways. The seed should be sown as early in the spring as possible. Handle the same as parsnips in every way. The roots, like parsnips, are the better for the winter freeze, but part

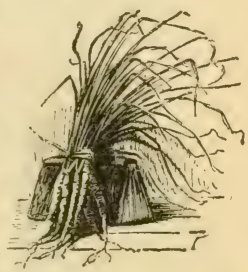

Salsify of the erop should be dug in the fall, and stored in soil or moss in a cellar for winter use.

Salvia. The ScARLET SALviA (or SAGE) is a well known tender perennial, blooming late ir the fall and making a fine effect in beds or borders. It is easily transplanted, and large plants removed to the house continue in bloom for some time. The blue and white species are both desirable summer-flowering plants, and the lowgrowing Silver Leaf Sage is well adapted for elging. Propagated from seed, cuttings, or by division. Height 2 to 3 feet.

San José Scale has now become a widespread pest. It has been introduced into the eastern states from the Pacific slope. It is a minute scale Salvia insect the size of a small pinhead, shield-shaped, coccinea with a raised center. There are various native and comparatively harmless scales which look very much like it, and an expert is usually needed to distinguish them. The San José Seale can usually be distinguished, however, by its very serious results. In favorable seasons it spreads with enormous rapidity, covering the branches of many kinds of plants, sapping their juices, and either killing or reducing them to such a low state of vitality as to render 
them useless; or they are killed by the winter. The indications are that the scale will never be so serious in the moist, cool climates of the northeastern states as it is in the hotter and drier climates of the West. It has been found by careful experiments that it can be killed by a spray of kerosene and water (see Kerosene) in a proportion of one part of kerosene to four or five of water. This material is applied with a mechanical pump mixer, and the application should be made on a sunny day so that evaporation soon takes place. Spraying with kerosene in cloudy weather is very likely to result in injury to the plants. Some experimenters have found crude petroleum to be a specific for the San José Scale.

It is not to be expected that the San José Scale can be exterminated any more than the tent caterpillar or apple scab can. It follows, therefore, that wo should spray for the San José Scale as we do for other pests. It is such a serious pest, however, that the state or province should take measures to hold it in check. Some system of inspection should be inaugurated, and it is probably best that nursery stock be fumigated with hydrocyanic gas before it is sold. This gas is exceedingly poisonous, however, and should never be handled by the inexperienced. Whenever it is used, it should be under the control of experts. Plants or plantations which are badly infested with the scale would better be destroyed.

Scabiosa. Mourning Bride. A useful annual, producing a profusion of bloom through the greater part of the summer if not allowed to go to seed. The flowers range in color from white to rich purple, are borne on long stems, and are very lasting. The seed may be sown where the plants are wanted, or to hasten the season of bloom may be sown in boxes in February and grown along to be planted out in April.

Scarlet Runner. One of the pole or running 
beans (Phaseolus multiflorus). It is a great favorite with people from the Old World, especially English and Germans. This bean is used either as an ornamental vine for porches or trellises, or as a screen to hide unsightly objects. The red flowers are very showy, either on the plant or in bouquets. The green pods are excellent as string beans, and the dried beans are of superior quality. Seed should not be sown until the ground has become thoroughly warm; or the plants may be started in the house.

Scraping of trees is rarely to be advised, except in fruit plantations. The old and hanging bark on apple and pear trees may be taken off in order to destroy the hiding places of insects and the breeding places of fungi, and also to make the plantation look more neat and kempt. Only the loose outer bark should be removed, however. Trees should not be scraped to the quick. If there is moss on trees, it can be destroyed readily by a spray of Bordeaux mixture.

A large part of the beauty of an ornamental tree lies in its characteristic bark, and it is very rare that such trees should be scraped.

Screens. See Windbreak.

Screw Pine. See Pandanus.

Sea-Kale shoots are very highly prized as a delicacy when blanched. The seed should be sown in a hotbed early in the spring, plants transplanted to the garden when from 2 to 3 inches high, and given high eultivation through the season, being covered with litter on the approach of winter. The young stalks are blanched early the following spring by covering with large pots or boxes, or by banking with sand or other clean material. The Dwarf Green Scotch, Dwarf Brown, and Siberian are among the leading varieties. Sea-kale is eaten much as asparagus is. Highly prized by those who know it.

Sea-Kale is also propagated by euttings of the roots 4 or 
5 inches long, planted directly in the soil in spring. The plant is perennial, and the early shoots may be bleached year after year.

Seed Sowing. The general rule in sowing seeds is to cover them twice or three times their thickness. This rule will apply to the majority of seeds, but in many plants of a naturally short season of bloom or growth, an instance of which is the sweet pea, it may be advisable to sow the seed deeper, that the roots may have sufficient moisture and be in a cool temperature through the hot summer months. Also, in sowing very minute seed, as tobacco, petunia, begonia, and others of like size, care should be taken to have them only under the surface of the soil,--simply pressed down with a smooth surface or allowed to settle into the soil with the soaking in of the water. The soil for all seeds should be loose and porous, in order to allow the excessive moisture to escape and the warmth to penetrate, but should be firmed directly over the seeds to induce an upward flow of moisture. One of the most common mistakes in sowing seed is in sowing all kinds at the same time without regard to the season, thus causing a failure with some, while others grow freely. All tender seed should be sown only when the ground has become thoroughly warm, while seeds of the so-called hardy plants may be sown as early in the spring as the ground is fit to work. A few kinds of seed are the better for soaking, especially such as for some reason have been delayed in sowing. Sweet pea seed is benefited by soaking if not put into the ground until the soil is warm. Seed of canna, moonflower and others with hard shells may be scraped until the outer shell is pierced or is very thin.

It is generally better to buy garden seeds than to grow them, for those who make a business of seed-growing become expert in the cultivation and selection of the plants.

Seeds of most plants should be kept dry and 
also rather cool. It is always better to rely upon fresh seeds. Test them in boxes in the house, if possible, before planting them in the open. If beans, peas, corn or other Seeds become buggy, pour a little bisulfide of carbon (very inflammable) into them. The material will not injure the Seeds even if poured on them. It soon evaporates. A teaspoonful will kill the inseets in four quarts of Seeds, if the receptacle is tight.

Most tree Seeds should be kept moist until planted. They are usually buried or kept in sand.

Sensitive Plant (Mimosa). This curious plant is often grown for the amusement it affords by its habit of closing its leaves and dropping the leaf-stalk whenever the plant is touched. Seed should be sown in heat early in the season, and the plants grown in pots or a protected border. The seed is sold by all seedsmen. The plant grows readily in a temperature suited to beans. It will not stand frost. The young plants are usually the most sensitive.

Shade Trees. The best Shade Trees are usually those which are native to the particular region, since they are hardy and adapted to the soil and other conditions. Elms, maples, basswoods, and the like, are nearly always reliable. In regions in which there are serious insect enemies or fungous diseases, the trees which are most likely to be attacked may be omitted. For instance, in parts of the East the elm leaf beetle is a very serious pest; and it is a good plan in such places to plant other trees than elms. Amongst the best exotic trees for shade in the northern parts of the country are the Norway maple, European lindens, horse chestnut, and the European species of elm. Trees for shade should ordinarily be given sufficient room that they may develop into full size and symmetrical heads. The trees may be planted as close as 10 or 15 feet apart for temporary effect; but as soon as they begin to erowd they should be thinned. 


\section{Shelter-belts. See Windbreak.}

\section{Shrubbery. Shrubs have two kinds of values} or uses: first, they are useful for their own sakes or as individual specimens; and second, for use in the making of foliage masses or groups. Ordinarily they are used only for the former purpose in home grounds; but their greatest use is, nevertheless, in heavy masses about the borders of the place or in the angles of the building. That is to say, they should contribute to the general design of the place or to its pictorial effect. If they are planted in Shrubberies or masses, the flowers are still as interesting and as showy as they are when the bushes are planted alone. In fact, the flowers usually show to better advantage, since they have a heavy background of foliage. In the Shrubbery mass the bushes are more easily cared for than when they are scattered as single specimens over the lawn. The single specimen which is irregular, or ragged, or untidy, is an undesirable object; but such a specimen may contribute an indispensable part to the border mass. In the border they do not need the attention to pruning that they do in the lawn. The main part of the Shrubbery mass should be made of the stronger, larger growing and coarser Shrubs; and the more delicate ones, or those with highly colored leaves or showy flowers, may be placed near the inner edge of the plantation. Shrubs which are valued chiefly for their flowers or showy foliage, as, for example, the Hydrangea paniculata, may be planted just in front of a bold Shrubbery mass, so that they will have a background to show off their beauties. Further directions for the layout of the grounds will be found under the articles Lawns and Borders.

It is ordinarily best to plow or spade the entire area in which the Shrubs are to be set. For a year or two the ground should be tilled between the Shrubs, either by horse tools or by hoes and rakes. If the place looks bare, seeds of 
quick-growing flowers may be scattered about the edges of the mass. The larger Shrubs, like lilaes and syringas, may be set about 4 feet apart; but the smaller ones should be set about 2 feet apart if it is desired to secure an immediate effect. If after a few years the mass becomes too erowded, some of the specimens may be removed. Throw the Shrubs into an irregular plantation, not in rows, and make the inner edge of the mass more or less undulating and broken. It is a good practice to mulch the plantation each fall with light manure, leaf-mold or other material. Even though the Shrubs are perfectly hardy, this mulch greatly improves the land and promotes growth. After the Shrub borders have become two or three years old, the drifting leaves of fall will be eaught therein and will be held as a mulch. It is often advisable not to remove these leaves, but to allow them to remain year after year, where they make a fine covering of leaf-mold. When the Shrubs are first planted, they are headed back one-half or more; but after they are established they are not to be pruned, but allowed to take their own way, and after a few years the outermost ones will droop and meet the greensward.

Good Shrubs are numerous. Some of the best are those to be found in woods and along roadsides. They are hardy. Of Shrubs which are generally adaptable for the North, the following are excellent:

Barberries.

Box.

Burning Bush, or Euonymus.

Bush Honeysuckles.

Bush Willows.

Caryopteris, blooming in August and September. Cotoneasters.

Desmodiums, or Lespedezas, blooming in fall.

Dwarf Sumac. Rhus copallina.

Elders. Native species are excellent.

Exochorda, with profuse white bloom in spring. 
Flowering Almond.

Flowering Crabs.

Flowering Currants.

Forsythias, or Golden Bells.

Fringe Tree, or Chionanthus.

Hawthorns.

Hydrangeas.

Indian Currant. Symphoricarpos vulgaris .

Japanese Quince.

Kerria, or Corchorus.

Lilaes.

Mock Orange, or Philadelphus.

New Jersey Tea, or Ceanothus.

Osiers, or Dogwoods.

Privet.

Rose Acacia.

Roses (see Roses).

Smoke Tree.

Snowballs. The Japanese is preferable.

Snowberry. Symphoricarpos racemosus.

Spireas of many kinds.

Viburnums of many kinds.

Weigelas.

White Alder. Clethra alnifolia.

Witch Hazel. Blooms on the eve of winter.

Xanthoceras sorbifolia.

Silene, or Catchfly. Some of the Silenes are hardy annuals of very easy culture. Sow seeds where the plants are to stand; or, if early results are desired, seeds may be started in boxes. The plants thrive in any garden soil, even if it is not very rich. Colors red, or sometimes running to white. One foot. Let plants stand 6 to 10 inches apart.

Smilax of the florists is closely allied to asparagus. While it cannot be recommended for house cul- 
ture, the ease with which it may be grown and the uses to which the festoons of leaves may be put, entitle it to a place in the conservatory or greenhouse. Seed sown in pots or boxes in January or February, the plants shifted as needed until planted on the bench in August, will grow fine strings of green by the holidays. The plants should be set on low benches, giving as much room as possible overhead. Green-colored strings should he used for the vines to climb on, the vines frequently syringed to keep down the red spider, which is very destructive to this plant, and liquid manure given as the vines grow. The soil should eontain a good proportion of sand and be enriched with well-rotted manure. After the first strings are eut, a second growth fully as good as the first may be had by cleaning up the plants and top-dressing the soil with rotted manure. Slightly shading the house through Angust will add to the color of the leaves. The odor from a vine of Smilax thickly covered with the small flower's is very agreeable.

Snapdragon, or ANTiRRhinum. An old garden favorite, flowering freely through a long season. The dwarf strain is well adapted for bedding or borders. Any light soil, well enriched with rotted manure, will grow Snapdragons to perfection. Distinct varieties should be propagated by cuttings, as they do not come true from seed. Sow seed early in the spring.

Although bloom may be obtained the first year, late sown plants sometimes persist over winter and bloom early in the spring. Snapdragons make good window plants.

Snowdrop (Galanthus). This is one of the earliest flowers of spring, always welcome. It should be planted in the edge of the border. The bulbs may be planted in October in any good border soil and left undisturbed for years; or they may be potted at that time, and after forming roots be gently forced into bloom in winter.

Snowflake (Leucoium). Culture same as for Snowdrop. 
Sodding. In general, the best way to secure a lawn is by the sowing of seed (see Lawn), since it is the least expensive way. For small areas, and along the sides of walks and drives, sods may be used. The results are quicker. Unless the sod is of the right kind, however, and very carefully laid, the results are not so good as with seed.

The sod which is best adapted to the Sodding of lawns is that which comes from an old, closely grazed pasture. Sod from a sheep pasture is supposed to be best. Such sod has been so closely grazed that it has made a very dense mat of roots, and all the weeds have been de-

ground rich. The sod should be cut in very thin strips.

It should not be more than an inch and one-half or two inches in thickness. If it is thicker than that, it is heavy and bulky to handle, and is not so easily laid. Ordinarily, the sod is eut in strips ten inches or a foot wide. A board is laid on the sod and the strip is cut along either side of it with a sod cutter or a sharp spade. Two men then roll up the sod. One stands on the strip of sod with his face toward the man who, with the spade, cuts it loose beneath. As it is cut loose, the man on the strip rolls the sod so that the upper surface is on the inside of the roll. Strips longer than ten or twelve feet make rolls which are too heavy to handle with ease.

The soil upon which the sod is to be placed should be very loose, so that the sod can be pounded down firmly. Some heavy pounder should be used, as a block of wood.

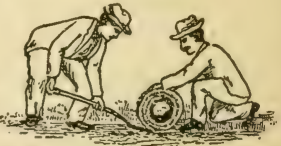

Cutting sod It is usually impossible to pound down sod with the back of a spade sufficiently firm unless the soil is very loose. The sod should be pounded until the top is about level with the surrounding soil. This insures contact with the soil beneath, so that there are no air spaces and no likelihood of drying out. Sod pounded down as firmly as this should 
grow very readily. If a sod edging is laid along walks and drives, it should be pounded down an inch or more lower than the surrounding loose land which is seeded, because the loose land will finally settle; otherwise the sod border is likely to be higher than adjacent land after a year or two.

If there are uneven places on the sodded area, these depressions can be filled in with very loose, fine soil; and the grass will grow through it. In dry weather, a sodded area may be mulched with a half inch of fine loam to protect it.

Soils. Soils are of many kinds. The classification of soils depends upon one's point of view. Gardeners ordinarily call a good, friable, dark-colored, rich Soil a garden loam. No Soil is so good that it cannot be improved. It is improved in two general ways: by tilling (see Tillage), and by the application of various substances.

In considering the improvement of lands by the application of foreign substances, two distinct things are to be considered: the improvement of the physical texture, or tilth, of the Soil; the increasing of its plant-food. These are coürdinate objects. In some cases one may be of prime importance, and in another case the other may be more necessary. Lands which have a fair store of available plantfood may be unproductive. Such lands may be very greatly benefited by stable manure, even though that manure may have lost a large part of fertility by being baptized under the eaves of the barn. If plant-food alone is needed, then some concentrated or commercial fertilizer may be the best thing to apply. In most cases the main or chief amelioration of the land is to be wrought by tillage, stable manures, mulches, green crops, and the like; if special results are desired, commercial fertilizers may be added more or less liberally, as the case demands (see Manures, Fertilizers).

The top-dressing of Soils is often very beneficial because it tends to prevent the escape of moisture, and often improves the physical texture. If the material contains plantfood, the land will also be directly enriched. The trim- 
mings from lawns may be a distinct protection to lands if allowed to remain (see Lawns); and the leaves which blow into elumps of shrubbery may often be allowed to remain with good results. However, if the leaves become too thick year after year, they tend to induce a surface rooting of the shrubs. This, however, may be no disadvantage unless the mulch were finally to be removed. One of the very best top-dressings for borders and shrubbery is spent tan bark, since it does not pile up on the ground, but tends to work into it. Well-rotted sawdust often has the same effect. These materials are much used by gardeners, when they can be had, since they can be raked into the soil in the spring, and need not be removed.

\section{Solidago. See Goldenrod.}

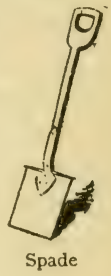

Spades and Shovels must be a part of every garden equipment. The common and most useful forms are shown in the euts, but long-handled tools are more useful for the loading of earth, the making of ditches, the

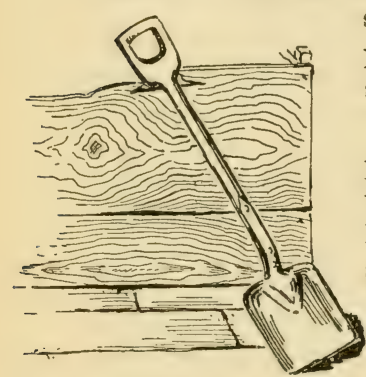

Shovel spreading of mulches, and the like. It pays to buy the steel tools, with strongly strapped handles.

Spearmint is prized by many people as a seasoning, particularly for the Thanksgiving and holiday cookery. It is a perennial and perfectly hardy, and will live in the open garden year after year. If a supply of the fresh herbage is wanted in winter, remove sods of it to the house six weeks before wanted. Place the sods in boxes, and treat as for house plants. The plants should have been frosted and become perfectly dormant before removal.

Spinach. Probably the most extensively grown 
early spring vegetable, being in great demand as greens. The earliest crop that finds its way to market is gathered from seed sown in September or October, often protected by frames or other means through the severe winter, and eut soon after growth starts in early spring. Even as far north as New York Spinach may stand over winter without protection. Spinach is forced by placing sash over the frames in February and March, protecting the young leaves from severe freezing by mats or straw thrown over the frames. Seed may be sown in early spring for a succession; later in the season seed of the New Zealand Summer Spinach may be sown, and this will grow through the heat of the summer and yield a fine quality of leaves. The seed of this [kind being very hard, should be scalded and allowed to soak a few hours before sowing. This seed is usually sown in hills about three feet apart, sowing four to six seed in each hill. The spring and winter Spinach should be sown in drills 12 to 14 inches apart, one ounce being sufficient for 100 feet of drill. Remember that common Spinach is a cool-weather (fall and spring) crop.

Spraying. Of late years Spraying has come to be one of the most important of all horticultural operations. Most kinds of injurious fungi and insects can be combated by a water spray in which various poisons or injurious substances are contained. There are two general classes of Spraying material : first, fungicides, or those which are used for the control of fungi or plant diseases; second, insecticides, or those which are used for the control of insect enemies.

The fungicides usually contain copper or sulfur, or both. The most popular and generally useful fungicide is the Bordeaux mixture (which see). It should be borne in mind that most injurious fungi work on the interior of the leaf or stem, and only the spore-bearing parts come to the surface. It is therefore very important that. Spraying with fungicides be done very early in order to prevent the fungus from get- 
ting a hold. It is much better to Spray once very thoroughly than to Spray a half dozen times carelessly. It is important that the entire surface of the foliage or stems be covered with the material in order to prevent the access of the fungi.

Of insecticides, there are two general types: those which kill by external contact and are applied to plant lice, scale insects, and all other insects which suck their food; and the poisonous compounds which are used for the chewing insects, as all the tribes of worms and beetles. Of the former class, the most important material is kerosene in various forms (which see). Of the latter kind is Paris green (which see). For insects, Spray just as soon as the attack is evident. Paris green and Bordeaux mixture may be used together.

The best pump for Spraying is the one which throws the stream the greatest distance with the least amount of liquid, and the best nozzle is that which distributes the material most finely and evenly. For Spraying plants close at hand, the Vermorel nozzle is now the most popular. If it is desired to reach the tops of large trees, some other nozzle should be used, as the MeGowen, Boss, or other types. Every outfit should have two or three kinds of nozzles for different kinds of work. Get a pump with much power.

Spray thoroughly. The general rule is to spray the entire plant until the material begins to drip, at which time it may be supposed that the plant is covered completely. When and how often one should Spray, and what material he should use, will depend entirely upon the difficulty which he is endeavoring to combat. Most fruit trees should be Sprayed before they bloom and again just afterwards. Sometimes they will need Spraying again.

\section{Sprekelia. Culture of Amaryllis.}

Squash. The time of planting, method of preparing the hills and after culture are the same as for cucum- 
bers and melons (which see), except that for the Early Bush varieties the hills should be 4 or 5 feet apart, and for the later running varieties from 6 to 8 feet apart. From eight to ten seeds should be planted in each hill, thinning to four plants after danger from bugs is over. Of the early Squashes, one ounce of seed will plant fifty hills; of the later varieties, one ounce will plant but eighteen to twenty hills. For winter

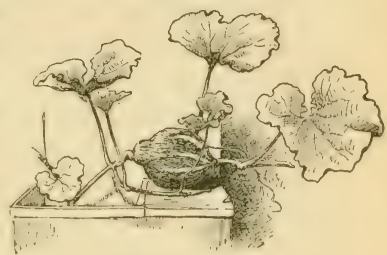

Hubbard Squash use, varicties of the Hubluard type are best. For summer use, the Crooknecks and Scallop Squashes are popular. In growing winter Squashes in a northern climate, it is essen-

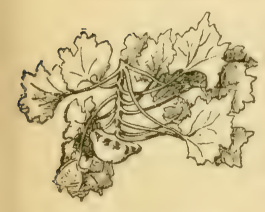

Scallop or Patty-pan Summer Squash tial that the plants start off quickly and vigorously: a little chemical fertilizer will help.

Pumpkins are grown the same as Squashes.

Squills (Scill $\iota)$. Blue Bell. Wild Hyacinth. Well-known bulbous plants, most of them hardy. They plant well with snowdrops and crocus, flowering at the same time, but continuing longer in bloom. The colors are red, pink, blue or white. The blue varieties have very fine shades of color. Should be planted in October and remain undisturbed.

Stocks. The Ten-weeks and the biemnial or Brompton Stocks, are found in nearly all old-fashioned gardens. Most gardens are thought to be incomplete without Stocks, and the use of the biennial flowering species as house plants is increasing. The Ten-weeks Stock is usually grown from seed sown in hotbed or boxes in March. The seedlings are transplanted several times previous to being planted out in early May. At each transplanting the soil should be made a little richer. The double flowers will be more numerous when the soil is rich. 
The biennial species should be sown the season previous to that in which flowers are wanted, the plants wintered over in a cool house, and grown on the following spring. They may bo planted out through the summer and lifted into pots in August or September for winter flowering. These may be increased by cuttings taken from the side shoots; but the sowing of seed is a surer method, and unless an extra fine variety is to be saved, it would be the best one to pursue. Height 10 to 15 inches.

Storing. The principles which are involved in the Storing of perishable products, as fruits and vegetables, differ with the different commodities. All the root crops, and most fruits, need to be kept in a cool, moist and uniform temperature if they are to be preserved a great length of time. Squashes, sweet potatoes, and some other things, need to be kept in an intermediate and what might be called a high temperature; and the atmosphere should be drier than for most other products. The low temperature has the effect of arresting decomposition and the work of fungi and bacteria. The moist atmosphere has the effect of preventing too great evaporation and the consequent shriveling. In the Storing of any commodity, it is very important to see that the produet is in proper condition for keeping. Discard all specimens which are bruised or which are likely to decay. Much of the decay of fruits and vegetables in Storage is not the fault of the Storage, but is really the work of diseases with which the materials are infested before they are put into Storage. For example, if potatoes and cabbages are affected with the rot, it is practically impossible to keep them any length of time.

Apples, winter pears, and all roots, should be kept at a temperature somewhat near the freezing point. It should not raise above $40^{\circ} \mathrm{F}$ ahr. for best results. Apples can even be kept at one or two degrees below the freezing point if the temperature is kept uniform. Cellars in which there are heaters are likely to be too dry and the temperature too high. 
In such cases it is well to keep fresh vegetables and fruits in tight receptacles, and pack the roots in sand or moss in order to prevent shriveling. In these places, apples usually keep better if headed up in barrels than if kept on racks or shelves. In moist and cool cellars, howerer, it is preferable for the home supply to place them on shelves, not piling: them more than five or six inches deep, for then they can be sorted over as occasion requires. In case of fruits, be sure that the specimens are not over-ripe when placed in storage. If apples are allowed to lie in the sun for a few days without being packed, they will ripen so much that it is very difficult to keep them.

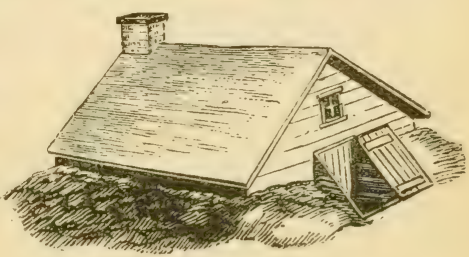

A good out-door cellar

Cabbages should be kept at a low and uniform temperature, and water should be drained away from them. They are Stored in many ways in the field, but success depends so much upon the season, particular variety, ripeness, and the freedom from injuries by fungi and insects, that uniform results are rarely secured by any method. The best results are to be expected when they can be kept in a house which is built for the purpose, in which the temperature can be kept uniform and the air fairly moist. When Stored out of doors, they are likely to freeze and thaw alternately; and if the water runs into the heads, mischief is likely to result. Sometimes they are easily Stored by being piled into a conical heap on well-drained soil and covered with dry straw, and the straw covered with boards. It does not matter if they are frosted, provided they do not thaw out frequently. Sometimes cabbages are laid head down in a shallow furrow plowed in well-drained land, and over them is thrown straw, the stumps being allowed to project through the cover. It is only in winters of rather uniform temperature that good results al'e to be expected from such methods. 
In the Storing of all things, especially those which have soft and green matter, as cabbages, it is well to provide for the heating of the produce. If the things are buried out of doors, it is important to put on a very light cover at first so that the heat may escape. Cover them gradually as the cold weather comes on. This is important with all vegetables that are placed in pits, as potatoes, beets and the like. If covered deeply at once, they are likely to heat and rot. All pits made out of doors should be on well-drained and preferably sandy land.

When vegetables are wanted at intervals during the winter from pits, it is well to make compartment pits, each compartment holding a wagon load or whatever quantity will be likely to be wanted at each time. These pits are sunk in well-drained land, and between each of the two pits is left a wall of earth about a foot thick. One pit can then be emptied in cold weather without interfering with the others.

An outside cellar is better than a house cellar in which there is a heater, but it is not so handy. If it is near the house, it need not be inconvenient, however. A house is usually healthier if the cellar is not used for storage. House cellars used for storage should have a ventilating shaft.

Strawberry. The saying that Strawberries will grow on almost any soil is misleading, although true.

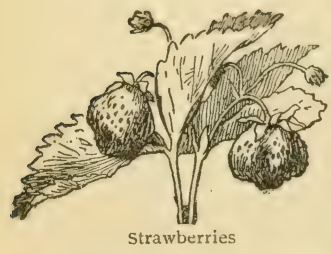
Some varieties of Strawberries will grow on certain soils better than other varieties. What these varieties are can only be determined by an actual test, but it is a safe rule to select such varieties as prove good in many localities. As to the methods of culture, so much depends on the size of the plot, the purpose for which the fruit is wanted, and the amount of care one is willing to give, that no set rule can be given for a garden in which but few plants are grown and extra care ean be 
given. Large fruits and a number of them may be had by growing to the single plant, keeping off all runuers and relying on numerous fruit-crowns on one plant for the crop of berries. Or Strawberries may be grown by the narrow matted-row system, in which the runners, before rooting, should be turned along the rows at a distance of from 4 to 6 inches from the parent plant. These runners should be the first ones made by the plant and should not be allowed to root themselves, but "set in." This is not a difficult operation; and if the runners are separated from the parent plant as soon as they become well established, the drain on that plant is not great. All other run-

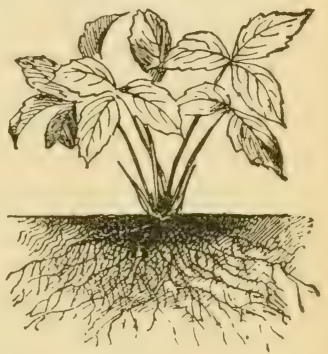

Well planted Strawberry ners should be eut off as they start. The row should be about 12 inches wide at fruiting time. Each plant should have sufficient feeding ground, full sunlight, and a firm hold in the soil. This matted-row system is perhaps as good a method, either in a private garden or field culture, as could be practiced. With a little care in hoeing, weed-

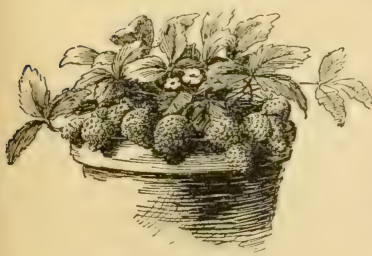

Pot-grown Strawberry ing and eutting off runners, the beds seem to produce as large crops the second year as the first.

The old way of growing a erop was to set the plants 10 to 12 inches apart, in rows 3 feet apart, and allow them to run and root at will, the results being a mass of small, crowded plants, each striving to obtain plant-food and none of them succeding in getting enough. The last, or outside runners, having but the tips of their roots in the ground, are moved by the wind, heaved by the frost, or have the exposed roots dried out by the wind and sun. 


\section{AMATEUR'S PRACTICAL GARDEN-BOOK}

Ground rich in potash produces the firmest and best flavored berries. Excessive use of stable manure, usually rich in nitrogen, should be avoided, as tending to make too rank growth of foliage and berries of a soft texture.

Except in the case of a skillful grower in a favored locality, the fall setting of plants is not to be recommended. The preparation of the soil and care of the plants more than overbalance the partial crop obtained the following spring.

In the single-plant or hill system the plants should be set 12 inches apart, in rows 3 feet apart. In the narrow matted row system the plants should be set 18 inches apart, in rows $3 \frac{1}{2}$ feet apart. The first method requires about 14,000 plants per acre, the second about 8,000 plants.

The winter treatment of a Strawberry bed should consist in covering the plants, when the ground is frozen, in November or December, with straw or hay. Salt marsh hay, if obtainable, is the best, as no weed seeds aro introduced. Corer the soil and the plants to the depth of 3 to 6 inches. As soon as growth begins in spring, rake the mulch off, allowing it to lie between the rows; or, if the soil is hard or weedy, it may be taken off the patch entirely, the ground tilled, and then replaced for the purpose of holding moisture and keeping the berries clean.

Usually, Strawberries may be fruited twice or three times; but on rich soil, with extra good care, the first crop may be very heavy, and the patch may be plowed up thereafter. Some varieties do not produce pollen, and not more than two rows of these should be planted without a row of a pollen-bearing kind.

The rust and mildew may be held in check by Bordeaux mixture. It is usually sufficient to spray after the blooming season (or at any time the first year the plants are set), in order to secure healthy foliage for the next year.

Sunflower (Helianthus). People who know only the coarse annual Sunflower are not aware of the 
beauty which it is possible to secure with the herbaceous perennials belonging to that family. No border should be without a few of the hardy species. Their blooming period extends from early in August until heavy frost. The color runs from light lemon to the richest orange, and the range of growth from 3 to 10 feet, thus enabling one to scatter them through the lorder without any formal arrangement. They are of the easiest culture. Plants may be dug in the wild or bought of nursery -

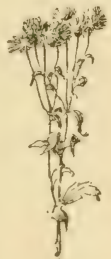

Double

Sunflower

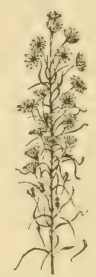

Orgyalis Sunflower men. The domesticated double Helianthus multiflorus is always valuable.

Of the annual Sunflowers, there are some which are not generally cultivated that should receive more attention. The silver-leaved species from Texas ( $H$. argophyllus), and the small, light lemon-yellow variety, are two of the best.

Swainsona. This makes a very desirable house plant, blooming through the late winter and early spring months. The blossoms, which resemble those of the pea, are borne in long racemes. The Wild Sunflower Plant foliage is fincly cut, resembling small locust leaves, and adds to the beauty of the plant, the whole effect being exceedingly graceful. It may be grown from seed or cuttings. Propagate a new stock each year. The flowers are large and pure white. The plant has been ealled the "Winter Sweet Pea," but the flowers are

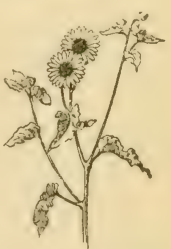

Wild Sunflower not fragrant.

Swan River Daisy (Brachycome iberidifolia) is a charming little border plant, growing to the height of 12 to 15 inches, and bearing quantities of blue or white flowers. 


\section{AMATEUR'S PRACTICAL GARDEN-BOOK}

The flowers last a long time when cut, and give a vase of flowers a light, graceful effect. The seed should be sown in boxes, hotbed, or windows ; or, in warm garden soil, the seed may be sown where the plants are to stand. Only half hardy, and should not be planted out until settled weather. Annual.

\section{Sweet Corn. See Comn.}

Sweet Herbs. The Herb garden should find a place on all amateur's' grounds. Herbs may readily be made profitable by disposing of the surplus to the green grocer and the druggist. The latter will often buy all that the housewife wishes to dispose of, as the general supply of medicinal herbs is grown by specialists, and goes into the hands of the wholesaler and is often old when received by the local dealer. The seedsmen's catalogues mention upwards of forty different Herbs, medicinal and eulinary. The majority of them are perennial, and will grow for many years if well taken care of. However, it is better to resow every three or four years. The annual kinds are raised from seeds each year. Beds 4 feet square of each of the Herbs will supply an ordinary family.

Sweet Pea. No annual receives greater attention these days than the Sweet Pea. Sweet Pea exhibitions are held in several sections of the country, the press gives considerable space to the discussion of varieties, and the public generally is interested in the growing or buying of the flower. On any oceasion the Sweet Pea is in place. A bouquet of shaded colors, with a few sprays of galium or the peremnial gypsophila, makes one of the choicest of table decorations. Deep, mellow soil, early planting and heavy mulching suit them admirably. Sow the seeds as soon as the ground is fit to work in the spring, making a drill 5 inches deep. Sow thickly and cover with 2 inches of soil. When the plants have made 2 or 3 inches growth above the soil, fill the drill nearly full, leaving a slight depression in 
which water may be eaught. After the soil is thoroughly soaked with water, a good mulch will hold the moisture. To have the ground ready in early spring, it is a good plan to trench the soil in the fall. The top of the soil then dries out very quickly in the spring and is left in good physical condition. Frequent syringing with clear water will keep off the red spider that often destroys the foliage, and attention to picking the seed pods will lengthen the season of bloom. If the finest flowers are wanted, do not let the plants stand less than 8-12 inches apart.

A succession of sowings may be made at intervals through May and June, and a fair fall crop obtained if care is taken to water and mulch; but the best results will be secured with the very early planting. In the middle and southern states, the seed may be planted in fall, particularly in

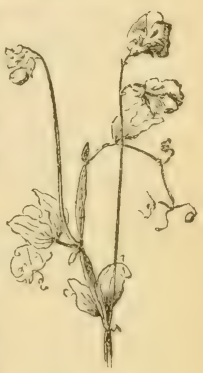

Sweet Pea lighter soils. It is easy to get soils too rich in nitrogen for Sweet Peas; in such case, they will run to vine at the expense of flowers. If the plants are watered, apply enough to soak the soil, and do not water frequently.

Sweet Potatoes are grown from sprouts planted on ridges or hills, not by planting the tubers, as with the common or Irish potato. The method of obtaining these sprouts is as follows: In April, tubers of Sweet Potatoes are planted in a partially spent hothed by using the whole tuber (or if a large one, by cutting it in two through the long way), covering the tuber's with 2 inches of light, well firmed soil. The sash should be put on the frames and only enough ventilation given to keep the Potatoes from deeaying. In ten or twelve days the young sprouts should begin to appear, and the bed should be watered if dry. The sprouts when pulled from the tuber will be found to have rootlets at the lower end and along the stems. These sprouts should be about 3 to 5 inches long by the time the ground is warm enough to plant them out. The ridges 
or hills should be prepared by plowing out a furrow 4 to 6 inches deep. Scatter manure in the furrow and plow back the soil so as to raise the center at least 6 inches above the level of the soil. On this ridge the plants are set, placing the plants well in to the leaves, and about 12 to 18 inches apart in the rows, the rows being from 3 to 4 feet apart. The after cultivation consists in stirring the soil between the ridges; and as the vines begin to run they should be lifted frequently to prevent rooting at the joints. When the tips of the vines have been touched by frost the crop may be harvested, the tuber's left to dry a fer days, and stored in a dry, warm place. To keep Sweet Potatoes, store in layers in barrels or boxes in dry sand, and keep them in a dry room. See that all bruised or chilled potatoes are thrown out.

Syringing plants with water has two general offices: to clean the plants of pests or of dirt; to check evaporation or transpiration from the plant itself.

Gardeners look upon water as a good insecticide. That is, if it can be thrown upon the plants somewhat forcibly by means of a syringe or pump, or by the hydrant hose, it will wash off the insects and drown many of them. The water should be applied in a fine and somewhat forcible spray. Care should be taken that the plant is not torn or bruised. The red spider is one of the most serious pests on house plants, and, in a dry season, on plants about the lawn. It thrives in a dry atmosphere. It usually lives on the under sides of the leaves. Syringing the plants frequently will destroy the pests. The thrips and slugs on rose bushes can nearly always be kept in check if one can spray or syringe his plants frequently. See spraying.

Syringing to check transpiration from the foliage is very useful with plants which are recently transplanted. For instance, when carnations are taken from the field and placed in the house, it is well to syringe them occasionally until they have become established. The same is true with euttings. 
In Syringing plants, it is well to take care that the ground does not become too wet; otherwise the plant may suffer at its root. In the house, plants should rarely be syringed except when the weather is bright, so that they may soon dry off. The plant should not go into the night with wet foliage. Out of doors in hot weather, it is best to syringe toward nightfall. The foliage will ordinarily not suffer in such cases. With plants in the house, it is necessary to keep the leaves dry most of the time in order that fungi may not breed. This is true of earnations, which are very liable to attacks of the rust.

Plants are sometimes syringed or sprayed to protect them from frost. See Frost.

Terraces may be desirable for two reasons: to hold a very steep slope; to afford an arehitectural base for a building.

It is rarely necessary to make a distinct Terrace m the lawn. Even if the lawn is very steep, it may be better to make a gradual slope than to ent the place in two with a Terrace. A Terrace makes a place look smaller. It is always difficult to make and to keep in repair. The surface is not readily cut with a lawn mower. Unless the sod is very dense, the upper corner tends to wash off with the rains and the foot tends to fill in. Nature does not have straight banks

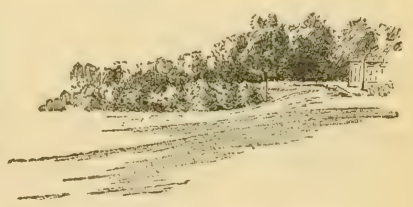

A slope is better than a terrace unless they are rock. The illustration in the margin shows how it is possible to treat a sloping lawn. In the distance is a distinct, sharp-angled Terrace; but in the foreground this Terrace has been carried out into the lawn, so that the slope is an agreeable one.

If it is necessary to Terrace a yard in order to hold it, the Terrace would better be at one side rather than in the middle. In that case, one is able to secure a good breadth 
of lawn. If the Terrace is at the outer side next the street, a perpendicular, mason-work, retaining wall may be constructed. If it is on the inner side of the lawn, it may be placed close to the building and be made to appear as a part of. the architecture : it may be made the base of the building. If this is done, there should be a balustrade around the edge of the Terrace to give it architectural feeling. The descent from the Terrace to the lawn may be made by means of steps, so as to add to the architectural aspect of the place. Terraces are most in place about buildings which have many strong horizontal lines; they do not lend themselves so well to buildings in the Gothic style. The general tendency is to make too many Terraces. The cases are relatively few in which they may not be dispensed with.

Thinning of fruit has four general uses: to cause the remaining fruit to grow larger ; to increase the chances of annual crops; to save the vitality of the tree ; to enable one to combat insects and diseases by destroying the injured fruit.

The Thinning of fruit is nearly always done soon after the fruit is thoroughly set. It is then possible to determine which of the fruits are likely to persist. Peaches are usually Thinned when they are the size of one's thumb. If Thinned before this time, they are so small that it is difficult to pick them off; and it is not so easy to see the work of the curculio and thereby to select the injured fruits. Similar remarks will apply to other fruits. The general tendency is, even with those who Thin their fruits, not to Thin enough. It is usually safer to take off what would seem to be too many than not to take off enough. The remaining specimens are better. Varieties which tend to overbear profit very greatly by Thinning. This is notably the case with many Japanese plums, which, if not Thinned, are very inferior.

Thinning may also be accomplished by pruning. If one 
knows where the fruit buds are, cutting them off will have the effect of removing the fruit. In the case of tender fruits, like peaches, however, it may not be advisable to Thin very heavily by means of pruning, since the fruit may be still further Thinned by the remaining days of winter, by late spring frost, or by the leaf-curl or other disease. However, the proper pruning of a peach tree in winter is, in part, a Thinning of the fruit. The peach is borne on the wood of the previous season's growth. The best fruits are to be expected on the strongest and heaviest growth. It is the practice of peach-growers to remove all the weak and immature wood from the inside of the tree. This has the effect of Thinning out the inferior fruit and allowing the en ergy of the tree to be expended on the remainder. Apples are rarely Thinned; but in many cases, Thinning can be done with profit. On all home grounds, fruits should be Thinned whenever the trees are very full. In general, the best time to thin the fruit, as already said, is when the fruits have become large enough to be seen and handled. The discarded fruits should be burned if they contain insects or fungi.

\section{Thunbergia. Tender' climbers, making very} pretty low screens. They are at their best when grown along the ground where the moisture keeps them free from the attacks of red spider. Some of the kinds are very fine vase or basket plants. All may be grown easily from seed. Annuals, 4 to 6 feet. Flowers white and yellow.

Tillage. By Tillage is meant the stirring of the soil. Tillage is the fundimental opera-

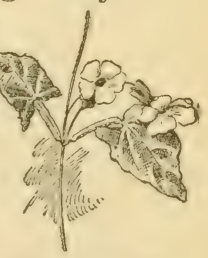
tion in agricultural practice. Most farmers till for three reasons: to get the seed into the land; to keep the weeds down; and to get the crop out of the land. The real reason for Tillage, however, is to ameliorate the land; that is, Tillage makes the soil mellow and fine, and an agreeable place in which plants may grow. It enables the 
soil to hold moisture, to present the greatest feeding surface to roots, to allow the circulation of air, and intensifies many chemical activities. Tilling the soil is the first means of making it productive. If one understands the many forces that are set at work, the Tilling of the soil becomes one of the most interesting and exciting of all agricultural operations.

The exact method of Tilling the soil in any particular ease must be determined by many cireumstances. Light soils are handled differently from heavy soils; and much depends also upon the season of the year in which the Tillage is done. In all ordinary soils, the effort shonld be made to work them deep, so that there is a deep reservoir for the storage of moisture and a large area in which roots can work. Subsequent Tillage throughout the growing season is performed very largely for the purpose of keeping the top of the soil loose and fine so that the moisture from beneath cannot pass off into the atmosphere. This loose layer of soil, extending two or three inches from the surface, may itself be very dry; but it breaks up the capillary connection between the lower soil and the air, and thereby prevents evaporation. This surface layer of loose, mellow soil is often

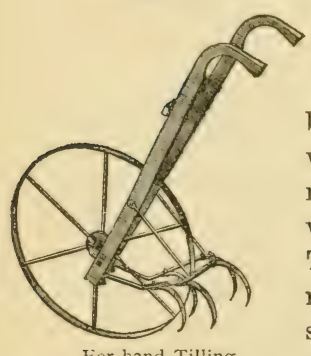

For hand Tilling spoken of as the earth-mulch. It answers much the same purpose as a mulch of straw or leaves in interposing a material between the moist soil and the air through which the moisture cannot rise. If this mulch is repaired as often as it should be, weeds cannot grow; but the object of the Tilling is more to make and maintain the mulch than to destroy weeds. The surface should be Tilled shallow in the growing season as often as it tends to become compact or encrusted. This will be after every rain, and usually as often as once in ten days when there is no rain. The tools to be used for this surface Tillage are those which will com- 
minute or fine the soil most completely without compacting it or leaving it in ridges or in furrows. In garden work, a fine rake is the ideal thing; whereas in field work, some of the wire-tooth weeders or smoothing harrows are excellent. In fields which are hard and lumpy, however, it will be necessary to use heavier and rougher tools.

In order to break down hard clay soils, one must exercise great care not to work them when they are wet; and also not to work them very murh when they are dry. There is a time, shortly after a rain, when clay lumps will break to pieces with a very slight blow. At this anders time it is well to go over them with a harrow or a Steel rake rake. After the next rain, they can be gone over again, and hefore the end of the season the soil should be in fine condition. An excellent way of breaking down clay land is to plow or spade it in the fall and allow it to weather in the winter. In such cases the land should not be raked or harrowed, but allowed to lie rough and loose. Tery hard clay lands sometimes run together or cement if handled in this way, but this will not occur if the land has stubble or sod or a dressing of manure, for the fibrous matter will then prevent it from pudlling. Lime sown on clay land at the rate of twenty to forty bushels to the acre also has a distinct effect in pulverizing it. This may be sown in fall, or preferably in spring when the land is plowed.

One of the most important ways of ameliorating land is to work vegetable matter into it so as to give it humus. Soils which are loose, black and friable contain much of this regetable mold. In many cases the chief valuo of stable manure is to add this humus to the soil. Many soils need humus more than they need plant-food, and hence stable manure gives better results in those cases than commercial fertilizers. The farmer secures the humus by plowing under stubble and sod, and occasional green crops.

Tomato. The early fruits are very easily grown by starting the plants in a greenhouse, hotbed or in 
shallow boxes placed in windows. A pinch of seed sown in March will give all the early plants a large family can use. When the plants have reached the height of two or three inches they should be transplanted into 3 -inch flower pots, old berry boxes or other receptacles, and allowed to grow slow and stocky until time to set them out, which is from May 15 on (in New York). They should be set in rows four or five feet apart, the plants being the same distance in the rows. Some support should be given to keep the fruits off the ground and to hasten the ripening. A trellis of chicken-wire makes an excellent support, as does the light lath fencing that may be bought or made at home. Stout

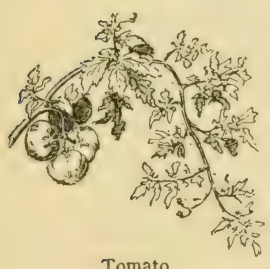

stakes, with wire strung the length of the rows, afford an excellent support. A very showy method is that of a frame made like an inverted $\mathrm{V}$, which allows the fruits to hang free; with a little attention to trimming, the light reaches the fruits and ripens them perfectly. This support is made by leaning together two lath frames. The late fruits may be picked green and ripened on a shelf in the sun; or they will ripen if placed in a drawer.

One ounce of seed will be enough for from twelve to fifteen hundred plants. A little fertilizer in the hill will start the plants off quickly. The rot is less serious when the vines are kept off the ground and the rampant suckers are cut out.

Tools of many kinds, and well chosen, are one of the joys of a garden. There is great satisfaction in a well-made, clean tool which does its work well. Keep the tools bright. They should be under cover, and in place, when not in use. A cupboard may be built by the rear porch, or in the warn or carriage house. See that the cupboard is in a dry place. Various Tools have been mentioned in the preceding pages, and other useful kinds are shown in the article on Weeds. 
Transplanting. This operation the gardener calls in one instance "pricking out." This means taking young seelling plants from the seed box as soon as they are large enough to be handled - usually when the first "rough" leaves have developed-and replanting them in other boxes or pots, either singly or at a greater distance apart than they were when in the seed boxes. The term is used in the operation of setting out plants from the hotbed, frame or house to the garden; also in removing shrubs or trees. Transplant on a cloudy day, and just hefore a rain, if possible.

Trimming is a term which is ordinarily confounded with pruning (which see). The word "Trimming," however, should be restricted to the shaping of the trees and not to the thinning of the tree or to pruning for wood, fruit or other special object. Trimming is only one of the means of pruning. Trimming is mostly used in the case of hedges. It is also used to keep evergreens in shape. Many ornamental plants are also Trimmed into various forms, although it is a question if such Trimming is usually wise. Fruit trees should be pruned, as a rule, rather than Trimmed: that is, they usually should be allowed to take their natural form, the pruner taking out the superfluous wood and keeping them within manageable bounds.

\section{Tropæolum. See Nasturtium.}

Tuberose. The Tuberose requires more heat to grow to perfection than it is usually possible to give here in the North. If planted in the border they will not start into growth until the ground has become thoroughly warm-usually after the middle of June,-making the season before frost too short for their perfect growth and flower. However, if started in loose soil or moss in a warm room or on benches of a greenhouse, the roots will soon start from the tuber and make a fine growth. If planted out in June with a good ball of roots they are likely to bloom before 
frost. If any danger of frost is feared they may be lifted into pots or boxes and taken into the house, when they will bloom without a check. As with other bulbs, a sandy soil will suit.

\section{Tuberous Begonia. A large bed of these covered} with erimson, pink, white, or yellow flowers, ranging from 2 to 4 and even 6 inches in diameter, some double, some single, is a striking sight. Yet such a sight is not uncommon about the large eastern eities where the Tuberous Begonia is now used somewhat for bedding.

Our interior summers are more trying, and so far, few in the west have succeeded so well with the Tuberous Begonia as a bedding plant. It makes a fine summer-blooming potplant, however, for the greenhouse or window, and with due attention to its requirements, it may be used as a bedding plant. It properly falls under greenhouse plants in its requirements.

C. L. Allen, writing of its culture in his work on "Bulbs and Tuberous-Rooted Plants," says: "The principal point learned in regard to its culture is, that it must be treated as a plant and not as a bulb. The enthusiastic florist, seeing

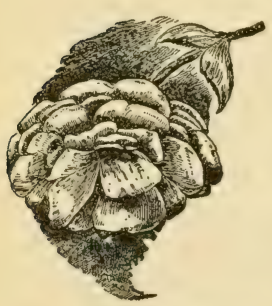

Duuble Tuberous Begonia the many good qualities of the plant, has led amateurs to believe it could be treated as a bulb, and planted out in the same manner as the gladiolus or tigridia and kept dormant during the winter in the same manner. This is a great mistake, as the tubers will not endure as long a period of rest and eannot be exposed to the air for a long time without seriously injuring their vitality. The tubers must be kept in dry earth or sand, until they show signs of growth, which will be not later than the first of March; then they may be started into rapid growth. After the eyes are fully developed the tubers may be divided: each eye will make a plant. Then they are treated in all respects like greenhouse plants, 
and grown on until the proper season for their planting out. This is not before the first of June, as Begonias are quite sensitive to cold nights, but not at all to heat. At that time the plants should be fully 6 inches in height and proportionately strong. Such plants will make a grand display the entire season, rather delighting in great heat."

In starting the tuher's in March, they should be placed in moist sand or moss in a temperature of $60^{\circ}$ to $65^{\circ}$, either in the greenhouse or window. After the buds are well started the tubers may be divided as pointed out, or planted whole. They prefer a rich, rather sandy soil. When they are well under way give them all the light and air they will bear, and keep them close to the glass to avoid "legginess" and to insure a firm, sturdy growth. A week before planting them out they should be

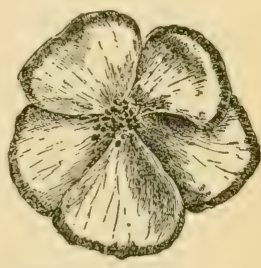

Tuberous Begonia, single. given abumdance of air and light to "harden off" the plants preparatory to setting them in sun and wind.

The beds should be in a somewhat sheltered place where they will be partially shaded from the hot midday sun. Let the soil be well enriched with old manure or humus and thoroughly worked over to a depth of one foot. During dry periods the beds will need watering from time to time; but never water them when the sun is shining full on them, or the foliage may be scorched. A mulch of leaf-mold or old manure will be helpful in keeping the soil moist and the roots cool.

Before frost the tubers should be carefully taken up and gradually dried in the shade, after which they are to be placed in dry sand or earth, in shallow boxes, and kept till time to start them in the spring. They should be kept in a cool place, secure from frost and away from stoves or heating pipes.

For amateurs it is better to recommend buying bulbs of the several colors, instead of attempting to grow them from 
seeds, which are extremely small and require early sowing, warmth and close attention.

Tulips are hardy and easy to grow. The advice given under Bulbs, Crocus and Hyacinth apply to Tulips. They may be forced for winter bloom (see under IIndow-Gardens). The garden bed will last several years if well eared for, but most satisfactory bloom is secured if the old bulbs are taken up every two or three years and replanted, all the inferior ones being cast aside. When the stock begins to run out, buy anew. Plant in October, 4 to 6 inches deep.

Tulip as a potplant

Turnips and Rutabagas are usually a fall crop, from seed sown in July and early August, although many kitehen gardens have them from spring sown seed. The culture is easy. Sow in drills 12 inches apart. They will become edible in from six to eight weeks. They are cool-weather crops, and the tops stand much frost. If maggots bother, do not raise them on the same land again for three or four years. Bordeaux mixture repels the flea-beetles. One ounce will sow 150 feet of drill.

Varieties. It is usually one of the first desires of the intending planter to inquire about Varieties. It is one of the secondary things to be considered, however, for the first thing to do is to prepare the land, to determine whether one's soil and site are adapted to the plant in questior, and to discuss other matters of a general nature. When all the fundamental things are settled, then the question of Varieties, which is a special matter, may be taken up. Although the selection of Varieties is a very special matter, it is nevertheless essential to success or satisfaction in the growing of any plant.

It should first be considered that the selection of Varieties is very largely a personal matter. The man should grow 
the Varieties which he likes. This is especially true in the selection of Varieties for the home grounds, in which case the market ideals enter very little into the problem. Having satisfied one's own mind as to what kinds of Varieties he would like, he may then inquire of the neighbors and of experts if those Varieties are adapter to the soil and elimate. If he intends to grow for market, he should canvass the market demands thoroughly hefore choosing the Varieties. The lists of Varieties in books, bulletins, and seedmen's catalogues are hints, not rules. As a general statement, it may be said that the only way to determine the best variety for one's own conditions is to experiment. There is intense satisfaction in the experimenting itself. The best lists of Varieties are those which are recommended for some specific purpose, and which represent the combined opinions of many expert growers. It is rare that one man's judgment should be final, particularly with respect to fruits or plants which are grown in general outdoor conditions. Under glass a gardener can make his climate and conditions, and therefore he can adapt his conditions to his plants. The experiment station test usually represents but one man's opinion. It may be a more valuable opinion than that of another man, but it is not final. It should be studied in connection with other lists, particularly those made by practical growers. If one desires to choose Varieties, therefore, he should consult the best growers of those plants in his immediate neighborhood; he should call upon the experiment station of his state or province; and he should consult the most recent writings on the subject.

Vegetable Garden. It is one of the choicest of pleasures to raise one's own vegetables. Make the Vegetable Garden ample, but economize labor. Plant the things in rows, not in beàs. Then they can be tilled easily, either by horse- or hand-tools. Wheel-hoes will accomplish most of the labor of tillage in a small garden. Have the rows long, to avoid waste of time in turning and to economize 
the land. One row can be devoted to one vegetable; or two or more vegetables of like requirements (as parsnips and salsify) may comprise a row. Have the permanent vegetables, as rhubarb and asparagus, at one side, where they will not interfere with the plowing or tilling. The annual vegetables should be grown on different parts of the area in sueceeding years, thus practicing something like a rotation of crops. If radish or cabhage maggots or club-root become thoroughly established in the plantation, omit for a year or more the vegetables on which they live.

Make the soil deep, mellow and rich before the seeds are sown. Time and labor will be saved. Rake the surface frequently to (keep down weeds and to prevent the soil from baking (see Tillage). Radish seeds sown with celery or other slow-germinating seeds will

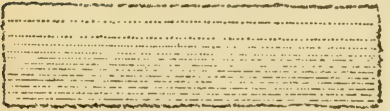

Lay-nut of a farm Vegetable Garden come up quickly, breaking the crust and marking the rows. About the borders of the Vegetable Garden is a good place for flowers to be grown for the decoration of the house and to give to friends. Along one side of the area rows of bush fruits may be planted.

A home Vegetable Garden for a family of six would require, exclusive of potatoes, a space not over 100 by 150 feet. Beginning at one side of the garden and running the rows the short way (having each row 100 feet long) sowings may be made, as soon as the ground is in condition to work, of the following:

Fifty feet each of parsnips and salsify.

One hundred feet of onions, 25 feet of which may be potato or set onions, the balance black-seed for summer and fall use.

Fifty feet of early beets, 50 feet of lettuce, with which radish may be sown to break the soil and be harvested before the lettuce needs the room.

One hundred feet of early cabbage, the plants for which 
should be from a frame or purchased. Set the plants 18 inches to 2 feet apart.

One hundred feet of early cauliflower; culture same as for eabbage.

Four hundred and fifty feet of peas, sown as follows:

100 feet of extra early.

100 feet of intermediate.

100 feet of late.

100 feet of extra early, sown late.

50 feet of dwarf varieties.

If trellis or hrush is to be avoided, frequent sowings of the dwarfs will maintain a supply.

After the soil has become warm and all danger of frost has passed, the tender vegetables may be planted, as follows :

Corn in five rows 3 feet apart, three rows to be early and intermediate, and two rows late.

One hundred feet of string beans. early to late varieties.

Vines as follows:

10 hills of cucumbers, $6 \times 6$ feet.

20 hills of muskmelon, $6 \times 6$ feet.

6 hills of early squash, $6 \times 6$ feet.

10 hills of Hubbard, $6 \times 6$ feet.

One hundred feet of okra.

Twenty eggplants.

Six large clumps of rhubarb.

An asparagus bed 25 feet long and 3 feet wide.

Late cabbage, cauliflower and celery are to occupy the space made vacant by removing early crops of early and intermediate peas and string beans.

A border on one side or end will hold all herbs, such as parsley, thyme, sage, hyssop, mints.

Verbena. The Verbena is one of the most satisfactory garden plants, blooming early. Bloom continues through the dry, hot days of summer. As the cool weather of the fall comes on, Verbenas increase in size of plant 
and flower until killed by severe frost. Plants grown from seed sown in a hotbed or house early in the spring, transplanted into pots or boxes when large enough, and planted out as soon as the ground has become warm, are more vigorous and seem to have more fragrance than those grown from cuttings. Many of the strains have become so well fixed

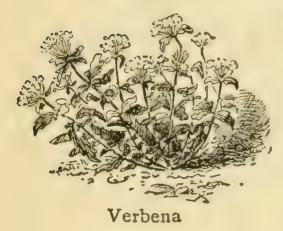
that the colors come true from seed. Cuttings are often employed, but the handling of stock plants is a difficult matter except in the hands of a professional, and when plants are wanted in quantity it is cheaper to buy them of the plantsman than to grow them from seed or attempt to keep over stock plants. Therefore, for the home garden, seedgrown plants are usually most satisfactory. Give a sunny position. Thin to 10 to 15 inches apart each way.

Vinca, or Periwinkle. Trailing plants. Useful in covering unsightly places, for vases, urus or baskets. Some of the species (as the common evergreen, mat-like "running myrtle") are hardy, but the most useful ones need the protection of a house through the winter. 'The variegated-leaved kinds are fine for winter decorations. Propagated mostly by cuttings. Perennials.

Vines. The use of Vines for screens and pillar decorations has increased in the last decade until now they may be seen in nearly all grounds. The tendency has been towards using the hardy Vines, of which the ampelopsis, or Virginia ereeper, is one of the most common. It is a very rapid grower, and lends itself to training more readily than many others. The Japan ampelopsis (A. tricuspidate or Veitchii) is a fine elinging Vine, growing very rapidly when once established, and being brilliantly colored after the first fall frosts. It elings eloser than the other, but is not so hardy. Either of these may be grown from euttings or division of the plants. Two woody twiners of recent introduction are the actinidia and the akebia, both from 
Japan. They are perfectly hardy, and are rapid growers. The former has large, thick, glossy leaves, not affected by insects or disease, growing thickly along the stem and branches, making a perfect thatch of leaves. It blooms in June. The flowers, which are white with a purple center, are borne in clusters, followed by round or longish edible fruits. The akebia has very neat ent foliage, quaint purple flowers, and often bears ornamental fruit. Other hardy Vines are the wistaria, clematis, tecoma (or trumpet-flower), aristolochia (or Dutchman's pipe), hedera (or ivy), and loniceras (or honeysuckles).

Of the tender Vines, the nasturtiums and ipomeas are the most common, while the adlumia (p. 3), balloon vine (p. 28), passion vine, and the gourds ( $p .115$ ), are frequently used. One of the hest of recent introduction

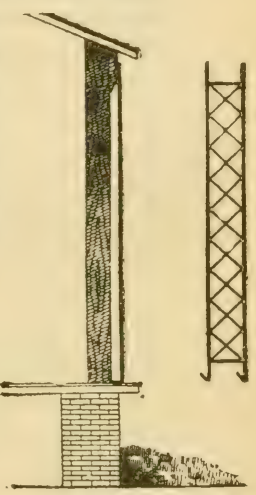

A vine support for a porch is the annual hop, especially the variegated variety. This is a very rapid growing Vine, seeding itself each year, and needing little care. See Hop. All the tender Vines should he planted after all danger of frost is over.

\section{ANNTAL HERBACEOUS OLIMBERS}

Tendrit-climbers

Adlumia (biennial).

Balloon Vine.

Cobea.

Gourds.

Nasturtiums.

Sweet Pea.

Wild Cucumber.

\section{Twiners}

Beans, Flowering.

Cypress Vine.

Dolichos.

Hop, Japanese.

Ipomea.

Moonflower.

Morning-glory.

Thunbergia.

Yam, Chinese, or Cinnamon Vine (perennial from a hardy tuber). 
PERENNIAL WOODY CLIMBERS FOR THE OPEN

Tendril-climbers

Ampelopsis tricuspidata. Clematis of many kinds. Grape of various kinds. Greenbrier.

Ivy (by roots).

Roses (scramblers).

Trumpet Creeper (by roots). Virginia Creeper.
Twiners

Actinidia polygama.

Akebia quinata.

Aristolochiz, or Dutchman's Pipe.

Bittersweet, or Celastrus. Honeysuckles.

\section{Moonseed.}

Wistaria.

Violet. While the culture of Violets as houseplants rarely proves successful, there is no reason why a good supply may not be had elsewhere through the greater part of the winter and the spring months. A sheltered lo-

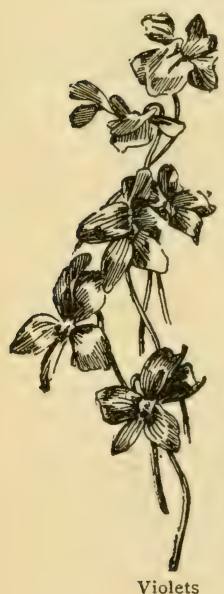

Violets

cation being selected, young plants from runners may be set in August or September. Have the ground rich and well drained. These plants will make fine crowns by December, and often will bloom before weather sufficiently cold to freeze them. In order to have flowers through the winter, it will be necessary to afford some protection to the plants. This may best be done by building a frame of boards large enough to cover the plants, making the frame in the same way as for a hotbed, four to six inches higher at the back than the front. Cover the frame with sash or boards, and as the weather becomes severe, mats or straw should be placed over and around the frame to protect the plants from freezing. Whenever the weather will permit, the covering should be removed and air admitted, but no harm will come if the frames are not disturbed for several weeks. A large amount of sunlight and a high temperature through the middle of winter are to be avoided, for if the plants are stimulated a shorter 
period of bloom will result. In April the frame may be removed, the plants yielding the later part of the erop without protection. Violets belong with the "cool" plants of florists. When well hardened off, considerable frost does not harm them. They should always be kept stocky. Start a new lot from runner-plants each year. They thrive in a temperature of $55^{\circ}$ to $65^{\circ}$.

Walks. The place for a Walk is where it is needed. It should go directly between two points. It need not be straight, but if it is curved, the curve should be direct. That is, the pedestrian should be conscious that he is going in the direction in which he desires to go, and is not making a detour for the simple purpose of following the walk. Convenience should be the first thing to be considered. After the Walks have been laid in the most convenient places, the question of ornamenting the borders may be considered. It is always well to avoid, so far as possible, the bisecting of lawns by Walks, as that makes two lawns where there should be only one. The larger a greensward can be made to look, the more park-like and natural is the place. Avoid taking the Walks eireuitously around the borders unless they are laid for the simple purpose of making a ramble to show off the grounds. All Walks which are designed for serious use should appear to be necessary, direct and convenient.

Some soils which contain considerable loam and sand will pack with tramping and will make good Walks, but it is usually necessary to lay some material on the soil. Gravel, cinders, and the like, may be better than the natural surface; but in many cases they are worse, since the surface is loose and is unpleasant to walk on. In Walks which are on decided slopes, and down which the water is likely to run, any loose material is very objectionable, since it runs to the low places. The best material for Walks, all things considered, is cement, or what is called artificial stone. If well made, it is as durable as flagging, and is not so likely to 
get out of place. It holds its surface perfectly year after year.

The only objection to cement Walks is when they are more or less temporary, for in such cases they cannot be moved. There is often very serious difficulty in securing good cement Walks, but the difficulties are easily overcome. They are chiefly two: there is not sufficient draining material beneath the cement; and the cement itself is not made strong enough. There should be at least a foot of loose material, as brickbats or cinders, below the cement cover; and if the place is low and likely to hold water, there should be still greater drainage. Pound the material down, or let it stand for some time until it becomes thoroughly settled together. Then lay the cement in two courses. The first course may be three or four inches thick and made of well mixed mortar, comprising three parts Portland cement, one part water lime, and two to three times as much sharp sand as Portland. When this has become partially hardened, but before it is set and while still moist, put on a finishing layer of one inch, made of one part Portland cement, one part water lime, and one part sharp sand. It is important that the materials be very thoroughly mixed. See that the edges of the walk are made square and true by laying down a form of boards lengthwise the area before the cement is put on. The edges should he as thick as the middle, for a thin crust on the edge tends to snap off. A walk made in this way on a well-drained foundation will last almost indefinitely. It is best that it be made in such season that it ean become thoroughly set before frosty weather comes.

Wallflower. A favorite plant for pots or garden, having a clove-like fragrance. Seed of most varieties should be sown the year before wanted. One kind, being an annual, will flower the same season the seed is sown. Hardy. Two to 3 feet.

Washing orchard trees is an old practice. It 
usually results in making a tree more vigorous. One reason is that it destroys insects and fungi which lodge underneath the bark; but probably the chief reason is that it softens the bark and allows the trunk to exprand. It is possible, also, that the potash from the soap or lye eventually passes into the ground and affords some plant-food. Trees are ordinarily Washed with soap suds or with a lye solution. The material is usually applied with an old broom or a stiff brush. The scrubbing of the tree is perhaps nearly or quite as beneficial as the application of the wash itself.

It is customary to wash trees late in spring or early in summer, and again in the fall, with the idea that such Washing destroys the eggs and the young of borers. It no doubt will destroy borers if they are just getting a start, but it will not keep away the inseets which lay the eggs, and will not destroy the borers which have found their way underneath the bark. It is perhaps quite as well to wash the trees very early in the spring, when they are starting into growth. It is an old practice to wash trees with strong lye when they are affected with the oyster-shell bark louse. The modern method of treating these pests, however, is to spray with some kerosene compound when the young growth is starting, for at that time the young insects are migrating to the new wood and they are very easily destroyed.

Watering House Plants. It is impossible to give rules for the Watering of plants. Conditions that hold with one grower are different from those of another. Advice must be general. Give one good Watering at the time of potting, after which no water should be given until the plants really need it. If, on tapping the pot, it gives out a clear ring, it is an indication that water is needed. In the case of a soft-wooded plant, just before the leaves begin to show signs of wilt, is the time for Watering. When plants are taken up from the ground, or when plants have their roots cut back in repotting, gardeners rely, after the first copious Watering, on syringing the tops of the plants two or three 
times each day, until a new root-growth has started, Watering at the roots only when absolutely necessary. Plants that have been potted into larger pots will grow without the extra attention of syringing, but those from the borders, that have had their roots mutilated or shortened, should be placed in a

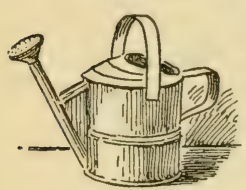

Watering pot cool, shady spot and be syringed often. One soon becomes familiar with the wants of individual plants, and can judge closely as to need of water. All soft-wooded plants with a large leaf-surface need more water than hard-wooded plants, and a plant in luxuriant growth of any kind more than a plant that has been eut back or become defoliated. When plants are grown in livingrooms, moisture must be supplied from some source, and if no arrangement has been made for having a moist air the plants should be syringed often. See Syringing.

Watermelon. The culture of this is essentially the same as that for muskmelons (which see), exeept that most varieties require a warmer place and longer period of growth. Give the hills a distance of from 6 to 10 feet apart. Choose a warm, "quick" soil and sunny exposure. It is essential, in the North, that the plants grow rapidly and come into bloom early. One ounce of seed will plant thirty hills.

Wax Plant. The Wax Plant, or HoyA, is one of the commonest of window-garden plants, and yet it is one which people usually have difficulty in flowering. However, it is one of the easiest plants to manage if a person understands its nature. It is naturally a summer-blooming plant, and should rest during the winter time. In the winter, keep it just alive in a cool and rather dry place. If the temperature does not go above $50^{\circ}$ Fahr., so much the better; neither should it go much lower. In late winter or spring, the plant is brought out to warm temperature, given water and started into growth. The old flower-stems 
should not be cut off, since new flowers come from them as well as from the new wood. When it is brought out to be started into growth, it may be repotted, sometimes into a size larger pot, but always with more or less fresh earth. The plant should increase in value each year. In conservatories, it is sometimes planted out in the ground and allowed to run over a wall, in which case it will reach a height of many feet.

Weeds. Many very strong Weeds are a compliment to one's soil: only good soil produces them. But they are not a compliment to one's tillage. If the soil is well prepared and well tilled to conserve moisture and

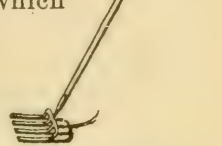

Potato hook and weed•puller

to unlock plant-food (see Tillage), Weeds will find little chance of growing. Stir the ground often: it benefits the ground and keeps out the Weeds. Plant vegetables in long straight rows rather than in beds, for thereby tillage is

Finger-weeder made easier. For beds and for small plants, the hand-weeders (as shown in the margin) are very efficient. They save laborious finger-work. Weed seeds are often distributed in manure, especially if Weeds have been allowed to grow and ripen on the piles. See that pernicious Weeds do not seed about the premises. For the treatment of weedy lawns, see the article Lawns.

Windbreaks. There is the greatest difference of opinion as to the value of Windbreaks for fruit plantations. These differences arise from the fact that a Windbreak

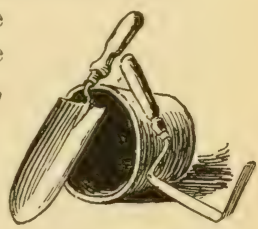

Trowel and angle-weeder may be of great benefit in one place, but a disadvantage in another. It is always advisable to break the force of very strong winds, for such winds tend to injure the trees when laden with fruit or ice, and they blow off the fruit; and in dry countries they cause the soil to berome parched. If the wind is usually warmer than the area, however, par- 
ticularly in the winter time, it is better not to stop it, but to allow it to circulate through the plantation. This is the case in areas which lie close to large bodies of water. The wind coming off the water is warmer than that off the land, and tends thereby to protect the fruit plantation from severe cold. A circulation of air is desirable in late spring and early fall in order to avoid the still frosts. Therefore, if the area is very closely surrounded by dense plantations, it may have what the fruit-growers call "stagnant air;" but thimning out the Windbreak on one or two sides, or cutting holes through it, may allow the air to move through, thereby affording atmospheric drainage and insuring greater immunity from the light local frosts.

It is ordinarily better to break the force of the winds than to stop or deflect them. That is, the Windbreak may be thin enough to allow the wind to take its normal direction, but its force is broken. A stone wall or a very dense hedge of evergreens may cause the wind to rise over the plantation or to be deflected to one side; and this, in many cases, as already said, may be a decided disadvantage. The philosophy of a good Windbreak for fruit plantations may be summed up in this way: the foree of heavy winds should be broken; warm winds should be allowed to circulate freely through the plantation; still air should be avoided.

Ordinarily, one or two rows of deciduous trees are sufficient protection. When the plantation is very much exposed to very cold or land winds, a thick evergreen screen may be a decided advantage. It is usually better to have the heavy Windbreak on the upper side of the area, so that it may not interfere with the natural drainage of the cold air down the slope. In making a Windbreak, it is important that those trees be chosen which will not become harboring places for orchard enemies. The wild cherry, for example, is inveterately attacked by the tent caterpillar, and the wild crabs and wild plums are likely to breed orchard insects. If the Windbreak is planted some time in advance of the 
orchard, the row of fruit trees next the Windbreak will be very likely to suffer from lack of moisture and food.

A different type of Windbreak is that which is desired for a shelter belt about the home grounds. The matter of atmospheric drainage does not enter into this problem to any great extent. Such shelter belt is usually placed at the extreme edge of the home yard, toward the heaviest or prevailing wind. It may be a dense plantation of evergreens. If so, the Norway spruce is one of the best for general purposes. For a lower belt, the arborvitæ is excellent. Some of the pines, as the Scotch $\mathrm{Ol}^{\circ}$ Austrian, are also to be advised, particularly if the belt is at some distance from the residence. As a rule, the coarser the tree the farther it should be placed from the house.

Persons may desire to use the Windbreak as a screen to hide undesirable objects. If these objects are of a permanent character, as a barn or an unkempt property, evergreen trees should be used. For temporary screens, any of the very large-growing herbaceous plants may be used. Very excellent subjects are sunflower's, the large-growing nicotianas, castor beans, large varieties of Indian corn, and plants of like growth. Very efficient summer screeus may be made with ailanthus, paulownia, basswood, sumac, and other plants which tend to throw up suceulent shoots from the base. After these plants have been set a year or two, they are cut back nearly to the ground every winter or spring, and strong shonts are thrown up with great luxuriance during the summer, giring a dense screen and presenting a semi-tropical effect. For such purposes, the roots should be planted only two or three feet apart. If, after a time, the roots become so crowded that the shoots are weak, some of the plants may he removed. Top-dressing the area every fall with manure will tend to make the ground rich enough to afford a very heavy summer growth.

Wind Flower. See Anemone.

Window-Gardens. The summer Window- 
Garden.-This type of gardening is particularly suited to those who live in the crowded city, where the want of other space makes the Window-Garden the only one possible.

Handsomely finished boxes, ornamental tiling, and bracket work of wood and iron suitable for fitting out windows for the growing of plants, are on the market; but such, while desirable, are by no means necessary. A stout pine

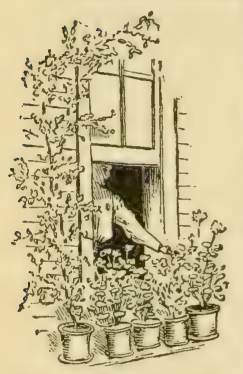

A summer window ledge box of a length corresponding to the width of the window, about 10 inches wide and 6 deep, answers quite as well as a finer box, since it will likely be some distance above the street, and its sides, moreover, are soon covered by the vines. A zine tray of a size to fit into the wooden box may be ordered of the tinsmith. It will tend to keep the soil from drying out so rapidly, but it is not a necessity. A few small holes in the bottom of the box will provide for drainage; but with carefulness in watering these are not necessary, since the box by its exposed position will dry ont readily during summer weather, unless the position is a shaded one. In the latter case provision for good drainage is always advisable.

Since there is more or less cramping of roots, it will be necessary to make the soil richer than would be required were the plants to grow in the garden. The most desirable soil is one that does not pack hard like clay, no: contract much when dry, but remains porous and springy. Such a soil is found in the potting soil used by florists, and it may be obtained from them at from $50 \mathrm{cts}$. to $\$ 1$ a barrel. Often the nature of the soil will be such as to make it desirable to have at hand a barrel of sharp sand for mixing with the soil, to make it more porous and prevent baking.

Some pot the plants and then set them in the windowbox, filling the spaces between the pots with moist moss. Again, they are planted directly in the soil. The former method, as a general rule, is to be preferred in the winter Window-Garden; the latter during the summer. 
The plants most valuable for the purpose are those of drooping habit, such as lobelias, tropæolums, Othonna crassifolia, Kenilworth ivy, and sweet alyssum. Such plants may occupy the front row, while back of them may be the erect-growing plants, like geraniums, heliotropes, begonias, etc.

Just what plants will be most suitable will depend on the exposure. For the shady side of the street, the more delicate kinds of plants may be used. For full exposure to the sun, it will be necessary to select the more vigorousgrowing kinds. In the latter position, suitable plants for drooping would be: *tropæolums, *passifloras, the single petunias, sweet alyssum, lobelias, verbenas, mesembryanthemums. For erect-growing plants: geraniums, heliotropes, ete. If the position is a shaded one, the drooping plants might be of the following : tradescantia, Kenilworth ivy, "senecio or parlor iry, sedums, *moneywort, vinea, *smilax, *lygodium or climbing fern. Erect-growing plants would be dracrenas, palns, ferns, coleus, centaurea, spotted calla, and others.

For shady situations the main dependence is upon plants of graceful form or handsome foliage; while for the sumny window the selection may be of blooming plants. Of the plants above mentioned for these two positions, those marked with an asterisk (*) are of climbing habit, and may be trained up about the sides of the window. Others will be found among the rlimbing plants mentioned under Fines, Anmuals and Basket Plants.

After the plants have filled the earth with roots, it will he desirable to give the surface of the soil among the plants a very light sprinkling of bone-dust or a thicker coating of rotted manure from time to time luring the summer; or instead of this, a watering with weak liquid manure about once a week. This is not necessary, however, until the growth shows that the roots have about exhausted the soil.

In the fall the box may be placed on tho inside of the 


\section{AMATEUR'S PRACTICAL GARDEN-BOOK}

window. In this case it will be desirable to thin out the foliage somewhat, shorten in some of the vines, and per. haps remove some of the plants. It will also be desirable to give a fresh coating of rich soil. Increased care will be necessary, also, in watering, since the plants will have less light than previously, aud, moreover, there may be no provision for drainage.

The Winter Window-Garden may consist simply of a jardiniere, or a few choice pot-plants on a stand at the window, or of a considerable collection, with more or less elaborate arrangements for their accommodation in the way of box, brackets, shelves and stands. Expensive arrangements are by no means necessary, nor is a large collection. The plants and flowers themselves are the main consideration, and a small collection well cared for is better than a large one unless it can be easily accommodated and kept in good condition.

The window for plants should have a southern, southeastern or eastern exposure. Plants need all the light they can get in the winter, especially those which are expected to bloom. The window should be tight-fitting. Shutters and a curtain. will be an advantage in cold weather.

Plants like a certain uniformity in conditions. It is very trying on them, and often fatal to success, to have them snug and warm one night and shivering in a temperature only a few degrees above freezing the next. Some plants will live in spite of it, but they camnot be expected to prosper. Those whose rooms are heated with steam, hot water or hot air will have to guard against keeping rooms too warm fully as much as keeping them too cool. Rooms in brick dwellings that have been warm all day, if shut up and made snug in the evening will often keep warm over night without heat except in the coldest weather. Rooms in frame dwellings, and exposed on all sides, soon cool down.

It is difficult to grow plants in rooms lighted by gas, is 
the burning gas vitiates the atmosphere. Most living-rooms have too dry air for plants. In such eases the bow window may be set off from the room by glass doors; one then has a miniature conservatory.

While keeping the plants at a suitable temperature, we must not forget that plants love moisture, or a humid atmosphere, and that our living-rooms ordinarily are very dry. A pan of water on the stove or on the register and damp moss among the pots, will afford plants the necessary humidity.

The foliage will need cleansing from time to time to free it from dust. A bath tub provided with a ready outlet for the water is an excellent place for this purpose. The plants may be turned on their sides and supported on a small box above the bottom of the tub. Then they may be freely syringed without danger of making the soil too wet. It is usually advisable not to wet the flowers, however, especially the white waxen kinds, like hyacinths. The foliage of Rex begonias should be cleansed with a piece of dry or only slightly moist cotton. But if the leaves

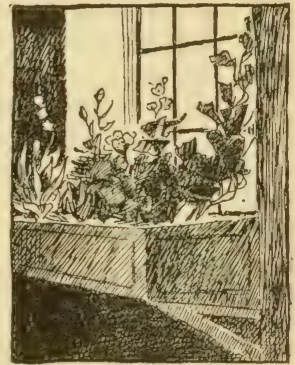

A window-box ean be quickly dried off by placing them in the open air on mild days, or moderately near the stove, the foliage may be syringed.

The window-box in the room will be seen near at hand, so may be more or less ornamental in character. The sicles may be covered with ornamental tile held in place by moulding; or a light lattice-work of wood surrounding the box is pretty. But a neatly made and strong box of about the dimensions mentioned on page 242, with a strip of moulding at the top and bottom, answers just as well; and if painted green, or some neutral shade, only the plants will be seen or thought of. Brackets, jardinieres and stands may be purchased of any of the larger florists. 
The window-box may consist of merely the wooden box; but a preferable arrangement is to make it about eight. inches deep instead of six, then have the tinsmith make a zine tray to fit the box. This is provided with a false wooden bottom, with eracks for drainage, two inches above the real bottom of the tray. The plants will then have a vacant space below them into which drainage water may pass. Such a box may he thoroughly watered as the plants require without danger of the water running on the carpet. Of course, a faucet should be provided at some suitable point on a level with the hottom of the tray, to permit of its being drained every day or so if the water tends to accumulate. It would not do to allow the water to remain long; especially should it never rise to the false bottom, as then the soil would be kept too wet.

Some persons attach the hox to the window, or support it on brackets attached below the window-sill; but a preferable arrangement is to supuort the box on a low and light stand of suitable height provided with rollers. It may then be drawn back from the window, turned around from time to time to give the plants light on all sides, or turned with the handsome side in as may be desired, and so on.

Often the plants are set directly in the soil; but if they are kept in pots they may be rearranged, changed about to give those which need it more light, ete. Larger plants which are to stand on shelves or brackets may be in porous earthenware pots; but the smaller ones which are to fill the window-box may be placed in heary paper pots. The sides of these are flexible, and the plants in them therefore may be crowded close together with great economy in space. When pots are spaced, damp sphagnum or other moss among them will hold them in place, keep the soil from drying out too rapidly, and at the same time give off moisture, so grateful to the foliage.

In addition to the stand, or box, a bracket for one or more pots on either side of the window, about one-third or 
half way up, will be desirable. The bracket should turn on a basal hinge or pivot, to admit of swinging it forward or backward. These bracket plants usually suffer for moisture, and are rather difficult to manage.

Florists now usually grow plants suitable for WindowGardens and winter flowering, and any intelligent florist, if asked, will take pleasure in making out a suitable collection. The plants should be orlered early in the fall; the florist will then not be so crowder for time and can give the matter better attention.

Most of the plants suitable for the winter Window-Garden helong to the groups which florists grow in their medium and cool houses. The former are given a night temperature of about $60^{\circ}$, the latter ahout $50^{\circ}$. In each case the temperature is 10 to $15^{\circ}$ higher for the daytime. Five degrees of variation below these temperatures will be allowable without any injurious effects; even more may be borne, but not without more or less check to the plants. In bright, sunny weather the day temperature may he higher than in cloudy and dark weather.

\section{PLANTS FOR AN ATERAGE NIGHT TEMPERATURE OF $60^{\circ}$}

Upright flowering plants.-Abutilons, browallias, ealceolaria "Lincoln Park," begonias, bouvardias, euphorbias, scarlet sage, richardia or calla, heliotropes, fuchsias, Chinese hibiscus, jasmines, single petunias, swainsona, billbergia, freesias, geraniums, cupheas.

Clright foliage plants.-Muehlenbeckia, Cycas revolutr, Dracana fragrans and others, palms, cannas, Farfigium grande, achyranthes, ferms, araucaria, epiphyllums, pandanus or "serew pine," Pilea arborea, Ficus elastica, Grevillea robusta.

Climbing plants.-Asparagus tenuissimus, A. plumosus, Cobcea scandens, smilax, Japanese hop, Madeira vine (Bous- 
singaultia), śnecio mikanioides and S. maeroglossus (parlor ivies). See also list below.

Low-growing, trailing, or drooping plants.-These may be used for baskets and edgings. Flowering kinds are: Sweet alyssum, lobelia, Fuchsia procumbens, mesembryanthemum, Oxatis pendula, O. floritumda and other's, Russetia juncea, Mahernia odorata or honey-bell.

Foliage plants of drooping habit.- Vincas, Saxifraga sarmentosa, Kenilworth ivy, tradescantia or Wandering Jew, *Festuea glauca, othonna, *Isolepsis gracilis, English ivy, Selaginella denticulata and others. Some of these plants flower quite freely, but the flowers are small and of secondary consideration. Those with an asterisk (*) droop but slightly.

\section{PLANTS FOR AN AVERAGE NIGHT TEMPERATURE OF $50^{\circ}$}

Upright flowering plants.-Azaleas, cyelamens, carnations, chrysanthemums, geraniums, Chinese primroses, stevia, marguerite or Paris daisy, single petunias, Anthemis coronaria, camellias, ardisia (berries), cineraria, violets, hyacinths, narcissus, tulips, the Easter lily when in bloom, and others.

Upright foliage plants.-Pittosporum, palms, aucuba, euonymus (golden and silvery variegated), araucaria, pandanus, dusty miller.

Climbing plants.-English ivy, maurandia, senecio or parlor ivy, lygodium (climbing fern).

Drooping or trailing plants.-Flowering kinds are: Sweet alyssum, Mahernia odorata, Russelia and ivy geranium.

Bulbs in the Window-Garden.-The single Roman hyacinth is an excellent house plant. Its flowers are small, but they are graceful and especially well suited for cutting. The bulbs are easily forced, and are managed like other hyacinths. The secret of forcing the Dutch bulbs and most others is to pot them and then, after watering the pots, 
set them away in a cool, dark place until the pot is filled with roots. They may be placed in the cellar "to root up," or be buried 3 or 4 inches deep in the soil. It is well to delay potting them until such time as they can be kept cool while forming their roots. A temperature of about $40^{\circ}$ to $45^{\circ}$ suits them during this period. In most cases it is well to select pots 5 or 6 inches in diameter and place from three to six bulbs in a pot, according to the size of the bulbs and the plants. The pot having been filled with soil, it is only necessary to press them down till the tip, or about one-fourth, shows above the soil. After this a slight jarring or sharp rap will settle the soil. They are then watered and set away, as before mentioned. If kept dark and cool they will need no more watering until they

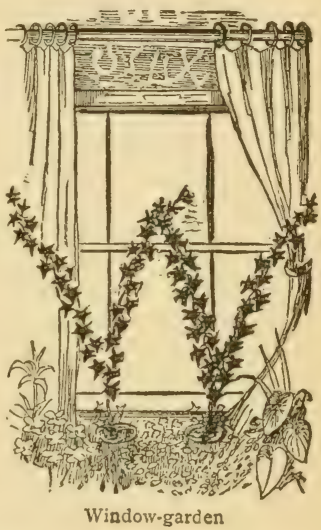
are brought out and begin to grow, when they may be watered freely.

Hyacinths, tulips and narcissus all require about the same treatment. When well rooted, which will be in six or eight weeks, they are brought out and given a temperature of some $55^{\circ}$ to $60^{\circ}$ till the flowers appear, when they should be kept in a cooler temperature, say $50^{\circ}$.

The Easter lily is managed the same way, only, to hasten its flowers, it should be kept at not lower than $60^{\circ}$ at night. Warmer will he hetter. Lilies may be covered an inch or more deep.

Freesias may be potted six or more in a pot of mellow soil, and then started into growth at once. At first they might be given a night temperature of $50^{\circ}$, and $55^{\circ}$ to $60^{\circ}$ when they have begun to grow.

Bulbs like the snowdrop and crocus are planted several or a dozen in a pot and buried, or treated like hyacinths; 
but they are very sensitive to heat, and require only to be given the light when they have started to grow, without any forcing. Forty to $45^{\circ}$ will be as warm as they ever need be kept. See the article on Bulbs; also, the advice given for the various plants under their respective names.

Pests.-Window-Garden pests are discussed under Insects.

Winter-killing is induced by a late fall growth, and also by a dry, unprotected soil. All tender woody plants should be well ripened before cold weather comes: cease tillage early: do not apply stimulating manures late in the season. Mulch all tender or half hardy plants (see Mulch). Even hardy plants are benefited by a mulch. When possible, it is better to bend plants to the ground and cover them than to wrap them up as they stand; but this cannot be done with tall or stiff subjects. Wrapping in straw or burlaps affords excellent protection, but it is possible to wrap too heavily. A barrel, less the heads, may bo set over small plants and then filled with leaves or other loose litter; or a eylinder of wire ehicken-sereen may be substituted for the barrel. Remove the protection in the spring before the buds start. See that mice do not nest in the barrel or in the mulch.

Zinnia. Showy hardy annuals. The old formal type of Zinnias has given place to a race of freer forms which are excellent plants either for color effect or for eutting. The colors have been varied and brightened, the flowers doubled and the plants dwarfed. Seed should be sown in a hotbed or house in March, transplanted once at least before planting out, and set in well enriched soil. Or, the seed may be sown where the plants are to grow. The tall varieties (3 feet) should stand 18 to 24 inches apart. These are best for masses at a distance. 


\section{The Best and Nervest}

Rural Books

DOOKS ON LEADING TOPICS $D$ CONNECTED WITH AGRICULTURAL AND RURAL LIFE ARE HERE MENTIONED. EACH BOOK IS THE WORK OF A SPECIALIST, UNDER THE EDITORIAL SUPERVISION OF PROFESSOR L. H. BAILEY, OF THE CORNELL UNIVERSITY, OR BY PROFESSOR BAILEY HIMSELF, AND IS READABLE, CLEAR-CUT AND PRACTICAL. 


\section{THE RURAL SCIENCE SERIES}

Includes books which state the underlying principles of agriculture in plain language. They are suitable for consultation alike by the amatem or professional tiller of the soil, the scientist or the student, and are freely illustrated and finely made.

The following volumes are now ready:

THE SOIL. By F. H. Kixe, of the University of Wiseonsin. 303 pp. 45 illustrations. 75 cents.

THE FERTILITY OF THE LAND. By I. P. RoBerts, of Cornell University. Second edition. $421 \mathrm{pp}$. 45 illustrations. $\$ 1.25$.

THE SPRAYING OF PLANTS. By E. (r. Lod)eman, late of ('ornell University. $399 \mathrm{pp} .92$ illustrations. $\$ 1$.

MILK AND ITS PRODUCTS. By H. H. WINA, of Comell U'niversity. 280 pp. 33 illustrations. $\$ 1$.

THE PRINCIPLES OF FRUIT-GROWING. By L. H. BAILEY. Second edition. 514 pp. 120 illustrations. $\$ 1.25$.

BUSH-FRUITS. By F. W. CARD, of Rhode Island College of Agrieulture and Mechanic Arts. 537 pp. 113 illustrations. $\$ 1.50$.

FERTILIZERS. By E. B. Voorhees, of New Jersey Experiment Station' Second edition. $335 \mathrm{pp}$. $\$ 1$.

THE PRINCIPLES OF AGRICUltuRe. By L. H. BaIley. Second edition. $300 \mathrm{pp}$. 92 illustrations. $\$ 1.25$.

IRRIGATION AND DRAINAGE. By F. H. KiNG, University of Wisconsin. $502 \mathrm{pp} .163$ illustrations. $\$ 1.50$.

THE FARMSTEAD. By I. P. ROBERTs. 3.50 pp. 138 illustrations. \$1.25.

RURAL WEALTH AND WELFARE. By George T. FAIRChild, Ex-President of the Agricultural College of Kansas. 381 pp. 14 charts. $\$ 1.25$.

New volumes will be adderl from time to time to the Rural Science Series. The following are in preparation:

PRINCIPLES OF VEGETABLE GARDENING. By L. H. BAILEY. In press. PHYSIOLOGY OF PlaAN'TS. By J. C. ARTHUR, Purdue University.

PRINCIPLES OF BREEDING OF ANIMALS. By W. H. BREWER, of Yale University.

PLANT PATHOLOGY. By B.T. TALLOWAY and associates of U. S. Department of Agriculture.

FEEDING OF ANIMALS. By W. H. Jordan, of New York State Experiment Station.

FARM POULTRY. By George C. WAtson, of Pennsylvania State College. 


\section{THE GARDEN-CRAFT SERIES}

Comprises practical hand-books for the hortireulturist, explaining and illustrating in detail the various important methods which experience lass demonstrated to be the most satisfactory. Thry may be malled manuals of practice, and thongh all are prepared by Professor Bander, of Comell Cniversity, they include the opinionis and methods of suceessful specialists in many lines, thus combining the results of the olservations and experieneess of numerous students in this and other lands. They are written in the clear, strong, concise English and in the entertaining style which charareterize the anther. The volumes are compart, uniform in style, relearly printed, and illustrated as the subject demands. They are of convenient slape: for the jockets, and

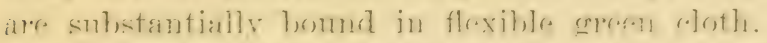

THE HORTICULTURIST'S RULE-BOOK. 'By L. H. BAILEX. Frghth edition. $312 \mathrm{pp} .75 \mathrm{cts}$.

THE NURSERY-BOOK. By L. H. BAHEY. Third mition. 3fis II. 15: illustrations. $\$ 1$.

PLANT-BREEDING. HY I. H. BALEY. 2y:; IJ. 2ij illntratirns. 21.

THE FORCING-BOOK. ISY L. H. BAILEY. 26fj IJ. Eb illu-trations. \&1.

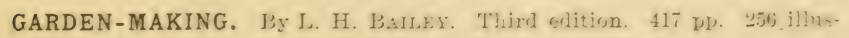
trations. $\$ 1$.

THE PRUNING-BOOK. HY L. H. BAILEY. Secomel alition. 545 [Is. illustrations. $\$ 1.50$.

AMATEUR'S PRACTICAL GARDEN-BOOK. PY C. E. HINY and L. H. BAILEY. $250 \mathrm{pp}$. MIany marginal cuts. \$1. 


\section{THE EVOLUTION OF OUR NA- 1 TIVE FRUITS. By L. H. BAIley, Pro- fessor of Horticulture in the Cornell University.}

472 PAGES - 125 ILLUSTRATIONS - $\$ 2.00$

In this entertaining volume, the origin and development of the fruits peculiar to North America are inquired into, and the personality of those horticultural pioneers whose almost forgotten labors have given us our most valuable fruits is touched upon. There has been careful research into the history of the various fruits, including inspection of the records of the great European botanists who have given attention to American economic botany. The conclusions reached, the information presented, and the suggestions as to future developments, cannot but be valuable to any thoughtful fruit-grower, while the terse style of the author is at its best in his treatment of the subject.

The Evolution of our Native Fruits discusses The Rise of the American Grape (North America a Natural Vineland, Attempts to Cultivate the European Grape, The Experiments of the Dufours, The Branch of Promise, John Adlum and the Catarva, Rise of Commercial Viticulture, Why Did the Early Vine Experiments Fail ? Synopsis of the American Grapes); The Strange History of the MIulberries (The Early Silk Industry, The "Multicaulis Craze,"); Evolution of American Plums and Cherries (Native Plums in General, The Chickasaw, Hortulana, Marianna and Beach Plum Groups, Paciric Coast Plum, Various Other Types of Plums, Native Cherries, Dwarf Cherry Group); Native Apples (Indigenous Species, Amelioration has begun); Origin of American Raspherry-growing (Early American History, Present Types, Outlying Types); Evolution of Blackberry and Dewberry Culture (The High-bush Blackberry and Its Kin, The Dewberries, Botanical Names); Various Types of Berry-like Fruits (The Gooseberry, Native Currants, Juneberry, Buffalo Berry, Elderherry, High-bush Cranberry, Cranberry, Strawberry); Various Types of Tree Fruits (Persimmon, Custard-Apple Tribe, Thorn-Apples, Nut-Fruits); General Remarks on the Improvement of our Native Fruits (What Has Been Done, What Probably Should Be Done). 


\section{THE SURVIVAL OF THE UNLIKE: A Collection of Evolution Essays Suggested by the Study of Domestic Plants. By L. H. BAILEY, Professor of Horticulture in the Cornell University.}

\section{THIRD EDITION-515 PAGES - 22 ILLUSTRATIONS- $\$ 2.00$}

'To those interested in the underlying philosophy of plant life, this volume, written in a most entertaining style, and fully illustrated, will prove welrome. It treats of the modification of plants under cultivation upon the evolution theory, and its attitucle on this interesting subjert is characterized by the author's well-known originality and independence of thought. Incidentally, there is stated much that will be valuable and suggestive to the working horticulturist, as well as to the man or woman impelled by a love of nature to horticultural pursuits. It may well be called, indeed, a philosophy of horticulture, in which all interested may find iuspiration and instruction.

THE SURVIAL OF THE LXLIhe comprises thirty essays touching upon The General Fact and Philosophy of Evolution (The Plant Individual, Experimental Evolution, Coxey's Army and the Russian Thistle, Recent Progress, etc.); Expounding the Fact and Causes of Variation (The Supposed Correlations of Quality in Fruits, Natural History of Synonyms, Reflectire Impressions, Relation of Seedbearing to Cultivation, Variation after Birth, Relation between American and Eastern Asian Fruits, Horticultural Geography, Problems of Climate and Plants, American Fruits, Acclimatization, Sex in Fruits, Norelties, Promising Varieties, ete.); ard Tracing the Evolution of Particular Types of Plants (the Cultivated Strawberry. Battle of the Plums, Grapes, Progress of the Carnation, Petunia. The Garden Tomato, etc.). 


\section{CYCLOPEDIA OF \\ AMERICAN HORTICULTURE}

COMPRISING DIRECTIONS FOR THE CULTIVATION OF HORTICULTURAL CROPS, AND ORIGINAL DESCRIPTIONS OF ALL THE SPECIES OF FRUITS, VEGETABLES, FLOWERS AND ORNAMENTAL PLANTS KNOWN TO BE IN THE MARKET IN THE UNITED STATES AND CANADA

\section{BY L. H. BAILEY}

ASSISTED BY MANY EXPERT CULTIVATORS AND BOTANISTS

\section{In Four Quarto Volumes,}

Illustrated with over Two Thousand Original Engravings

TTHIS monumental work, the most comprehensive review of the vegetable world yet made by an American, is now in the press. Though distinctly an American work, not only plants indigenous to the North American continent are mentioned, but also all the species known to be in the horticultural trade in North America, of whatever origin. It is really a survey of the cultivated plants of the world.

The Editor, Professor L. H. Bailey, has been gathering material for this Cyclopedia for many years. He has enlisted the coöperation of men of attainments, either in science or practice everywhere, and the Cyclopedia has the mique distinction of presenting for the first time, in a carefully arranged and perfectly accessible form, the best knowledge of the best specialists in Americal mpon gardening, fruit-growing, vegetable culture, forestry, and the 
like, as well as exact botanical information. It is all fresh, and not a rehash of old material. No precedent has been followed; the work is upon its own original plan.

Many scientific botanical authors of justly high repute decline to give attention to the important character's of cultivated plants, confining their work to the species in the original forms only. Professor Bailey takes the view that a subject of commercial importance, one which engages the attention and affects the livelihood of thousands of bright people, is decidedly worthy the investigation of the trained botanist. In the Cyclopedia of American Horticulture, therefore, very full accounts are given of the botanical features of all important commercial plants, as the apple, cabbage, rose, etc. At the same time, practical cultivators submit observations upon culture, marketing, and the like, and frequently two opinions are presented upon the same subject from different localities, so that the reader may have before him not only complete botanical information, but very fully the best practice in the most favorable localities for the perfection of any fruit or vegetable or economic plant.

\section{ILLUSTRATIONS}

The pictorial character of the work is likewise notable. There are over two thousand illustrations, and they are all made expressly for this work, either from accurate photographs or from the specimens. These illustrations have been drawn by competent 
horticultural artists, in nearly every case under the eye of the Editor, or with the supervision of some one of the sub-editors. No "trade" cuts are used.

In planning the illustrations, artistic effect has been kept in view, and while no drawing is used which does not show its subject with perfect scientific accuracy, the monotonous so-called "botanical" outlines, often made from lifeless herbarium specimens, are notably absent. The intention is to show the life of the plant, not merely its skeleton.

\section{CONTRIBUTORS, SVSTEM, ETC.}

As above mentioned, the contributors are men eminent as cultivators or as specialists on the various subjects. The important articles are signed, and it is expected that the complete work will include fully 5,000 signed contributions by horticulturists, cultivators and botanists.

The arrangement is alphabetical as to the genera, but systematic in the species. A very simple but complete plan of key-letters is used, and the whole arrangement is toward ease of reference as well as completeness of information. To each large genus there is a separate alphabetic index.

Important commercial subjects are treated usually under the best known name, whether it be the scientific or "common" designation. Thus, the apple is fully discussed as apple, rather than as Pyrus Malus, and the carnation comes into view in the third letter of the alphabet, not as Dianthus Caryophyllus. Carefully edited cross-references make it 
easy to find any desired subject, however, in the shortest time.

The plan of presenting the full details of culture of important plants, through the views of acknowledged practical experts upon the various subjects, assures the great value of the book to the man or woman who is obtaining a living from horticultural pursuits.

A special feature of the Cyclopedia of American Horticulture is its wealth of bibliographic reference. The world's horticultural literature has been thoroughly searched, and most carefully indexed, so that the student will find citations to every available article or illustration upon any subject consulted.

\section{DETAILS OF PUBLICATION}

The Cyclopedia of American Horticulture is to be completed in four handsome quarto volumes, embracing about two thousand pages, with more than that number of original illustrations. It is carefully printed upon specially made paper of a permanent character. The first volume (A to D, 509 pages, 743 illustrations, 9 plates) is now ready, and the work is expected to be completed during the year 1900 .

The work is sold only by subscription, and orders will be accepted for the full set only. Terms and further information may be had of the Publishers,

\section{THE MACMILLAN COMPANY}

No. 66 Fifth Avenue

NEW YORK 


\section{ESSONS WITH PLANTS: Sugges- tions for Seeing and Interpreting Some of the Common Forms of Vegetation. By L. H. BAILEY, Professor of Horticulture in the Cornell University, with delineations from nature by W. S. HOLDSWORTH, of the Agricultural College of Michigan.}

\section{SECOND EDITION-491 PAGES-446 ILLUSTRATIONS-I2 MO- CLOTH-\$1.10 NET}

There are two ways of looking at nature. The old way, which you have found so unsatisfactory, was to classify everything-to consider leaves, roots, and whole plants as formal herbarium specimens, forgetting that each had its own story of growth and development, struggle and success, to tell. Nothing stifles a natural love for plants more effectually thad that old way.

The new way is to watch the life of every growing thing, to look upon each plant as a living creature, whose life is a story as fascinating as the story of any favorite hero. "Lessons with Plants" is a book of stories, or rather, a book of plays, for we can see each chapter acted out if we take the trouble to look at the actors.

"I have spent some time in most delightful examination of it, and the longer I look, the better I like it. I find it not only full of interest, but eminently suggestive. I know of no book which begins to do so much to open the eyes of the student-whether pupil or teacher - to the wealth of meaning contained in simple plant forms. Above all else, it seems to be full of suggestions that help one to learn the language of plants, so they may talk to him."-DARWIN L. BARDwELL, Superintendent of Schools, Binghamton.

"It is an admirable book, and cannot fail both to awaken interest in the subject, and to serve as a helpful and reliable guide to young students of plant life. It will, I think, fill an important place in secondary schools, and comes at an opportune time, when helps of this kind are needed and eagerly songht."-Professor V. M. SPALDING, University of Michigan.

\section{FIRST LESSONS WITH PLANTS}

An Abridgement of the above. 117 pages-116 illustrations -40 cents net. 

MAR 231900 



\section{LIBRARY OF CONGRESS}

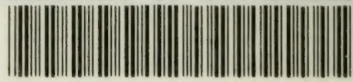

00009318951 